Florida International University FIU Digital Commons

FIU Electronic Theses and Dissertations

University Graduate School

7-6-2016

\title{
Database-Assisted Analysis and Design of Wind Loads on Rigid Buildings
}

Filmon Fesehaye Habte

Florida International University, fhabt003@fiu.edu

DOI: $10.25148 /$ etd.FIDC000749

Follow this and additional works at: https://digitalcommons.fiu.edu/etd

Part of the Civil Engineering Commons, Computer-Aided Engineering and Design Commons, and the Structural Engineering Commons

\section{Recommended Citation}

Habte, Filmon Fesehaye, "Database-Assisted Analysis and Design of Wind Loads on Rigid Buildings" (2016). FIU Electronic Theses and Dissertations. 2573.

https://digitalcommons.fiu.edu/etd/2573

This work is brought to you for free and open access by the University Graduate School at FIU Digital Commons. It has been accepted for inclusion in FIU Electronic Theses and Dissertations by an authorized administrator of FIU Digital Commons. For more information, please contact dcc@fiu.edu. 


\section{FLORIDA INTERNATIONAL UNIVERSITY}

Miami, Florida

\section{DATABASE-ASSISTED ANALYSIS AND DESIGN OF WIND LOADS ON RIGID BUILDINGS}

A dissertation submitted in partial fulfillment of

the requirements for the degree of

DOCTOR OF PHILOSOPHY

in

CIVIL ENGINEERING

by

Filmon Fesehaye Habte

2016 
To: Interim Dean Ranu Jung

College of Engineering and Computing

This dissertation, written by Filmon Fesehaye Habte, and entitled Database-Asssited Analysis and Design of Wind Loads on Rigid Buildings, having been approved in respect to style and intellectual content, is referred to you for judgment.

We have read this dissertation and recommend that it be approved.

$\begin{array}{r}\hline \text { Emil Simiu } \\ \hline \text { Ioannis Zisis } \\ \hline \text { Ping Zhu } \\ \hline \text { Atorod Azizinamini } \\ \hline \text { Arindam Gan Chowdhury, Major Professor }\end{array}$

Date of Defense: July 6, 2016

The dissertation of Filmon Fesehaye Habte is approved.

Interim Dean Ranu Jung College of Engineering and Computing

Andrés G. Gil

Vice President for Research and Economic Development and Dean of the University Graduate School

Florida International University, 2016 
(C) Copyright 2016 by Filmon Fesehaye Habte

All rights reserved. 


\section{DEDICATION}

This dissertation work is dedicated to my parents Fesehaye Habte and Ghenet Ande, my sisters Winta and Danait, my brother Giorgio, and to my entire family. 


\section{ACKNOWLEDGMENTS}

I would like to express my deepest gratitude to my major professor Dr. Arindam Gan Chowdhury, for his patience, guidance, encouragement and endless support. I wish to thank him for creating a very conducive research atmosphere, and giving me the opportunity to participate in research works outside my dissertation with excellent team members from within and outside FIU. Special thanks goes to Dr. Emil Simiu for his support, advice and encouragement along every step of this dissertation work. Working with him was very inspirational, and I truly appreciate his humbleness, patience and quick responses. This dissertation would have been extremely difficult without his guidance. I would like to thank my committee members, Dr. Ioannis Zisis, Dr. Ping Zhu, and Dr. Atorod Azizinamini, for their cooperation in this dissertation work.

I gratefully acknowledges the scholarship support provided by the Presidential Fellowship (FIU, Graduate School). The Wall of Wind (WOW) experiment was conducted with financial support from the National Science Foundation (NSF Award No. 1234004). The help from the WOW team Dr. Peter Irwin, Walter Conklin, Roy Liu Marquis, James Erwin, and all the graduate and undergraduate students involved with the WOW is greatly appreciated. I also like to thank Dr. Donghun Yeo of NIST for his contribution to this research work.

Finally yet very importantly, I would like to thank my parents Fesehaye and Ghenet, my siblings Giorgio, Winta and Danait, my entire family and friends for their unconditional love, unrelenting support and understanding throughout my $\mathrm{PhD}$ study. 


\section{ABSTRACT OF THE DISSERTATION \\ DATABASE-ASSISTED ANALYSIS AND DESIGN OF WIND LOADS ON \\ RIGID BUILDINGS}

by

Filmon Fesehaye Habte

Florida International University, 2016

Miami, Florida

\section{Professor Arindam Gan Chowdhury, Major Professor}

The turbulent nature of the wind flow coupled with additional turbulence created by the wind-building interaction result in highly non-uniform, fluctuating wind-loading on building envelopes. This is true even for simple rectangular symmetric buildings. Building codes and standards should reflect the information on which they are based as closely as possible, and this should be achieved without making the building codes too complicated and/or bulky. However, given the complexity of wind loading on low-rise buildings, its codification can be difficult, and it often entails significant inconsistencies. This required the development of alternative design methods, such as the DatabaseAssisted-Design (DAD) methodology, that can produce more accurate and risk-consistent estimates of wind loads or their effects.

In this dissertation, the DAD methodology for rigid-structures has been further developed into a design tool capable of automatically helping to size member cross sections that closely meet codified strength and serviceability requirements. This was achieved by the integration of the wind engineering and structural engineering phases of designing for wind and gravity loads. Results obtained using this method showed DAD's 
potential for practical use in structural design. Different methods of synthesizing aerodynamic and climatological data were investigated, and the effects of internal pressure in structural design were also studied in the context of DAD. This dissertation also addressed the issues of (i) insufficiently comprehensive aerodynamic databases for various types of building shapes, and (ii) the large volume (in size) of existing aerodynamic databases, that can significantly affect the extent to which the DAD methodology is used in engineering practice.

This research is part of an initiative to renew the way we evaluate wind loads and perform designs. It is transformative insofar as it enables designs that are safe and economical owing to the risk-consistency inherent in DAD, meaning that enough structural muscle is provided to assure safe behavior, while fat is automatically eliminated in the interest of economy and $\mathrm{CO}_{2}$ footprint reduction. 


\section{TABLE OF CONTENTS}

CHAPTER

PAGE

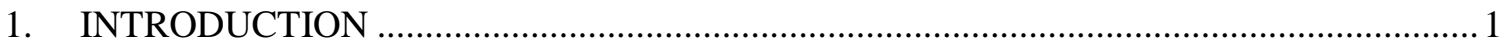

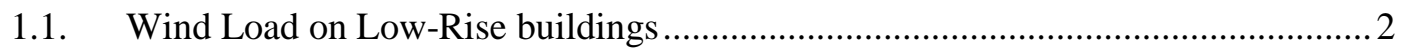

1.2. The Need for Wind Load Codification and the ASCE 7 Standard .......................... 4

1.3. The Need for Alternative Methods for Estimating Wind Loads ............................... 5

1.4. Introduction to Database-Assisted Design (DAD) ................................................. 6

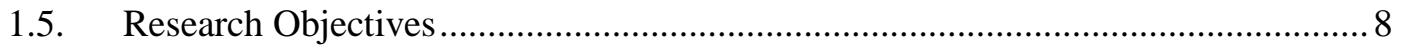

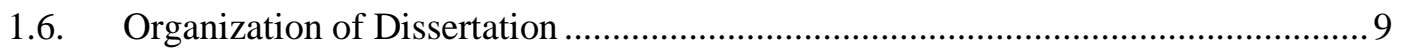

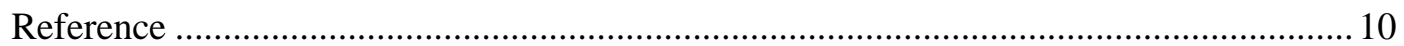

2. DESCRIPTION OF AERODYNAMIC AND CLIMATOLOGICAL DATASETS USED ..... 12

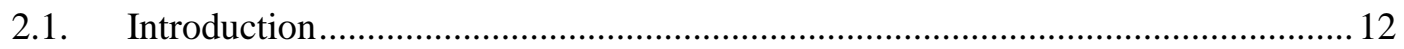

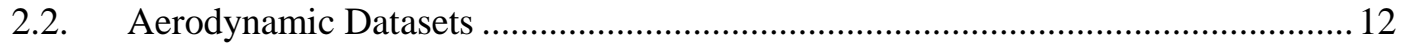

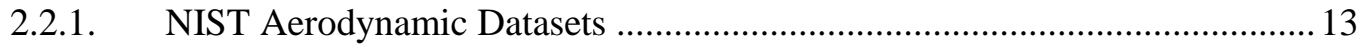

2.2.2. TPU Aerodynamic Datasets ....................................................................... 14

2.2.3. Experimental Data from Testing at the Wall of Wind (WOW) ..................... 16

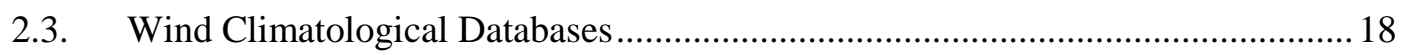

2.3.1. Climatological Database for Hurricane Prone Regions ................................. 19

2.3.2. Climatological Databases for Non-Hurricane Wind Regions .........................20

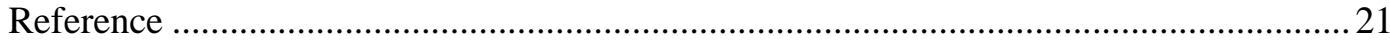

3. DEVELOPMENT OF DESIGN METHODOLOGY OF RIGID STRUCTURES FOR WIND USING TIME SERIES OF DEMAND-TO-CAPACITY INDEXES ............................... 23

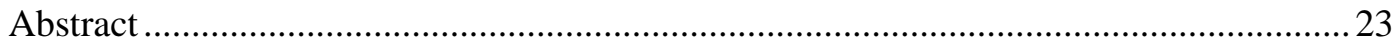

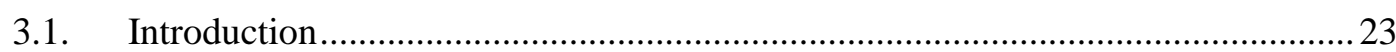

3.2. Description of the Time-Series of DCI based Iterative Design Procedure .............26

3.2.1. Estimation of Time-histories of Demand to Capacity Indexes (DCI)............26

3.2.2. Estimation of Peak DCIs and Deflections for Specified MRIs ....................... 30

3.2.3. Overview of the Design Procedure ............................................................... 31

3.3. Application of the Time-Series of DCI based Iterative Design Procedure .............. 32

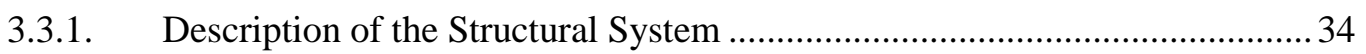

3.3.2. Transforming of Building Loads to Internal Frame Forces ........................... 35

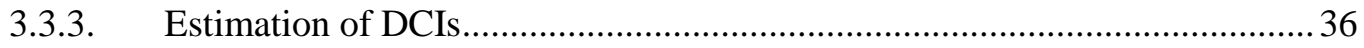

3.3.4. Time-Series Based Methods for Stability Analysis ........................................ 39

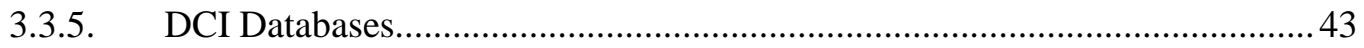


3.3.6. Estimation of Peak DCIs with Specified MRIs............................................ 44

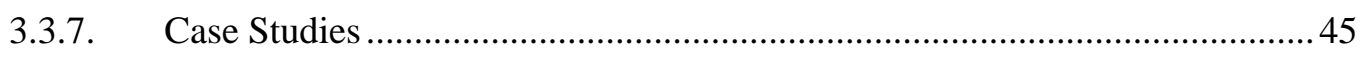

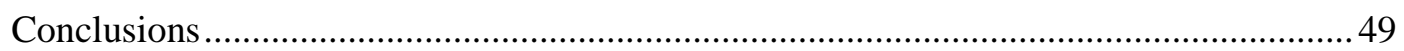

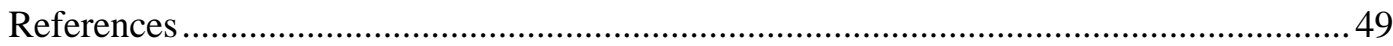

4. SYNTHESIS OF AERODYNAMIC AND CLIMATOLOGICAL DATA, WIND

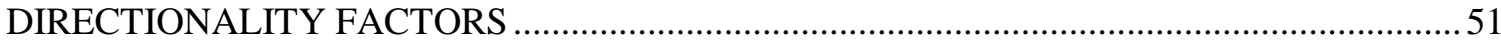

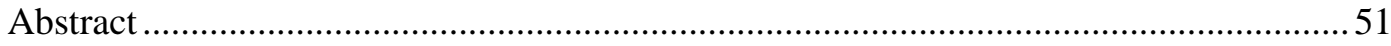

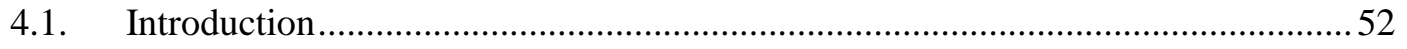

4.2. Synthesizing DCI Databases and Climatological Databases .................................54

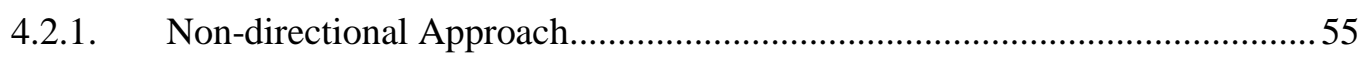

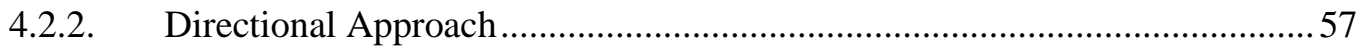

4.2.3. Comparisons of DCIs Evaluated using the Non-directional and Directional Approaches....................................................................................5

4.3. Wind Directionality Factors for Wind-Induced Loads and Responses...................63

4.3.1. Determination of Wind Directionality Factor ................................................ 65

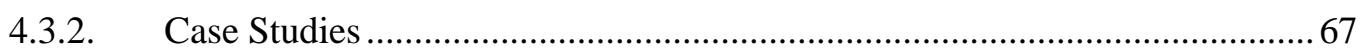

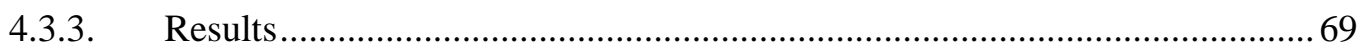

4.3.4. Structural Reliability Considerations .......................................................... 76

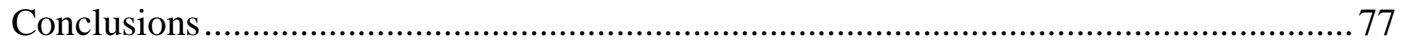

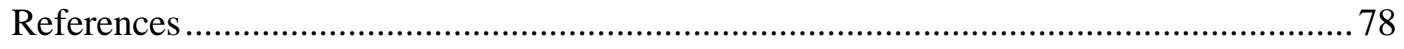

5. EFFECT OF WIND INDUCED-INTERNAL PRESSURES ON FRAME FORCES

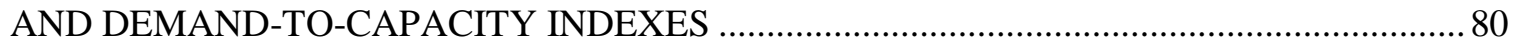

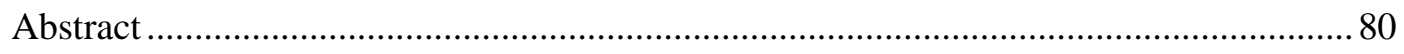

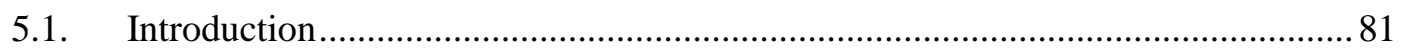

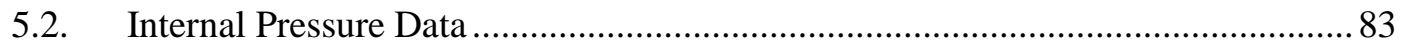

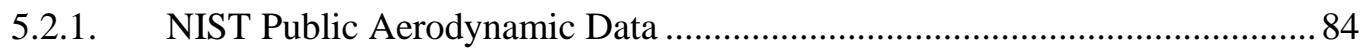

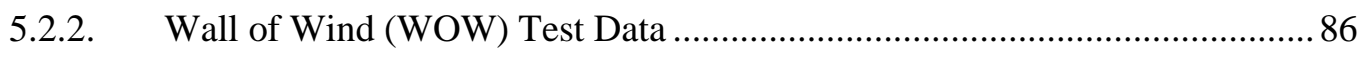

5.3. ASCE 7-10 Provision for Internal Pressure - Low-rise Buildings .......................... 89

5.4. Effects of Internal Pressure on Global Roof Uplift............................................. 91

5.4.1 Single Dominant Opening ........................................................................ 93

5.4.2 Multiple Dominant Openings.................................................................... 94

5.5. Effects of Internal Pressure on Frame Forces .......................................................97

5.5.1. Peak Estimation Methods, and Validation of NIST and WOW

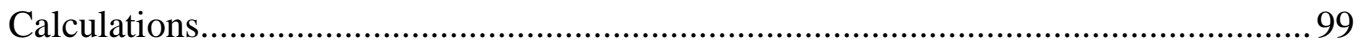

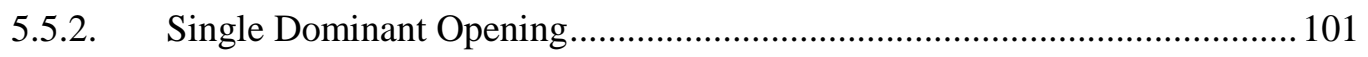




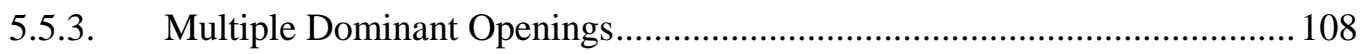

5.6. Effects of Internal Pressure on Frame DCI's …........................................................ 110

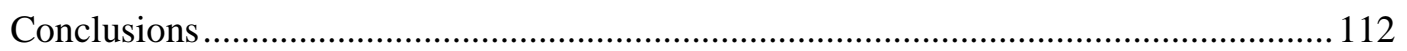

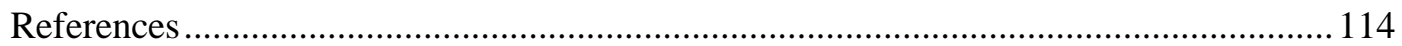

6. INTERPOLATION AND AERODYNAMIC DATA COMPARISON TO ALLEVIATE SCARCITY OF COMPREHENSIVE AERODYNAMIC DATABASES ...........116

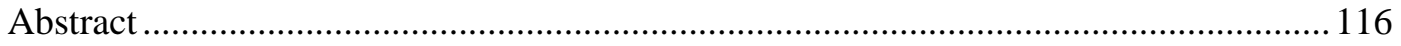

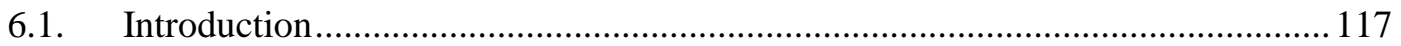

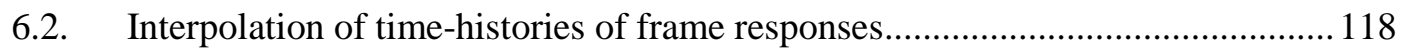

6.2.1. Comparison of Frame Responses............................................................ 121

6.2.2. Comparison of Demand-to-Capacity Indexes (DCIs) ................................. 124

6.3. Comparison of the NIST and TPU Aerodynamic Databases .............................. 127

6.3.1. Comparison of Aerodynamic Pressures ....................................................... 128

6.3.2. Comparison of Internal Frame Responses ................................................. 136

6.3.3. Comparison of Demand-to-Capacity Index (DCI) ...................................... 139

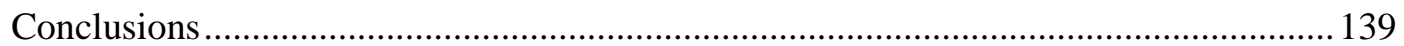

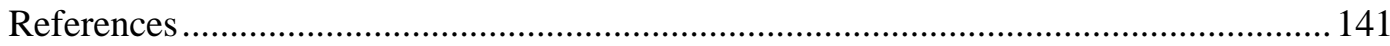

7. REDUCTION OF AERODYNAMIC DATA VOLUME AND COMPUTATIONAL TIMES FOR DATABASE-ASSISTED DESIGN CALCULATIONS ..................................... 143

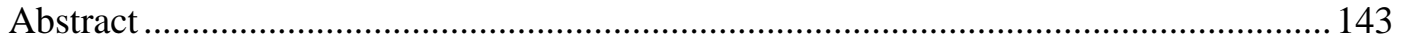

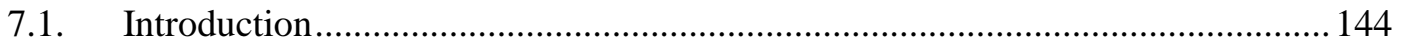

7.2. Data Volume Reduction Based on Original Time Series.................................... 147

7.2.1. Data Compression using Transformational Methods................................... 147

7.2.2. Data Compression using Direct Methods .................................................... 154

7.3. Data Volume Reduction Based on Moving Averaged Time Series...................... 163

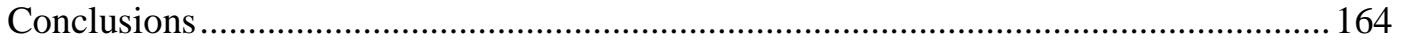

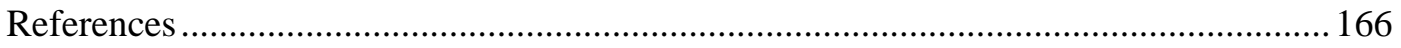

8. CONCLUSION AND FUTURE RESEARCH RECOMMENDATIONS ......................... 167

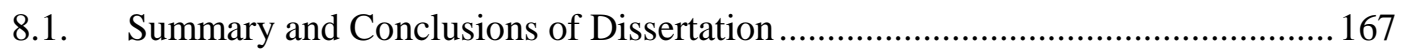

8.2. Recommendation for Future Research........................................................... 173 


\section{LIST OF TABLES}

TABLE

PAGE

Table 4.1 Distribution of Ratios of DCI-directional to DCI-non directional ................... 63

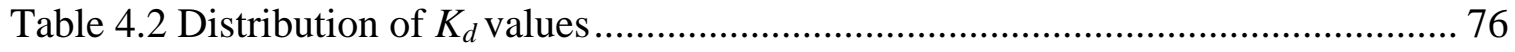

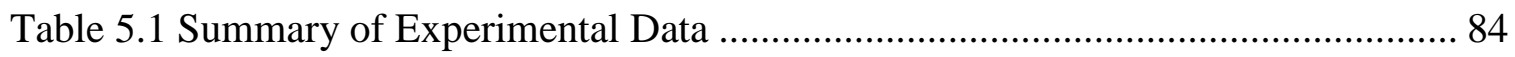

Table $5.2 G_{p i ~ e q}$ for the NIST and WOW models - partially enclosed ........................ 90

Table 6.1. Dimensions and Roof Slopes of Buildings Selected for Comparisons.......... 130

Table 6.2. Distribution of relative differences between TPU and NIST estimates of expected peak pressures.

Table 7.1 Ratios $r_{M}$ and $r_{P}$ based on time series of length $(100 / n) \mathrm{s}$ with the least expected peak, obtained from original $(500 \mathrm{~Hz}, 100 \mathrm{~s}$ length) time series.

Table 7.2 Ratios $r_{M}$ and $r_{P}$ based on time series with sampling rates $500 \mathrm{~Hz} / m$ with the least estimated peak, obtained from original $(500 \mathrm{~Hz}, 100 \mathrm{~s}$ length) time series. .... 157

Table 7.3 Ratios $r_{M}$ for five samples with reduced sampling rate obtained from original time series (frame 2, open, $m=5$ ).

Table 7.4 Ratios $r_{M}$ and $r_{P}$ based on time series with sampling rates $500 \mathrm{~Hz} / \mathrm{m}$ and adjusted $v_{m d}$ values 162 


\section{LIST OF FIGURES}

FIGURE

PAGE

Figure 1.1 Low-rise Industrial Buildings Damaged by High-Wind Events ..................... 3

Figure 2.1 UWO Boundary Layer Wind Tunnel Building Model (Ho et al. 2003a)........ 14

Figure 2.2 Wall of Wind (WOW) Facility at Florida International University (FIU) ...... 16

Figure 2.3 Simulation of open terrain ABL in the WOW: a) mean wind speed profile,

b) turbulence intensity profile, and c) turbulence spectrum ...................................... 17

Figure 2.4 Wall of Wind (WOW) large scale model ............................................... 18

Figure 2.5 Location Mileposts / Locator Map with Coastal Distances in Nautical

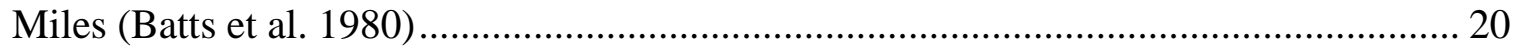

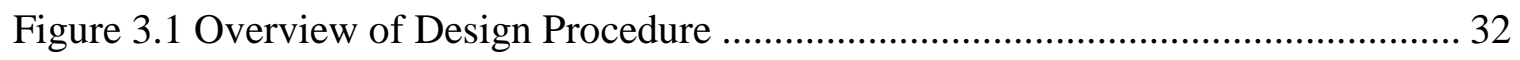

Figure 3.2 Layout of Addressed Structural System ................................................. 34

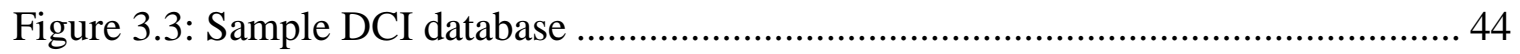

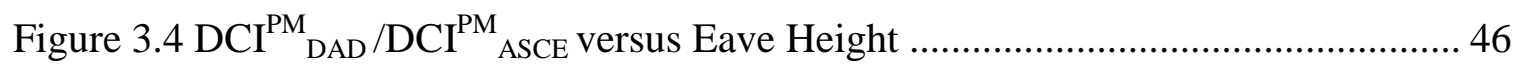

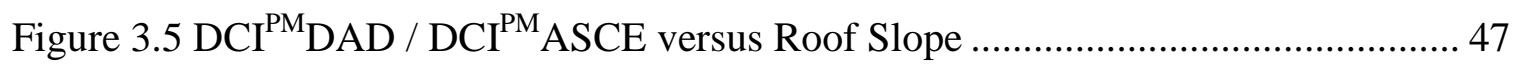

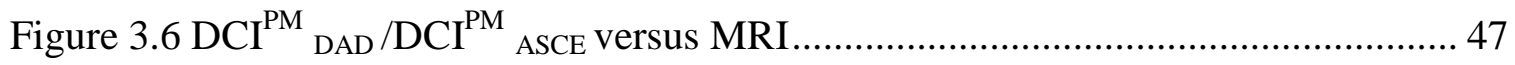

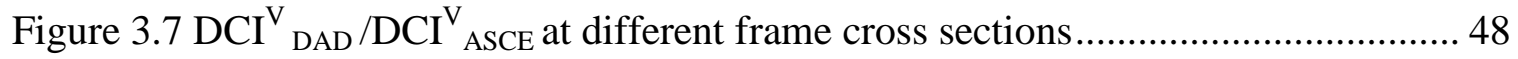

Figure 4.1 Ratio of DCI-directional to DCI-non directional, Model 1, Hurricane

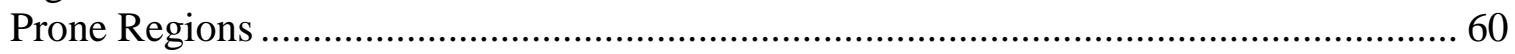

Figure 4.2 Ratio of DCI-directional to DCI-non directional, Model 2, Hurricane

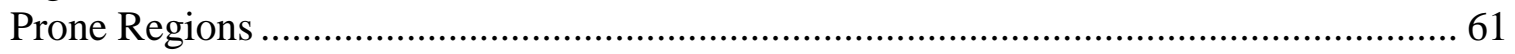

Figure 4.3 Ratio of DCI-directional to DCI-non directional, Model 1, Non-hurricane

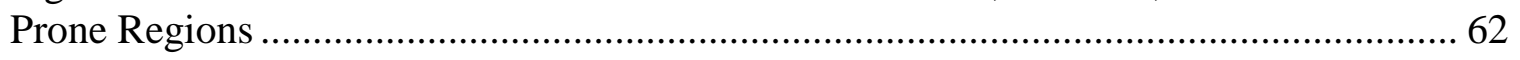

Figure 4.4 Ratio of DCI-directional to DCI-non directional, Model 2, Non-hurricane

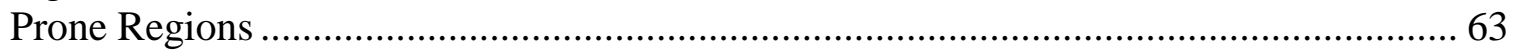

Figure 4.5 Location of Frames, and Taps for Pressure on Claddings ............................. 68

Figure 4.6 $K_{d}$, Internal Responses at MWFRS, Hurricane Prone Regions ..................... 70 
Figure 4.7 $K_{d}$, Internal Responses at MWFRS, Non-hurricane Prone Regions..... 71

Figure $4.8 K_{d}$, Pressures on Claddings, Hurricane Prone Regions ............................... 72

Figure $4.9 K_{d}$, Pressures on Claddings, Non-Hurricane Prone Regions .......................... 73

Figure $4.10 K_{d}$, Global Torsion and Shear, Hurricane Prone Regions ........................... 74

Figure $4.11 K_{d}$, Global Torsion and Shear, Non-Hurricane Prone Regions .................... 75

Figure 5.1 Orientation of Large and Small Openings for NIST models ......................... 85

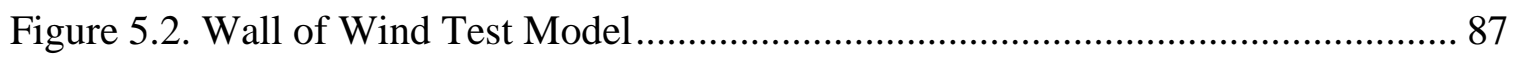

Figure 5.3. Large-Scale Model used in Experimental Investigation: Layout (upper)

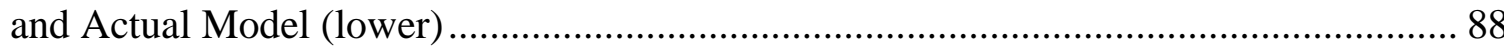

Figure 5.4. Mean and Maximum Roof Uplift Force Coefficients, $C_{f z}$, Single Opening ... 93

Figure 5.5. Mean and Maximum Roof Uplift Force Coefficients, $C_{f z}$, Multiple

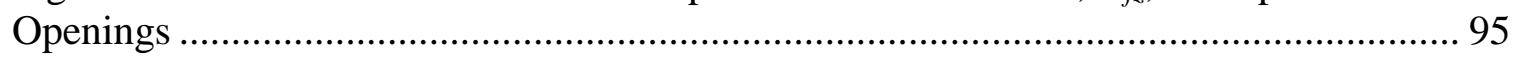

Figure 5.6. Mean and Maximum Roof Uplift Force Coefficients, $C_{f z} \ldots \ldots \ldots \ldots \ldots \ldots \ldots \ldots \ldots . . . . . . . . . . . . .66$

Figure 5.7 Comparison of $\hat{C}_{m}$ Evaluated Using the WOW Model and a NIST Model .. 101

Figure 5.8 Layout of Frames, Opening, and Wind Directions for the NIST Models ..... 102

Figure 5.9 External, Internal and Net Moments, NIST Model 1, Frame 1 ................... 103

Figure 5.10 External, Internal and Net Moments, NIST Model 1, Frame 4 .................. 103

Figure 5.11 Correlation Coefficients, NIST Models 1 and 2 ................................... 105

Figure $5.12 \hat{C}_{m \text { int }} / \hat{C}_{m A S C E}$ versus wind directions, NIST model 1 ............................ 106

Figure 5.13 Experimental Computed $\hat{C}_{m}$ versus $\hat{C}_{m} A_{S C E}$ and $\hat{C}_{m}(\mathrm{GCpi}= \pm 1.0) \ldots \ldots \ldots \ldots \ldots \ldots . . . . . . .107$

Figure 5.14 Peak External, Internal and Net Moment Coefficients, WOW Model,

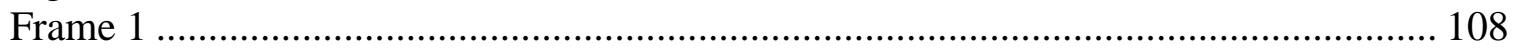

Figure 5.15 Peak External, Internal and Net Moment Coefficients, WOW model, Frame 3

Figure 5.16 Correlation Coefficients, WOW model ................................................ 109

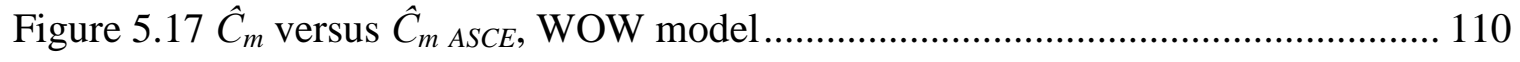


Figure $5.18 D C I_{n e t} / D C I_{\text {ext }}$ versus wind directions, NIST model 1

Figure 5.19DCI $I_{n e t} / D C I_{\text {asce }}$ versus wind directions, NIST model 1

Figure 6.1 Interpolation between Models with Different Eave Heights 122

Figure 6.2 Interpolation between models with different roof slopes

Figure 6.3 $\mathrm{DCI}^{\mathrm{PM}} \mathrm{s}$ Based on Model of Building and on Interpolations From Models with Different Eave Heights. 125

Figure 6.4 $\mathrm{DCI}^{\mathrm{PM}}$ s Based on Scaled Model of Building and on Interpolations from Models with Different Roof Slopes. 126

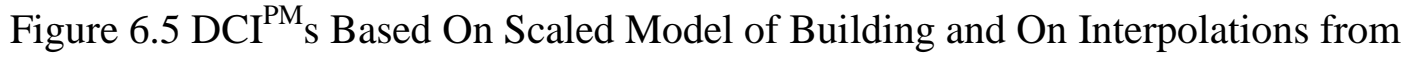
Models with Different Eave Heights and Roof Slopes.

Figure 6.6 Exploded View: Buildings with Taps (Case 1-1), a. NIST and b. TPU...... 130

Figure 6.7 Details of Pressure Taps Selected for Comparison (Case 1-1), a. Roof and $b$. Wall.

Figure 6.8 Expectation of Peak Pressure Coefficients (Case 1-1), a. 0 deg, b. 45 deg and c. $90 \mathrm{deg}$, roof.

Figure 6.9 Expectation of Peak Pressure Coefficients (Case 1-2), a. 0 deg, b. 45 deg and c. $90 \mathrm{deg}$, wall.

Figure 6.10 Exploded View: Buildings with Taps (Case 1-2), a. NIST and b. TPU..... 133

Figure 6.11 Details of Pressure Taps Selected for Comparison (Case 1-2), a. Roof and $b$. Wall

Figure 6.12 Expectation of Peak Pressure Coefficients (Case 1-2), a. 0 deg, b. 45 deg and c. $90 \mathrm{deg}$, roof.

Figure 6.13 Expectation of Peak Pressure Coefficients (Case 1-2), a. 0 deg, b. 45 deg and c. $90 \mathrm{deg}$, wall.

Figure 6.14 Plan View and Frame Layout of a. NIST and b. TPU Models Considered in Comparison

Figure 6.15 Expectation of Peak Moment Coefficients, a. Frame 1, b. Frame 2 and c. Frame 3 138

Figure 6.16 Comparison of DCI ${ }^{\mathrm{PM}}$ s Calculated using NIST and TPU Databases.... 139 
Figure 7.1 Plan view of the building.

Figure 7.2 Amplitudes of Fourier Complex Coefficients at Different Levels of Compression

Figure 7.3 Multi-Level Discrete Wavelet Transformation

Figure 7.4. Comparison of Original Pressure Time Series to $d w t$ Compressed Time Series, Tap 3712

Figure 7.5 Comparison of Moment Evaluated Using Original Time Series and Compressed Data

Figure 7.6 Comparison of $r_{M}$ and $r_{P}$ Evaluated at 90\% Compression using $f f t$ and $d w t$ Methods.

Figure 7.7 Example of frame response valuated using $500 \mathrm{~Hz}$ sampling rate $(m=1)$ vs. obtained from data with reduced sampling rate $(m=4$, and $m=8)$.

Figure 7.8 Comparisons of CDF of original time series to compressed time series....... 160

Figure 7.9 Median up-crossing rates at different $m$................................................. 162

Figure 7.10 Example of original record (solid line) vs. record obtained from it by moving-averaged operation (dotted line). 


\section{INTRODUCTION}

Conventional methods of determining wind loads on building main wind force resisting systems (MWFRS) involve the use of tables and plots associated with provisions of standards such as the Standard on Minimum Design Loads for Buildings and Other Structures (ASCE 7). Such provisions need to be risk-consistent, and should reflect the information on which they are based as transparently, completely and realistically as possible. However, conventional standards have information storage limitations that impose the reduction of vast amounts of aerodynamic data randomly varying in time and space to a far smaller number of enveloping time-invariant data that can be included in tables and plots. Such reduction might distort the wind-loading picture, entails susceptibility to errors, and leads to designs that are not risk-consistent.

With the rapid growth of computational power, the need to summarize aerodynamic and climatological data can be eliminated or reduced. The data can therefore be used directly in computing wind effects and performing designs. With this in mind, the database-assisted design (DAD) concept was proposed as a means of providing alternatives that would make direct use of stored pressure time series and produce risk-consistent designs. DAD is a computer-intensive, user-friendly automated design procedure for the calculation of wind effects on structures. Although significant progress has been accomplished in the past decade, for DAD to be a routine tool resulting in safe and economical design of rigid buildings, much work is needed to exploit its full potential. This dissertation is devoted to advancing the current state of art of DAD for lowrise buildings, by developing DAD into a design tool capable of automatically sizing member cross sections that closely meet codified strength and serviceability requirements, and addressing certain shortcomings that can hinder its widespread use.

The current study is part of an initiative to renew the way we evaluate wind loads and perform designs. The proposed research is transformative insofar as it will enable designs that are safe and economical owing to the risk-consistency inherent in $\mathrm{DAD}$, meaning that enough 
structural "muscle" is provided to assure safe behavior, while "fat" is automatically eliminated in the interest of economy and $\mathrm{CO}_{2}$ footprint reduction. By satisfying the research objectives, this research work will not only advance the state of the art of DAD methodology for rigid buildings, but also promote the widespread use of methods for designing structures for wind loads that will make full use of modern experimental and computational capabilities.

\subsection{Wind Load on Low-Rise buildings}

Low-rise buildings used for residential, commercial, industrial, and other purposes account for most building construction in the US and are recognized as the most vulnerable structures to high wind loads during hurricanes or other windstorms. According to the ASCE 7, the term "lowrise" is used to describe buildings whose mean roof heights: (i) are less than $60 \mathrm{ft}$, and (ii) do not exceed the buildings' least horizontal dimension. Most low-rise buildings are classified as rigid. A building is called rigid if its fundamental natural frequency exceeds $1 \mathrm{~Hz}$ (in which case it is not expected to vibrate under wind loads).

Early wind engineering research was mainly focused on high-rise structures. Typically, only high-rise structures projects could afford the high costs of wind tunnel testing. However, major wind events, such as hurricanes, resulted in far more wind damage and consequent financial loss to low-rise homes and industrial buildings (Cochran 2004). The significant losses incurred during such events highlighted the need for wind-loading research on low-rise buildings. Sample photos of low-rise structures damaged by high-wind events are shown in Figure 1.1. 


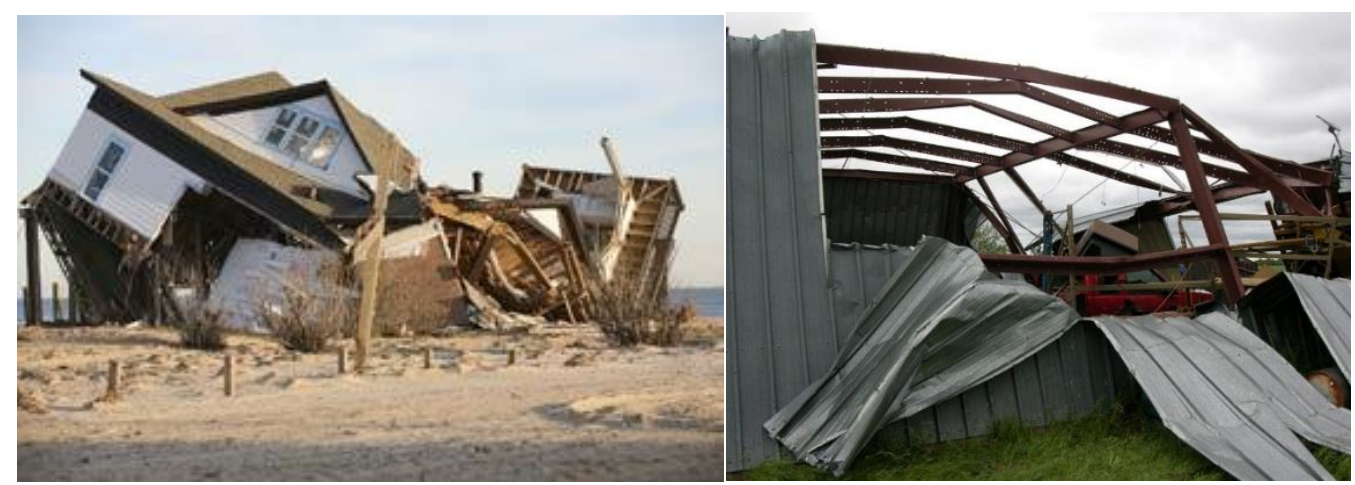

Figure 1.1 Low-rise Industrial Buildings Damaged by High-Wind Events (sources http://www.ARA.gov/ and http://www.weather.gov/)

The turbulent nature of wind coupled with additional turbulence created by the windbuilding interaction results in highly non-uniform wind loading on a building envelope. The shape of the pressure distribution also changes rapidly with time. Even simple rectangular symmetric buildings with wind direction perpendicular to one side can experience instantaneous wind distributions which are asymmetrical (Tamura et al. 2000). This makes accurate quantification of wind loads and wind-induced responses highly complicated. Wind loading on low-rise buildings can be further complicated by interference and sheltering effects which can be difficult to quantify. Wind-induced internal pressures created during breach of an opening can also pose significant threats to a low-rise building by modifying its internal pressures. Also, correlations between external and internal pressure fluctuations need to be assessed. The effects of internal pressures can be particularly significant in cases where the low-rise buildings have a dominant opening, which is often the case in storage facilities and industrial buildings. Such openings, if unprotected, can be breached by wind pressure or wind-borne debris.

Wind-induced internal forces in members are induced by surface pressures, appropriately weighted by their influence at the point under consideration by using influence coefficients, and integrated over the surface area tributary to that point. Rigid buildings are assumed to respond instantaneously to wind loading fluctuations. Hence, fluctuating forces on rigid structures can be 
directly calculated from the aerodynamic pressure fluctuations measured in a steady flow as shown in Eq. (1.1)

$$
F(t)=\int_{0}^{L} \int_{0}^{B} \frac{1}{2} \rho \bar{V}^{2} C_{p}(x, y, t) N(x, y) d x d y
$$

where $F(t)$ is wind-induced fluctuating force/response at any point on a structure; $\rho$ is air density; $\bar{V}$ denotes mean wind speed; $C_{p}(x, y, t)$ represents the net-fluctuating pressure coefficient measured on the structure; $N(x, y)$ denotes the influence coefficients; and $B$ and $L$ denote the width (along xaxis) and length (along y-axis), respectively, of the area tributary to the point under consideration.

\subsection{The Need for Wind Load Codification and the ASCE 7 Standard}

Although the cost of wind-tunnel testing has decreased over the last few decades, it is still not feasible to conduct extensive wind tunnel testing when designing regularly shaped structures. This creates the need for codification of wind loads on buildings, at least on regular shaped buildings. However, the complexity of wind loading on low-rise buildings can make the codification process a daunting task. According to A. G. Davenport "The precision of code specifications must be balanced with the advantages of simplicity; conservatism must be balanced with the need for economic design; and reality must be the final judge" (Lee Shoemaker 2014). That is, wind loading provisions should reflect the information on which they are based as precisely as possible, given that this should be achieved without making building codes too complicated and/or bulky. This can be difficult to achieve.

In the ASCE 7 Standard, there currently exist two main methods of estimating wind loading on Main Wind Force Resisting System (MWFRS) of low-rise buildings: the directional method and envelope method. The directional method applies to buildings of all heights and was adopted from the American National Standards Institute's Minimum Design Loads for Buildings and Other Structures, ANSI A58.1-1982. The pressure coefficients provided by the directional method reflect the actual loading on each surface of the building as a function of wind direction 
(ASCE 7-10). The envelope method for low-rise buildings provides values of "pseudo" loading conditions that induce responses, which conservatively envelop the maximum structural responses (bending moment, shear, and thrust) independent of wind direction. Those values were developed on the basis of wind tunnel tests in which the measured external loads were multiplied on-line by influence coefficients for a few generic rigid frames with flat or gable roofs. This representation of wind loading was first developed by researchers at the University of Western Ontario (UWO) in 1978 and was adopted by the ASCE 7 after almost 20 years (Stathopoulos 2003). The directional and envelope methods can produce different values of wind loading for the same structures. Inconsistencies are present even within the envelope method. For details see Simiu (2011). Shoemaker (2014) suggested that the difference in wind loads estimated using inconsistencies should not lead to an indictment of the standard, but rather as an outgrowth of different research efforts. Nevertheless, they show the need for refining current building codes and/or developing more accurate methods of wind load estimation.

\subsection{The Need for Alternative Methods for Estimating Wind Loads}

Although design codes have advanced significantly, as stated previously their storage limitations can result in significant inconsistencies among their various provisions. Moreover, wind loads determined by such methods can differ from wind loads consistent with laboratory measurements by amounts found in some cases to exceed $50 \%$ (Coffman et al. 2009). These facts necessitate the development of alternative design methods that can produce more accurate and risk-consistent estimates of wind loads.

Researchers at the National Institute of Standards and Technology (NIST) proposed an alternative method of computing wind effects and performing designs which has the potential of producing highly accurate results; this method is commonly referred to as Database-Assisted Design (DAD). DAD is a computer-intensive, user-friendly automated design procedure for the calculation of wind effects on structures. DAD is made possible by advances in wind tunnel 
technology which enabled simultaneous measurement of pressures at hundreds of pressure taps on the surface of building models, and parallel advances in computational and digital storage capabilities which enable analysis of large quantities of pressure data (Main and Fritz 2006). Previous research has shown that DAD has the potential for achieving designs for buildings subjected to wind action that are far more risk-consistent than those based on conventional standard provisions.

\subsection{Introduction to Database-Assisted Design (DAD)}

Database-assisted design (DAD) is a time-domain technique for estimating wind loads on structures that can preserve the phase relationships between pairs of pressures occurring at different locations on the building envelope. This technique is made possible by the development of scanners that record simultaneously pressures at large number of taps and thus rigorously preserve the phase information between all pairs of pressure records. DAD possesses the potential of being used for determining wind effects on buildings, required to design the MWFRS, the secondary components and the cladding. DAD is a transparent methodology that unifies the wind engineering and structural engineering aspects of the design process, and clearly delineates the complementary contributions to the design process of the wind and structural engineer. Transparency - and accountability - are achieved in part because, unlike the calculations on which the ASCE envelope procedure is based, all the test data are publicly available. The fact that all calculations are performed in the time domain renders all requisite superposition of wind effects simple and rigorously correct, an attribute not possessed by calculations performed in the frequency domain (Simiu 2011).

DAD makes use of influence lines in calculating the wind effects of interest. Influence lines/ functions provide a direct link between the load pattern and the response and deserve wider usage (Davenport 1995). Moreover DAD accounts for the effects of design variables such as distance 
between frames, hence, it automatically accounts in a realistic fashion for the loading tributary to each individual frame in the actual structure being designed (Rigato et al. 2001).

DAD uses as inputs:

(i) Aerodynamic information, supplied by an aerodynamic database containing simultaneous records of time histories of pressure coefficients for different wind directions, for a sufficiently large number of building types and geometries, or, in the future, by Computational Fluid Dynamics (CFD) calculations;

(ii) Climatological information, which contains simulated data consisting of the highest directional wind speeds in hurricane or non-hurricane wind storm events covering time periods of the order of thousands of years, as required for the estimation of wind effects with long mean recurrence intervals; and

(iii) Structural information on the type and features of the structure being designed (e.g. for an industrial metal building with portal frames, the distance between frames, the cross sections of the elements that constitute the MWFRS, requisite influence coefficients obtained from preliminary designs, the locations of purlins and girts, and types of supports).

Using these inputs, the DAD methodology can produce realistic estimates of peak internal forces, as well as final designs of the MWFRS and components corresponding to the specified mean recurrence intervals of the wind effects (Simiu et al. 2003). DAD is currently applicable in practice with databases obtained via wind tunnel testing, adjusted as needed on the basis of comparisons with full scale results, or via full-scale tests. Computational Wind Engineering capabilities may be expected to replace the wind tunnel as a source of aerodynamic data. DAD has also been developed with this potential in mind. 


\subsection{Research Objectives}

In the last decade significant progress has been accomplished in the determination of wind effects on rigid buildings using the DAD procedure. On commission from the National Institute of Standard and Technology (NIST) and Texas Tech University, comprehensive aerodynamic testing on low-rise gable buildings was conducted at the University of Western Ontario (UWO) for the purpose of being used in DAD (Simiu et al. 2003); the data is available for public use. Easy to use Graphical User Interface (GUI) programs have been developed for determining wind effects on MWFRS of structures (Whalen et al. 2002; Main and Fritz 2006) and are being updated and enhanced. Interpolations schemes have been devised and are being used to calculate data for building with dimensions intermediate between those buildings for which aerodynamic databases are available (Main 2007; Kopp and Chen 2006). DAD has also been used to accurately estimate wind effects on wood frame buildings (Mensah et al. 2011). Nevertheless, for DAD to be a successful tool for designing and analyzing wind loads on rigid-buildings further research and development is required.

As stated previously, this study attempts to develop DAD for rigid-structures into a design tool capable of automatically helping to size member cross sections that closely meet codified strength and serviceability requirements. This is achieved by the integration of the wind engineering and structural engineering phases of designing for wind and gravity loads, similar to the existing integration of earthquake engineering and structural engineering phases of structural design for seismic and gravity loads. In this DAD based design method, the structure's Demandto-Capacity Indexes (DCIs) are evaluated by direct computation that enables the rigorous combination of imperfectly correlated time series of wind forces and effects, thus eliminating errors due to subjective estimates of combined effects. The effects of accurately estimating timehistories of internal wind pressures, and different method of synthesizing aerodynamic databases 
(including DCI databases, which are described in chapter 3) and climatological databases (wind speed databases) have been investigated.

This dissertation also addresses some key issues that can significantly affect the extent to which the DAD methodology is used in engineering practice. Those issues include; (i) the scarcity of available comprehensive aerodynamic databases, and (ii) the large volume (in size) of aerodynamic databases, which can create issues related to data transmission, required PC computation memory and computation times. The insufficiency of comprehensive aerodynamic data available in the NIST/UWO database has been mentioned in the Commentary to the ASCE 7-10 Standard (Sect. C31.4) as the main barrier to the widespread use of the DAD methodology. In this dissertation, a novel interpolation scheme allowing the design of buildings with dimensions not covered in the databases is developed. A thorough comparison of the two largest publicly available aerodynamic databases - NIST/UWO and Tokyo Polytechnic University -- is also performed to alleviate the shortage of databases and enhance user confidence. A novel interpolation scheme allowing the design of buildings with dimensions not covered in the databases is also developed. To address the issue of aerodynamic data volumes, the efficiency of different direct and transformational data volume reduction methods have been investigated, and recommendations have been made accordingly.

\subsection{Organization of Dissertation}

The dissertation is organized in the following subsequent chapters

Chapter 2 provides a brief description of the aerodynamic and climatological datasets used throughout this dissertation.

In Chapter 3 an efficient DAD-based iterative design procedure which integrates the wind engineering and structural engineering phases of designing for wind and gravity loads is developed. 
Chapter 4 analyses and compares different methods of synthesizing aerodynamic DCI databases and climatological or wind speed databases in the context of the DAD-based iterative design method developed in Chapter 3. DAD techniques are also used to make recommendations on appropriate directionality factors for both hurricane and non-hurricane prone regions.

Chapter 5 shows the significance of accurately representing the time-histories of internal pressures in buildings with single and multiple openings, in the context of the DAD-based iterative design method developed in Chapter 3.

Chapter 6 helps to reduce the scarcity of aerodynamic database which might hinder the wide spread of DAD by (i) developing a novel interpolation scheme, and (ii) performing comparisons between the current two largest available aerodynamic databases.

In Chapter 7, several aerodynamic data compression methods are investigated in an effort to reduce the computation times of $\mathrm{DAD}$ calculations and storage requirements without compromising the accuracy of the results being sought.

Chapter 8 summarizes the major findings and contributions of this study, and suggests future research recommendations.

\section{References}

ASCE 7-10. (2010). Minimum design loads for building and other structures. American Society of Civil Engineers, Reston, VA.

Cochran, L. S. (2004). "Wind Effects on Lowrise Buildings." Proceedings of the Second National Conference on Wind Engineering, Commemorative Volume to Honour Professor Prem Krishna, 79-99.

Coffman, B. F., Main, J. A., Duthinh, D., and Simiu, E. (2009). "Wind effects on low-rise metal buildings: Database-assisted design versus ASCE 7-05 standard estimates." Journal of Structural Engineering, 136(6), 744-748.

Davenport, A. G. (1995). "How can we simplify and generalize wind loads?" Journal of Wind Engineering and Industrial Aerodynamics, 54, 657-669.

Kasperski, M. (1996). "Design wind loads for low-rise buildings: a critical review of wind load specifications for industrial buildings." Journal of wind engineering and industrial aerodynamics, 61(2), 169-179. 
Kopp, G. A., and Chen, Y. (2006). "Database-assisted design of low-rise buildings: aerodynamic considerations for a practical interpolation scheme." Journal of structural engineering, 132(6), 909-917.

Main, J. A. (2007). “Interpolation procedures for database-assisted design.” Proc., 12th Int. Conf. on Wind Engineering, 1-6.

Main, J. A., and Fritz, W. P. (2006). Database-assisted design for wind: concepts, software, and examples for rigid and flexible buildings. National Institute of Standards and Technology, Technology Administration, US Department of Commerce.

Mensah, A. F., Datin, P. L., Prevatt, D. O., Gupta, R., and Van de Lindt, J. W. (2011). "Databaseassisted design methodology to predict wind-induced structural behavior of a lightframed wood building.” Engineering Structures, 33(2), 674-684.

Rigato, A., Chang, P., and Simiu, E. (2001). "Database-Assisted Design, Standardization, and Wind Direction Effects.” Journal of Structural Engineering, 127(8), 855-860.

Simiu, E. (2011). Design of buildings for wind: a guide for ASCE 7-10 standard users and designers of special structures. John Wiley \& Sons, Inc., Hoboken, New Jersey.

Simiu, E., Sadek, F., Whalen, T. M., Jang, S., Lu, L.-W., Diniz, S., Grazini, A., and Riley, M. A. (2003). "Achieving safer and more economical buildings through database-assisted, reliability-based design for wind." Journal of wind engineering and industrial aerodynamics, 91(12), 1587-1611.

Stathopoulos, T. (2003). "Wind loads on low buildings: in the wake of Alan Davenport's contributions." Journal of wind engineering and industrial aerodynamics, 91(12), 15651585 .

Tamura, Y., Kikuchi, H., and Hibi, K. (2000). "Wind load combinations and extreme pressure distributions on low-rise buildings." Wind \& Structures, 3(4), 279-289.

Whalen, T. M., Sadek, F., and Simiu, E. (2002). "Database-assisted design for wind: basic concepts and software development." Journal of Wind Engineering and Industrial Aerodynamics, 90(11), 1349-1368.

Shoemaker, L.W. (2014). "Insights into Wind Loads for Low-Rise Buildings." STRUCTURE megazine: Articles, Codes and Standards, 8-10. 


\section{DESCRIPTION OF AERODYNAMIC AND CLIMATOLOGICAL DATASETS USED}

\subsection{Introduction}

As defined in Chapter 1, Database-assisted design (DAD) is a computer-intensive, userfriendly automated design procedure for the calculation of wind effects on structures. In addition to the structural information of the building being analyzed, DAD uses, as inputs, large sets of electronically recorded aerodynamic pressure data measured simultaneously in the wind tunnel at large numbers of points on building models' surfaces, and recorded or simulated climatological data consisting of the highest directional wind speeds in hurricane or non-hurricane wind storm events covering time periods of the order of thousands of years. The following sections provide brief descriptions of the aerodynamic and climatological data used in this dissertation.

\subsection{Aerodynamic Datasets}

Aerodynamic data provide the spatio-temporal distribution of wind pressures on building surfaces for various wind directions and terrain conditions. They are typically obtained from pressures measured in wind tunnels at large numbers of ports on the external and/or internal surfaces of building models. Wind pressure on buildings are typically presented in nondimensional form as pressure coefficients, $C_{p}(x, y, t)$, which are evaluated from pressures measured on the building facades, $P(x, y, t)$, as shown in Eq. (2.1), where $\rho$ denoted air density, $P_{o}$ is ambient pressure, and $V_{\bar{t}}$ represents wind velocity averaged over a time-duration $\bar{t}$.

$$
C_{p}(x, y, t)=\frac{P(x, y, t)-P_{o}}{\frac{1}{2} \rho V_{\bar{t}}^{2}}
$$

In this study, aerodynamic datasets from two public aerodynamic databases; the National Institute for standards and Technology (NIST), and the Tokyo Polytechnic University (TPU) are used. Pressure data experimentally collected at Florida International University's (FIU) Wall of 
Wind (WOW) facility are also used. The following sections provide description of the aerodynamic datasets used in this dissertation.

\subsubsection{NIST Aerodynamic Datasets}

The NIST aerodynamic database (http://fris2.nist.gov/winddata/) was constructed as part of the "NIST/TTU Cooperative Agreement-Windstorm Mitigation Initiative", which was a testing program initiated by E. Simiu of National Institute of Standards and Technology (NIST). All the wind tunnel tests were carried out in the Boundary Layer Wind Tunnel at University of Western Ontario (UWO) in the early 2000s. The UWO wind tunnel had a cross-section of $11 \mathrm{ft}$ wide and a height variable between $6 \mathrm{ft}$ and $9 \mathrm{ft}$. The mean wind speed profile of UWO wind tunnel conformed approximately to the logarithmic law with prototype roughness lengths of $z_{0}=0.098 \mathrm{ft}$ and $z_{0}=0.98 \mathrm{ft}$, corresponding to open and suburban exposure respectively. The turbulence intensities at $33 \mathrm{ft}$ (in prototype) were approximately 0.18 and 0.25 in the simulated open terrain and suburban exposures respectively.

The NIST aerodynamic database covers only one generic building configuration characterized by a rectangular shape in plan, gable roofs with various slopes, and no overhangs. The total number of buildings with distinct dimensions and roof slopes covered by the database is 37. The prototype eave heights range from $12 \mathrm{ft}$ to $40 \mathrm{ft}$, and the roof slopes range between 1/4:12 to 6:12. Each of the models were tested in both open terrain and suburban exposures for 39 wind directions at $5^{\circ}$ increments. The geometric scale was 1:100, and the time scale was approximately 3:100. A sample NIST/UWO model with its pressure taps is shown in Figure 2.1. 


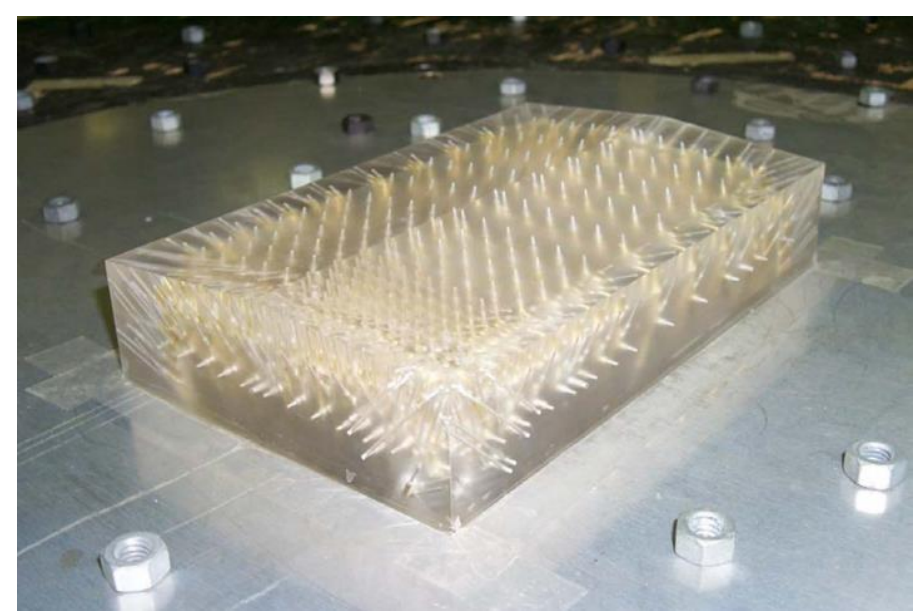

Figure 2.1 UWO Boundary Layer Wind Tunnel Building Model (Ho et al. 2003a)

A tubing system of 30 inch total length (consisting of 12 inch long PVC tube with internal diameter of 0.053 inch connected to the model, two 1.25 inch long brass tubing, two restrictors and a 13 inch long PVC tube with internal diameter of 0.035 inch connecting to the pressure scanner) was used to connect the pressure taps to the pressure scanners. The transfer function of the tubing system used to correct pressure signals, was measured by inputting white noise signal and collecting the signal after it passed through the tubing system. Pressure data were collected at sampling frequency of $500 \mathrm{~Hz}$ for a model duration of $100 \mathrm{~s}$, and saved in Hierarchical Data Format (HDF) format. The above information on the NIST aerodynamic database was taken from Ho et al. (2003a; 2003b), and Ho et al. (2005). More information regarding the database can be acquired from those documents.

\subsubsection{TPU Aerodynamic Datasets}

The Tokyo Polytechnic University (TPU) aerodynamic database (http://wind.arch.tkougei.ac.jp/system/eng/contents/code/tpu) was constructed by TPU as one part of the Wind Effects on Buildings and Urban Environment, the 21st Century Center of Excellence Program, 2003-2007. The wind pressure measurements were conducted in the $5.9 \mathrm{ft}$ high by $7.2 \mathrm{ft}$ wide wind tunnel at TPU. For the TPU wind tunnel's flow, the mean wind speed profile fitted the power law with exponent 0.20 and gradient height of $1476 \mathrm{ft}$; the simulated wind velocity and 
turbulence intensity at $33 \mathrm{ft}$ elevation were approximately $52.3 \mathrm{mph}$ and 0.25 ; and the integral longitudinal turbulence scale at $50 \mathrm{ft}$ elevation for strong flow conditions was on average $L_{u x} \approx$ $213 \mathrm{ft}$ (prototype values). The geometric scale was 1:100, and the time scale was approximately 3:100 (Quan et al. 2007).

The TPU database includes five distinct building categories that cover low-rise, medium-rise, and high-rise buildings. The TPU database buildings used here are similar in geometric shape to their gable-roof counterparts in the NIST database and cover four ratios of building height to building width $(1 / 4,2 / 4,3 / 4$, and $4 / 4)$, three ratios of building depth to building width $(2 / 2,3 / 2$ and $5 / 2)$, and eight roof slopes, totaling 96 distinct building geometries. The TPU models were tested in suburban exposure for 7 wind directions (i.e. $0^{\circ}$ to $90^{\circ}$ at $15^{\circ}$ increments). The building sizes are given in non-dimensional form. However, the lengths, widths and depths of the buildings are restricted by the requirement that the integral length scale of the longitudinal component of the atmospheric turbulence be modeled at approximately the same scale as the scale used to model the building (ASCE 7-10 Standard, Section 31.2). Thus, the total number of distinct building sizes and roof slopes is 4 x $3 \times 8=96$, that is, almost three times larger than for the NIST database.

The effect of the tube system on the measured wind pressure was largely removed by dividing the transfer function from the power spectra of the raw wind pressure. For each models, the sampling frequency was $500 \mathrm{~Hz}$ and the sampling period was 18 seconds, corresponding to $15 \mathrm{~Hz}$ and 10 minutes in full scale. The time series data were moving averaged every $0.006 \mathrm{~s}$, corresponding to $0.2 \mathrm{~s}$ in full scale. Time series of point wind pressure coefficients are stored in MATLAB data format.

For more information in the TPU aerodynamic database, the reader is directed to the TPU aerodynamic database website from which the above information was extracted. 


\subsubsection{Experimental Data from Testing at the Wall of Wind (WOW)}

External and internal pressure measurements on a large-scale model with multiple dominant openings were conducted at FIU's WOW facility (Figure 2.2). The WOW is an open jet facility capable of producing up to category 5 wind speeds on the Saffir-Simpson hurricane scale. It has 12 electric fans arranged in a two row by six-column pattern that produce a wind field $20 \mathrm{ft}$ wide and $14 \mathrm{ft}$ high, allowing aerodynamic testing of large-scale models or full-scale portions of buildings.

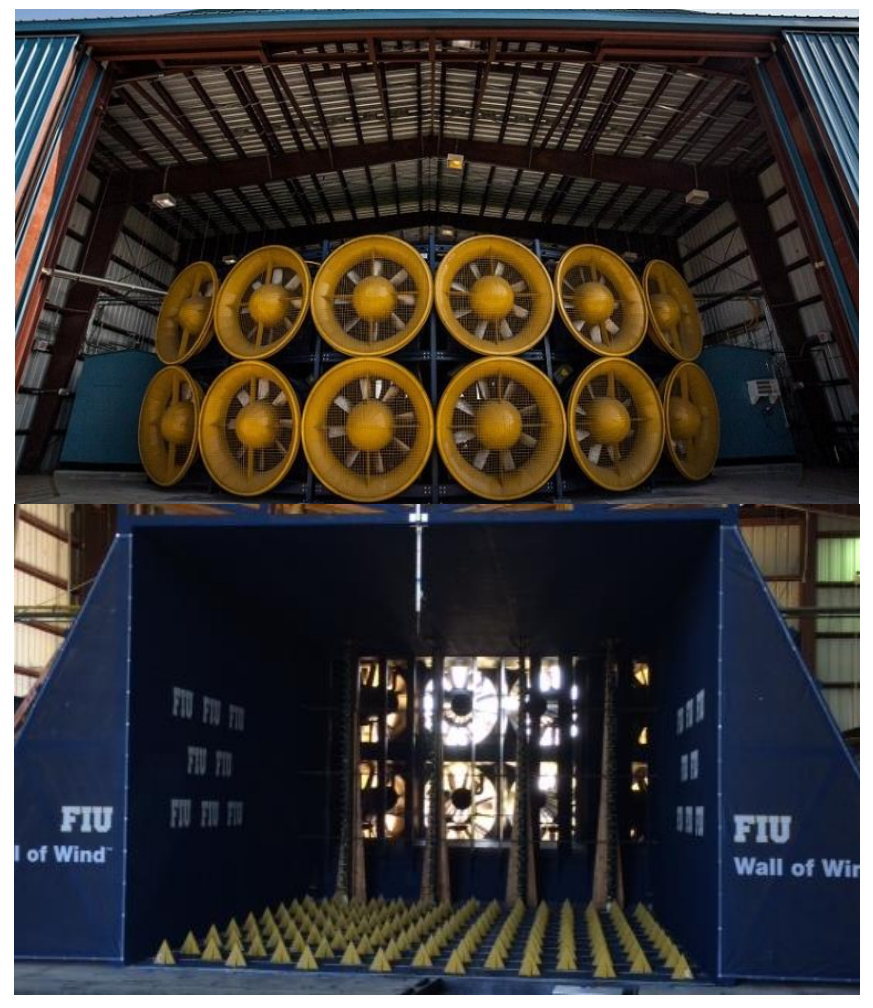

Figure 2.2 Wall of Wind (WOW) Facility at Florida International University (FIU)

Figure 2.3 shows WOW simulated open country conditions mean wind speed profile (with target ABL of $\alpha=1 / 6.5$ ), turbulence intensity profile, and content of the WOW generated turbulence spectrum at $1.5 \mathrm{ft}$ height and its comparison with the modified Kaimal spectrum. The Kaimal spectrum shown in Figure 2.3 is generated using a full-scale roughness length, $z_{0}$ of 0.066 $\mathrm{ft}$ (which is the typical roughness length of an open terrain exposure, as listed in the Commentary 
to ASCE 7-10, p. 540). It can be seen from Figure 2.3 that the WOW tests were conducted in a turbulence in which only the high-frequency components of a typical Atmospheric Boundary Layer (ABL) have been correctly simulated, i.e. in a so-called "Partial Turbulence Spectrum". Such conditions are common in large-scale tests as the limited size of the wind facilities hinders the simulation of the low-frequency turbulence and only the high frequency end of the turbulence spectrum can be simulated. Correct simulation of the high frequency fluctuations has been noted by a number of previous researchers as necessary for the correct simulation of local flow aerodynamics. Using different approaches Fu et al. (2014) and Asghari Mooneghi (2014) have shown that the effects of the low-frequency fluctuations can be included in post experiment analysis to produce accurate estimates of peak wind pressures/loads.
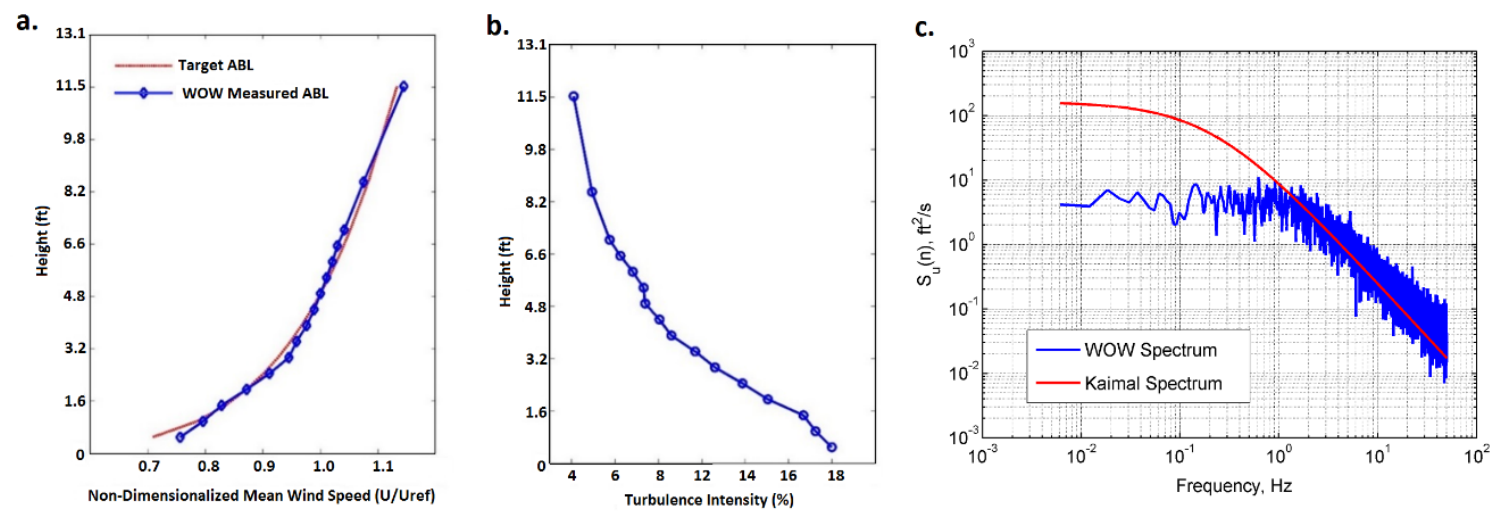

Figure 2.3 Simulation of open terrain ABL in the WOW: a) mean wind speed profile, b) turbulence intensity profile, and c) turbulence spectrum

The model used was a 1:8 scale model of a low-rise gable building having a geometric configuration similar to the NIST models. The prototype had width $\mathrm{B}=40 \mathrm{ft}$, length $\mathrm{L}=62.5 \mathrm{ft}$, eave height $\mathrm{H}=12 \mathrm{ft}$ and roof slope, $\theta=1 / 12$ (Figure 2.4). The experiments were conducted in a simulated open terrain and eave height wind speed of $33.6 \mathrm{mph}$ for 8 wind directions (i.e., $0^{\circ}$ to $315^{\circ}$ at $45^{\circ}$ increments). Time histories of global forces and pressures were measured simultaneously using load cells and large number of pressure tubes connected to a Scanivavle data acquisition system respectively. Measurements were conducted for a duration of 2 min 
(corresponding to 16 minutes in full-scale) at sampling rates of $100 \mathrm{~Hz}$ and $520 \mathrm{~Hz}$ for the global forces and pressures respectively. A tubing transfer function was developed (Irwin et al. 1979) and necessary corrections for pressure tubing length were performed. More details on the WOW model and the testing protocol are provided in Section 4.2.2.

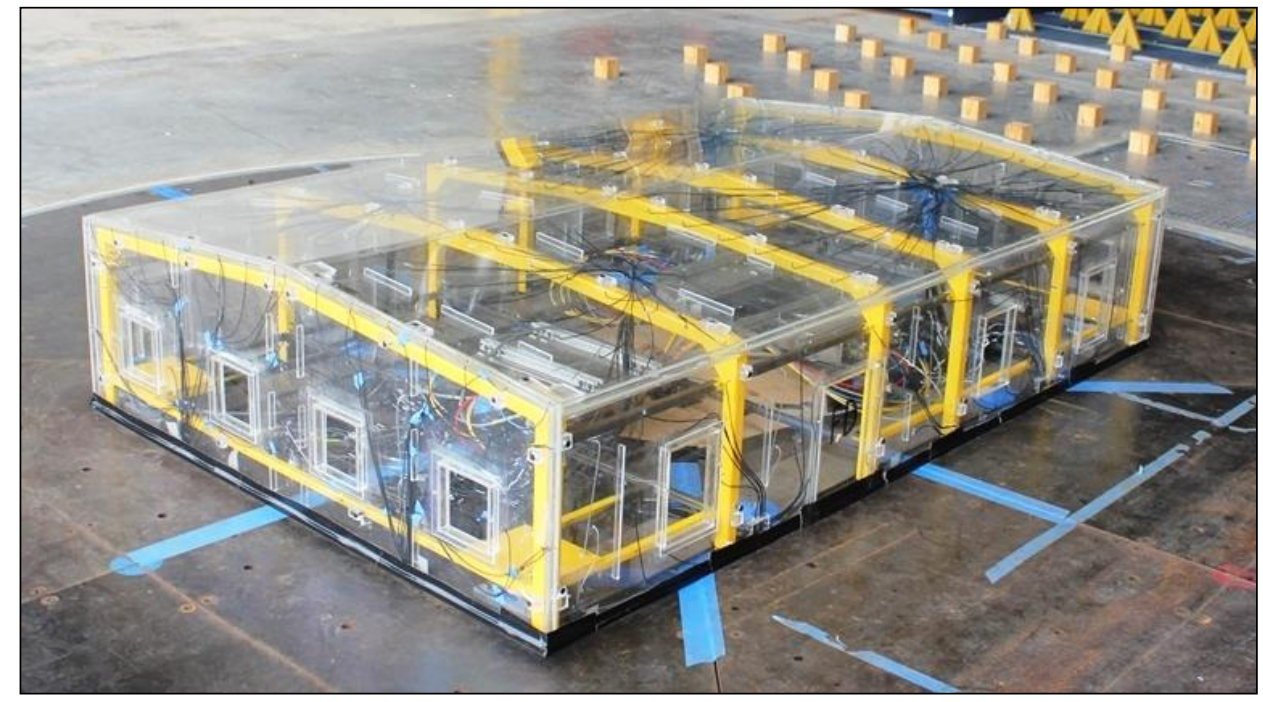

Figure 2.4 Wall of Wind (WOW) large-scale model

\subsection{Wind Climatological Databases}

Climatological databases typically consist of matrices of recorded or simulated extreme wind speeds versus their directions for different locations of interest. In this dissertation, climatological databases for hurricane and non-hurricane wind regions were used. The following sections provide descriptions of climatological databases for hurricane and non-hurricane prone regions used in this dissertation. The simulated hurricane and non-hurricane wind speeds used in this dissertation are supplied as 1 minute average wind speeds at $33 \mathrm{ft}$ height over open terrain exposure (roughness length $z_{0}$ open), in knots. The expression shown in Eq. (2.2) was used to convert those speeds to hourly average wind speed $\left(V_{\text {hourly }}^{H}\right.$ in $\left.\mathrm{ft} / \mathrm{s}\right)$ at desired heights, $H$, with terrain exposures of roughness length $z_{0}$. 


$$
V_{\text {hourly }}^{H}=1.35 *\left(\frac{z_{0 \text { open }}}{z_{0}}\right)^{0.0706} * \frac{\ln \left(\frac{32.8}{z_{0 \text { open }}}\right)}{\ln \left(\frac{H}{z_{0}}\right)}
$$

\subsubsection{Climatological Database for Hurricane Prone Regions}

The climatological databases for hurricane-prone regions used for this study consists of estimates of largest hurricane wind speeds generated by Batts et al. (1980) using Monte Carlo simulations. Batts et al. (1980) used probabilistic models of climatological characteristics of hurricanes, and physical models of hurricane wind structure in their Monte Carlo simulations. Statistical information on climatological characteristics of hurricanes were taken from Cry (1965) and Ho et al. (1975). The estimated hurricane characteristic models included hurricane occurrence rate (described as a constant rate Poisson process); pressure difference between center and periphery of storm $\left(\Delta P_{\max }\right.$, described as a log-normal distribution, and assumed to be below 0.135 bar to eliminate unrealistically high values); radius of maximum wind speeds ( $R$, described as a log-normal distribution, and assumed to be between 5 miles and 62 miles to avoid unrealistically tight or broad storms); speed of storm translation $(S$, described in a normal distribution, and assumed to be between $1.25 \mathrm{mph}$ and $40.4 \mathrm{mph}$ ); direction of storm motion and crossing point of storm along coast line (described in cumulative distribution function generated from historical data). And the assumed physical models of hurricane structure included wind speed as function of $\Delta P_{\max }, R, S$, latitude, and position of site being considered; rate at which the storm decays when it travels over land; reduction in storm wind speed due to overland travel friction; and dependence of wind speed over averaging times. 


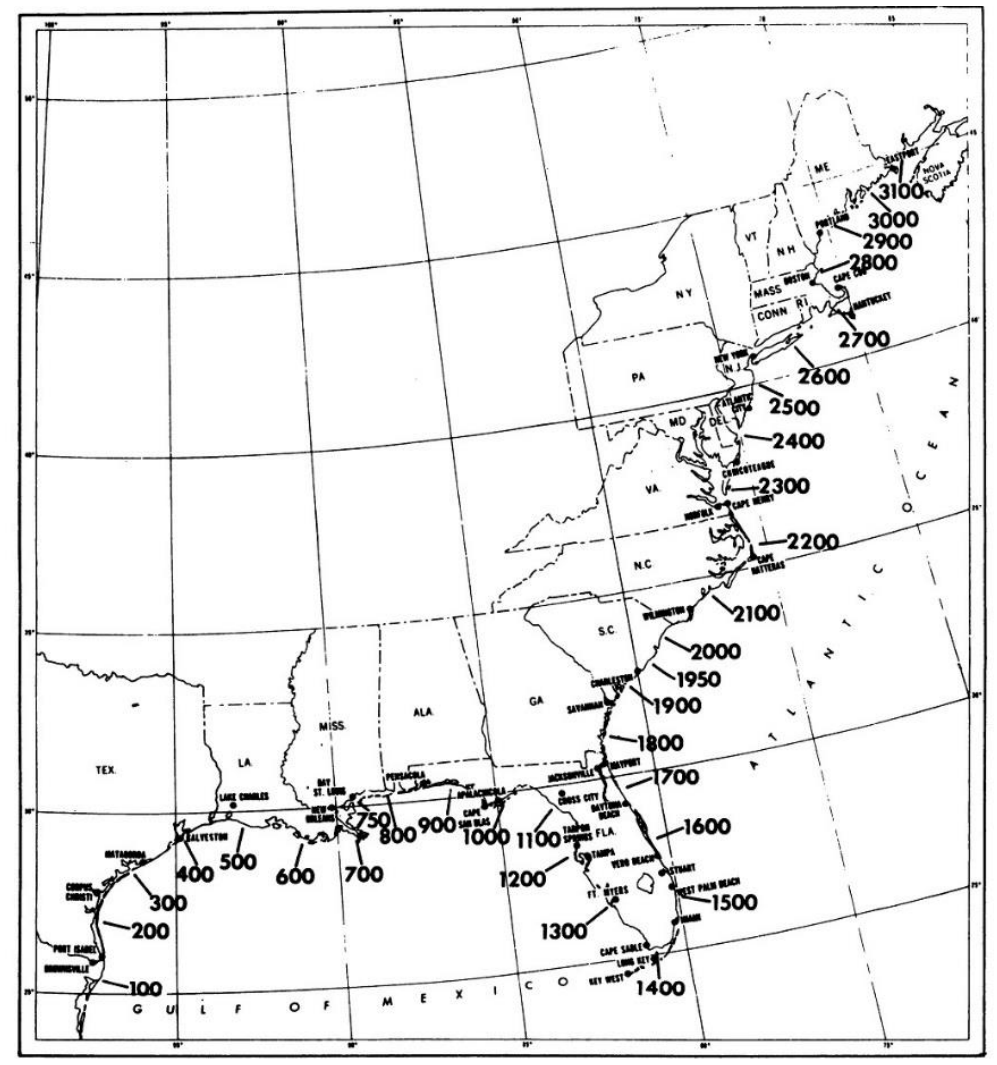

Figure 2.5 Location Mileposts / Locator Map with Coastal Distances in Nautical Miles (Batts et al. 1980)

Hurricane wind speeds were generated for 16 wind directions and 999 simulated storm events for 56 sites along the Gulf of Mexico and North Atlantic coast (Figure 2.5). Database of the generated hurricane wind speeds, along with the annual hurricane arrival rate for each of the 56 mileposts is available for public use at http://www.itl.nist.gov/div898/winds/hurricane.htm. The wind speeds are given as 1 min averaged speeds (in knots) at $33 \mathrm{ft}$ above open terrain exposure.

\subsubsection{Climatological Databases for Non-Hurricane Wind Regions}

For regions not prone to hurricanes, large directional climatological databases required for the estimation of wind effects with 300-yr to 3,000-yr MRIs were simulated using the procedure described in Yeo (2014). This procedure operates under the following assumptions, (i) the wind speed data contained in any two wind directional sectors are assumed to be independent, and (ii) 
The generalized Pareto distribution (GPD) is an appropriate model of extreme wind speeds. The procedure involves the following general steps; (1) the number of elemental sectors is selected, e.g. 18 sectors, with central angle of $360^{\circ} / 18=20^{\circ}$, (2) adjacent elemental sectors are consolidated if the number of data in the sectors is not sufficiently large to allow precise estimates of probability distributions, (3) for each directional sector (elemental or consolidated), an extreme value probabilistic model is fitted to the respective data sample (GPD model in conjunction with the peak over threshold (POT) approach is used), (4) finally a Monte Carlo simulation that uses the model of step (3) is used to generate the required simulated data for each sector. To ensure precise estimation of wind speed with a certain mean recurrence internal, the number of wind storms generated is recommended to be three or more times the total number of wind events which are expected to occur during that period of time.

For this dissertation, wind climatological database for four non-hurricane regions (Fort Worth, Texas; Indianapolis, Indiana; Kansas City, Missouri; and Phoenix, Arizona) were generated. The wind climatological databases for the non-hurricane regions were simulated for a maximum MRI of 7000 years for 18 wind-directions using thunderstorm and non-thunderstorm measured wind speed databases developed by Lombardo (http://www.itl.nist.gov/div898/winds/NIST TN/nist tn.htm) using the format presented in Lombardo et al. (2009).

\section{References}

ASCE 7-10. (2010). Minimum design loads for building and other structures. American Society of Civil Engineers, Reston, VA.

Asghari Mooneghi, M. (2014). "Experimental and Analytical Methodologies for Predicting Peak Loads on Building Envelopes and Roofing Systems." FIU Electronic Theses and Dissertations. FIU. (http://digitalcommons.fiu.edu/etd/1846)

Batts, M. E., Simiu, E., and Russell, L. R. (1980). "Hurricane wind speeds in the United States." Journal of the Structural Division, 106(10), 2001-2016. 
Cry, G. W. (1965). "Tropical Cyclones of the North Atlantic Ocean: Tracks and Frequencies of Hurricanes and Tropical Storms, 1871-1963, Technical Paper No. 55. US Department of Commerce." Weather Bureau, Washington, DC.

Fu, T.-C., Chowdhury, A. G., Bitsuamlak, G., and Baheru, T. (2014). "Partial turbulence simulation and aerodynamic pressures validation for an open-jet testing facility." WIND AND STRUCTURES, 19(1), 15-33.

Ho, F. P., Schwerdt, R. W., and Goodyear, H. V. (1975). "Some climatological characteristics of hurricanes and tropical storms, Gulf and East Coasts of the United States."

Ho, T. C. E., Surry, D., and Morrish, D. (2003a). NIST/TTU Cooperative Agreement-Windstorm Mitigation Initiative: Wind Tunnel Experiments on Generic Low Buildings. Tech. Rep. BLWT-SS20-2003, The Boundary Layer Wind Tunnel Laboratory, The University of Western Ontario, London, Ontario, Canada.

Ho, T. C. E., Surry, D., Morrish, D., and Kopp, G. A. (2005). "The UWO contribution to the NIST aerodynamic database for wind loads on low buildings: Part 1. Archiving format and basic aerodynamic data." Journal of Wind Engineering and Industrial Aerodynamics, 93(1), 1-30.

Ho, T. C. E., Surry, D., and Nywening, M. (2003b). "NIST/TTU cooperative agreementwindstorm mitigation initiative: further experiments on generic low buildings." BLWTSS21-2003, Phase, 2.

Irwin, H., Cooper, K. R., and Girard, R. (1979). "Correction of distortion effects caused by tubing systems in measurements of fluctuating pressures." Journal of Wind Engineering and Industrial Aerodynamics, 5(1), 93-107.

Lombardo, F. T., Main, J. A., and Simiu, E. (2009). "Automated extraction and classification of thunderstorm and non-thunderstorm wind data for extreme-value analysis." Journal of Wind Engineering and Industrial Aerodynamics, 97(3), 120-131.

Lombardo, F.T. (2013). Standardized extreme wind speed database for the United States, http://www.itl.nist.gov/div898/winds/NIST_TN/nist_tn.htm

Quan, Y., Tamura, Y., Matsui, M., Cao, S., and Yoshida, A. (2007). "TPU aerodynamic database for low-rise buildings.” 12th International Conference on Wind Engineering, 2-6.

Yeo, D. (2014). "Generation of large directional wind speed data sets for estimation of wind effects with long return periods." Journal of Structural Engineering, 140(10). 


\title{
3. DEVELOPMENT OF DESIGN METHODOLOGY OF RIGID STRUCTURES FOR WIND USING TIME SERIES OF DEMAND-TO-CAPACITY INDEXES
}

\begin{abstract}
Estimates of wind effects on rigid buildings by database-assisted design (DAD) methods can be far more accurate than those based on information available in building codes. A DAD based design procedure is presented that streamlines the wind engineering/structural engineering components of the design process by allowing the direct computation of Demand-to-Capacity Indexes (DCIs). The computation achieves the rigorous combination of imperfectly correlated time series of wind forces and effects thus eliminating errors due to subjective estimates of combined effects. While the basic approach being presented is applicable to any rigid building, the focus in this work is on simple buildings with gable roofs, portal frames, and bracing parallel to the ridge. Useful features of this work include: the capability to use the two largest building aerodynamics databases available worldwide; the use of large simulated extreme wind databases for hurricane- and non-hurricane-prone regions; time-series based first order and direct analysis methods for stability design; an effective multiple-points-in-time algorithm for estimating peaks; and parameter-free methods for estimating DCIs with specified mean recurrence intervals. The results obtained confirm the existence of inadequacies of the ASCE 7-10 envelope procedure, and DAD's potential for practical use in structural design.
\end{abstract}

\subsection{Introduction}

Conventional methods of determining wind loads on main wind force resisting systems (MWFRS) of rigid buildings involve the use of tables and plots provided in standards and codes. As was mentioned in Chapter 1, severe data storage limitations inherent in conventional standards can lead to estimates of wind loads which differ significantly from the actual loads experienced. Moreover, some building codes including the Minimum Design Load for Buildings and Other 
Structures (ASCE 7) are based on wind tunnel experiments conducted between three and four decades ago with obsolete pressure measurement technology, no available records of pressure measurements, and inadequate numbers of building geometries and pressure taps. In addition, calculations performed using different building codes have been observed to yield significantly different estimates of wind loads. For instance, Holmes et al. (2009) conducted comparison of wind load calculations on a typical steel portal-framed industrial warehouse building located in a rural area using fifteen different wind loading codes and standards from the Asia-Pacific Region, including the ASCE 7 and the National Building Code of Canada (NBCC). For net pressures coefficients, coefficients of variations (COV) of up to $31 \%$ and $26 \%$ were observed across the building roofs and window respectively. The observed variation was reported to be large considering the relative simplicity of the building.

Now that structural analysis has become highly sophisticated through use of finite element software, and powerful computers, more precise wind provisions are needed (Irwin 2009). Increased computational power and major advances in pressure measurement capabilities has led to the development of the database-assisted design (DAD) concept. DAD makes direct use of stored pressure time-histories calculate wind effects (see, e.g., Simiu et al. (2003)). One of DAD's useful features is that it allows wind effect combinations to be performed objectively via simple algebraic time series summations. For example, internal forces in structural members are in general induced by wind loads that act in the directions of the two principal axes of the structure, $x$ and $y$, and are therefore imperfectly correlated. Also, cross sections of the MWFRS are simultaneously acted upon by bending moments and axial forces that, typically, are also imperfectly correlated. The capability to perform rigorously correct combinations of wind effects distinguishes time-domain from frequency-domain techniques since, as typically used in wind engineering, the latter do not preserve phase relationships and therefore force designers to combine wind effects subjectively. 
Furthermore, gravity loads including dead and live loads induce negative bending moments at frame corners (a positive bending moment is defined to create tension at the bottom), but wind loading can impose extreme positive bending moment due to suction or negative bending moment due to a momentarily positive pressure on the roof. The latter wind action and so the wind effect is not taken into account in most building codes and standards, and this may lead to considerable underestimation of the total design moments (Kasperski 1996). However DAD possess the capability of rigorously analyzing for such cases through direct and thorough combination of gravity and wind loads.

The application of the DAD approach to rigid structures has so far been developed primarily for frames of simple gable roof buildings (Main and Fritz 2006). A main purpose of the procedure presented in this chapter is to expand the capabilities DAD by using time series of Demand-toCapacity Indexes (DCIs, i.e., left-hand sides of the design interaction equation) for structural design purposes. As shown in subsequent sections, this eliminates or reduces inaccuracies in the representation of wind effects and can result in more efficient designs. Moreover, this design method uses influence coefficients to evaluate internal frame forces induced by wind and/or gravity loads, and the influence coefficients are continuously updated as the member sizes change during the iterative-design process.

In this chapter, description of the DCI-based design methodology for rigid buildings is first provided. Then a practical application of this methodology is shown for the case of gable-roofed low-rise industrial buildings. However, it should be noted that the procedure can, with modest modifications, be adapted for use for any rigid buildings, including mid-rise buildings. Results of several case studies comparing designs based on the DCI-based procedure to those estimated using the ASCE 7-10 are also provided. A final section presents the conclusions of this work. 


\subsection{Description of the Time-Series of DCI based Iterative Design Procedure}

Structures tend to experience different types of internal forces simultaneously including axial forces, bending moment and shear forces, which must be considered in design. The interaction of some internal forces (e.g., combined flexure and axial loading), also need to be evaluated as shown in the design-interaction equations. Deflections are also required for serviceability considerations. For design purposes, it is necessary to evaluate the values of such load effects corresponding to a specified mean recurrence interval (MRI).

Besides the structural information of the building being analyzed, DAD based procedures use aerodynamic databases (Section 2.2) and climatological databases (Section 2.3) to evaluate load effects with specified MRI. Generally, pressure time histories from aerodynamic databases are used along with the structural properties, to compute wind effects corresponding to unit wind speed. Directional wind speeds from climatological databases are then combined with those wind effects to obtain peak wind effects corresponding to specified MRIs. In the design methodology presented here, time-histories of DCIs are evaluated first using building structural information and pressure data (this is described in section 3.2.1). Peak DCIs corresponding with specified MRI are then systematically evaluated by synthesizing with wind speed databases (this is described in section 3.2.2). This process is repeated until satisfactory DCIs are obtained, overview of the procedure is described in section 3.2.3.

\subsubsection{Estimation of Time-histories of Demand to Capacity Indexes (DCI)}

Different forms of design-interaction equations are applicable depending on type of material (i.e. steel, concrete, etc....), type of internal forces being considered, etc. For instance, for doubly and singly symmetric steel members, the American Institute of Steel Construction Manual (AISC 2010) recommends the use of Eqs. (3.1) when considering the combined effects of axial forces and bending moment; 


$$
\begin{array}{ll}
\frac{P_{r}}{\phi P} \geq 0.2, & \frac{P_{r}}{\phi P}+\frac{8}{9}\left(\frac{M_{r}^{X}}{\phi_{b} M^{X}}+\frac{M_{r}^{Y}}{\phi_{b} M^{Y}}\right) \leq 1 \\
\frac{P_{r}}{\phi P}<0.2, & \frac{P_{r}}{2 \phi P}+\left(\frac{M_{r}^{X}}{\phi_{b} M^{X}}+\frac{M_{r_{i}^{Y}}^{Y}}{\phi_{b} M^{Y}}\right) \leq 1
\end{array}
$$

where $P_{r}$ and $M_{r}$ denote axial and moment loads on member cross-section respectively; $P$ and $M$ represent member axial and flexural strengths, respectively; $\phi$ and $\phi_{b}$ are axial and flexural resistance factors, respectively; and superscripts $X$ and $Y$ used are used to represent in-plane and out-of-plane cross-sections, respectively. The left hand side of a design-interaction equation is known as the demand-to-capacity index (DCI). The sizing of the structural members is typically accomplished via the calculation of their DCIs. The final design is achieved when the member DCIs are less than and as close as possible to unity, to within specified serviceability and constructability constraints. Although the design procedure described herein can be used with different design interaction equations, Eq. (3.1) has been selected for demonstration.

The design-interaction-equation shown in Eqs. (3.1 a \& b) can be expressed in time-histories of DCIs pertaining to time-histories of axial forces and bending moments at cross section $j$ of frame $i$, denoted by $\operatorname{DCI}_{i j}(t, \theta)$, as follows

$$
\begin{array}{ll}
\frac{P_{r_{i j}(t, \theta)}}{\phi P_{i j}} \geq 0.2: & D C I_{i j}(\mathrm{t}, \theta)=\frac{P_{r i j}(\mathrm{t}, \theta)}{\phi P_{i j}}+\frac{8}{9}\left(\frac{M_{r i j}^{X}(\mathrm{t}, \theta)}{\phi_{b}^{M_{i j}^{X}}}+\frac{M_{r i j}^{Y}(\mathrm{t}, \theta)}{\phi_{b} M_{i j}^{Y}}\right) \leq 1.0 \\
\frac{P_{r_{i j}}(t, \theta)}{\phi P_{i j}}<0.2: & D C I_{i j}(\mathrm{t}, \theta)=\frac{P_{r i j}(\mathrm{t}, \theta)}{2 \phi P_{i j}}+\left(\frac{M_{r i j}^{X}(\mathrm{t}, \theta)}{\phi_{b}^{M_{i j}^{X}}}+\frac{M_{r i j}^{Y}(\mathrm{t}, \theta)}{\phi_{b} M_{i j}^{Y}}\right) \leq 1.0
\end{array}
$$

where $P_{r_{i j}}(t, \theta), M_{r_{i j}}^{X}(t, \theta)$, and $M_{r_{i j}}^{Y}(t, \theta)$ are time-histories of total axial load, in-plane bending moment, and out-of-plane bending moment respectively, which also vary with wind direction; $P_{i j}$, $M_{i j}^{X}$, and $M_{i j}^{Y}$ are the nominal axial, in-plane flexural and out-of-plane flexural strengths, respectively, of cross-section $j$ frame $i$. Equations (3.2) maintain the phase relationship between 
the different load effects (i.e., axial and bending moments), hence they produce DCIs rigorously commensurate with the actual combined wind effects.

For a given frame cross section subjected to wind loading, each internal force is a sum of contributions due to gravity loads (which are assumed to be constant in time) and wind forces (which are time-varying, and direction dependent). For rigid structures, wind-induced internal forces are proportional to the square of the wind speeds. Therefore, time histories of the windinduced internal forces $R_{i j}^{w}(t, \theta)$ at cross section $j$ of frame $i$, can be written as

$$
R_{i j}^{w}(t, \theta)=r_{i j}^{w}(t, \theta) V_{H, \theta}^{2}
$$

where $r^{w}{ }_{i j}(t, \theta)$ denotes the time series of the wind-induced internal forces at cross section $j$ of frame $i$ due to a unit wind speed at reference height $H$, and $V_{H, \theta}$ represents wind speed at height $H$ and wind direction $\theta$. Time-histories of the wind-induced internal forces due to a unit wind speed are estimated from the building's time-histories of net pressure coefficients, $C_{p, \text { net }}(t, \theta)$. Timehistories of net pressure coefficients are evaluated as algebraic sums of the external and internal pressure coefficients. Time-histories of external pressure coefficients can be taken from aerodynamic databases, but internal pressure data are not provided in most public databases, probably owing to the technical difficulties associated with conducting internal pressure measurements. However, internal pressures can be taken from building code provisions, or they can be numerically estimated from external pressure measurements using internal pressure models available in literature (for example Oh et al. 2007). Chapter 5 of this dissertation shows the significance of using correct internal pressure measurements in estimating wind induced effects and performing designs.

Time histories of the total internal forces on cross-section $j$ of frame $i, R_{i j}(t, \theta)$ induced by gravity and wind loads can then be expressed as

$$
R_{i j}(t, \theta)=f_{g} r_{i j}^{g}+f_{w} r_{i j}^{w}(t, \theta) V_{H, \theta}^{2}
$$


where $r_{i j}^{g}$ is the internal force at cross-section $j$ of frame $i$ due to gravity loads; and $f_{g}$ and $f_{w}$ are load combination factors for gravity and wind loads, respectively. This representation is considered advantageous as it allows direct combination of the simultaneously occurring gravity and wind forces, for each considered time-step, according to the levels of importance stipulated in each case of loading combination. Estimation of the internal forces, $r_{i j}^{g}$ and $r^{w}{ }_{i j}(t, \theta)$ makes use of influence coefficients as they provide a direct link between the load pattern and the internal forces/responses induced. During the iterative design procedure as the member sizes change the influence coefficients are updated.

Replacing the load terms in Eqs. (3.2) with the representation for total loading shown in Eq. (3.4), and separating the gravity and wind load terms gives

$$
\begin{aligned}
\mathrm{V}_{H, \theta} & \geq\left(\frac{0.2 \phi P_{i j}-f_{g} p_{i j}^{g}}{f_{w} p_{i j}^{w}(t, \theta)}\right)^{0.5} \\
D C I_{i j}(t, \theta) & =f_{g}\left(\frac{p_{i j g}}{\phi P_{j}}+\frac{8}{9}\left(\frac{m_{i j g}^{X}}{\phi_{b} M_{j}^{X}}+\frac{m_{i j g}^{Y}}{\phi_{b} M_{j}^{Y}}\right)\right)+f_{w}\left(\frac{p_{i j w}(t, \theta)}{\phi P_{j}}+\frac{8}{9}\left(\frac{m_{i j w}^{X}(t, \theta)}{\phi_{b} M_{j}^{X}}+\frac{m_{i j w}^{Y}(t, \theta)}{\phi_{b} M_{j}^{Y}}\right)\right) * \mathrm{~V}_{H, \theta}^{2} \\
\mathrm{~V}_{H, \theta} & <\left(\frac{0.2 \phi P_{i j}-f_{g} p_{i j}^{g}}{f_{w} p_{i j}^{w}(t, \theta)}\right)^{0.5} \\
D C I_{i j}(t, \theta) & =f_{g}\left(\frac{p_{i j g}}{2 \phi P_{j}}+\frac{m_{i j g}^{X}}{\phi_{b} M_{j}^{X}}+\frac{m_{i j g}^{Y}}{\phi_{b} M_{j}^{Y}}\right)+f_{w}\left(\frac{p_{i j w}(t, \theta)}{2 \phi P_{j}}+\frac{m_{i j w}^{X}(t, \theta)}{\phi_{b} M_{j}^{X}}+\frac{m_{i j w}^{Y}(t, \theta)}{\phi_{b} M_{j}^{Y}}\right) * \mathrm{~V}_{H, \theta}^{2}
\end{aligned}
$$

In Eqs. (3.5a \& b), the DCIs are divided into gravity loads-induced DCIs and wind-induced DCIs. The wind induced DCIs are evaluated for unit wind speeds and combined with winds from climatological databases as described briefly in the next section, and in details in Chapter 4. Equations (3.5) also shows that different DCI expressions apply for different wind speeds, hence peak DCIs are not proportional to the squares of the wind speeds inducing them (i.e. the DCIs depend nonlinearly upon the axial load, which in turn depends on wind speed). 


\subsubsection{Estimation of Peak DCIs and Deflections for Specified MRIs}

Peak DCIs with specified MRIs are obtained by combining the DCIs corresponding to unit or specified wind speeds with the directional wind speeds from wind climatological databases. The climatological database consists of (i) a $p \times q$ matrix ( $p$ rows and $q$ columns) of largest directional wind speeds $V_{s \theta}$ (the index $s=1,2, \ldots, p$ denotes the storm event and the index $\theta=1$, $2, \ldots, q$, e.g., $q=16$, denotes the wind direction), and (ii) the mean annual rate of storm occurrence $\lambda$. It is recommended that, for the precision of the estimates to be acceptable, the number of storm events in climatological database be $p>3 N \lambda$, where $N$ is the MRI of interest in years (Yeo 2012; Simiu 2011).

For buildings with known orientation, the estimation of the peak DCI (for a frame crosssection) with an $N$-year MRI proceeds as follows. In the matrix [ $\left.V_{s \theta}\right]$ each wind velocity $V_{s \theta}$ is replaced by the demand-to-capacity index $\mathrm{DCI}_{s \theta}$, corresponding to that wind velocity. In the matrix so obtained all but the entries $\max _{\theta}\left[\mathrm{DCI}_{s \theta}\right]$ are disregarded, since only the largest of the DCIs induced in that cross section in any one storm is of interest in design. The vector $\max _{\theta}$ $\left[\mathrm{DCI}_{s \theta}\right](s=1,2, \ldots, p)$ so obtained is then rank-ordered. The MRI $N$ of the DCI with rank $r$ is $N$ $=(p+1) /(r \lambda)$ (Simiu 2011). The procedure just described accounts for wind directionality effects directly, without the intervention of a wind directionality factor, and it yields a physically correct estimation of the pressures or forces with an $N$-year MRI.

For buildings with unknown orientation, two different approaches maybe followed. In the first approach which is referred to as the non-directional approach, the procedure described for the case of buildings with known orientation is modified by replacing the wind speeds $V_{s \theta}$ in each row $s$ of the matrix $\left[V_{s \theta}\right]$ by the largest wind speed regardless of direction, $\max _{\theta}\left[V_{s \theta}\right]$. The DCI with an $N$-year MRI obtained following this modification is then multiplied by the directionality reduction factor $K_{d,}$, smaller that unity to account for the fact that the most critical aerodynamic and climatological directions typically do not coincide. In the second approach, which is referred 
to as the directional approach, a large numbers of building orientations with a uniform probability of occurrence are considered, and several DCIs with N-year MRI are obtained for each considered orientation. The required DCI with N-year MRI is then estimated as the mean of those DCIs. Detailed explanations and applications for both the non-directional and directional methods of synthesizing aerodynamic and climatological information for estimation of peak DCIs with specified MRIs are provided in Chapter 4. The estimation of deflections with specified MRI can be performed in a manner similar to that described for DCIs.

\subsubsection{Overview of the Design Procedure}

The design follows the phases represented in Figure 3.1. The preliminary design must start with an informed guess as to the MWFRS's member sizes (i.e., with a preliminary design denoted by $D e s_{0}$ ), to which there corresponds a set of influence coefficients denoted by $I C_{0}$. The wind loads applied to this preliminary design can be taken from the standard or code being used. The next step is the calculation of the DCIs inherent in the design $D e s_{0}$. The cross sections are then modified so that their DCIs are close to unity. This results in a new design, Des $_{1}$, for which the corresponding set of influence coefficients, $I C_{1}$, and a new set of DCIs are calculated. The procedure is repeated until a design $D e s_{n}$ is achieved such that the effect of using a new set of influence coefficients, $I C_{n+1}$, is negligible, that is, until the design $D e s_{n+1}$ is in practice identical to the design $D e s_{n}$. Next, the procedure is repeated by using, instead of the Standard wind loads, the loads based on the time histories of the pressure coefficients taken from the aerodynamics database. This results in a design $\operatorname{Des}_{n+2}$, to which there corresponds a set of influence coefficients $I C_{n+2}$ and a new set of DCIs. The cross sections are then modified so that the DCIs

are close to unity. Typically this will be the final design $\operatorname{Des}_{f i n a l}$, although the user may perform an additional iteration to check that convergence of the DCIs to unity has been achieved, to within constructability and serviceability constraints. 


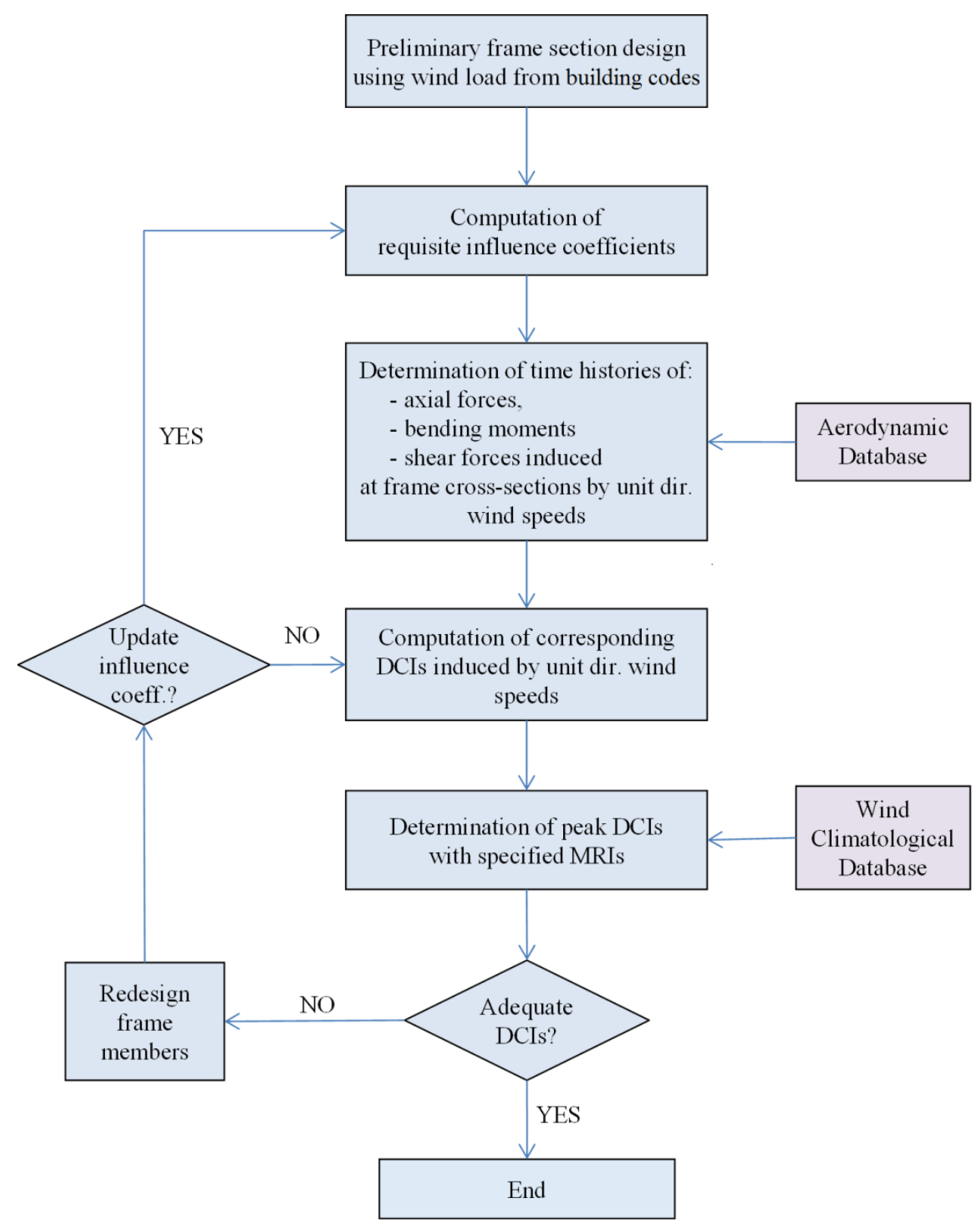

Figure 3.1 Overview of Design Procedure

\subsection{Application of the Time-Series of DCI based Iterative Design Procedure}

This section presents an application of the time-series of DCIs based iterative design procedure, demonstrating DAD's capability of being used as a design tool instead of being limited to estimating wind effects. Gable roofed industrial buildings with no overhang, and their MWFRS consisting of equally spaced moment resisting steel portal frames are selected for this 
application. This type of building configuration is selected because it represents the majority of building shapes in the NIST and TPU aerodynamic databases for low-rise buildings. Detailed description of the structural configuration, and methods employed in transferring gravity and wind load from building cladding to building frames are provided in Sections 3.3.1 and 3.3.2, respectively.

The Load Resistance Factor Design (LRFD) method, with loading combinations for strength design stipulated in the ASCE 7-10 is followed. The calculation of the DCIs makes use of the procedures for determining member capacities specified in the AISC (2010), and frame stability analysis is performed according to a time-series based first-order analysis method which is described in Section 3.3.4.

Checking the adequacy of a cross section's design consists of ascertaining that, subject to possible serviceability constraints, its DCI is close to and less than unity. If the DCI of a cross section does not satisfy this condition, the cross section is redesigned. The structural member properties based on this iteration process are then used to recalculate the requisite influence coefficients and perform checks based on those recalculated values. Owing to the dependence of DCI on the axial force, peak DCIs are not proportional to the squares of the wind speeds inducing them. Therefore, databases of peak DCIs induced by winds with a sufficient number of directions and speeds were developed for the structure being designed (this is described Section 3.3.5). The calculations of peak DCIs use an economical multiple-points-in-time (MPIT) method developed by Yeo (2012) as is shown in subsequent sections. The peak DCI databases are properties of the structure that depend upon the structural system's configuration, member sizes, and terrain exposure, and are independent of the wind climate. The databases are then combined with wind speed datasets and used to estimate peak DCIs with any specified MRI by using non-parametric statistics (this is described Section 3.3.6). Section 3.3.7 presents results of several case studies illustrating the capabilities of this design procedure. 
The application described here has been implemented in a MATLAB based software. The Graphic User Interphase (GUI) and source codes of software, user manual, sample building input files, and aerodynamic and climatological databases are available at www.nist.gov/wind - under Wind Design.

\subsubsection{Description of the Structural System}

The MWFRS being considered consists of equally spaced moment-resisting steel portal frames (with compact flange and web elements) spanning the width of the building (Figure 3.2). Portal frames are the most commonly used structural forms in low-rise industrial buildings, and are typically designed using web-tapered members. Roof and wall panels form the exterior envelope of the buildings, and are attached to purlins and girts supported by the frames.

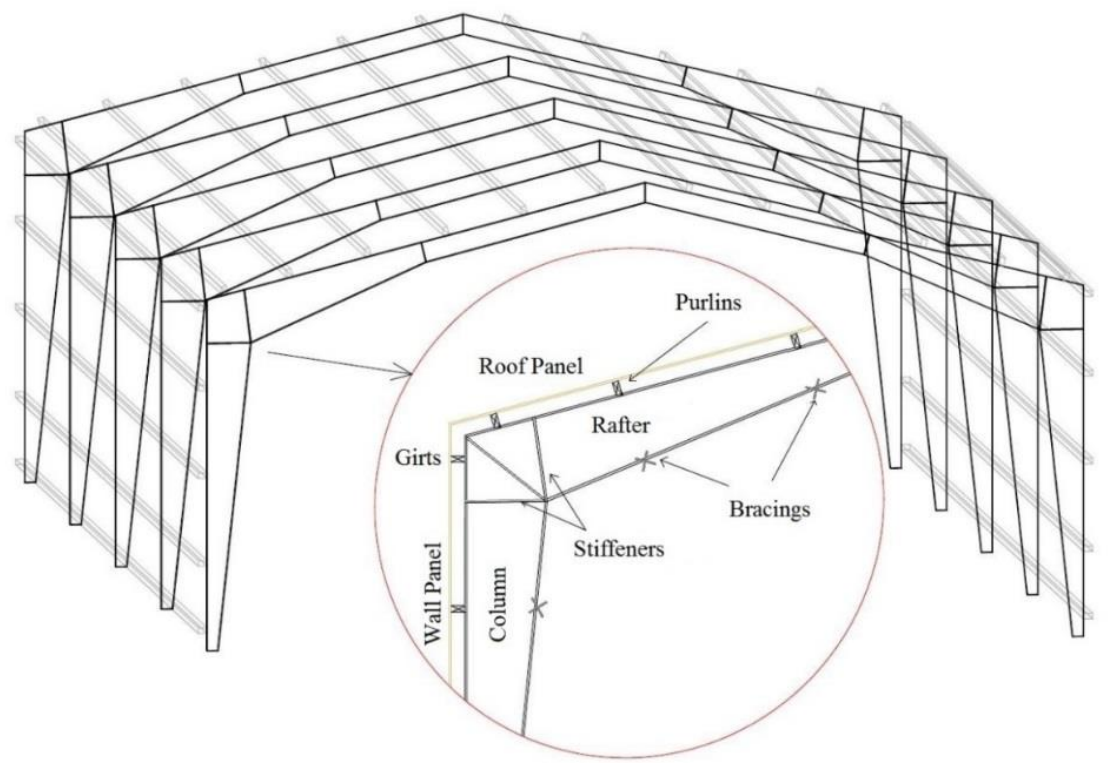

Figure 3.2 Layout of Addressed Structural System

The design procedure is based on the following assumptions: (1) bracing is provided in the planes of the exterior walls parallel to the ridge, hence responses to loads in that direction are not considered, (2) the coupling between frames due to the roof diaphragms is neglected, (3) the purlins and girts are attached to the frames by hinges, (4) the purlins and girts act as bracings to the outer flanges, and the inner flanges are also braced. The following limitations are imposed: 
(1) The taper should be linear or piecewise linear and (2) its slope should typically not exceed $15^{\circ}$ (Kaehler et al. 2011).

\subsubsection{Transforming of Building Loads to Internal Frame Forces}

This section describes the assumptions and procedures used to evaluate internal frame forces induced by gravity and wind loads.

Gravity Loads. Gravity loads can be assumed static. Herein, the gravity loads are divided into two groups i.e. superimposed loads and frame self-weight. The superimposed loads represent imposed dead-load and roof-live-load, and are assumed to be distributed uniformly on the roof surface acting in the vertical downward direction. Hence, superimposed loads acting through the framepurlin connections are functions of the spacing between adjacent frames and adjacent purlins (i.e. the frame-purlin connection's tributary area, $A_{p}$ ). Gravity loads due to self-weights are determined by dividing the frames into large number of elements and assuming the weight of each element, $W_{e}$, to act vertically downward at the element's center. Gravity loads-induced internal forces at cross section $j$ of frame $i, r_{i j}^{g}$ are then evaluated as

$$
r_{i j}^{g}=\sum_{k=1}^{n z} N_{i j, S I}^{k} A_{p} U_{S I}+\sum_{e=1}^{n e} N_{i j, S W}^{e} W_{e}
$$

where $N_{i j, \text { sI }}^{k}$ represents influence coefficient of the superimposed load acting on the $k$-th purlin attachment to the internal force (i.e. axial, bending moment, etc..) at cross section $j$ of frame $i$; $N^{k}{ }_{i j, \text { SW }}$ denotes influence coefficient of the self-weight of the $e$-th element to the internal force at cross section $j$ of frame $i$; $n_{z}$ and $n_{e}$ are number of purlin-frame attachments and number of frame elements (divisions) respectively; and $U_{S I}$ and $W_{e}$ represent the uniform superimposed load and weight of frame element $e$ respectively.

Wind Loads. Wind loads are non-uniform and time varying. Pressures on wall and roof claddings are first transferred to the purlins under the assumption that the claddings and purlins are connected using hinges. The wind pressure is then transferred to the frames by analyzing each 
purlin as a simply supported beam. The assumptions and procedures followed in transferring wind loading from pressure taps on the exterior building surfaces to structural frames are similar to those used in Main and Fritz (2006), which contains detailed descriptions and explanations.

Time histories of the wind-induced internal forces at cross section $j$ of frame $i$, due to a unit wind speed with direction $\theta$ at eave height $H, r^{w}{ }_{i j}(t, \theta)$ are computed as shown in Eq. (3.7),

$$
r_{i j}^{w}(t, \theta)=1 / 2 \rho \sum_{k=1}^{n_{z}} N_{i j}^{k} A_{i}^{k} C_{p, n e t}^{k}(t, \theta)
$$

where $\rho$ is air density; $N_{i j}^{k}$ is the influence coefficient representing the internal force at cross section $j$ of frame $i$, due to a unit force applied at the $k$-th point of attachment of a purlin or girt to the frame $i$; and $A^{k}$ represents the tributary area of the $k$-th point; $C_{p, n e t}^{k}(t, \theta)$ is the net pressure coefficient applicable at the $k$-th attachment point, associated with a wind speed at direction $\theta$ and height $H$; and $n_{z}$ is the number attachment points on frame $i$.

\subsubsection{Estimation of DCIs}

In the particular case of the type of structure addressed here the wind forces acting along the axis parallel to the ridge are resisted by secondary bracing members; hence the wind force contributions to the DCIs are due only to forces normal to the building's ridge, and Eq. (3.4) can be reduced to

$$
\begin{array}{ll}
\frac{P_{r_{i j}}(t)}{\phi P_{i j}} \geq 0.2: & D C I_{i j}(t)=\frac{P_{i j}(t)}{\phi P_{i j}}+\frac{8}{9}\left(\frac{M_{r_{i j}^{X}}^{X}(t)}{\phi_{b} M_{i j}^{X}}\right) \\
\frac{P_{r_{i j}}(t)}{\phi P_{i j}}<0.2: & D C I_{i j}(t)=\frac{P_{r_{i j}}(t)}{2 \phi P_{i j}}+\frac{M_{r_{i j}}^{X}(t)}{\phi_{b} M_{i j}^{X}}
\end{array}
$$

The effects of shear load are also considered and the demand-to-capacity index for shear forces $D C I^{V}{ }_{i j}(t)$ at cross section $j$ of frame $i$ is computed as follows

$$
D C I_{i j}^{V}(t)=\frac{S_{r_{i j}(t)}}{\phi_{v} S_{i j}}
$$


where $S_{r i j}(t)$ denotes the time history of the total shear load, $S_{i j}$ is the nominal shear strength of cross-section $i-j$, and $\phi_{v}$ is the resistance factor for shear forces. Note that the significance of the $D C I^{P M}$ is broader than that of the $D C I^{V}$, in that a cross section's $D C I^{P M}$ can take into account the action of more than one internal force. The force time histories in Eqs. (3.8) and (3.9) are computed using Eq (3.4) as sums of factored load effects due to gravity and wind loads, by considering the following five LRFD load combination cases; Case 1: $1.4 \mathrm{D}$, Case $2: 1.2 \mathrm{D}+0.5 \mathrm{~L}_{\mathrm{r}}$, Case 3: $1.2 \mathrm{D}+1.6 \mathrm{~L}_{\mathrm{r}}+0.5 \mathrm{~W}$, Case $4: 1.2 \mathrm{D}+1.0 \mathrm{~W}+0.5 \mathrm{~L}_{\mathrm{r}}$, and Case $5: 0.9 \mathrm{D}+1.0 \mathrm{~W}$, where $\mathrm{D}$, $\mathrm{L}_{\mathrm{r}}$, and $\mathrm{W}$ denote dead load (including both superimposed dead load and frame self-weight), roof live load and wind load, respectively.

The calculation of the DCIs makes use of the procedures for determining member capacities specified in the AISC (2010) and Steel Design Guide 25: Frame Design Using Web-Tapered Members (Kaehler et al. 2011). Preliminary investigation of the stability of the frame members showed that secondary moments have typically negligible effects on the type of structure being considered. However, in order to comply with the AISC's design for stability requirements, the first order analysis method of design was followed. In the first order analysis, second-order effects are neglected and equilibrium conditions are formulated on the un-deformed structure (AISC 2010). This method, accounts for geometric imperfections, and requires that the total member moments be multiplied by an amplifier $B_{1}$, and that lateral notional loads be applied in every loading combination. Description of a time-series based first order analysis method used in this application is provided in section 3.3.4. Note that this design method can also be used with the direct analysis, effective length method or any other method for analyzing the secondary moment effects.

The frame members' elastic in-plane buckling capacity, which is required for computing the axial capacity of the frame cross-sections, $P_{i j}$, where the subscripts $i$ and $j$ identify the frame and the cross section, respectively, is computed using the method of successive approximations as 
described in Timoshenko (1936) and Timoshenko and Gere (1961). Note that for straight, geometrically perfect prismatic members with constant axial forces, the Euler's buckling equation can be used to calculate the member's flexural buckling capacity. However, in tapered members subjected to constant or varying internal axial force, there is no practical exact closed form solution of the buckling strength. Nonetheless, it can be approximated using methods such as; the equivalent moment of inertia method, method of successive approximations, or the Eigenvalue buckling analysis method (Kaehler et al. 2011). In this study, the method of successive approximations was selected because it is simple, easily programmable, and gives accurate estimates of buckling strengths. Moreover, this method can handle multiple tapers, plate changes, and changes in axial loading along the length of the member. Step-by-step description of the used method of successive approximations is available in Timoshenko and Gere (1961), pp. 116. The in plane and out-of-plane buckling capacities were compared and the critical ones were selected for calculating the axial capacity of the frame cross sections.

Once time histories of total individual internal forces are determined, the estimation of combined internal forces associated with the axial forces and bending moments required for DCI calculations is performed using the multiple points-in-time (MPIT) approach for estimating peak wind effects (Yeo 2012). In this approach, the largest $n$ local peaks (in absolute value) from the time series of each force or moment are selected first. Next, the ordinates at the times of occurrence of those $n$ peaks are selected in each of the $m-1$ time series to be combined with that force or moment, where $m$ is the total number of time series being combined. The combination of internal forces is then performed only for the $m \times n$ points so selected, rather than for the whole length of the time series. The estimated peak of the combined effects is then computed as the largest of the $m \times n$ combinations. This method significantly reduces the amount of computation required. Comparisons of DCIs computed using the entire time-histories of axial and bending 
moments to those calculated using the MPIT method with $n=20$ showed that the MPIT approach produces highly accurate results, and was used in this application.

\subsubsection{Time-Series Based Methods for Stability Analysis}

In this application, a time-series based first order analysis method is used for stability analysis. According to the AISC (2010), the first order analysis method is permitted for use when the ratio of frame drift estimated by a second-order analysis to its counterpart estimated by a firstorder analysis, $\Delta_{2 \text { nd }} / \Delta_{1 \mathrm{st}}$, is less than or equal to 1.5 . The ratio $\Delta_{2 \mathrm{nd}} / \Delta_{1 \mathrm{st}}$ can be estimated by the amplifier $B_{2}$ that is defined in Eq. (3.10). In addition, the required axial compressive strength, $P_{r}$ should be less than $0.5 P_{y}$, where $P_{y}$ is the lowest axial yield strength of member. The software pertaining to this work assures that this requirement is satisfied. The first order analysis method requires that the non-sway amplification of the moments be accounted for by applying the $B_{1}$ amplifier to the total member moments. Moreover, notional loads must be applied in addition to any lateral loads in each load combination. In cases where the requirements for using the first order method are not satisfied, the approximate second order analysis can be used. This section provides description of those two stability analysis methods, and how they can be used in this application of the DAD/DCI method of design.

\section{First order analysis method}

Estimation of $B_{\underline{2}}$. According to the AISC (2010) the moment amplifier $\mathrm{B}_{2}$ can be estimated as;

$$
B_{2}=\frac{1}{1-\alpha P_{\text {story }} / P_{\text {estory }}}
$$

where $\alpha=1.0$ (for LRFD), $P_{\text {story }}$ represents the total vertical load on frame, and $P_{e \text { story }}$ is story critical buckling strength, which is evaluated as shown in Eq. (3.11)

$$
P_{\text {estory }}=R_{M} \frac{F H}{\Delta_{H}}
$$


where $F$ represents story shear in the direction of lateral loading, $H$ is eave height, $\Delta_{H}$ denotes first order inter-story drift calculated using the lateral wind load, and $R_{M}$ is evaluated as shown in Eq.

$$
R_{M}=1-0.15\left(P_{m f} / P_{\text {story }}\right)
$$

where $P_{m f}=$ total vertical load in columns that are part of moment frames. For this application the total vertical load, $P_{\text {story }}$ is calculated conservatively as the factored sum of the dead and live loads only. For the type of structure addressed herein $P_{m f}=P_{\text {story }}$, hence $R_{M}=0.85$. The time history of story critical buckling strength, $P_{e \text { story }}(t, \theta)$ is calculated using Eq. (3.13).

$$
P_{\text {estory }}(t, \theta)=0.85 \frac{F(t, \theta)^{*} H}{\Delta_{H}(t, \theta)}=0.85 H \frac{\sum_{k=1}^{n} N_{i j, F}^{k} A^{k} C_{P}^{k}(t, \theta)}{\sum_{k=1}^{n} N_{i j, \Delta}^{k} A^{k} C_{P}^{k}(t, \theta)}
$$

where $N_{i j, F}^{k}$ and $N_{i j, 4}^{k}$ denote the influence coefficient for the $k$-th attachment point (i.e. purlin or girt) on $F$ and $\Delta_{H}$ respectively; $A^{k}$ represents the tributary area of the $k$-th attachment point; and $C_{p}^{k}(t, \theta)$ is time-series of pressure coefficients for the $k$-th attachment point and wind direction $\theta$ normalized at height $H ; n$ is the number attachment points on frame $i$. For each wind direction being considered the mean $P_{e}$ story is then evaluated and its smallest value is selected for the evaluation of $B_{2}$ using Eq. (3.10).

Estimation of $B_{1 .} B_{1}$ is calculated using Eq. (3.14):

$$
B_{1 i j}(t, \theta)=\frac{C_{m}}{1-\alpha P_{r i j}(t, \theta) / P_{e, i j}}
$$

where $C_{m}$ is conservatively taken as $1.0, \alpha=1.0$ (for LRFD), $P_{r i j}(t, \theta)$ is the time history of the total factored axial loads on the cross section $j$ of frame $i$, and $P_{e, i j}$ is the in-plane flexural buckling strength of cross section $j$ of frame $i$. Note that each bending moment in the time series of responses at every frame's cross section is multiplied by the estimated value of $B_{1 i j}(t, \theta)$. 
Estimation of Notional Loads. When using the first order analysis method, it is required that notional loads, $Y_{n o t}$, calculated using Eq. (3.15), be applied laterally in all loading combination cases. In the $\mathrm{DAD} / \mathrm{DCI}$ approach, time histories of notional loads, and the internal frame responses, $R_{n o t}$, they induce are calculated using Eq. (3.16) and Eq. (3.17) respectively.

$$
\begin{aligned}
& Y_{\text {not }}=2.1 \alpha(\Delta / H) Y_{i} \geq 0.0042 Y_{i} \\
& Y_{n o t}^{k}(t, \theta)=\frac{2.1}{H}\left(\frac{1}{2} \rho \mathrm{V}_{H}^{2} \sum_{k=1}^{n} N_{i j, \Delta}^{k} A^{k} C_{P}^{k}(t, \theta)\right) Y_{i}^{k} \geq 0.0042 Y_{i}^{k} \\
& R_{i j}^{\text {not }}(t, \theta)=\sum_{k=1}^{n} N_{i j, Y}^{k} Y_{n o t}^{k}(t, \theta)
\end{aligned}
$$

where $Y_{i}$ is total gravity loads on each story; $\rho$ is air density; $V_{H}$ is the wind velocity at height; $N_{i j, Y}^{k}$ denotes the influence coefficient of the notional load acting on the $k$-th attachment point (i.e. purlin or girt) on $R_{i j}{ }^{n o t}, A^{k}$ is the tributary area of the $k$-th attachment point, and $Y^{k}{ }_{n o t}$ is the lateral notional load acting on attachment $k$.

\section{Approximate Second Order Analysis Method}

In the approximate second order analysis method, second order effects can be accounted for by using the amplified first-order analysis method as specified in the Appendix 8 of the AISC (2010). The effects of initial imperfections on structure stability are taken into account using the notional loads method, and stiffness reduction due to member inelasticity (due to residual stresses) is also considered. According to the approximate second-order analysis, the required axial, $P_{r}$, and bending moment, $M_{r}$, loads can be written as:

$$
\begin{aligned}
& P_{r}=P_{n t}+B_{2} P_{l t} \\
& M_{r}=B_{1} M_{n t}+B_{2} M_{l t}
\end{aligned}
$$

where subscripts " $n t$ " and " $l t$ " refer to non-translational and translational respectively, and $B_{l}$ and $B_{2}$ represent amplifications due to member effects (i.e. P- $\delta$ effects) and frame effects (i.e. P$\Delta$ effects) respectively. $B_{1}$ and $B_{2}$ are calculated using Eq. (3.14) and Eq. (3.10) respectively, 
however, after accounting for stiffness reduction as explained below. For this case of gable roofed low-rise buildings, the wind load on the walls and the horizontal component of wind load on the roof constitute the lateral (translational) loads while the non-translational loads are caused by the gravity loads and the vertical component of the wind load on the roof. Time-histories of the required axial (i.e. $P_{r i j}(t, \theta)$ ) and (i.e. $M_{r i j}(t, \theta)$ ) bending moments at cross-section $j$ of frame $i$ can be computed as shown in Eq. (3.20) and Eq. (3.21) respectively

$$
\begin{aligned}
& P_{r i j}(t, \theta)=f_{g}\left(\sum_{k=1}^{n_{z}} N_{i j, S I}^{k} A^{k} U_{S I}+\sum_{e=1}^{n e} N_{i j, S W}^{e} W_{e}\right) \\
& +f_{w} * \frac{1}{2} \rho \mathrm{V}_{H, \theta}^{2}\left(\sum_{k=1}^{n z} N_{i j, n t}^{k} A^{k} C_{P}^{k}(t, \theta)+B_{2}(t, \theta)\left(\sum_{k=1}^{n_{z}} N_{i j, l t}^{k} A^{k} C_{P}^{k}(t, \theta)\right)\right) \\
& M_{r i j}(t, \theta)=f_{g} * B_{1 i j}(t, \theta)\left(\sum_{k=1}^{n_{z}} N_{i j, S I}^{k} A^{k} U_{S I}+\sum_{e=1}^{n e} N_{i j, S W}^{e} W_{e}\right) \\
& +f_{w} * \frac{1}{2} \rho \mathrm{V}_{H, \theta}^{2}\left(B_{1 i j}(t, \theta) \sum_{k=1}^{n z} N_{i j, n t}^{k} A^{k} C_{P}^{k}(t, \theta)+B_{2}(t, \theta) \sum_{k=1}^{n_{z}} N_{i j, l t}^{k} A^{k} C_{P}^{k}(t, \theta)\right)
\end{aligned}
$$

where $f_{g}$ and $f_{w}$ represent gravity and wind loading factors; $\rho$ denotes air density; $V_{H, \theta}$ represents wind speed at height $H ; N_{i j, S I}^{k}, N_{i j, n t}^{k}$, and $N_{i j, l t}^{k}$ denote the influence coefficient of superimposed dead load, non-translational wind load and translational wind load, respectively, for the $k$-th attachment point (i.e. purlin or girt) on response at cross-section $j$ of frame $i ; N_{i j, S W}^{e}$ denotes the influence coefficient for the self-weight of element $e$ on response at cross-section $j$ of frame $i$; $A^{k}$ represents the tributary area of the $k$-th attachment point; $U_{S I}$ is uniform superimposed load, and $W_{e}$ denotes weight of element e; $C_{p}^{k}(t, \theta)$ is area-averaged time-series of pressure coefficients for the $k$-th attachment point and wind direction $\theta$ normalized at height $H$; and $n_{z}$ and $n_{e}$ denote number attachment points on and number of element divisions, respectively, of frame $i$.

The effect of initial imperfection on the stability of the structure is accounted for by the application of notional loads (which are calculated as 1/500 of the gravity loads applied at every 
level, $Y_{i}$ ) as in Eq. (3.22). Time-histories of frame forces induced by the notional loads can then be computed as shown in Eq. (3.23)

$$
\begin{aligned}
& Y_{\text {not }}=0.002 \alpha Y_{i} \\
& R_{i j}^{n o t}(t, \theta)=0.002 *\left(f_{w} * \frac{1}{2} \rho \mathrm{V}_{H}^{2} \sum_{k=1}^{n z} N_{i j, n t}^{k} A^{k} C_{P}^{k}(t, \theta)+f_{g}\left(\sum_{k=1}^{n_{z}} N_{i j, S I}^{k} A_{p} U_{S I}+\sum_{e=1}^{n e} N_{i j, S W}^{e} W_{e}\right)\right)
\end{aligned}
$$

To account for stiffness reduction due to inelasticity, a factor of 0.80 shall be applied to all stiffness that are considered to contribute to the stability of the structure. In addition, if the required axial compressive strength, $P_{r}$ is larger than $0.5 P_{y}$, where $P_{y}$ is the lowest axial yield strength of member, the flexural stiffness of the members shall be multiplied by a factor $\tau_{b}$, computed as shown below, where $\alpha=1$.

$$
\tau_{b i j}(t, \theta)=\frac{4 *\left(\alpha P_{r i j}(t, \theta) / P_{y i j}\right)}{1-\left(\alpha P_{r i j}(t, \theta) / P_{y i j}\right)}
$$

\subsubsection{Databases}

As shown in Eqs. (3.5), DCIs are not directly proportional to the square of wind speed, and the choice of DCI expression for each time-step depends on wind speed. Moreover, for member cross sections in compression, the DCI induced by a wind speed $V$ is not proportional to the square of that wind speed. This is due to the dependence of the axial load capacity $P_{i j}$ upon the buckling effects associated with the applied axial load.

Use of peak DCI databases (hence forth referred to as DCI databases) greatly simplifies estimation of DCI without compromising accuracy of the results. DCI databases are properties of the structure that incorporate its aerodynamic and mechanical characteristics at all cross sections of interest, and are independent of the wind climate. For rigid structures a DCI database for a member cross section consists of peak DCIs corresponding, for each of the incremental wind 
directions considered, to incremental wind speeds within a range that encompasses all speeds of interest.

DCI databases are calculated for specified cross sections of all members being designed for all the loading combination cases being considered. Loading combination cases 1 and 2 include dead and live loads only, hence response databases need not be prepared for those combinations. However, for each of the remaining loading combinations two sets of response databases are computed, one for positive and one for negative internal pressures. Effects of wind-induced positive and negative internal pressures are computed using internal pressure coefficients specified by the ASCE 7-10 for enclosed, partially enclosed, or open buildings.

Figure 3.3 shows the DCI database associated with the axial force and bending moment acting on the knee cross section of a frame in a building with the following dimensions: width $B$ $=80 \mathrm{ft}$, length $L=125 \mathrm{ft}$, eave height $H=24 \mathrm{ft}$, roof slope $=4.8 \mathrm{deg}$, loading combination 0.9D + $1.0 \mathrm{~W}$.

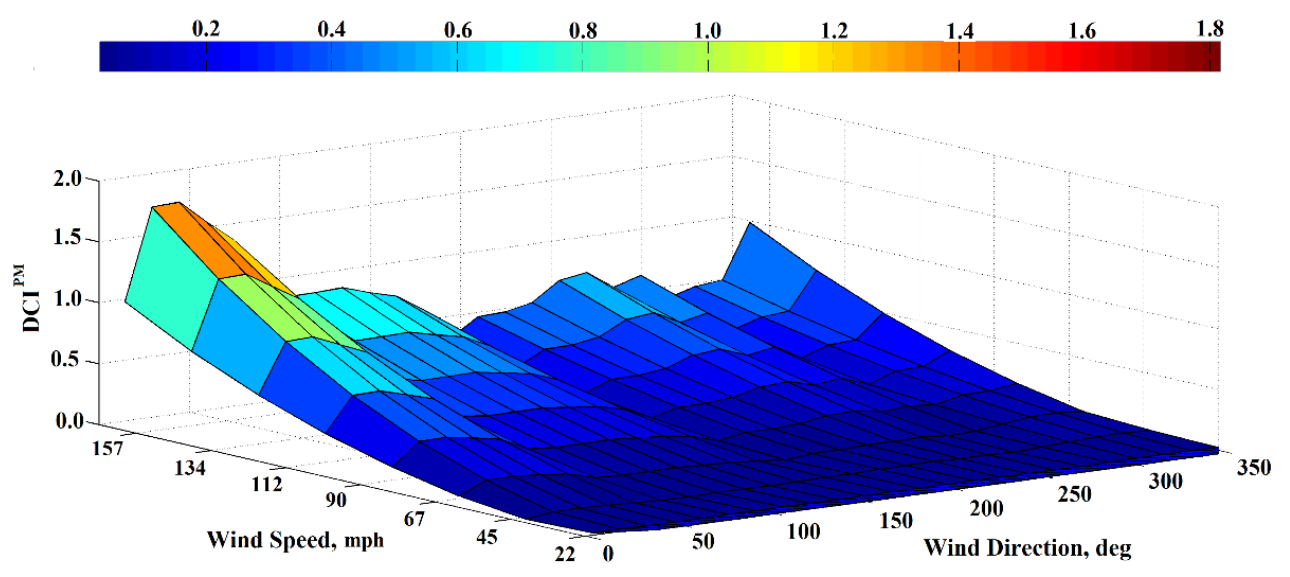

Figure 3.3: Sample DCI database

\subsubsection{Estimation of Peak DCIs with Specified MRIs}

Peak DCIs with specified MRIs are obtained by combining the DCI databases with directional wind speeds from wind climatological databases. The DCI database provide peak DCI values for all wind directions and wind speeds being considered at discrete increments, e.g., $15^{\circ}$ 
and $20 \mathrm{ft} / \mathrm{s}$. In this application, the non-directional procedure for buildings with unknown orientation (described in Subsection 5.2.1) is used, i.e. the wind speeds in each row of the wind speed matrix $\left[V_{s \theta}\right]$ is replaced by the largest wind speed regardless of direction, $\max _{\theta}\left[V_{s \theta}\right]$. The DCI with an $N$-year MRI is then estimated using non-parametric statistics, which is then multiplied by a factor of 0.85 .

\subsubsection{Case Studies}

This section presents results of case studies which compare: (i) DAD-based $\mathrm{DCI}^{\mathrm{PM}} \mathrm{s}$ and $\mathrm{DCI}^{\mathrm{V}} \mathrm{s}$ to their counterparts based on ASCE 7-10 Standard, Chapter 28, and (ii) DAD-based $\mathrm{DCI}^{\mathrm{PM}}$ s computed using influence coefficients obtained from the last iteration based on the ASCE 7-10 Standard Chapter 28 wind loads, to those computed using influence coefficients resulting from the first iteration based on wind loads obtained from pressure time series.

Note that for low-rise buildings of the type covered by Chapter 28 of the ASCE 7-10 Standard, the specified wind loads, referred to in the Standard as "pseudo-loads," induce responses which conservatively envelop the maximum structural responses (bending moment, shear, thrust) independent of wind direction. Those loads do not account for (i) the dependence of the actual load fluctuations upon the distances between frames, which can affect the transformation of wind pressures into wind loads on the frames, and (ii) the dependence of the "pseudo-loads" on the MWFRS's member sizes and, therefore, on the influence coefficients implicit in those sizes.

The buildings were assumed to be located in Miami, FL. The assumed frame spacing was 25 ft. Results are shown for the first interior frame unless otherwise indicated. If results are shown for more than one frame, the end, first interior, and second interior frame are designated in the

figures as Frame 1, Frame 2 and Frame 3, respectively. The assumed superimposed dead load (exclusive of the frame self-weight, accounted for as indicated in Section 3.2) is 2 psf, and the live load was assumed to be 20 psf. The frames supports were assumed to be pinned, and all the 
calculations were conducted for the "enclosed" building enclosure category (i.e. internal pressure coefficients of \pm 0.18 were used).

Case Study 1. For buildings with different heights Figure 3.4 shows ratios of $\mathrm{DCI}^{\mathrm{PM}}$ s computed using DAD to those computed by using ASCE 7-10 Standard, Chapter 28. The buildings have the following dimensions: $B=80 \mathrm{ft}, L=125 \mathrm{ft}$, roof slope $=14 \mathrm{deg}$, and $H=16 \mathrm{ft}, 24 \mathrm{ft}$, and $32 \mathrm{ft}$. The calculations were performed for MRI $=700$ years, and open terrain and suburban exposures. The NIST aerodynamic database was used. The ASCE produced values of DCI less than those estimated using DAD in almost all of the cases, and the discrepancies between the DAD and ASCE 7-10 results are typically larger for suburban exposure.
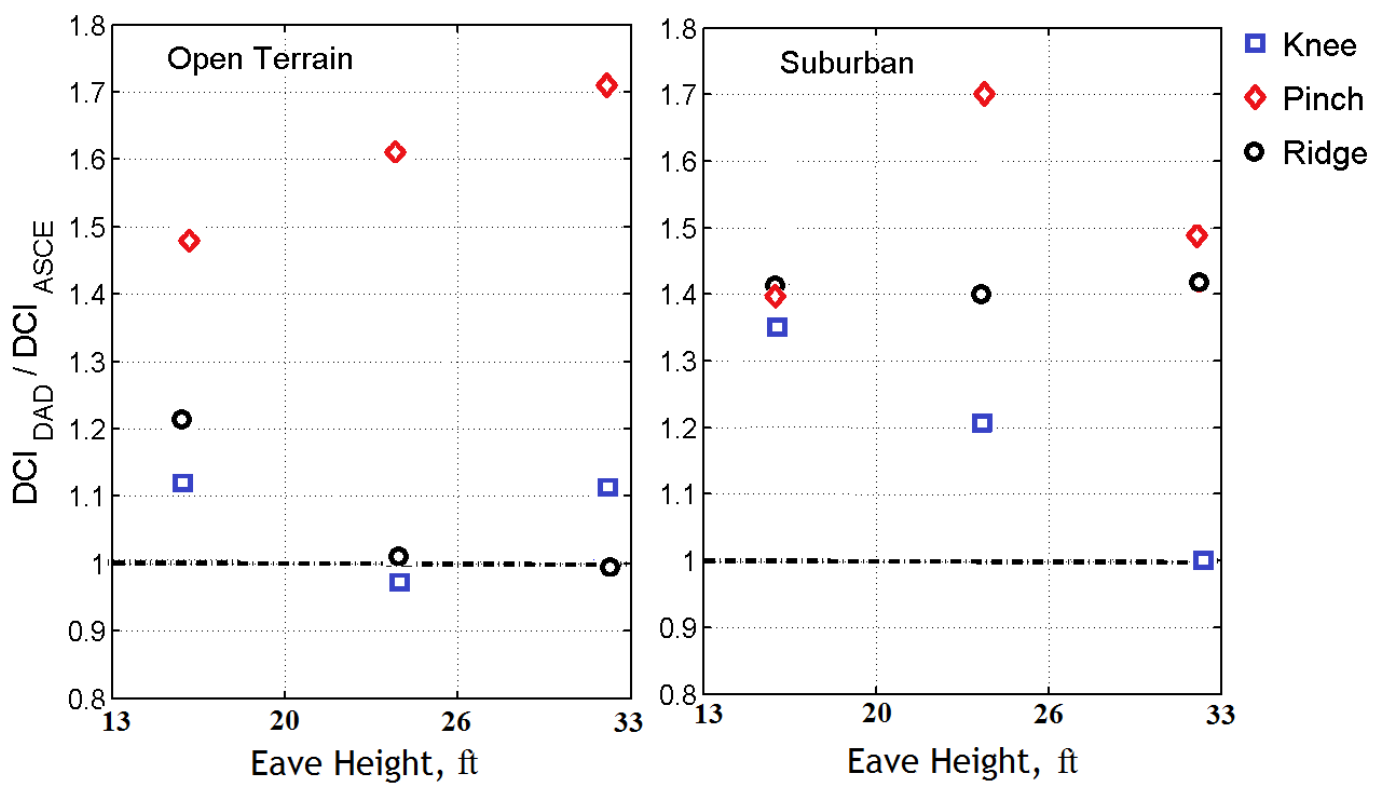

Figure 3.4 $\mathrm{DCI}^{\mathrm{PM}}{ }_{\mathrm{DAD}} / \mathrm{DCI}^{\mathrm{PM}}{ }_{\mathrm{ASCE}}$ versus Eave Height

Case Study 2 For buildings with different roof slopes Figure 3.5 shows ratios between $\mathrm{DCI}^{\mathrm{PM}} \mathrm{S}$ computed by using DAD and by using the ASCE 7-10 Standard, Chapter 28. The buildings have the following dimensions: $B=80 \mathrm{ft}, L=125 \mathrm{ft}, H=24 \mathrm{ft}$, roof slope $=4.8 \mathrm{deg}$., $14.0 \mathrm{deg}$, and 26.7 deg. The calculations were performed for MRI $=700$ years, and open and suburban terrain exposures. The NIST aerodynamic database was used. As the roof slope increases, a general increase of the ratio $\mathrm{DCI}^{\mathrm{PM}}{ }_{\mathrm{DAD}} / \mathrm{DCI}^{\mathrm{PM}}{ }_{\mathrm{ASCE}}$ is observed at the frame knee and ridge. 

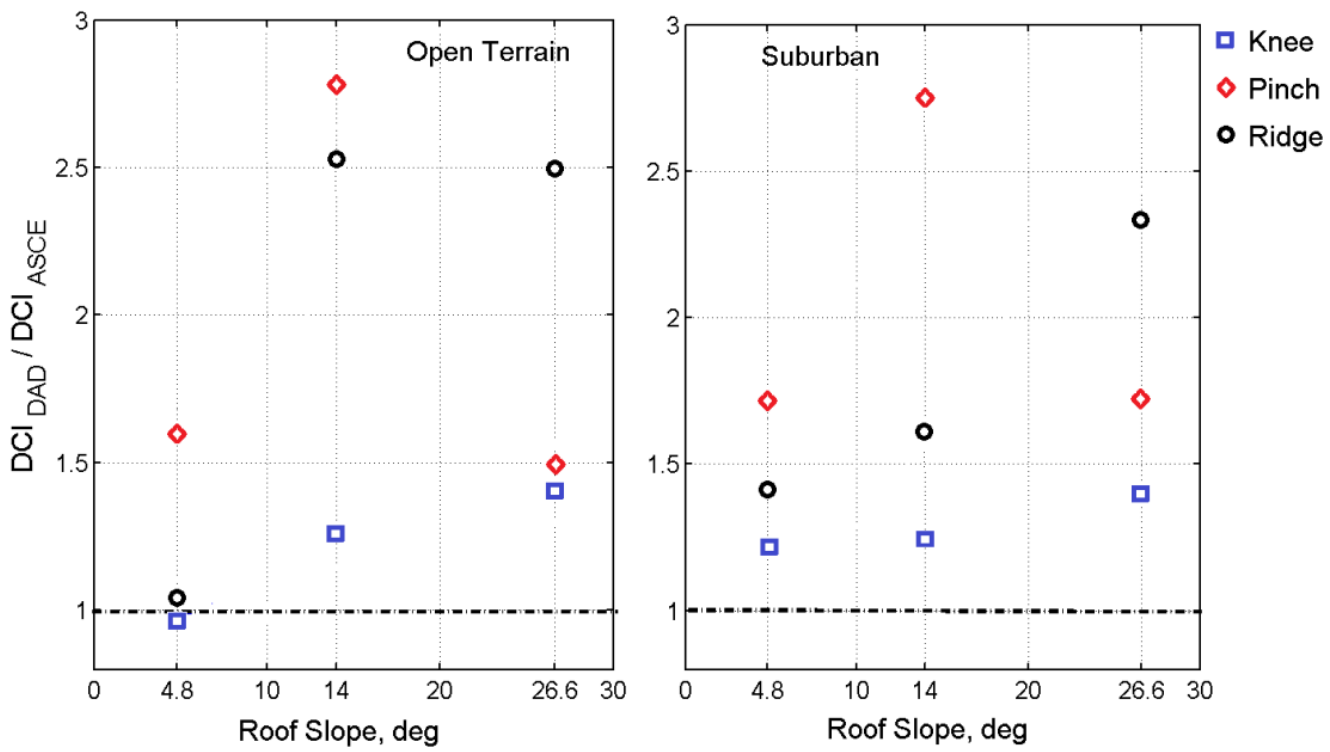

Figure 3.5 DCI ${ }^{\mathrm{PM}} \mathrm{DAD} / \mathrm{DCI}^{\mathrm{PM}} \mathrm{ASCE}$ versus Roof Slope

Case Study 3. For three MRIs of design, Figure 3.6 shows ratios between $\mathrm{DCI}^{\mathrm{PM}_{\mathrm{s}}}$ computed using DAD and using ASCE 7-10, Chapter 28. The building had the following dimensions: $B$ $=80 \mathrm{ft}, L=125 \mathrm{ft}, H=24 \mathrm{ft}$, roof slope $=4.8 \mathrm{deg}$. MRIs of 300,700 , and 1700 years were considered for both open and suburban terrain exposures, using the NIST aerodynamic database. In most cases the ratio $\mathrm{DCI}^{\mathrm{PM}}{ }_{\mathrm{DAD}} / \mathrm{DCI}^{\mathrm{PM}}{ }_{\mathrm{ASCE}}$ increases as the MRI decreases.
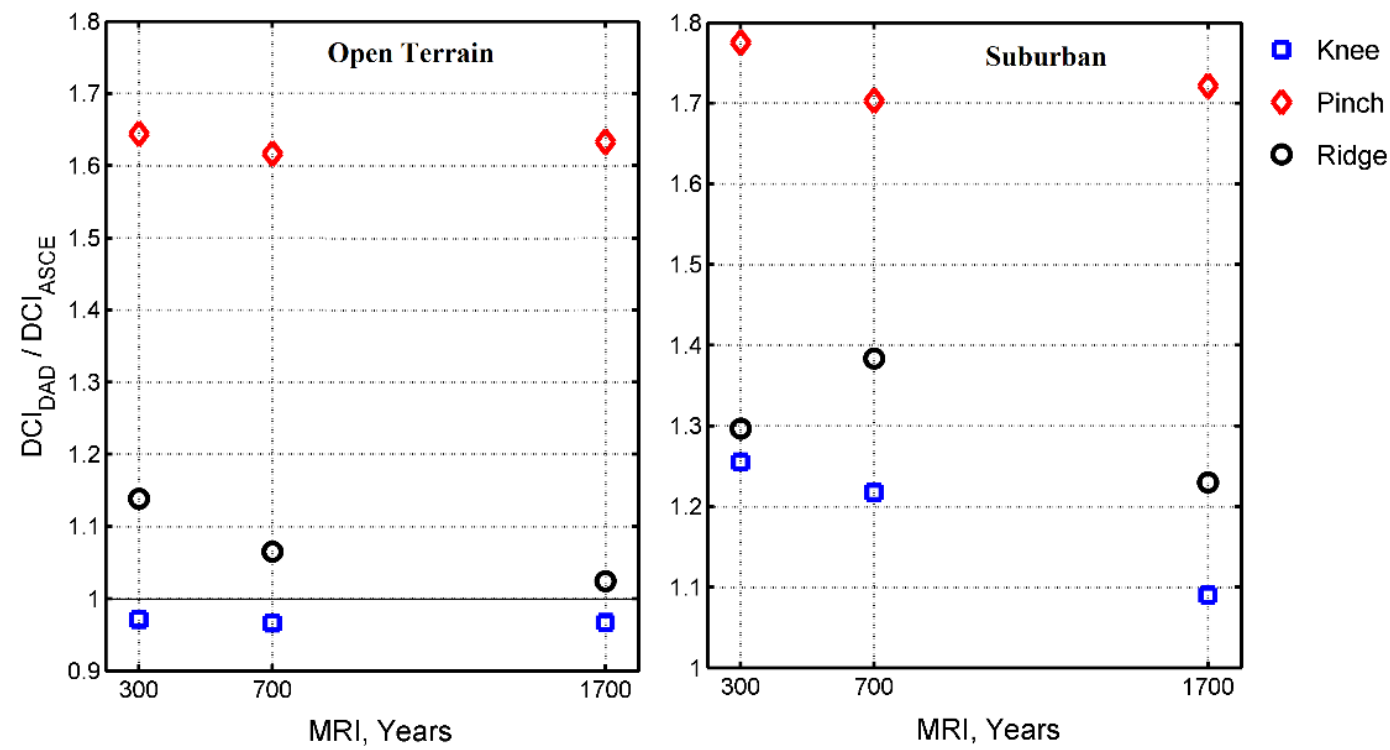

Figure 3.6 $\mathrm{DCI}^{\mathrm{PM}}{ }_{\mathrm{DAD}} / \mathrm{DCI}^{\mathrm{PM}}{ }_{\text {ASCE }}$ versus MRI 
Case Study 4. Figure 3.7 compares $700-\mathrm{yr} \mathrm{DCI}^{\mathrm{V}} \mathrm{s}$ computed using the DAD procedure to those computed using ASCE 7-10, Chapter 28, for a building with the following dimensions: $B=80 \mathrm{ft}$, $L=125 \mathrm{ft}, H=24 \mathrm{ft}$, and roof slope $=4.8 \mathrm{deg}$, for the end frame (Frame 1), first interior frame (Frame 2), and second interior frame (Frame 3). Note that Figure 3.7 shows ratios of $\mathrm{DCI}^{\mathrm{V}}$ at the column base, the knee and the ridge. The ASCE produces more unconservative results for suburban than for open terrain exposure.
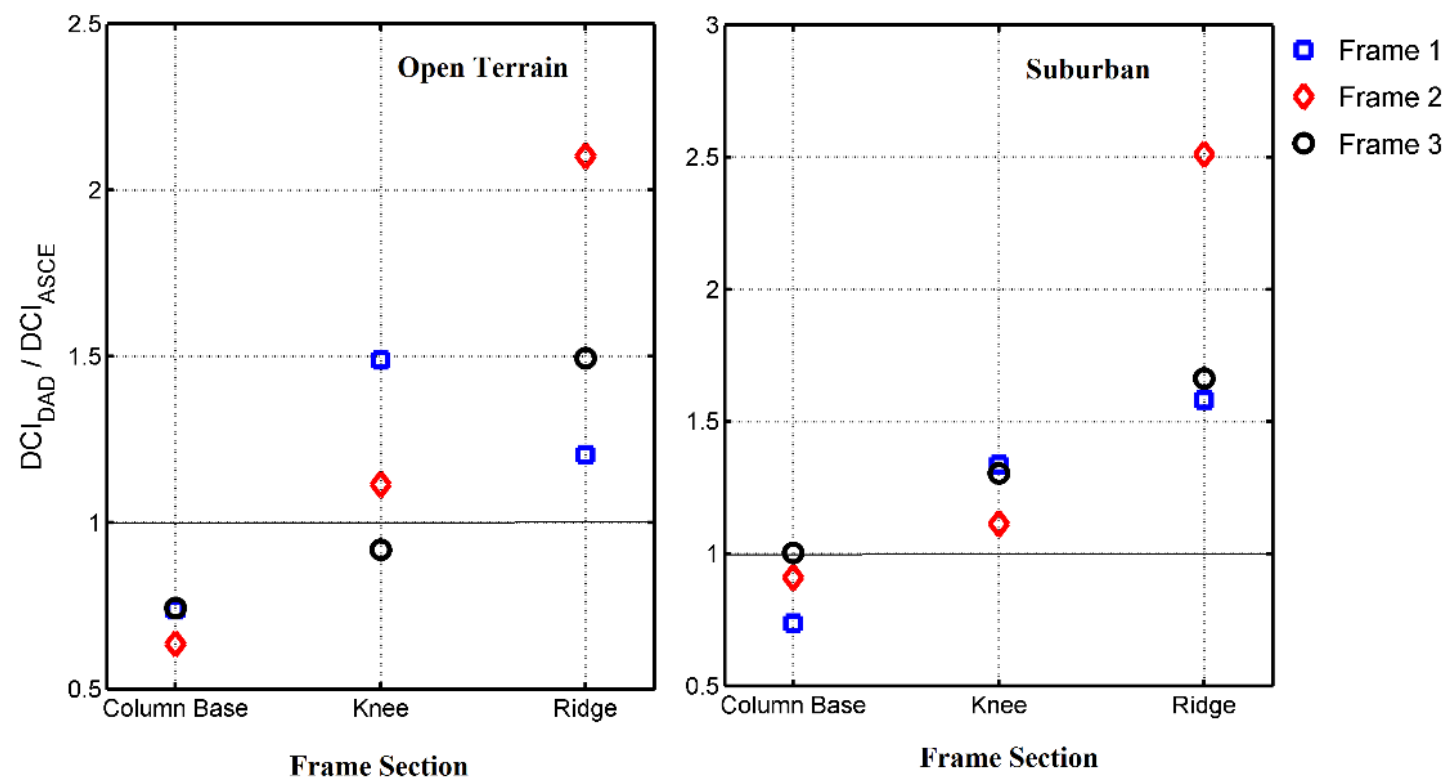

Figure 3.7 $\mathrm{DCI}^{\mathrm{V}}{ }_{\mathrm{DAD}} / \mathrm{DCI}^{\mathrm{V}}{ }_{\mathrm{ASCE}}$ at different frame cross sections

Case Study 5. Recall that the iteration procedure found to be the most effective consisted of performing iterations of the DCIs based on the ASCE 7-10 wind loading. Once the calculated DCI was consistent with the ASCE 7-10 loading an iteration was performed to ensure that the DCIs are compatible with the DAD loading (i.e., the loading based on the measured time series of the pressure coefficients). In this Case Study, DAD-based $\mathrm{DCI}^{\mathrm{PM}} \mathrm{s}$ computed using influence coefficients obtained from the last iteration based on the ASCE 7-10 Standard Chapter 28 wind loads were compared to the $\mathrm{DCI}^{\mathrm{PM}} \mathrm{s}$ computed using influence coefficients resulting from the first iteration based on wind loads obtained from pressure time series. The dimensions of the building 
used in the comparisons were $B=80 \mathrm{ft}, L=125 \mathrm{ft}, H=16 \mathrm{ft}$, and the roof slope was $4.8 \mathrm{deg}$. The differences between the two sets of DCIs were found to be negligible.

\section{Conclusions}

A DAD based design procedure was presented that streamlines the wind engineering/structural engineering components of the design process by allowing the direct computation of the design interaction equation's left-hand side (i.e. of Demand-to-Capacity Indexes, or DCIs) for each of the MWFRS's cross sections of interest. This computation rigorously combines imperfectly correlated time series of wind forces and effects (e.g., forces along each of the building's principal axes; simultaneously acting axial forces and bending moments), thus eliminating errors due to subjective estimates of combined effects.

While the design approach is applicable to any rigid low- or mid-rise buildings, this chapter presented an application focused on simple buildings with gable roofs, steel portal frames, and bracing parallel to the ridge. In addition to the incorporation of DCI-based iterative structural design, useful features include: access to the two largest aerodynamics databases available worldwide; use of large simulated extreme wind databases for hurricane-prone and nonhurricane-prone regions; an effective multiple-points-in-time algorithm for estimating time series peaks; and parameter-free methods for estimating DCIs with specified mean recurrence intervals, applicable to buildings with known or unknown orientation. Case studies indicated that the proposed interpolation scheme was satisfactory. The results obtained in this work confirm the existence of serious inadequacies of the ASCE 7-10 envelope procedure; and the DAD's potential for routine, practical use in structural design.

References

ANSI/AISC. (2010). Specification for Structural Steel Buildings. American Institute of Steel Construction, Chicago, Illinois.

ASCE. (2010). Minimum design loads for buildings and other structures. American Society of Civil Engineers, Reston, VA. 
Coffman, B. F., Main, J. A., Duthinh, D., and Simiu, E. (2009). "Wind effects on low-rise metal buildings: Database-assisted design versus ASCE 7-05 standard estimates." Journal of Structural Engineering, 136(6), 744-748.

Holmes, J., Tamura, Y., and Krishna, P. (2009). "Comparison of wind loads calculated by fifteen different codes and standards, for low, medium and high-rise buildings." Proceedings of 11th American Conference on Wind Engineering, San-Juan, Puerto Rico.

Irwin, P. A. (2009). "Wind engineering research needs, building codes and project specific studies." Proceedings of the 11th Americas Conference on Wind Engineering.

Kaehler, R. C., White, D. W., and Kim, Y. D. (2011). Frame design using web-tapered members. American Institute of Steel Construction.

Kasperski, M. (1996). "Design wind loads for low-rise buildings: a critical review of wind load specifications for industrial buildings." Journal of wind engineering and industrial aerodynamics, 61(2), 169-179.

Main, J. A., and Fritz, W. P. (2006). Database-assisted design for wind: concepts, software, and examples for rigid and flexible buildings. National Institute of Standards and Technology, Technology Administration, US Department of Commerce.

NBCC (2005). "National Building Code of Canada." Ottawa, Canada: National Research Council of Canada (NRCC).

Oh, J. H., Kopp, G. A., and Inculet, D. R. (2007). "The UWO contribution to the NIST aerodynamic database for wind loads on low buildings: Part 3. Internal pressures." Journal of wind engineering and industrial aerodynamics, 95(8), 755-779.

Simiu, E. (2011). Design of buildings for wind: a guide for ASCE 7-10 standard users and designers of special structures. John Wiley \& Sons, Inc., Hoboken, New Jersey.

Simiu, E., Sadek, F., Whalen, T. M., Jang, S., Lu, L.-W., Diniz, S., Grazini, A., and Riley, M. A. (2003). "Achieving safer and more economical buildings through database-assisted, reliability-based design for wind." Journal of wind engineering and industrial aerodynamics, 91(12), 1587-1611.

Timoshenko, S. (1936). Theory of Elastic Stability. McGram-Hill Book Co. Inc.

Timoshenko, S., and Gere, J. M. (1961). Theory of elasticity stability. McGraw.

Yeo, D. (2012). "Multiple Points-In-Time Estimation of Peak Wind Effects on Structures." Journal of Structural Engineering, 139(3), 462-471.

Yeo, D. (2014). "Generation of large directional wind speed data sets for estimation of wind effects with long return periods." Journal of Structural Engineering, 140(10). 


\title{
4. SYNTHESIS OF AERODYNAMIC AND CLIMATOLOGICAL DATA, WIND DIRECTIONALITY FACTORS
}

\begin{abstract}
Wind does not approach from all directions with equal frequency or intensity; instead it tends to blow more strongly from a few preferred directions. Hence, the final step in DatabaseAssisted-Design (DAD) involves synthesizing site specific climatological data with building aerodynamics to evaluate peak wind effects or perform designs for a specified return period. This process should account rigorously for building orientation and wind directionality. In this chapter, two methods of combining demand-to-capacity (DCI) databases with climatological databases, with and without accounting for building orientation, named directional and non-directional respectively, are described in detail. Comparison of DCIs evaluated using the two methods led to the recommendation of factors of 0.90 and 0.85 for use with the non-directional approach, in hurricane and non-hurricane prone regions respectively. The second part of this chapter presents a DAD based discussion on the topic of directionality factor as used by building codes and standards. The results show that the directional factor $K_{d}$ varies as a function of type of wind storm, geographical location within an area with a given type of wind climate, type of wind effect and position of the wind effect being considered in the structure. These results confirm a recent finding that $K_{d}$ values are larger for hurricane-prone than for non-hurricane regions. For pressures at individual points on building envelopes, the value $K_{d}=0.85$ is typically found to be adequate for hurricane-prone regions and conservative for non-hurricane regions. For internal forces in wind force resisting systems (e.g., frames), the value $K_{d}=0.85$ is typically adequate for nonhurricane regions while $K_{d}=0.90$ is required for hurricane-prone regions, in spite of its conservatism in some situations. Finally, for global effects, such as building base shears and
\end{abstract}


global building torsion, the values $K_{d}=0.90$ and $K_{d}=0.95$ are appropriate for non-hurricane and hurricane-prone regions, respectively.

\subsection{Introduction}

Wind does not approach from all directions with equal frequency or intensity; instead it tends to blow more strongly from a few preferred directions. Moreover, structures typically experience wind-induced loads and effects that depend on wind direction. Hence when predicting wind effects it is required to take into account the directional dependence of the building aerodynamics, and site's directional wind speeds. The final step in Database-Assisted-Design (DAD) involves synthesizing site specific climatological data with building aerodynamics to evaluate peak wind effects or perform designs for a specified return period. This process should account rigorously for building orientation and wind directionality.

Some of the commonly used approaches for combining aerodynamic and climatological data include directionality factor method, sector-by-sector approach, out-crossing of the response boundary approach, and the storm passage method. The directionality factor approach involves computing wind effects by first disregarding wind directionality and combining peak aerodynamic effects with the maximum wind speed regardless of direction, then a directionality factor (smaller than unity) is used to reflect the fact that the climatologically and aerodynamically most unfavorable wind directions typically do not coincide. This approach is the simplest, but can either overestimate or underestimate the response, and is therefore typically not used by wind engineering laboratories for estimating wind effects on special structures (Simiu 2011). However this approach is used in some Building Codes and Standards including the Minimum Design Loads for Buildings and Other Structures (ASCE 7).

In the sector-by-sector approach, the directional wind speeds and aerodynamic coefficients are first grouped into a number of wind-direction sectors. The maximum aerodynamic response for each sector is then determined and combined with the extreme wind speed for that sector. 
Simiu and Filliben (2005) showed that except in cases of strong positive correlations between sectorial wind speeds, the sector-by-sector approach can produce unconservative estimates of wind-induced effects.

In the Out-crossing of the response boundary approach (Davenport (1997), Lepage and Irwin (1985), and Irwin et al. (2005)) a response boundary of wind speeds producing a certain wind effect is computed for different directions. The mean out-crossing rate of the response boundary curve is then estimated, the inverse of which gives the return period corresponding to the required wind effect. A drawback of this approach is that it relies on data assumed to constitute a parent population from which extremes can be derived. In reality such a parent population may not exist in practice, at least for some types of wind, including hurricanes.

In the Storm passage method, which is also referred to as Time history analysis approach (Gamble et al. 2001) aerodynamic data collected from a wind tunnel study is converted into time history of wind-induced responses, then for each storm event peak values of the wind-induced responses are selected from the time history data for extreme value analysis. This approach has the advantage of taking into account the time domain variations of wind speed and direction during particular storm events (Isyumov et al. 2003).

In the DAD based iterative design method developed in Chapter 3, it is required to combine DCI databases (which depend on the structure's aerodynamic and mechanical characteristics, and are independent of the wind climate) with the building site's wind speed data. The DCI database provides peak DCI values for wind directions and wind speeds at discrete increments, e.g., $15^{\circ}$ and $20 \mathrm{ft} / \mathrm{s}$. Wind climate data comes in several forms including the form of (i) matrices of directional wind speeds for a large number of storm events, or (ii) maximum wind speeds regardless of direction with specified mean-recurrence-intervals (MRIs), e.g., 3-sec gust wind speeds provided in the ASCE 7-10. In cases where directional wind speeds are used, statistical approaches have been developed that synthesize the directional aerodynamic and wind climate 
effects in a transparent and rigorous manner. If maximum wind speeds regardless of direction with specified MRIs are used, the simple directionality factor approach can be used. In this chapter, directional and non-directional statistical approaches for synthesizing DCI databases with wind speed matrices are discussed.

DAD techniques offer the possibility of rigorously estimating directionality factors, $K_{d}$, for large numbers of cases of practical interest. These techniques, which use large directional wind speed and aerodynamics databases, are used in the second part of this chapter, with the view to estimating $K_{d}$ values for hurricane-prone and non-hurricane locations, various mean recurrence intervals (MRIs) of the wind effects, and pressures, forces, and internal forces in various parts of a structure.

\subsection{Synthesizing DCI Databases and Climatological Databases}

This section discusses two statistical approaches for combining DCI databases with a climatological database, in both single and mixed wind climate regions. Note that a DCI database consists of $d \times p$ matrix ( $d$ rows and $p$ columns) of $D C I_{i, \theta}$ (the index $i=1,2 \ldots, d$, denotes the incremental wind speeds and the index $\theta=1,2 \ldots, p$, denotes the aerodynamic wind direction). And a climatological database consists of (i) $m \times q$ matrix ( $m$ rows and $q$ columns) of largest directional wind speeds $V_{s, \alpha}$ (the index $s=1,2 \ldots, m$, denotes the storm event and the index $\alpha=1$, $2 \ldots, q$, denotes storm wind direction), and (ii) the mean annual rate of storm occurrence, $\lambda$. For regions with mixed climates, e.g. with thunderstorm and non-thunderstorm winds, a climatological database consists of wind speed matrices and $\lambda$ for each of the different types of wind climates.

In the first approach, referred to as the non-directional approach, only the maximum wind speed from each storm event is retained and used in estimating the design DCI. In this approach building orientations are not accounted for. In the second approach, referred to as the directional 
approach, a sufficiently large number of building orientations with uniform probability of occurrence are considered. The second approach is more rigorous and requires more computation. Those two approaches are explained in detail below, followed by comparisons of DCIs evaluated using the two methods.

\subsubsection{Non-directional Approach}

The non-directional approach is applied to the case where the orientation of the building is unknown, and consists of the following steps:

i. Only the maximum wind speed from each storm event is retained, and that speed is assumed to be the same for all directions. That is, from the $m \times q$ matrix of largest directional wind speeds $V_{s, \alpha}$, a column vector $\hat{V}_{s}$ with the maximum wind speed of each storm event, i.e. $\hat{V}_{s}=$ $\max _{\alpha}\left[V_{s, \alpha}\right]$ is created. Then $m \times p$ matrix, $V_{s, \theta}$ ( $p$ being the number of wind directions in the DCI database) with all its columns identical to column vector $\hat{V}_{s}$ is constructed.

ii. Each wind speed in $V_{s, \theta}$ is then replaced by a value obtained by interpolation from the DCI database. This operation will create a $m \times p$ matrix of interpolated DCI values, $D C I_{s, \theta}$. Note that the wind speeds in matrix $V_{s, \theta}$ should first be adjusted to match the reference height and gust duration of the wind speeds used in the DCI databases before being replaced by corresponding DCI values.

iii. Once $D C I_{s, \theta}$ is created, all but the entries $\max _{\theta}\left[D C I_{s, \theta}\right]$ are disregarded since only the largest of the DCIs induced in that cross section in any one storm is of interest for design. This creates a vector $D \hat{C} I_{s}$ with $m$ values, in which the $i^{\text {th }}$ element of vector $D \hat{C} I_{s}$ is the highest DCI for the $i^{\text {th }}$ storm.

iv. The wind speeds used in this study are from synthetic storm events generated by Monte Carlo simulation; hence a non-parametric statistics approach is used to determine the design DCI for a specified mean recurrence interval (MRI) from the vector $D \hat{C} I_{s}$. In this approach, the 
elements of vector $D \hat{C} I_{s}$ are first rank ordered in a descending manner. The MRI, $\bar{N}$, of a $D C I$ with rank $q, D C I_{q}$ can be then be evaluated as shown in Eq. (4.1)

$$
\left.\bar{N}=\frac{1}{1-P\left(d c i \leq D C I_{q}\right)}\right]
$$

where $P\left(d c i \leq D C I_{q}\right)$ is the cumulative distribution function of $D C I_{q}$. For regions with mixed wind climates (e.g., hurricane and non-hurricane winds or thunderstorm and nonthunderstorm winds), the cumulative distribution functions of the different types of winds for that region are calculated separately, and are then combined to produce the cumulative distribution functions of the mixed wind climate. Let the values of the cumulative distribution functions of $D C I_{q}$ corresponding to thunderstorm and non-thunderstorm climates be denoted by $P_{T}\left(d c i \leq D C I_{q}\right)$ and $P_{N T}\left(d c i \leq D C I_{q}\right)$, respectively. The probability that both the thunderstorm and non-thunderstorm $d c i$ s do not exceed $D C I_{q}$ is, $P_{m i x}\left(d c i \leq D C I_{q}\right)=$ $P_{T}\left(d c i \leq D C I_{q}\right) P_{N T}\left(d c i \leq D C I_{q}\right)$. Hence for sites with mixed wind climates, say with $n_{c}$ number of different wind climates, Eq. (4.2) can be used to determine the MRI of $D C I_{q}$

$$
\bar{N}=\frac{1}{\left[1-\prod_{i=1}^{n_{c}} P_{i}\left(d c i \leq D C I_{q}\right)\right]}
$$

The cumulative distribution function, $P\left(d c i \leq D C I_{q}\right)$ can be expressed in non-parametric statistics based on the theory of Poisson processes as shown in Eq. (4.3)

$$
P\left(d c i \leq D C I_{q}\right)=\exp \left(\frac{-\lambda * q}{m+1}\right)
$$

where $\lambda$ is the mean annual storm arrival rate, and $m$ is the total number of storm events. For single climate regions with large number of storm events, Eqs. (4.1) and (4.3) can be further simplified, and the rank $(q)$ of a peak DCI corresponding to $\bar{N}$ years, $D C I_{\max }^{\bar{N}}$ can be computed as $\mathrm{q}=(m+1) /(\bar{N} \lambda)(\operatorname{Simiu} 2011)$. 
v. The design DCI is then evaluated by multiplying $D C I_{\max }^{\bar{N}}$ by a factor less than unity to account for the fact the worst aerodynamic direction might not coincide with the worst climatological direction. Section 5.2.3 develops an appropriate factor for use with this approach.

\subsubsection{Directional Approach}

This approach is applicable to both the cases where the orientation of the building is known and, with an additional step (step (v) listed below), where the orientation is unknown. The directional approach consists of the following steps:

i. The number of wind directions available in a climatological database may not coincide with those available in the DCI databases. In such cases, resampling is performed to adjust the aerodynamic directions for which the DCI's are computed to the wind speed directions in the wind climatological databases. Resampling of DCI is performed as follows; let $\overline{\theta_{j}}=\left[\theta_{1}, \ldots, \theta_{p}\right]$ be a vector of wind directions available in a DCI database and let $\overline{\alpha_{j}}=\left[\alpha_{1}, \ldots, \alpha_{q}\right]$ be a vector of wind directions available in a wind climatological database. For both databases it is assumed that a parameter reported for a direction, say $\beta_{j}$ could potentially correspond to any wind direction within the sector bound above by the midpoint between $\beta_{j}$ and $\beta_{j+1}$, and bounded below by the midpoint between $\beta_{j}$ and $\beta_{j-1}$ (Main and Fritz 2006). Based on this $\Delta \overline{\theta_{j}}$ and $\Delta \overline{\alpha_{j}}$ which are vectors of directional sector angles associated with the DCI database and wind speed database, respectively, are evaluated. The resampled DCI corresponding to a climatological wind direction can then be computed as the weighted sum of the DCIs whose sector angles $\Delta \overline{\theta_{j}}$ fall inside $\Delta \overline{\alpha_{j}}$. Let the DCI in sector $\Delta{\overline{\theta_{j}}}_{\text {be denoted by }} D C I_{\theta}$, then the resampled DCI, $D C I_{\alpha k}$ which corresponds to sector $\Delta \overline{\alpha_{k}}$ can be expressed as:

$$
D C I_{\alpha_{k}}=\sum_{j=1}^{z} P\left(\theta \in \Delta \overline{\theta_{j}} \mid \theta \in \Delta \overline{\alpha_{k}}\right) . D C I_{\theta_{j}}
$$


where $P\left(\theta \in \Delta \overline{\theta_{j}} \mid \theta \in \Delta \overline{\alpha_{k}}\right)$ denotes the probability of the wind direction being in sector $\Delta \overline{\theta_{j}}$ given that the winds are known to be in sector $\Delta \overline{\alpha_{k}}$, and is non-zero only for sectors that overlap (Main and Fritz 2006). Once resampling of peak DCIs is performed, a DCI database with wind directions that match the wind directions available in the climatological database is created i.e. $D C I_{i, \alpha}$ (the index $i=1,2 \ldots, d$, denotes the incremental wind speeds and the index $\alpha=1,2 \ldots, q$, denotes the climatological wind direction).

ii. Similar to step (ii) of the non-directional method, each wind speed in matrix $V_{s, \alpha}$ is replaced by a DCI value from the resampled DCI database, and matrix $D C I_{s, \theta}$ is created.

iii. Similar to as in step (iii) and step (iv) of the non-directional method, all but the entries $\max _{\theta}\left[D C I_{s, \theta}\right]$ are disregarded.

iv. Similar to step (iv) of the non-directional method, non-parametric statistical methods are used to estimate $D C I_{\max }^{\bar{N}}$.

v. The first four steps are repeated for all the building orientations considered. This will create a vector of peak DCI values, $\overline{D C I}{ }_{\max }^{\bar{N}}=\left[D C I_{\max }^{\bar{N}, 1} D C I_{\max }^{\bar{N}, 2} \cdots D C I_{\max }^{\bar{N}, n_{o}}\right]$, with $n_{o}$ number of elements. Finally, since all orientations have equal probability of occurrence the design DCI is evaluated as mean of vector $\overline{D C I} \max$.

\subsubsection{Comparisons of DCIs Evaluated using the Non-directional and Directional}

\section{Approaches}

In this section DCIs evaluated using the non-directional and directional approaches of synthesizing DCI databases and climatological databases described in sections 4.2.1 and 4.2.2, respectively, are compared. The results are provided as ratios of DCIs evaluated using the directional approach (DCI-directional) to those evaluated using the non-directional approach (DCI-non directional). The non-directional approach combines the worst aerodynamic and 
climatological directions, while the directional method assumes several possible building orientations with equal probabilities of occurrence; hence ratios of DCI-directional to DCI-non directional are expected to be less than unity. These results will assist in selecting appropriate factors to be used with the DCI-non directional approach, as it has advantages of being simpler and requiring less computation.

Two building models from the NIST database were selected for analysis. The first model (Model 1) has the following dimensions; width, $\mathrm{B}=80 \mathrm{ft}$., length, $\mathrm{L}=125 \mathrm{ft}$., eave height, $\mathrm{H}=$ $24 \mathrm{ft}$. and roof slope, $\theta=14 \mathrm{deg}$, and the second model (Model 2) has the following dimensions; $\mathrm{B}=80 \mathrm{ft}$., $\mathrm{L}=125 \mathrm{ft}$., $\mathrm{H}=40 \mathrm{ft}$. and $\theta=4.56 \mathrm{deg}$. Frame spacing of $25 \mathrm{ft}$ were used in both models, and the calculations are performed for the first, second and third upwind frames (which are named Fame 1, Frame 2 and Frame 2 respectively). Wind speeds databases of both hurricane and non-hurricane prone regions were used. Databases of simulated wind speeds for 14 locations along the US coasts of the Gulf of Mexico and North Atlantic Ocean (i.e. Mileposts 150, 250, $450,650,850,1250,1450,1650,1850,2050,2250,2450,2650$, and 2850 from the http://fris2.nist.gov/winddata/) were selected to represent hurricane prone regions. And for the non-hurricane prone regions, wind speed databases for two locations in the central USA (i.e. Kansas City, KS and Phoenix, AZ) were used. Ratios of DCI-directional to DCI-non directional were calculated for both open-terrain and suburban exposures. Since gravity loads are independent of wind direction, only wind-induced responses were used in all calculations of DCIdirectional and DCI-non directional. In the directional approach, 24 building orientations at 15 deg increments were considered. 


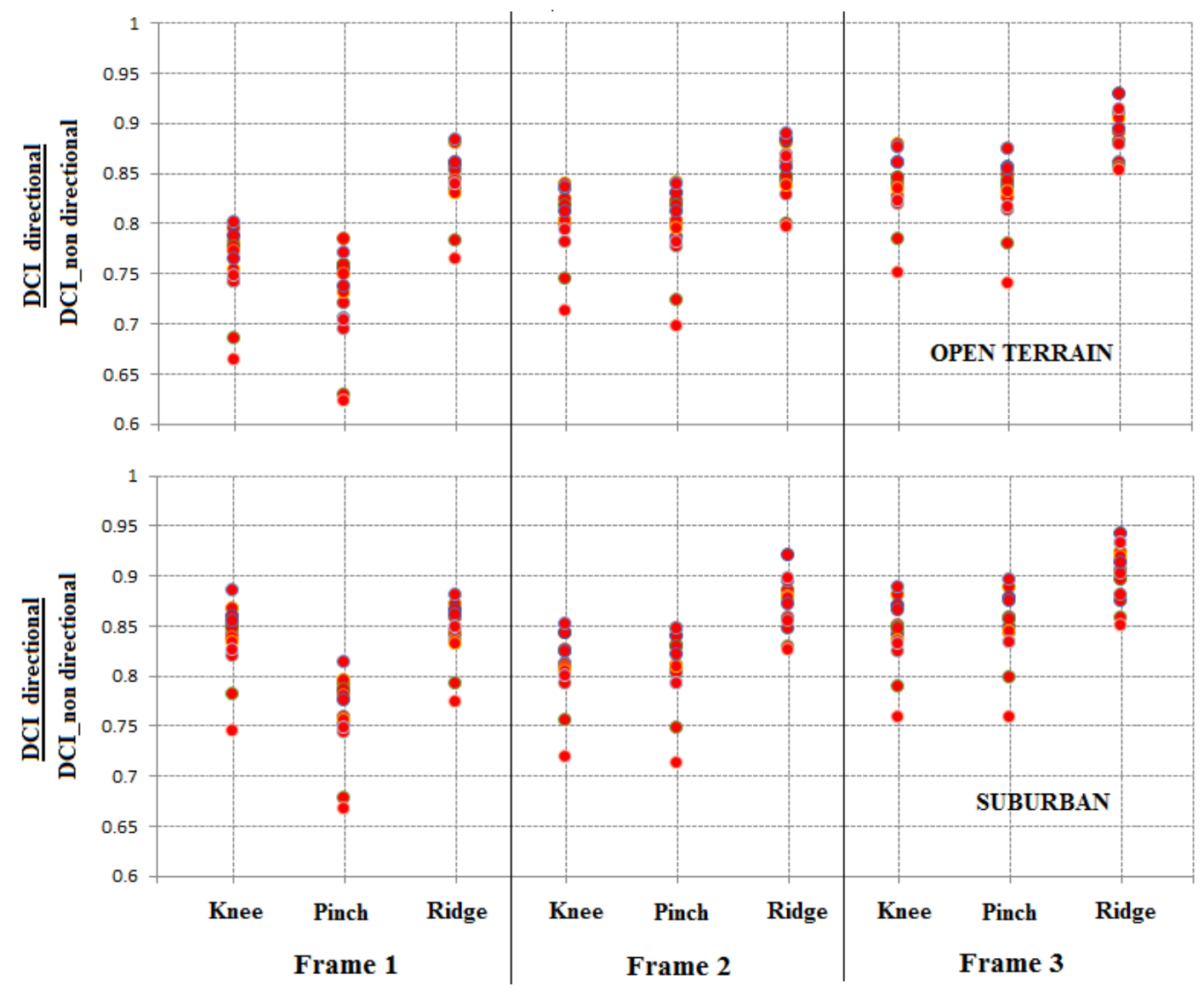

Figure 4.1 Ratio of DCI-directional to DCI-non directional, Model 1, Hurricane Prone Regions

For hurricane prone regions, ratios of DCI-directional to DCI-non directional, at frames' knee, pinch and ridge sections of Models 1 and 2 are shown in Figure 4.1 and Figure 4.2 respectively. The ratios ranged from less than 0.7 to greater than 0.95 , and they seem to be higher in suburban exposures than in open-terrain. Higher ratios were also obtained at the ridge crosssections. Ratios of DCI-directional to DCI-non directional, at frames' knee, pinch and ridge cross-sections for Model 1 and Model 2 evaluated for the non-hurricane prone regions of Kansas City and Phoenix are shown in Figure 4.3 and Figure 4.4 respectively. Higher ratios were obtained for Phoenix than for Kansas City, and similar to the hurricane prone regions higher ratios were obtained at the ridge cross-sections. It can be seen that lower ratios were obtained in non-hurricane regions when compared to the hurricane wind regions. 


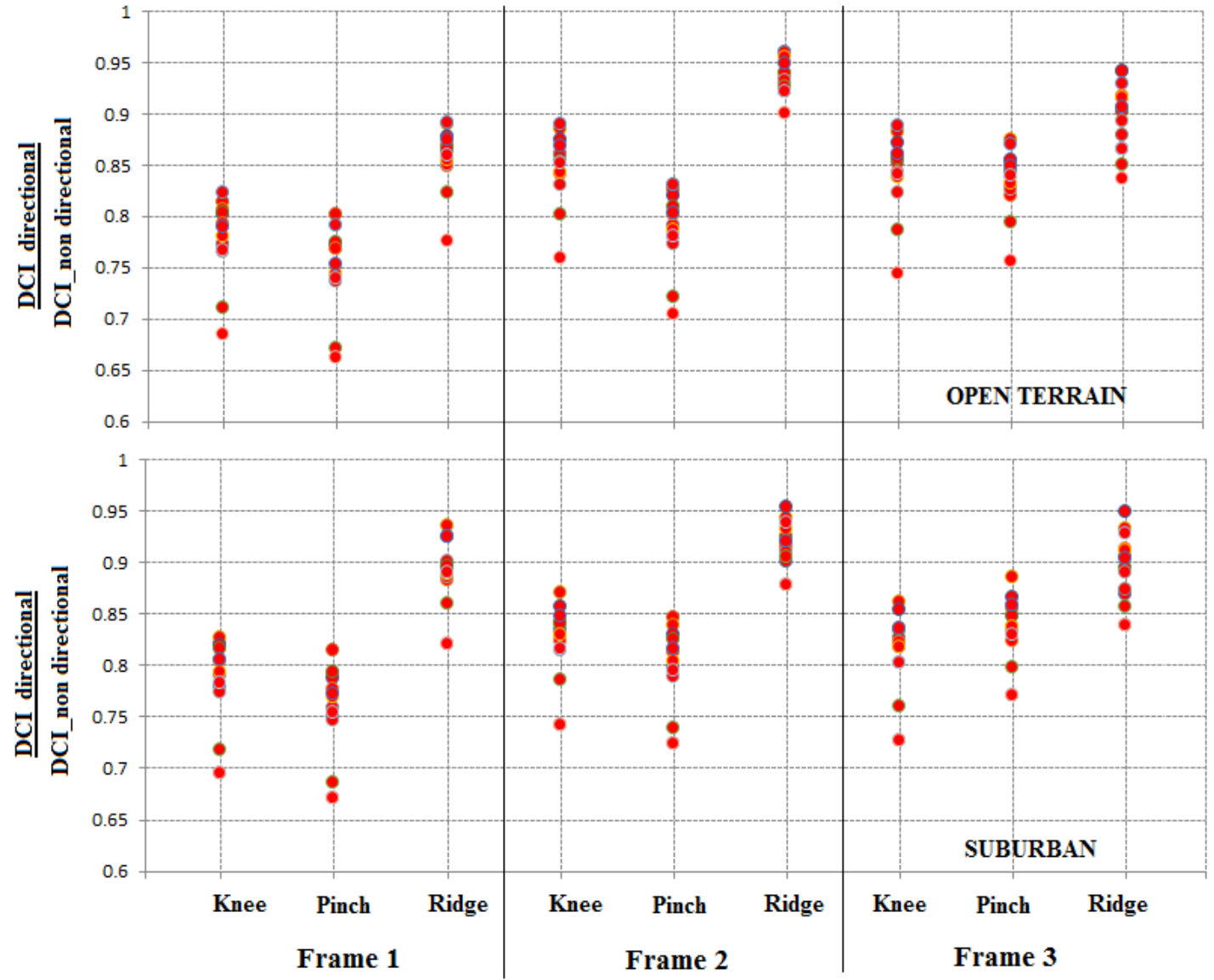

Figure 4.2 Ratio of DCI-directional to DCI-non directional, Model 2, Hurricane Prone Regions 


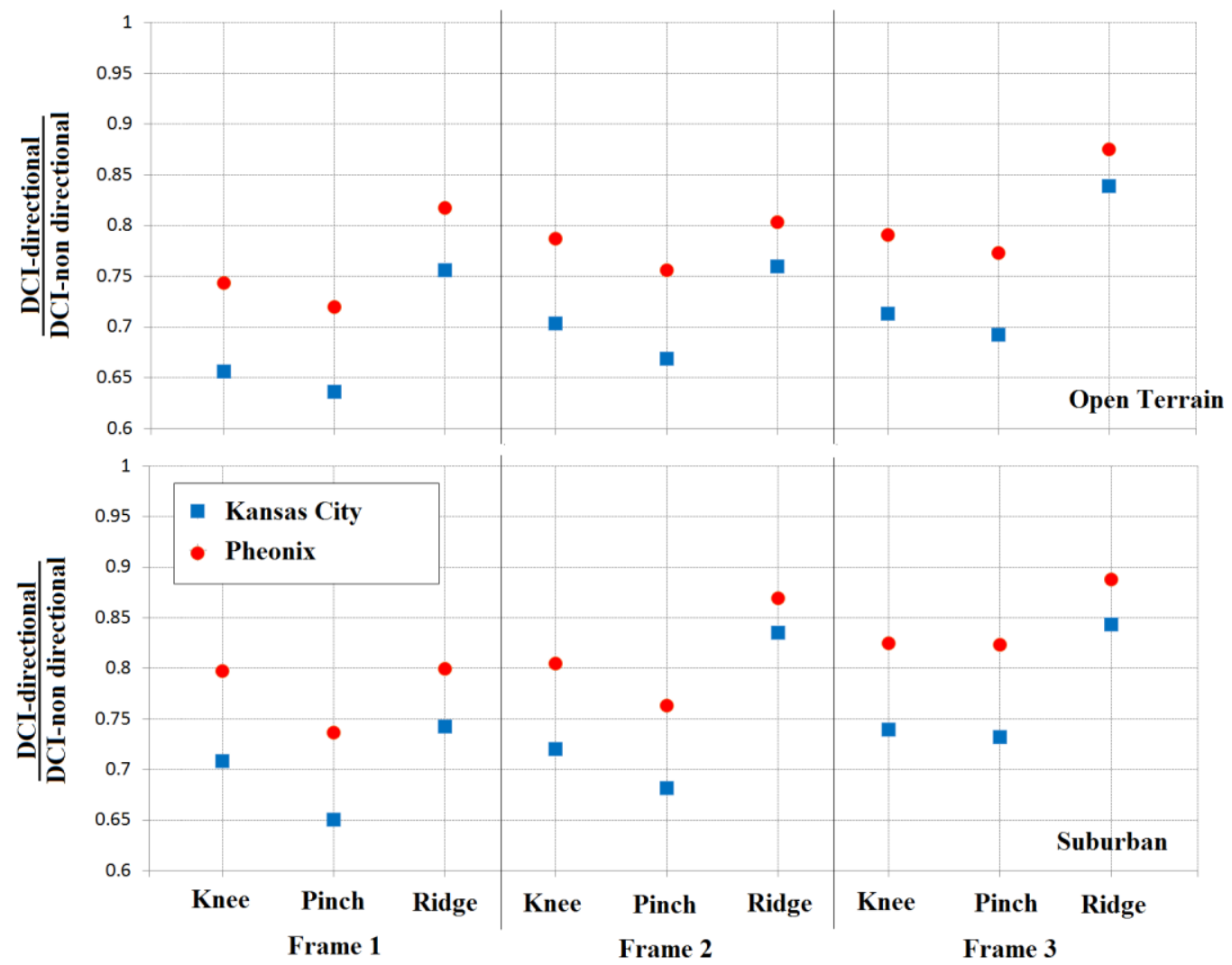

Figure 4.3 Ratio of DCI-directional to DCI-non directional, Model 1, Non-hurricane Prone Regions

Table 4.1 shows the distributions of ratios of DCI-directional to DCI-non directional for both hurricane and non-hurricane prone regions. For hurricane prone regions, in less than $63 \%$ of the cases were the ratios less than 0.85 ; they were less than 0.90 in more than $86 \%$ of the cases. However for the non-hurricane prone regions, in more than $88 \%$ of the cases the ratios were less than 0.85 , which makes 0.85 an appropriate factor for use with the non-directionality approach in non-hurricane prone regions. Hence, factors of 0.90 and 0.85 are recommended for use with the non-directional approach in hurricane prone and non-hurricane prone regions respectively. 


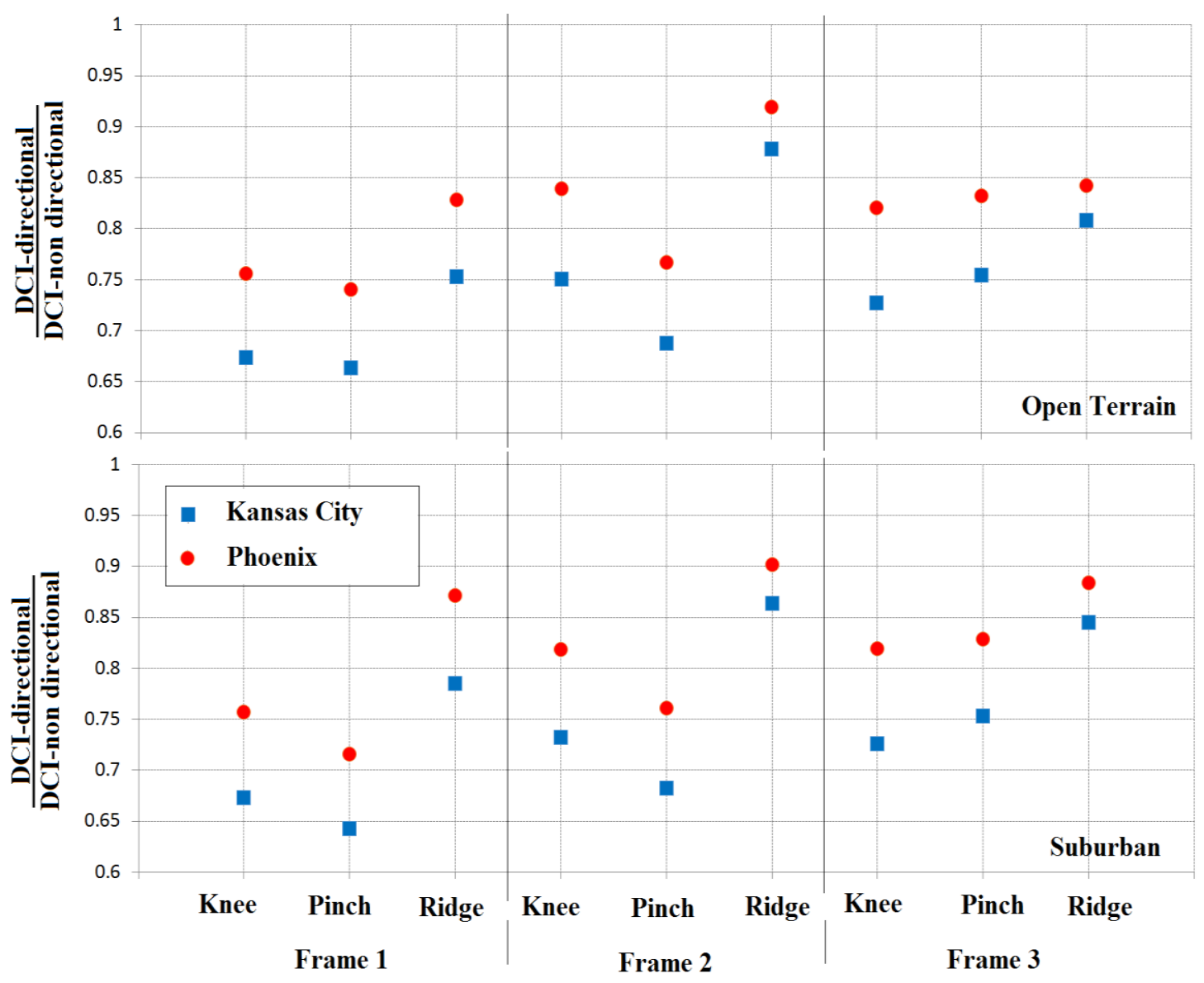

Figure 4.4 Ratio of DCI-directional to DCI-non directional, Model 2, Non-hurricane Prone Regions

Table 4.1 Distribution of Ratios of DCI-directional to DCI-non directional

\begin{tabular}{|l|c|c|c|c|c|}
\hline \multicolumn{1}{|c|}{ Ratio } & $<0.7$ & $0.70-0.85$ & $0.85-0.90$ & $0.90-0.95$ & $>0.95$ \\
\hline Hurricane prone regions & $3 \%$ & $60 \%$ & $24 \%$ & $12 \%$ & $1 \%$ \\
\hline Non hurricane prone regions & $17 \%$ & $71 \%$ & $9 \%$ & $3 \%$ & $0 \%$ \\
\hline
\end{tabular}

\subsection{Wind Directionality Factors for Wind-Induced Loads and Responses}

The directionality factor method is commonly used by building codes and standards including the ASCE 7. In the ASCE 7-10, directionality factors of 0.85 and 0.95 are specified for direction-sensitive and direction-insensitive structures respectively. The directionality factor, $K_{d}$ 
provided by the ASCE 7 for direction sensitive structures considers the effects of neither building location nor wind climate, and this has been a topic of debate. The $K_{d}$ of 0.85 specified in the ASCE 7-10 for MWFRS and C\&C of typical low-rise buildings was first used by Ellingwood et al. (1980). No justification was adduced for this value. Davenport (1977) had suggested very tentatively values as low as 0.72 and 0.56 .

In a study conducted by Isyumov et al. (2014) directionality factors were determined for tall buildings located in hurricane and non-hurricane prone regions using the Sector-to-Sector, Upcrossing, and Storm Passage approaches. The results indicated that the ASCE 7's $K_{d}=0.85$ is appropriate for structures located in areas where extra-tropical winds dominate, however, somewhat higher value; say $K_{d}=0.90$ would be appropriate in hurricane-prone wind regions. Another recently conducted study by Laboy-Rodriguez et al. (2014) developed a methodology that uses a Monte Carlo framework to quantify a directionality factor based on risk. This method was developed for components and cladding $(\mathrm{C} \& \mathrm{C})$ of low-rise structures located in hurricaneprone regions, the results suggested $K_{d}$ values of 0.95 and 0.90 for roof and wall claddings, respectively.

Database-assisted design techniques offer the possibility of rigorously estimating $K_{d}$ for large numbers of cases of practical interest. These techniques, which use large directional wind speed and aerodynamics databases, are used in this section with the view to estimate $K_{d}$ values for hurricane-prone and non-hurricane regions, various MRIs of the wind effects, and pressures, forces, and internal forces in various parts of a structure. The methodology used to calculate $K_{d}$ is developed first. Results of calculations based on that methodology are then presented for internal forces in the main wind force resisting system, pressure on claddings, global torsional moment, and global base shear forces. The specification of $K_{d}$ values is then discussed within a simple and effective structural reliability framework. 


\subsubsection{Determination of Wind Directionality Factor}

Expressions for external wind-induced forces or pressures are typically specified for design purposes in the form

$$
F_{\text {std }}(N)=a K_{d} K_{z}\left(G C_{p}\right) V(\bar{N})^{2}
$$

where the subscript "std" stands for "standard" ; $a$ is a dimensional constant that may include a factor accounting for topography and tributary area; $\bar{N}$ is the specified MRI in years; $K_{z}$ is the terrain exposure factor, assumed here for simplicity of exposition to be independent of wind direction; $\left(G C_{p}\right)=\max _{i}\left(G_{i} C_{p i}\right) ; G_{i}$ is the gust response factor, and $C_{p i}$ is the force or pressure coefficient, both corresponding to wind direction $i$ ( $i=1,2, \ldots, n_{d}$; for example $\left.n_{d}=16\right) ; V(\bar{N})$ is the non-directional wind speed, estimated from sufficiently large samples of measured or simulated wind speed data $V_{j}=\max _{i}\left(V_{i j}\right), j=1,2, . ., m$, where $m$ is the number of storm events being considered; $V_{i j}$ is the largest directional wind speed from direction $i$ during the storm event $j$, defined for standard terrain exposure, height above ground, and averaging time. $F_{\text {std }}(\bar{N})$ is estimated from a set of data of the form

$$
F_{j s t d}=a K_{d} K_{z} \max _{i}\left(G_{i} C_{p i}\right)\left[\max _{i}\left(V_{i j}\right)\right]^{2}
$$

$(j=1,2, \ldots, m)$, where the subscript "std" stands for "standard." The product $\max _{i}\left(G_{i} C_{p i}\right)$ $\left[\max _{i}\left(V_{i j}\right)\right]^{2}$ overestimates the actual largest force induced by the storm event $j$, and the role of the directionality factor $K_{d}$ is to correct this overestimation.

Wind forces or pressures with an $\bar{N}$-year MRI, denoted by $F_{d i r}(\bar{N})$, and determined by taking directionality explicitly into account, are obtained from the set:

$$
F_{j d i r}=a K_{z} \max _{i}\left[\left(G_{i} C_{p_{i}}\right) V_{i j}^{2}\right]
$$

$(j=1,2, \ldots, m)$, where the index "dir" stands for "directional". This procedure accounts for wind directionality effects directly, without the intervention of a wind directionality factor, and yields a physically correct estimation of the pressures or forces. The terms $\max _{i}\left[\left(G_{i} C_{p i}\right) V_{i j}{ }^{2}\right]$ are always 
smaller than or equal to the product $\max _{i}\left(G_{i} C_{p i}\right)\left[\max _{i}\left(V_{i j}\right)\right]^{2}$ of Eq. (4.6). The value of the directional force or pressure with an $\bar{N}$-yr MRI, $F_{d i r}(\bar{N})$, is obtained from the set of values $F_{j}$ dir using the non-parametric statistics approach discussed previously and shown in Simiu (2011).

The wind directionality factor $K_{d}$ can therefore be calculated as a function of MRI $\bar{N}$ as follows:

$$
K_{d}(\bar{N})=\frac{F_{d i r}(\bar{N})}{F_{s t d}(\bar{N})}
$$

Note that, more generally, Eq. (4.8) can be applied not only to forces or pressures, but also to, e.g., internal forces, global torsion and global shear. Also, Eq. (4.8) can easily be extended to the case where $K_{z}$ depends upon direction.

For regions with only one type of windstorm climate, for any given mean rate of arrival of the storm events, the quantities $V(\bar{N})$ and $V_{e q}(\bar{N})$ can be estimated conveniently by using nonparametric statistics (described in section 4.2.1). As pointed out in section 4.2.1, for regions with mixed wind climates (e.g., hurricane and non-hurricane winds or thunderstorm and nonthunderstorm winds), the cumulative distribution functions of the different types of winds for that region are calculated separately, and are then combined to produce the cumulative distribution functions of the mixed wind climate.

So far the wind effects being considered have been aerodynamic pressures or forces applied to the structure. It is of interest to also consider internal forces in the structure's main wind force resisting system. In this case the calculated forces on the frame due to pressures on the outside envelope times the respective tributary areas need to be multiplied by the appropriate influence coefficients. The influence coefficients consist of the internal forces of interest induced by unit normal forces to the frame at appropriate locations. 


\subsubsection{Case Studies}

The directional distribution of the pressure coefficients is a function of building orientation, since as the orientation changes, so do the pressure coefficients corresponding to any given azimuth. Since code provisions are typically applicable to buildings with unknown orientation, statistics of the directional factor are obtained for any one building from its orientation-dependent $K_{d}$ values.

The building being considered is a gable roof low-rise building from the NIST database with $L=187.5 \mathrm{ft}, B=120 \mathrm{ft}, H=18 \mathrm{ft}$, and $\theta=4.76 \mathrm{deg}$., in both open and suburban terrain exposures. This study took into account 16 building orientations for hurricane-prone regions and 18 building orientations for non-hurricane regions. Figure 4.5 shows the positions of the portal frames that constitute its main wind force resisting system, the positive $x$ and $y$ axes, and the positive rotational direction. The bending moments at the upwind bent, and axial forces in the upwind columns of frames 2 and 5 were calculated, and four pressure taps were selected for the study of pressure on cladding (Figure 4.5). The time histories of the base shear along the $x$ - and $y$ axis are sums of the time histories of the pressures or components thereof, times the respective tributary areas, at all the taps for which those pressures or components are parallel to the $x$-axis and $y$-axis, respectively. To calculate the global torsional moment time history, the moments of those pressures or components are multiplied by their tributary areas and their eccentricities with respect to the center of the structure.

In all cases, estimates of the expectation of the peaks of the pressures or forces were obtained by using the methodology in Sadek and Simiu (2002). The justification for selecting the expectation of the peak aerodynamic pressures or forces is that the expected wind effect is determined from the expectations of the various factors (micrometeorological, aerodynamic, climatological, dynamic) that contribute to the wind effect, hence the need to calculate the expectation of the peak aerodynamic response. The fluctuating part of the wind effect is due to 
the errors and uncertainties associated with those factors. These errors and uncertainties must be considered collectively, that is, rather than considering peaks of the individual errors and uncertainties, it is appropriate to consider the peak of the total fluctuating part of the wind effect. It was determined in this work that the contribution of the uncertainties in the peak aerodynamic pressures or forces to the peak of the total response is negligible. For further details see Simiu (2011) and Gabbai and Simiu (2013).

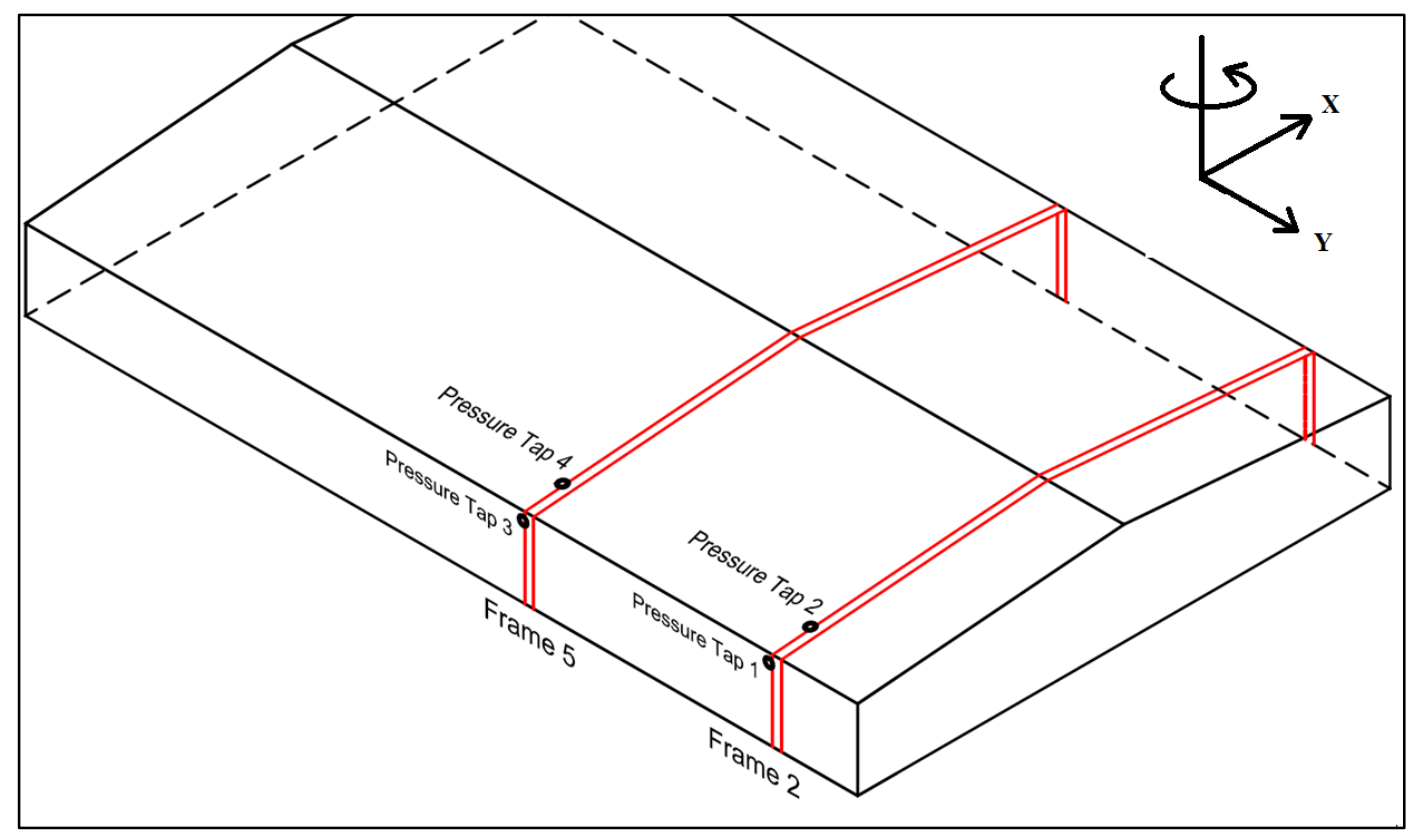

Figure 4.5 Location of Frames, and Taps for Pressure on Claddings

For hurricane prone regions, 27 geographical locations along the Gulf of Mexico and North Atlantic coast (i.e. Mileposts 150, 250, 350_.. 2750) were considered. Directional wind speed data for 16 azimuths were obtained for 999 simulated hurricanes listed on that site for the selected locations (see Chapter 2 for the site locations and details on the generation of their wind speeds). Because at those locations the wind climate is overwhelmingly dominated by hurricanes, nonhurricane winds were not taken into account in the calculations. For non-hurricane regions, four geographical locations (Fort Worth, Texas; Indianapolis, Indiana; Kansas City, Missouri; and Phoenix, Arizona) were studied; see Chapter 2 for details on the generation of non-hurricane 
winds. Each location experiences thunderstorm and non-thunderstorm winds, and hence the procedure applicable to mixed wind climates explained in the previous section was employed to compute the directionality factors. For all cases, $K_{d}$ factors for 300-, 700- and 1700-yr MRIs were considered.

\subsubsection{Results}

The directionality factors pertaining to the main wind force resisting system are shown in Figure 4.6 and Figure 4.7 for hurricane and non-hurricane regions respectively. The results consist of mean values and coefficients of variation $(\mathrm{COV})$ of $K_{d}$ for the wind-induced axial load in the upwind column and the bending moment in the upwind bent of frames 2 and 5 (Figure 4.5), for 300-, 700- and 1700-yr MRI, for open and suburban exposures. The mean values and COVs were obtained from the sets of $K_{d}$ values corresponding to 16 building orientations for hurricaneprone regions and 18 building orientations for non-hurricane regions under the assumption that the probability distribution of the building orientation is uniform. $K_{d}$ generally increases with increasing MRI, and highly depends upon geographical location.

From Figure 4.6 and Figure 4.7, it can be observed that $K_{d}$ depends more on the position of the frame than on the type of exposure or the type of internal force (i.e., whether axial force in upwind column or bending moment at the upwind bent). For example, the mean $K_{d}$ values for the axial forces at frame 2 are larger than all their frame 5 counterparts, but the COV is larger for frame 5 (Figure 4.6). The mean and COV values of $K_{d}$ for internal forces at open terrain and suburban exposures are almost identical. 

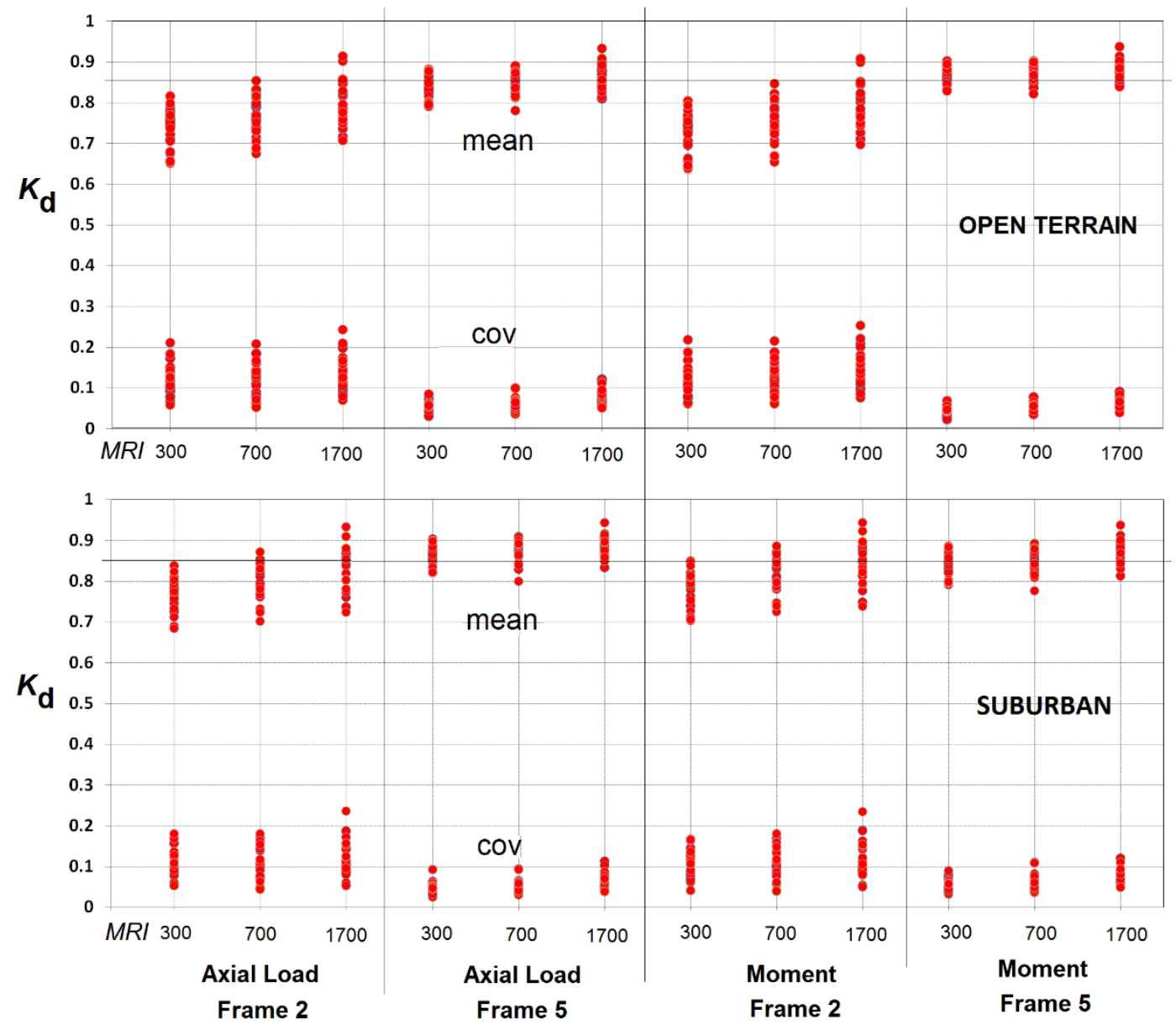

Figure 4.6 $K_{d}$, Internal Responses at MWFRS, Hurricane Prone Regions 

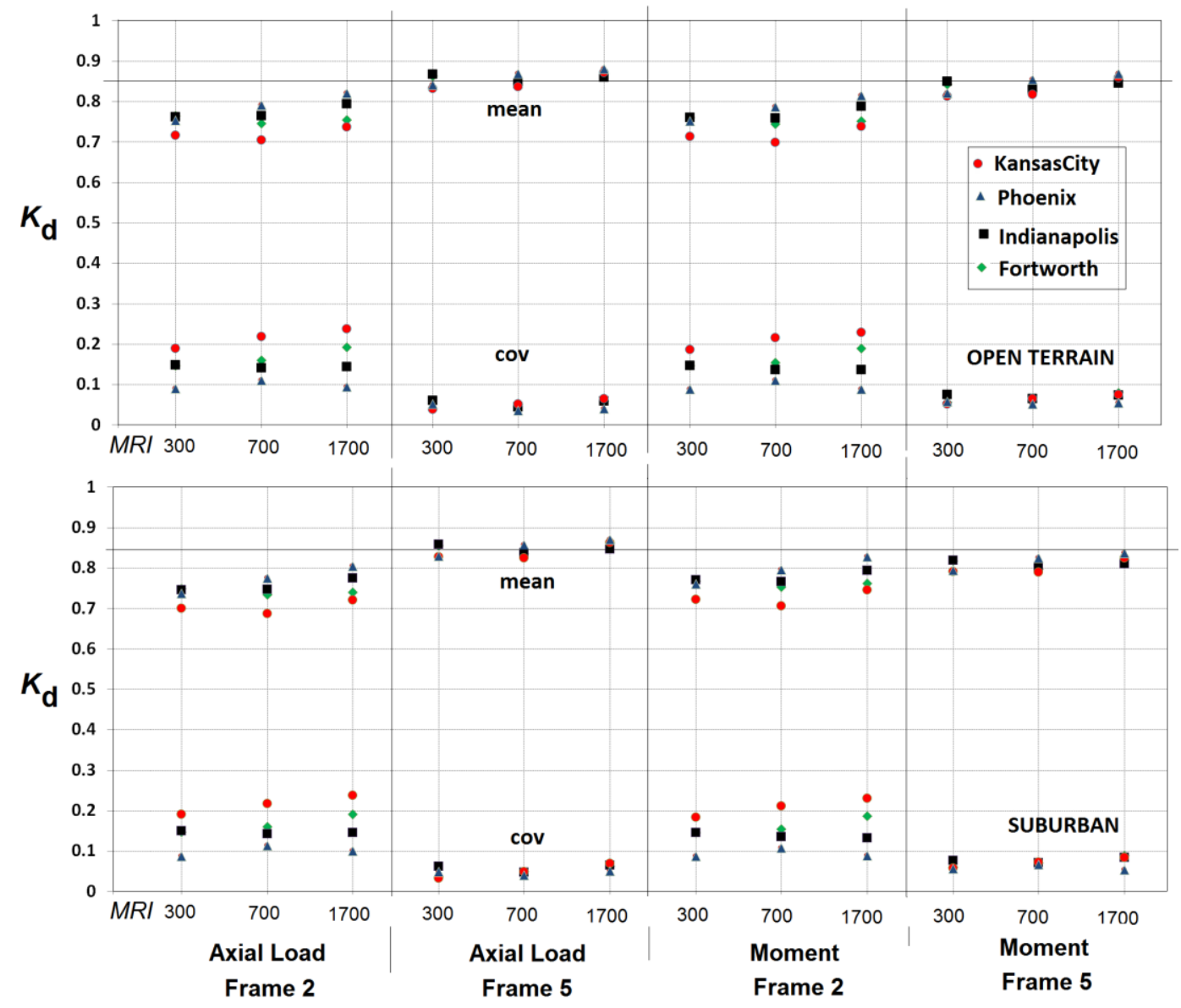

Figure 4.7 $K_{d}$, Internal Responses at MWFRS, Non-hurricane Prone Regions

The directionality factors for pressures on cladding for hurricane and non-hurricane regions are shown in Figure 4.8 and Figure 4.9 respectively, and those for global torsion and shear for hurricane and non-hurricane regions are shown in Figure 4.10 and Figure 4.11, respectively. The mean $K_{d}$ values for pressures on cladding are larger in open terrain than in suburban exposure in all cases. In most of the cases the mean values of $K_{d}$ for the global forces were larger than those for internal responses and components and cladding. The directionality factors for non-hurricane regions were consistently smaller than those for hurricane prone regions, a fact to be considered when formulating an adequate $K_{d}$ factor for codification purposes. 


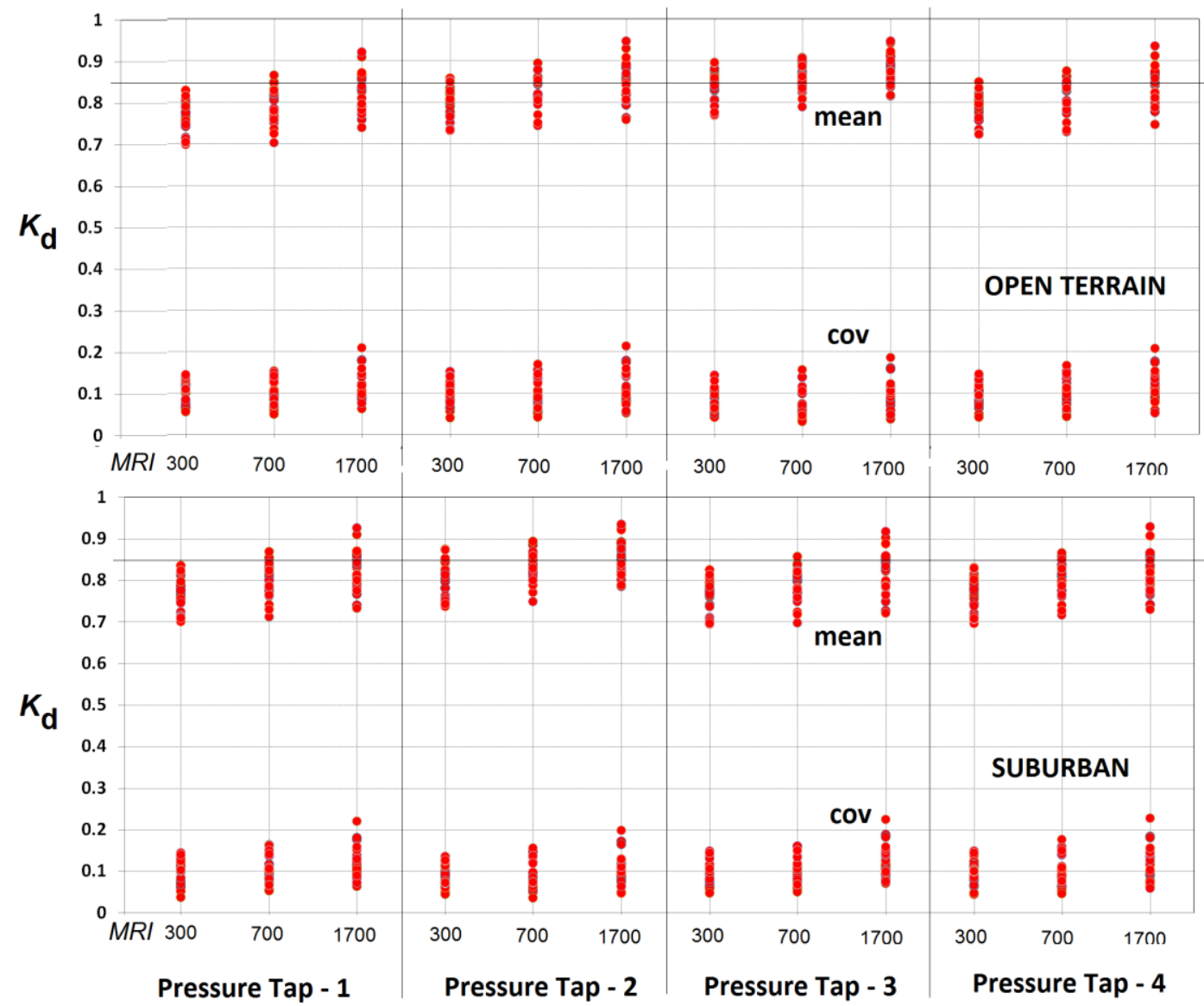

Figure 4.8 $K_{d}$, Pressures on Claddings, Hurricane Prone Regions 

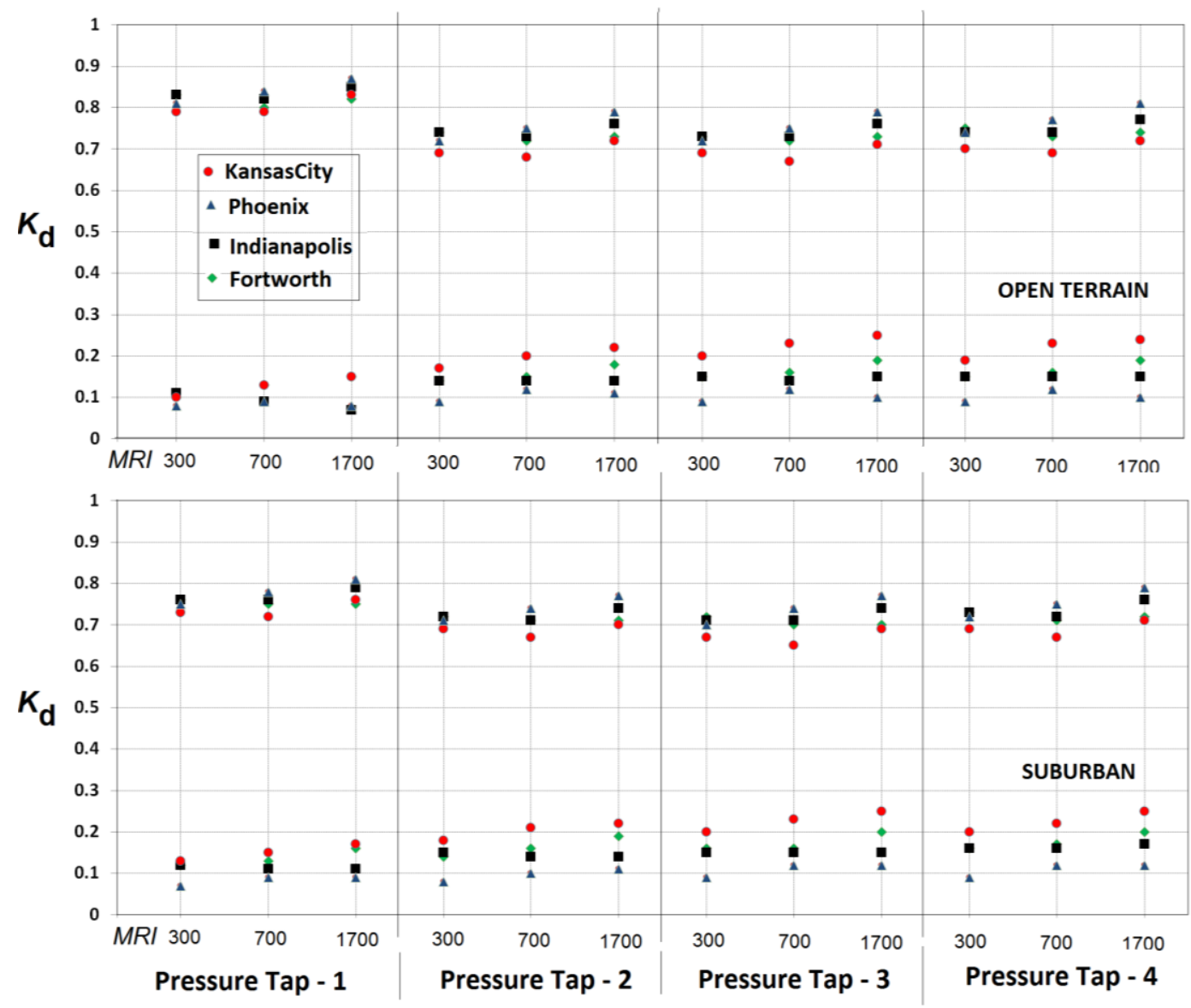

Figure $4.9 K_{d}$, Pressures on Claddings, Non-Hurricane Prone Regions 


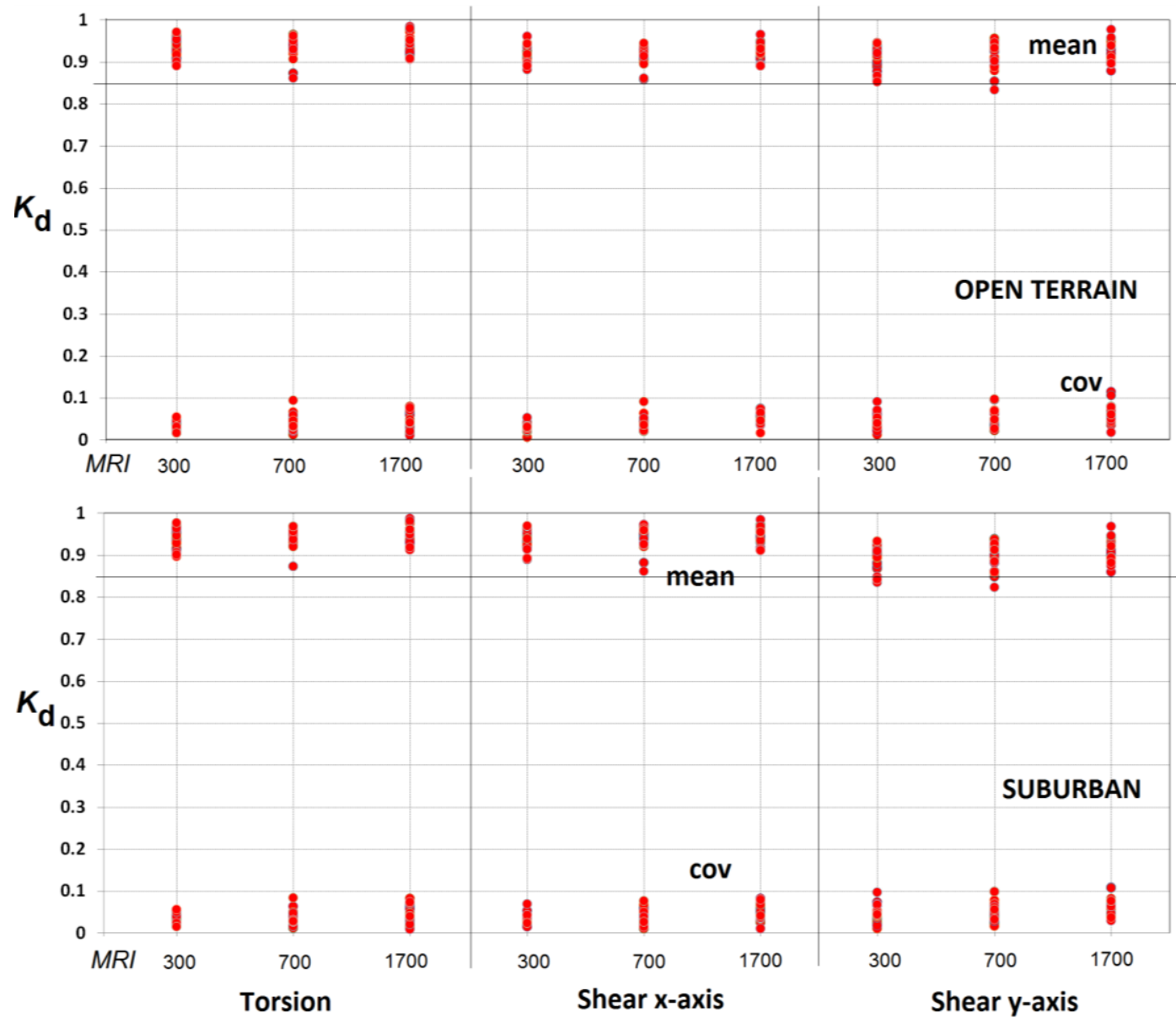

Figure 4.10 $K_{d}$, Global Torsion and Shear, Hurricane Prone Regions 


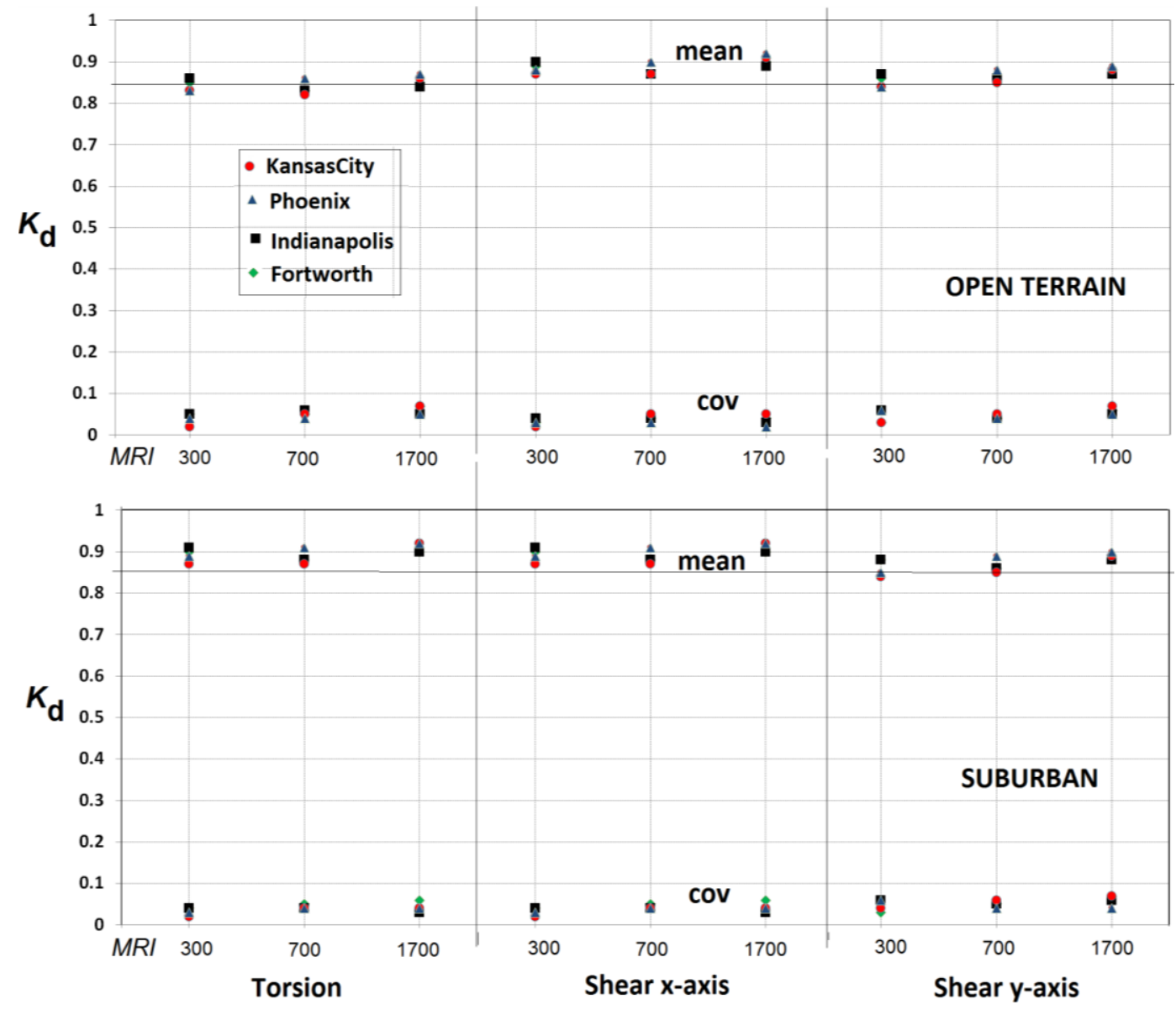

Figure $4.11 K_{d}$, Global Torsion and Shear, Non-Hurricane Prone Regions

The results of the calculations show that in many though not all cases the dependence of the directionality factors on MRIs is negligible. This dependence is in many instances obscured by errors in the non-parametric estimation of the extreme wind effects. Summary of the distributions of the $K_{d}$ results for both hurricane and non-hurricane prone regions are shown in Table 4.2. In hurricane-prone regions, the $K_{d}=0.85$ value was exceeded for more than $42 \%, 24 \%$ and $65 \%$ of the internal forces, cladding forces and global forces respectively. However, in the studied nonhurricane regions, the mean $K_{d}$ value exceeded 0.85 in $9 \%, 7 \%$ and $65 \%$ of the internal forces, cladding forces and global forces cases respectively. The results clearly indicate that $K_{d}$ highly depends on the type of wind climate, confirming the recommendation of Isyomov et al. (2014) for using higher $K_{d}$ values in hurricane prone regions. 
Table 4.2 Distribution of $K_{d}$ values

\begin{tabular}{|c|c|c|c|c|c|c|}
\hline & \multicolumn{3}{|c|}{ Hurricane Prone Regions } & \multicolumn{2}{l|}{ Non-Hurricane Prone Regions } \\
\hline$K_{\boldsymbol{d}}$ & $<\mathbf{0 . 8 5}$ & $\mathbf{0 . 8 5}-\mathbf{0 . 9 0}$ & $>\mathbf{0 . 9 0}$ & $<\mathbf{0 . 8 5}$ & $\mathbf{0 . 8 5}-\mathbf{0 . 9 0}$ & $>\mathbf{0 . 9 0}$ \\
\hline Internal forces & $58 \%$ & $36 \%$ & $6 \%$ & $91 \%$ & $9 \%$ & $0 \%$ \\
\hline Cladding forces & $76 \%$ & $20 \%$ & $4 \%$ & $93 \%$ & $7 \%$ & $0 \%$ \\
\hline Global forces & $35 \%$ & $13 \%$ & $52 \%$ & $35 \%$ & $35 \%$ & $30 \%$ \\
\hline
\end{tabular}

\subsubsection{Structural Reliability Considerations}

Inherent in the calculated wind forces or pressures are uncertainties. Based on a first-order second moment analysis of Eq. (4.5), the following expressions for the mean and coefficient of variation $(\mathrm{COV})$ of the force or pressure $F_{\text {std }}(N)$ at any given location have been proposed by Ellingwood et al. (1980):

$$
\begin{aligned}
& \overline{F_{s t d}(N)}=\bar{a} \overline{K_{d}} \overline{K_{z}} \bar{G}{\overline{C_{p}}}_{\overline{V(N)}}^{2} \\
& \operatorname{COV}\left[F_{s t d}(N)\right] \approx\left\{\operatorname{COV}^{2}(a)+\operatorname{COV}^{2}\left(K_{d}\right)+\operatorname{COV}^{2}\left(K_{z}\right)+\operatorname{COV}^{2}(G)+\operatorname{COV}^{2}\left(C_{p}\right)+2 \operatorname{COV}^{2}[V(N)]\right\}^{1 / 2}
\end{aligned}
$$

(To see why Eq. (4.10) is correct consider the product of two independent random variables $x=\bar{x}+x^{\prime}$ and $y=\bar{y}+y^{\prime}$. We have $x \cdot y=\left(\bar{x}+x^{\prime}\right)\left(\bar{y}+y^{\prime}\right)$. The result $\operatorname{COV}(x \cdot y) \approx\left[\operatorname{COV}^{2}(x)+\right.$ $\left.\operatorname{COV}^{2}(y)\right]^{1 / 2}$ is obtained from this relation from the definition of the variance and of the COV by neglecting higher order terms.) Ellingwood et al. (1980) assumed for the uncertain variates $a, K_{d}$, $K_{z}, G, C_{p}$, and $V(N)$, the $\operatorname{COVs}$ as $\operatorname{COV}(a)=0, \operatorname{COV}\left(K_{d}\right)=0, \operatorname{COV}\left(K_{z}\right)=0.16, \operatorname{COV}\left(C_{p}\right)=0.12$, $\operatorname{COV}(G)=0.11, \operatorname{COV}[V(N=50 \mathrm{yrs})] \approx 0.1$, respectively. By Eq. (4.10), these values yield $\operatorname{COV}\left[\left.F_{\text {std }}(N=50 \mathrm{yrs})\right|_{\operatorname{Cov}(K d)=0}\right]=0.27$. However, $\operatorname{COV}\left(K_{d}\right)>0$, as can be seen from Figure 4.6 to Figure 4.11. For most cases of interest, in which $\bar{K}_{d}$ tends to exceed 0.85 , Figure 4.6 to Figure 4.11 show that it may be assumed $\operatorname{COV}\left(K_{d}\right) \approx 0.1$, say, rather than $\operatorname{COV}\left(K_{d}\right)=0$. Therefore the 
somewhat larger value, $\operatorname{COV}\left[\left.F_{\text {std }}(N=50 \mathrm{yrs})\right|_{\operatorname{Cov}(K d)=0.1}\right]=0.285$, rather than $\operatorname{COV}\left[F_{\text {std }}(N=50\right.$ $\left.\mathrm{yrs})\left.\right|_{\operatorname{COV}(K d)=0}\right]=0.27$, would be obtained instead.

The design value of the force or pressure with a 50-yr MRI is

$$
F_{\text {std }}(N=50 \mathrm{yrs})=\overline{F_{\text {std }}(N=50 y r s)}\left\{1+k \operatorname{COV}\left[F_{\text {std }}(N=50 \mathrm{yrs})\right]\right\}
$$

where the peak factor $k \approx 3$, say. It follows that, for given $\bar{K}_{d}$, if $\operatorname{COV}\left(K_{d}\right) \approx 0.1$,

$$
\begin{aligned}
& \left.F_{\text {std }}(N=50 \mathrm{yrs})\right|_{\operatorname{COV}\left(K_{d}\right)=0.1} \\
& \left.\approx F_{\text {std }}(N=50 \mathrm{yrs})\right|_{\operatorname{Cov}\left(K_{d}\right)=0}\left\{\frac{1+k \operatorname{COV}\left[F_{\text {std }}(N=50 \mathrm{yrs}) \mid \operatorname{COV}\left(K_{d}\right)=0.1\right]}{1+k \operatorname{COV}\left[\left.F_{\text {std }}(N=50 \mathrm{yrs})\right|_{\operatorname{COV}\left(K_{d}\right)=0}\right]}\right\}
\end{aligned}
$$

For $N=50$ years the multiplying factor $\left[1+k \operatorname{COV}\left[\left.\mathrm{F}_{s t d}(N)\right|_{\operatorname{Cov}(K d)=0.1}\right] /\left[1+k \operatorname{COV}\left[\left.\mathrm{F}_{s t d}(N)\right|_{\operatorname{Cov}(K d)=0}\right]\right.\right.$ $\approx 1$. For $N>50$ years, $\operatorname{COV}(V(N))>\operatorname{COV}(V(50$ years $))$ (see, e.g., Coles and Simiu (2003)). As can be inferred from Eq. (4.12), the contribution of $\operatorname{COV}\left(K_{d}\right)$ to $\operatorname{COV}\left[F_{\text {std }}(N)\right]$ is therefore smaller than for $N=50 \mathrm{yrs}$, and the multiplying factor is typically even closer to 1 . For this reason, the simplifying assumption by Ellingwood et al. (1980) that $\operatorname{COV}\left(K_{d}\right)=0$, and therefore that $K_{d} \approx \bar{K}_{d}$, is acceptable for practical purposes.

\section{Conclusions}

This chapter provided detailed description of two methods, namely directional and nondirectional, for synthesizing building DCI databases with site climatological databases. The former accounts rigorously for building orientation, while the later only considers the highest directional wind speed of each event. In an effort to estimate directionality factors for use with the second approach, which is simpler and less computationally intensive, DCIs computed using those two methods were also compared, and factors of 0.90 and 0.85 are recommended for use with the non-directional approach in hurricane and non-hurricane prone regions respectively.

This chapter also adduces new data on wind directionality factors that complement and confirm to a significant extent the results of a Delphi consensus estimation survey Ellingwood and Tekie (1999), and can therefore provide a useful basis for current discussions of this topic by 
the engineering and codification communities. The results of this work show that the directional factor $K_{d}$ varies as a function of type of wind storm, geographical location within an area with a given type of wind climate, type of wind effect (e.g., pressure, internal force, global shear or torsion), and position of the wind effect being considered within the structure. The dependence upon mean recurrence interval of the extreme wind effect is typically though not in all cases negligible.

The results also confirm the finding by Isyumov et al. (2014) that $K_{d}$ values are larger for hurricane-prone than for non-hurricane regions. For pressures at individual points on building envelopes the value $K_{d}=0.85$ is typically adequate for hurricane-prone regions and conservative for non-hurricane regions. For internal forces in wind force resisting systems (e.g., frames), the value $K_{d}=0.85$ is typically adequate for non-hurricane regions, while the value $K_{d}=0.90$ would be required for hurricane-prone regions, in spite of its conservatism in some situations. Finally, for global effects, such as building base shears and global building torsion, $K_{d}=0.90$ and $K_{d}=$ 0.95 would be appropriate for non-hurricane and hurricane-prone regions, respectively.

\section{References}

ASCE. (2010). Minimum design loads for buildings and other structures. American Society of Civil Engineers, Reston, VA.

Coles, S., and Simiu, E. (2003). "Estimating Uncertainty in the Extreme Value Analysis of Data Generated by a Hurricane Simulation Model." Journal of Engineering Mechanics, 129(11), 1288-1294.

Davenport, A. G. (1977). "The prediction of risk under wind loading." Proceeding of the 2nd International Conference on Structural Safety and Reliability, Munich, Germany.

Ellingwood, B., Galambos, T., and McGregor, J. "Cornell. CA (1980), Development of a probabilitybased load criterion for American National Standard A58." National Bureau of Standards Special Publication, 577.

Ellingwood, B. R., and Tekie, P. B. (1999). "Wind load statistics for probability-based structural design.” Journal of Structural Engineering, 125(4), 453-463.

Gabbai, R. D., and Simiu, E. (2013). "Evaluation of mean recurrence intervals of wind effects for tall building design.” Journal of Structural Engineering, 140(1), 04013037. 
Gamble, S. L., Miltenburg, R. J., Cicci, M. D., and Accardo, M. (2001). "Prediction of local exterior wind pressures from wind tunnel studies using a time history analysis approach." Americas, 1.

Irwin, P., Garber, J., and Ho, E. (2005). "Integration of wind tunnel data with full scale wind climate." Proceedings of the 10th Americas Conference on Wind Engineering Baton Rouge, Louisiana, May.

Isyumov, N., Ho, E., and Case, P. (2014). "Influence of wind directionality on wind loads and responses." Journal of Wind Engineering and Industrial Aerodynamics, 133, 169-180.

Isyumov, N., Mikitiuk, M. J., Case, P. C., Lythe, G. R., and Welburn, A. (2003). "Predictions of wind loads and responses from simulated tropical storm passages." Proceedings of the 11th International Conference on Wind Engineering. DA Smith and CW Letchford, eds., Lubbock, Texas.

Laboy-Rodriguez, S. T., Gurley, K. R., and Masters, F. J. (2014). "Revisiting the directionality factor in ASCE 7." Journal of Wind Engineering and Industrial Aerodynamics, 133, 225233.

Lepage, M. F., and Irwin, P. A. (1985). "A technique for combining historical wind data with wind tunnel tests to predict extreme wind loads." Proc. Fifth US National Conf. on Wind Engineering.

Main, J. A., and Fritz, W. P. (2006). Database-assisted design for wind: concepts, software, and examples for rigid and flexible buildings. National Institute of Standards and Technology, Technology Administration, US Department of Commerce.

Sadek, F., and Simiu, E. (2002). "Peak non-Gaussian wind effects for database-assisted low-rise building design.” Journal of Engineering Mechanics, 128(5), 530-539.

Simiu, E. (2011). Design of buildings for wind: a guide for ASCE 7-10 standard users and designers of special structures. John Wiley \& Sons, Inc., Hoboken, New Jersey.

Simiu, E., and Filliben, J. J. (2005). "Wind tunnel testing and the sector-by-sector approach to wind directionality effects." Journal of structural engineering, 131(7), 1143-1145.

Yeo, D. (2011). "Database assisted design for high-rise structures in mixed extreme wind climates." Proceedings of the 13th International Conference on Wind Engineering ICWE13,Amsterdam. 


\title{
5. EFFECT OF WIND INDUCED-INTERNAL PRESSURES ON FRAME FORCES AND DEMAND-TO-CAPACITY INDEXES
}

\begin{abstract}
Given the significant role of internal pressures in the loading of low-rise buildings, their correct estimation is critical for accurately determining the total wind effects. However, previous research on DAD was entirely focused on external pressures, and internal pressures were taken from building codes if needed. This chapter presents results of an investigation conducted to understand and quantify the characteristics of the global roof uplift, structural frame forces, and demand-to-capacity indexes (DCIs) induced by net pressures on low-rise buildings with single or multiple dominant openings. The highest responses occurred when the model had a single dominant opening on the windward side. High roof uplift was also experienced when the model had multiple openings on parallel walls, and increased with increasing ratio of windward to leeward openings. The ASCE 7-10 was found to underestimate global roof uplift when the model had windward and leeward wall openings of equal sizes. Calculations of frame forces and DCIs were also performed using the Database-Assisted-Design (DAD) methodology for different opening configurations. Internal pressure significantly increased the frame forces corresponding to the most unfavorable wind direction and acting on the frames located close to the building openings. However, it had a smaller effect on the critical forces on the frames located away from the building openings. Effects of internal pressure also varied between different cross-sections of the same frame depending on the correlation between forces induced by external and internal pressures. Relatively high correlations (i.e. 0.67 and 0.55 correlation coefficients in single and multiple dominant openings, respectively) were observed. Comparisons of frame forces and DCIs calculated using experimentally measured internal pressures to their counterparts evaluated by using ASCE 7-10 provision for internal pressures showed that ASCE 7-10 can produce unconservative estimates.
\end{abstract}




\subsection{Introduction}

Design of building structures for wind should account for possible wind loading increase due to opening failures. The characteristics of wind-induced internal pressures are affected by several parameters including the size, geometry and location of the openings, the volume, shape and envelope flexibility of the building structure, and the characteristics of the external wind pressure. An opening failure on the windward side can induce high positive internal pressures, which when combined with negative external pressures on the roof might produce high net pressures that can lead to building failures. This is a particularly common scenario in severe events such as tropical cyclones and hurricanes, during which openings can be breached by windborne debris or by direct wind loading (Holmes and Ginger 2012). The importance of understanding the effects of wind-induced internal pressures on the Main Wind Force Resisting System (MWFRS) and on Components and Cladding $(\mathrm{C} \& \mathrm{C})$ of low-rise buildings is widely recognized and has been the subject of research. However, difficulties associated with model scaling requirements needed for the correct measurement of internal pressures in wind tunnels has limited the amount of reliable experimental data available.

Most previous research on internal pressure has dealt with understanding the characteristics of internal pressures under various opening configurations. However, in structural design it is not isolated internal pressures that are important, rather it is the net loads induced by the combination of internal and external pressures. Net fluctuating pressures/responses are highly affected by the correlation between the fluctuating internal and external pressures, and between the respective responses they induce. High correlation coefficients entail net peaks higher than peaks observed separately in the external and internal pressures (Sharma and Richards 2005). Some researchers, including Mehta et al. (1993), Beste and Cermak (1997), Ginger and Letchford (1999), and Sharma and Richards (2005), have studied the nature of net wind-induced loads on cladding of 
low-rise buildings, in which high correlations between external and internal pressures were observed, leading to increased net loads.

The presence of a dominant opening can modify the characteristics of the wind loads. It can alter both the magnitude and the directions of the most unfavorable wind velocity. Unlike wind loads on cladding, which are determined by the pressure distribution within a relatively small surface area, wind-induced forces on structural systems, for example a frame, are affected by the correlation of the external and internal pressures in the entire area tributary to the system. Effects of internal pressure can be complicated in the case of demand-to-capacity indexes (DCIs), which incorporate the effect of gravity loads.

This chapter presents results of a comprehensive study aimed at understanding the effects of internal pressure on (i) global roof uplift, (ii) frame forces, and (iii) frame DCIs, in low-rise industrial buildings with various dominant opening configurations. According to Holmes and Ginger (2012), if the size of an opening is greater than approximately twice the total background leakage area, the opening can be considered as dominant. Typically, the single dominant opening on the windward side is the case usually considered critical in design, however, the accurate evaluation of internal pressures in building with single or multiple openings can be essential as well (Oh et al. (2007); Karava and Stathopoulos (2011)). Hence, this study also included multiple opening cases.

The low-rise industrial buildings addressed in this study are characterized by rectangular shapes, gable roofs with no overhangs, no ceilings or wall partitions, and a structural system composed of equally spaced moment resisting steel frames (Fig. 3.2). Data on internal pressures, for single dominant opening, available in the National Institute of Standards and Technology (NIST) aerodynamic database (reference) were used. Large-scale testing was also conducted at the Florida International University (FIU) Wall of Wind (WOW) facility to measure windinduced internal and external pressure on a low-rise building model with multiple dominant 
openings. Global roof uplift forces were measured directly using load cells, while net windinduced frame forces were evaluated from time-histories of external and internal pressures using Database-Assisted Design (DAD) methodology.

In the absence of test based data, users of database-assisted-design (DAD) may need to substitute internal pressure provisions from building codes, for instance the Minimum Design Loads for Buildings and Other Structures (ASCE 7), as was done in Chapter 3. For this reason, this study presents comparison of wind effects computed using experimentally measured internal pressures on the one hand to wind effects evaluated using code recommended values on the other.

In this study, instead of comparing the experimentally recorded isolated internal pressures with those recommended by ASCE 7-10, as was done in most previous researches, the effective influence of internal pressures on the net wind-induced forces are experimentally determined and compared to those computed using ASCE 7-10.

The results of this research can also assist in developing improved code provisions on windinduced internal pressures for design purposes. Section 5.2 provides a brief description of the aerodynamic data used in this study. Description of the internal pressure provision for low-rise buildings in the ASCE 7-10 is presented in Section 5.3. The effect of internal pressures on globalroof uplift is considered in Section 5.3. Sections 5.4 and 5.5 consider the effect of internal pressure on frame forces and DCIs, respectively, and compare wind effects estimated using experimentally measured internal pressures, to those estimated using ASCE 7-10. Finally a conclusion is provided.

\subsection{Internal Pressure Data}

In this study, data from the NIST public aerodynamic database, and from experimental measurements conducted at FIU's WOW facility, were used. Two models from the NIST database have been used to study the effects of internal pressures on frame forces in low-rise buildings with single dominant openings. Since internal pressure measurements in the NIST 
database are limited to models with single dominant opening, a large-scale experimental testing was conducted at the WOW using a model with multiple dominant openings. Comparison of responses evaluated using a NIST and WOW model was also conducted. Table 5.1 provides summary of the experimental data used for the different analysis.

Table 5.1 Summary of Experimental Data

\begin{tabular}{|c|c|c|c|c|c|l|}
\hline \multirow{2}{*}{ Model } & \multicolumn{2}{|c|}{ Prototype Dimensions (ft) } & $\begin{array}{c}\text { Roof } \\
\text { slope }\end{array}$ & $\begin{array}{c}\text { Length } \\
\text { Scale }\end{array}$ & \multicolumn{1}{|c|}{ Analysis } \\
\cline { 2 - 4 } $\begin{array}{c}\text { WIST } \\
\text { Model 1 }\end{array}$ & 80.0 & 125.0 & 40.0 & $1: 12$ & $1: 100$ & $\begin{array}{l}\text {-Frame Forces - } \\
\text { Single opening } \\
\text {-DCI - } \\
\text { Single opening }\end{array}$ \\
\hline $\begin{array}{c}\text { NIST } \\
\text { Model 2 }\end{array}$ & 80.0 & 125.0 & 16.0 & $1: 12$ & $1: 100$ & $\begin{array}{l}\text {-Frame Forces - } \\
\text { Single opening }\end{array}$ \\
\hline $\begin{array}{c}\text { NIST } \\
\text { Model 3 }\end{array}$ & 40.0 & 62.5 & 12.0 & $1: 12$ & $1: 100$ & $\begin{array}{l}\text {-WOW - NIST } \\
\text { comparison }\end{array}$ \\
\hline $\begin{array}{c}\text { WOW } \\
\text { Model }\end{array}$ & 40.0 & 62.5 & 12.0 & $1: 12$ & $1: 8$ & $\begin{array}{l}\text {-Frame Forces - } \\
\text { Multiple openings } \\
\text {-WOW and NIST } \\
\text { comparison }\end{array}$ \\
\hline
\end{tabular}

The following subsections provide descriptions of the NIST and WOW experimental data.

\subsubsection{NIST Public Aerodynamic Data}

The two NIST models that include dominant opening induced internal pressure measurements have identical dimensions except for their eave heights. The models have equivalent full-scale width $\mathrm{B}=80 \mathrm{ft}$ and length $\mathrm{L}=125 \mathrm{ft}$, and roof slope 1:12. The first model, henceforth referred to as NIST Model 1 has eave height, $\mathrm{H}=40 \mathrm{ft}$, and the second model, NIST Model 2, has eave height, $\mathrm{H}=16 \mathrm{ft}$. The models, constructed of acrylic glass at a scale of 1:100, had uniform background leakage provided by 80, 0.02 in diameter holes (model scale). They each 
had a large opening with area equal to $3.3 \%$ of the area of the wall containing the opening, and additional small openings. As can be seen in Figure 5.1, the large openings were rectangular in shape, and the small openings had a circular shape. During testing, only the dominant opening was open at a time; while the openings for the background leakage were always open (Oh et al. 2007)

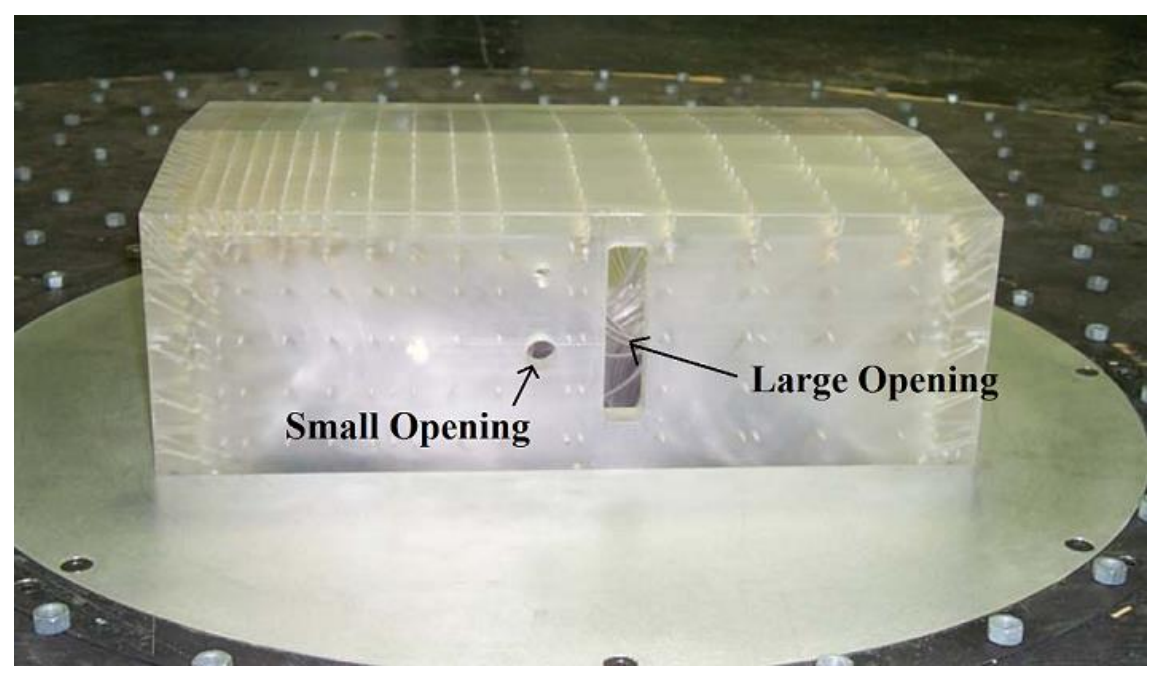

Figure 5.1 Orientation of Large and Small Openings for NIST models

Wind-induced pressure measurements were conducted for equivalent full-scale duration of $3600 \mathrm{~s}$, at a velocity scaling of 1:4. Holmes (1978) and Vickery (1986), using Helmholtz resonance and unsteady flow (with inertial term included) models, respectively, showed that during experimental investigations of internal pressure fluctuations in a micro-meteorological laboratory (wind tunnel or open jet facility), if a scaled down wind velocity is used, which is true in most cases, additional volume should be incorporated into the building model. This is required in-order to scale correctly the frequencies of the internal pressure fluctuations to those associated with the external pressures. To satisfy this requirement, additional volume was added underneath the wind tunnel (Ho et al. 2003a). Further details of the test models, wind tunnel characteristics, and test protocols can be found in Ho et al. (2003a; 2003b). 
A third model from the NIST database (referred herein as NIST model 3), with dimensions identical to the WOW model (described in the next section), was also used to compare results computed using the NIST model with those evaluated using the WOW model.

\subsubsection{Wall of Wind (WOW) Test Data}

Since the internal pressure in the NIST aerodynamic database only represent models with single dominant openings, experimental measurement of internal pressures in a model with multiple openings was conducted at FIU's WOW facility. Description of the characteristics of the WOW flow field used during testing is provided in Section 2.2.3.

The WOW model is a 1:8 scale model of a low-rise gable building having a geometric configuration similar to the NIST models. The model has $\mathrm{B}=40 \mathrm{ft}, \mathrm{L}=62.5 \mathrm{ft}, \mathrm{H}=12 \mathrm{ft}$ and roof slope, $\theta=1 / 12$ (Figure 5.2). The model was fabricated using double layer acrylic glass with a total wall thickness of $0.5 \mathrm{ft}$ at full-scale. This enabled the accurate scaling of the wall opening thickness, which is important for the correct simulation of the internal pressure, particularly for small openings (Sharma et al. 2010). The model was designed to be supported by four load-cells, one at each building corner (Figure 5.2). This setup enabled the direct measurement of internal and external wind-induced global forces in all three main axes of the model. The model had 17 openings distributed on its four walls; it also had background porosity (leakage) of $0.01 \%$ of the entire wall area, which was simulated using uniformly distributed holes on the model walls. The orientation of the building openings and wind direction is shown in Figure 5.3. 


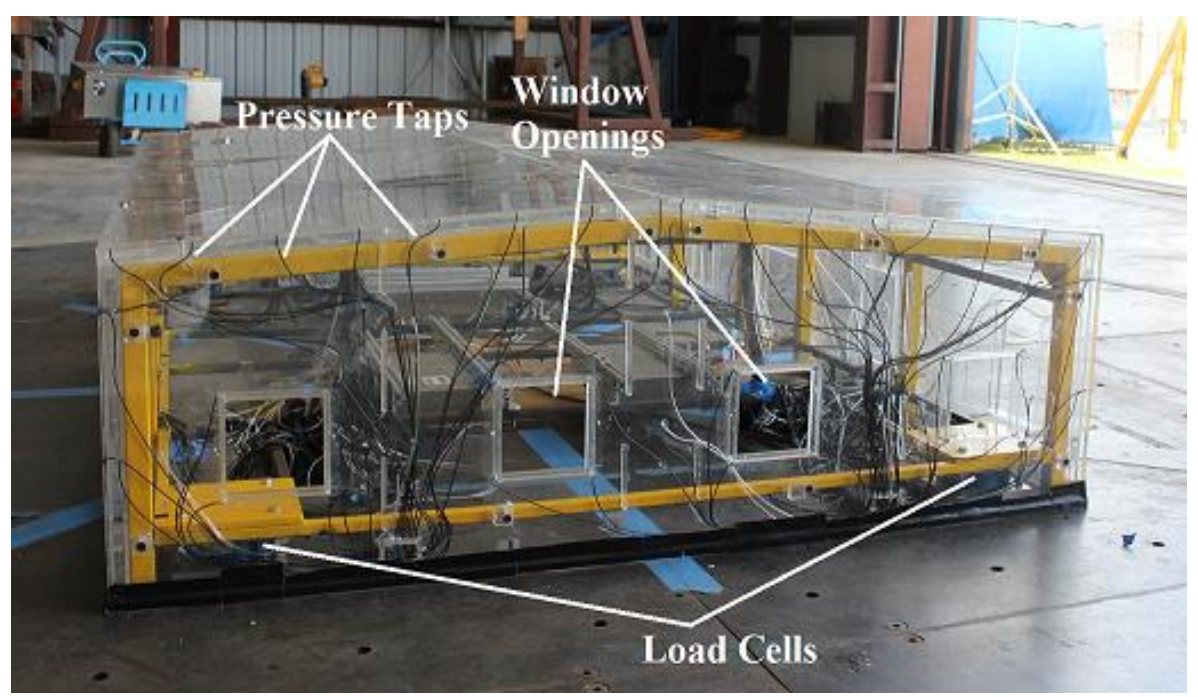

Figure 5.2. Wall of Wind Test Model

For the case of buildings with cross-openings (openings on opposite and/or adjacent walls), Womble (1994) showed that scaling of the internal volume has no effect on the internal pressure fluctuations. Moreover, using particle image velocimetry (PIV) it was shown in Karava and Stathopoulos (2011) that providing additional internal volume violates the internal shape similarity between the prototype and the model and can produce airflow patterns inside the building that are not realistic. In the WOW testing, by using a large-scale model (1:8 as opposed to $1: 50$ to $1: 100$, which is mostly the case in wind tunnel testing) and assuming a velocity scale of unity, the internal volume distortion requirement was avoided. 

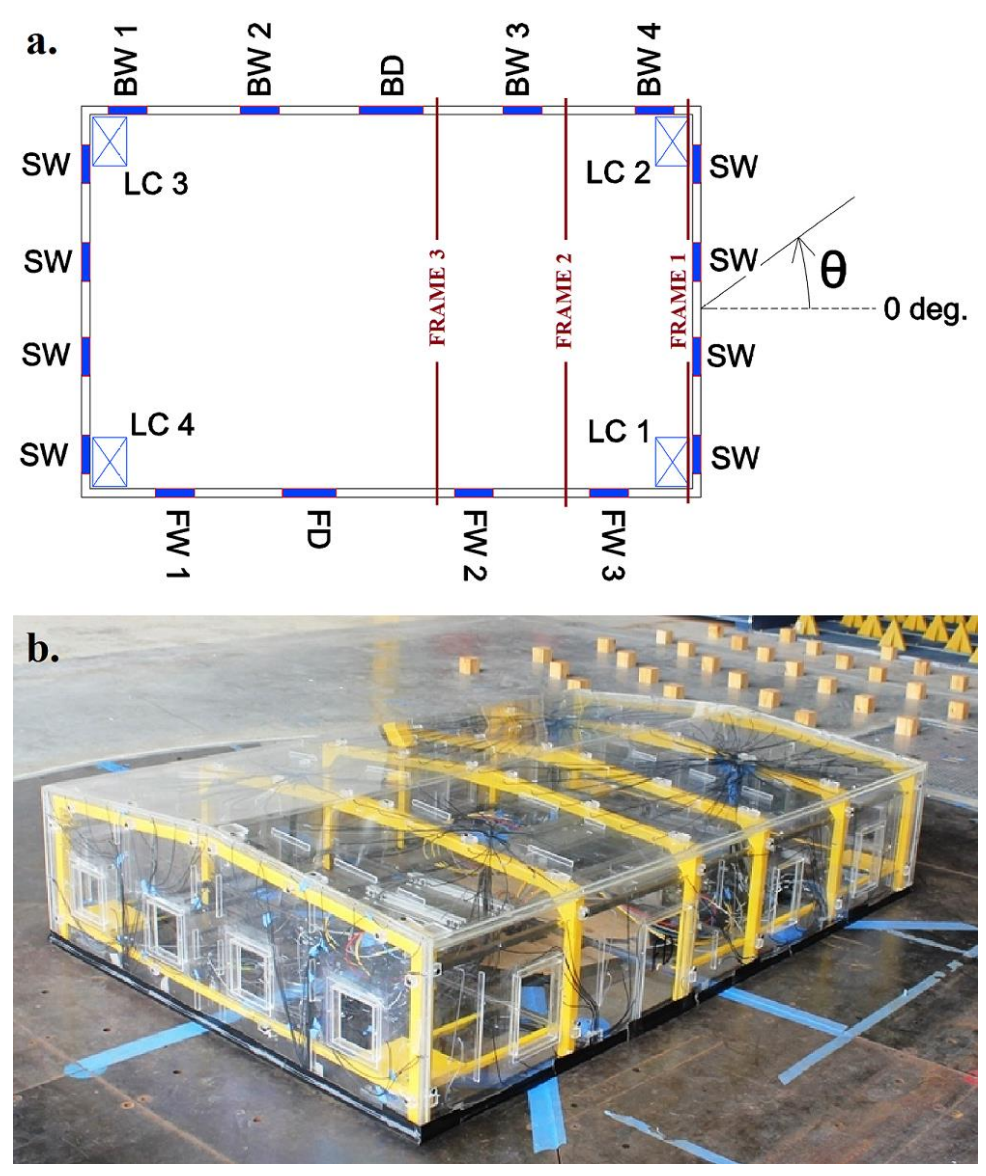

Figure 5.3. Large-Scale Model used in Experimental Investigation: Layout (upper) and Actual Model (lower)

The experiments were conducted in a simulated open terrain exposure and eave height wind speed of $50.1 \mathrm{mph}$ for 8 wind directions (i.e., $0^{\circ}$ to $315^{\circ}$ at $45^{\circ}$ increments). The time histories of global forces were recorded using 6-degree of freedom JR3 multi-axis load cells at sampling rate of $100 \mathrm{~Hz}$ for model duration of 2 minutes (corresponding to 16 minutes in full-scale). A custommade Windows based software that can export the load-cell measurements in different file formats including ASCII and EXCEL was used for data acquisition. The test model was also instrumented with 286 external pressure taps (200 on the roof and 86 on the walls) and 57 internal pressure taps ( 24 on the roofs and 33 on the walls). To estimate the external pressures at the openings, 4 pressure taps, one at each corner, were placed at selected model openings. Large numbers of internal taps were used to capture any possible internal pressure non-uniformities that 
might exist, as has been noted for buildings with multiple dominant openings. Time-histories of wind pressures were collected using 0.025-in) internal diameter (ID) polyurethane pressure tubes and a DSA4000, ZOC 33 Scanivalve data acquisition system. Each test lasted for 2 minutes, and pressure data was collected at a sampling rate of $520 \mathrm{~Hz}$. A tubing transfer function was developed (Irwin et al. 1979) and necessary corrections for pressure tubing length were performed.

\subsection{ASCE 7-10 Provision for Internal Pressure - Low-rise Buildings}

The internal wind pressure provisions in the ASCE 7-10 categorize buildings into open, partially enclosed and enclosed categories. For an open building, defined as having each wall at least $80 \%$ open, the specified internal pressure coefficient is $G C_{p i}=0$. The highest $G C_{p i}$, which is equal to \pm 0.55 , is specified for partially enclosed buildings. These are buildings which satisfy the following two conditions; (1) The total area of openings in a wall that receives positive external pressure exceeds the sum of the areas of openings in the balance of the building envelope (walls and roof) by more than $10 \%$, and (2) The total area of openings in a wall that receives positive external pressure exceeds $0.37 \mathrm{~m}^{2}$ or $1 \%$ of the area of that wall, whichever is smaller, and the percentage of openings in the balance of the building envelope does not exceed $20 \%$. A building that does not comply with the requirements for an open or partially enclosed building is categorized as an enclosed building and $G C_{p i}= \pm 0.18$ should be used. If a building complies with both the open and partially enclosed definitions then it should be considered as an open building. ASCE also recommends that for partially enclosed buildings containing a single, non-partitioned large volume, the $G C_{p i}$ be multiplied by a reduction factor (kept less than one), which is function of the ratio of the non-partitioned internal volume to the total area of wall and roof openings.

To compare those ASCE 7-10 provided internal pressure values with the experimental results, equivalent pressure coefficients, $G C_{\text {pi eq }}$, were calculated using Eq. (5.1) (St Pierre et al. 2005) 


$$
G C_{p i \text { eq }}=\left(\frac{\frac{1}{2} \rho V_{10 m, 3 \mathrm{sec}}^{2} K_{z} K_{z t} K_{d}}{\frac{1}{2} \rho V_{H}^{2}}\right) G C_{p i}
$$

where $V_{H}$, is mean wind speed at eave height, $H ; V_{10 \mathrm{~m}, 3 \mathrm{sec}}$ is the 3 -sec wind speed at $10 \mathrm{~m}$ height; $K_{z}$ is the velocity pressure exposure factor (taken from Table 27.3-1 in ASCE7-10); $K_{z t}$ is the topographic factor (assumed to be one); and $K_{d}$ is the directionality factor (assumed to be one). Table 5.2 shows values of $G C_{p i}$ eq, for the cases of NIST and WOW models considered in this study.

Table 5.2 $G C_{p i \text { eq }}$ for the NIST and WOW models - partially enclosed

\begin{tabular}{|c|c|c|c|c|c|c|c|}
\hline \multirow{3}{*}{ Model } & \multirow{3}{*}{$\begin{array}{l}\text { Model } \\
\text { Height } \\
\text { (m) }\end{array}$} & \multicolumn{2}{|r|}{$K_{z}$} & \multicolumn{4}{|c|}{$G C_{p i e q}$} \\
\hline & & \multirow{2}{*}{$\begin{array}{c}\text { Open } \\
\text { Terrain } \\
\text { Exposure }\end{array}$} & \multirow{2}{*}{$\begin{array}{l}\text { Suburban } \\
\text { exposure }\end{array}$} & \multicolumn{2}{|c|}{$\begin{array}{l}\text { Open Terrain } \\
\text { Exposure }\end{array}$} & \multicolumn{2}{|c|}{ Suburban exposure } \\
\hline & & & & $\begin{array}{l}\text { Partially } \\
\text { Enclosed }\end{array}$ & Enclosed & $\begin{array}{l}\text { Partially } \\
\text { Enclosed }\end{array}$ & Enclosed \\
\hline $\begin{array}{c}\text { NIST } \\
\text { Model } 1\end{array}$ & 12.2 & 1.04 & 0.76 & \pm 1.24 & - & \pm 1.71 & - \\
\hline $\begin{array}{c}\text { NIST } \\
\text { Model } 2\end{array}$ & 4.9 & 0.86 & 0.58 & \pm 1.42 & - & \pm 2.48 & - \\
\hline $\begin{array}{l}\text { WOW } \\
\text { Model }\end{array}$ & 3.66 & 0.85 & - & \pm 1.56 & \pm 0.51 & - & - \\
\hline
\end{tabular}

The commentary C26.11 of the ASCE 7-10, states "the code provided internal pressure coefficients, $G C_{p i}$ include a reduction factor to account for the lack of perfect correlation between the internal pressure and the external pressures on the building surfaces not containing the opening. Taken in isolation, the internal pressure coefficients can reach values of \pm 0.8 (or possibly even higher on the negative side)." Hence, in order to get accurate comparisons, it's not experimentally recorded isolated internal pressures that should be compared (as was done is most previous researches), instead, the effective contributions of internal pressures to the net wind- 
induced forces need to be determined and compared to those computed using the ASCE 7-10. In this study, the effective contributions of internal pressure were determined by deducting the forces induced by external pressures only from those induced by net pressures. To explain this, let $\hat{F}_{e x t}, \hat{F}_{\text {int and }} \hat{F}_{n e t}$ denote peak forces induced on a building by external, internal and net pressure. Since internal and external pressure are not perfectly correlated, $\hat{F}_{n e t} \neq \hat{F}_{\text {ext }}+\hat{F}_{\text {int. }}$. According to the commentary of the ASCE 2010 (i.e. C26.11), a reduction factor, say $r$, need to be included, i.e. $\hat{F}_{n e t}=\hat{F}_{e x t}+r \hat{F}_{\text {int, }}$, where $r \hat{F}_{\text {int }}$ is the effective contribution of the internal pressure to the net windinduced forces, and can be computed as $r \hat{F}_{\text {int }}=\hat{F}_{n e t}-\hat{F}_{\text {ext }}$.

Each subsequent section contains comparison experimental results to those estimated using ASCE 7-10 provisions for internal pressure.

\subsection{Effects of Internal Pressure on Global Roof Uplift}

In this section, the effects of internal pressure on roof uplift are quantified for different opening configurations. The results are presented as global roof uplifts that were measured using load-cells. Global roof uplift represents the total averaged roof uplift on a building structure, and is a good estimate of the wind load expected by a roof's structural support systems (which are typically influenced by distribution of wind pressures over large roof or wall areas). Unlike external pressures that can be highly non-uniform in space, internal pressures are fairly uniform. As a result, the effects of internal pressures on structural forces (particularly forces influenced by distributions of wind pressures over large roof or wall areas), can be significantly higher than the effects of external pressures. Note that the non-uniformity of external pressures causes the induced peak forces to decrease as the effective area being considered increases. This is particularly important in design of the main structural components, such as frames, rather than in the design of components and cladding, which are typically controlled by pressure loads on relatively smaller areas. 
The resolution of pressure taps can have significant influence on the test results. Habte and Chowdhury (2015) conducted a comparison of global forces on a low-rise building measured using load cells to those calculated from pressure taps, and demonstrated the high sensitivity of global forces to pressure-tap density. In an another study, Asghari Mooneghi et al. (2014) demonstrated that net uplift force coefficients and net moment coefficients recorded on roof pavers are sensitive not only to the resolution of pressure taps but also to their arrangement. Hence, to maintain high accuracy, global roof uplift forces were measured directly using loadcells on the WOW Model for different opening configurations.

Global uplift forces measured when the model had no openings (leakage only) were compared to those measured when the building had single or multiple dominant openings. In buildings with leakage only, internal pressure fluctuations are in practice negligible owing to damping of the flow through small holes (Oh et al. 2007). Hence in the no opening test case, internal pressures can be assumed to have an insignificant contribution to the net uplift load. Therefore, any difference in uplift force coefficient between the "no opening" case and other test cases with dominant openings can be considered to be predominantly due to differences in building internal pressure.

Time-histories of wind-induced global uplift forces, $F(t)$, on the WOW Model were obtained by computing the vector sum of uplift forces measured by the four load cells (LC1 to LC4, Figure 5.2a). Time-histories of uplift force coefficients, $C_{f}(t)$ were then computed using the expression

$$
C_{f}(t)=\frac{F(t)}{0.5 \rho V_{H}^{2} \cdot B \cdot L}
$$

where $\rho$ is air density, and $V_{H}$ is the mean wind speed at eave height, H. Note that uplift force coefficients provided herein represent wind-induced uplift forces acting on the entire roof area; positive values indicate upward (uplift) force. The following subsections present results for single and multiple dominant opening cases. 


\subsubsection{Single Dominant Opening}

Figure 5.4 shows results of minimum, mean and maximum uplift force coefficients versus wind direction for two cases of single dominant opening (denoted by FW 2 and FD) and no opening case. FW 2 has area of $17.5 \mathrm{ft}^{2}$, and constitutes around $2.5 \%$ of the total front wall area, and FD has area of $40.0 \mathrm{ft}^{2}$, and constitutes around $5.5 \%$ of the total front wall area.

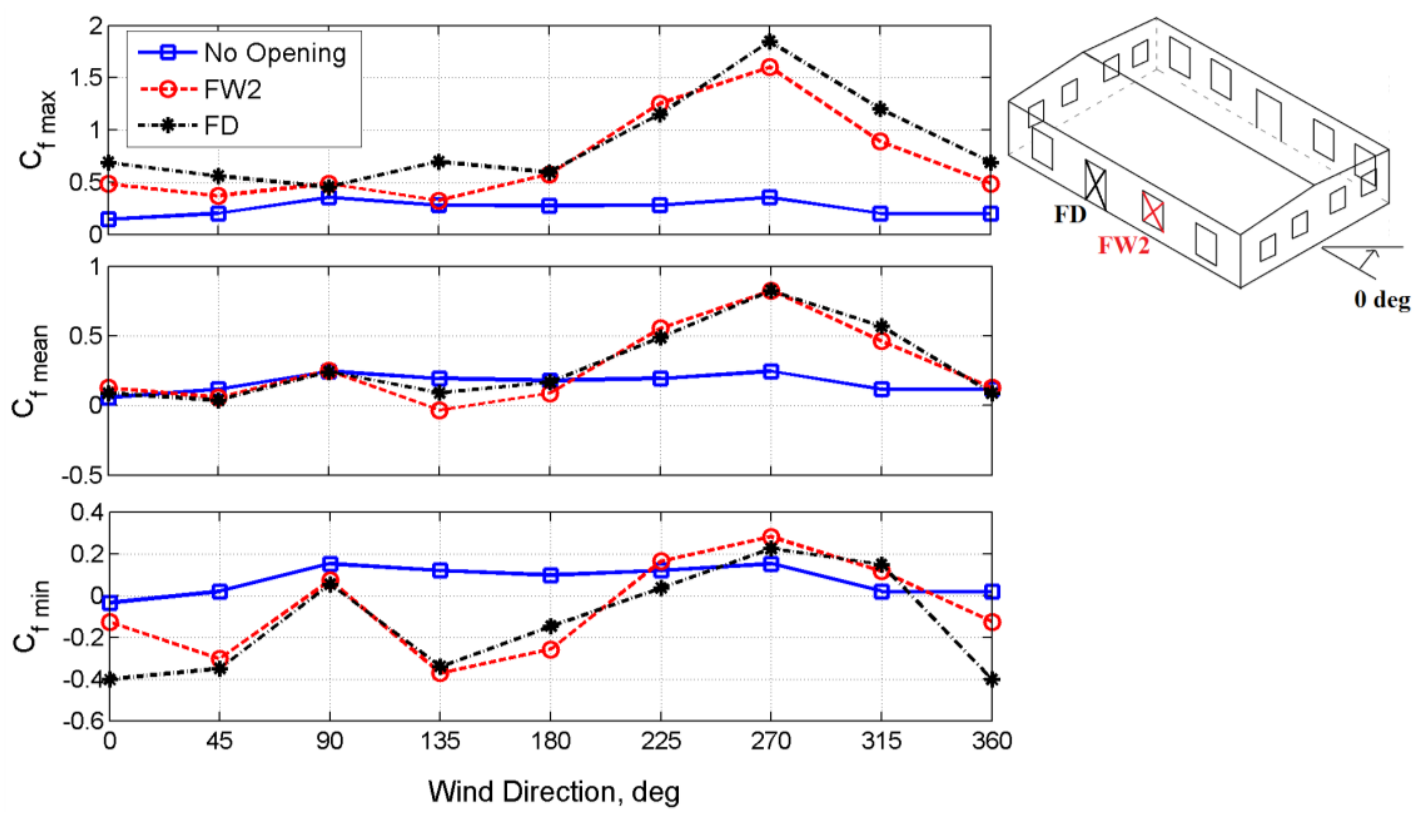

Figure 5.4. Mean and Maximum Roof Uplift Force Coefficients, $C_{f z}$, Single Opening

During the no opening case, the highest and lowest uplift coefficients were recorded when the wind direction was normal to the model's long side and short side, respectively. The highest recorded uplift coefficient was 0.41 . The presence of a single dominant opening was observed to significantly affect the total uplift force, especially when the dominant opening is located on the upwind side of the building. At wind direction of 270 deg (i.e. when FW 2 was on the windward side) opening FW 2 increased the mean uplift force to more than three times its value measured when FW 2 was closed. This substantial increase in uplift force may be attributed to the high uniformity of internal pressures for dominant opening cases. When FW 2 was open, uplift and downward force coefficients of up 1.50 and -0.40 were observed respectively. At a mean wind 
speed of $90 \mathrm{mph}$, these corresponding to forces of approximately 48 psf and -10 psf respectively. Note that in an industrial low-rise building with metal cladding covers, superimposed dead loads and live loads are normally taken as 5 psf and 20 psf respectively. This comparison shows the significance of loading due to wind-induced internal pressure.

Closing FW 2 and opening FD (i.e. increasing the size of the dominant opening more than twice) had small effects on the mean values of the total uplift forces. But slightly higher values of maximum and minimum uplift forces were observed, i.e. the standard deviation (std) of uplift forces was observed to increase with increasing size of dominant opening. This agrees with the observation by Kopp et al. (2008) that increasing the opening area for a given building increases the peak internal pressures by enhancing Helmholtz resonance, particularly for wind directions normal to the opening.

\subsubsection{Multiple Dominant Openings}

Figure 5.5 shows the minimum, mean and maximum uplift forces experienced when the model had multiple dominant openings. Two cases of multiple building openings (i.e., FW 2 with BW 3, and FD with BD) were selected and compared with the no opening case. Openings on opposite exterior walls were observed to have a milder effect on total uplift when compared to the single dominant opening cases, and the highest uplift forces were experienced when one of the openings was on the windward wall.

To further investigate the effect of multiple building openings on total uplift force, an experiment was conducted where several openings were progressively simulated, and the uplift forces recorded were compared with internal pressure provisions in the ASCE 7-10. This corresponds to cases where multiple openings are breached in progression during hurricanes. This experiment included 11 test cases in which openings were simulated sequentially in the following order; FW 2, FW 3, FW 1, FD, BD, BW 2, BW 3, BW 1, BW 4, SW 1 - SW 4 and SW 5 - SW 8. Once an opening was created, it remained open for the rest of the test. The front windows (FW) 
and back windows (BW) had full-scale sizes of $17.5 \mathrm{ft}^{2}$ each, the side windows (SW) had an area of $12.27 \mathrm{ft}^{2}$ each, and the doors (FD and BD) had an area of $40.0 \mathrm{ft}^{2}$ each. This experiment was conducted at 270 deg wind direction.
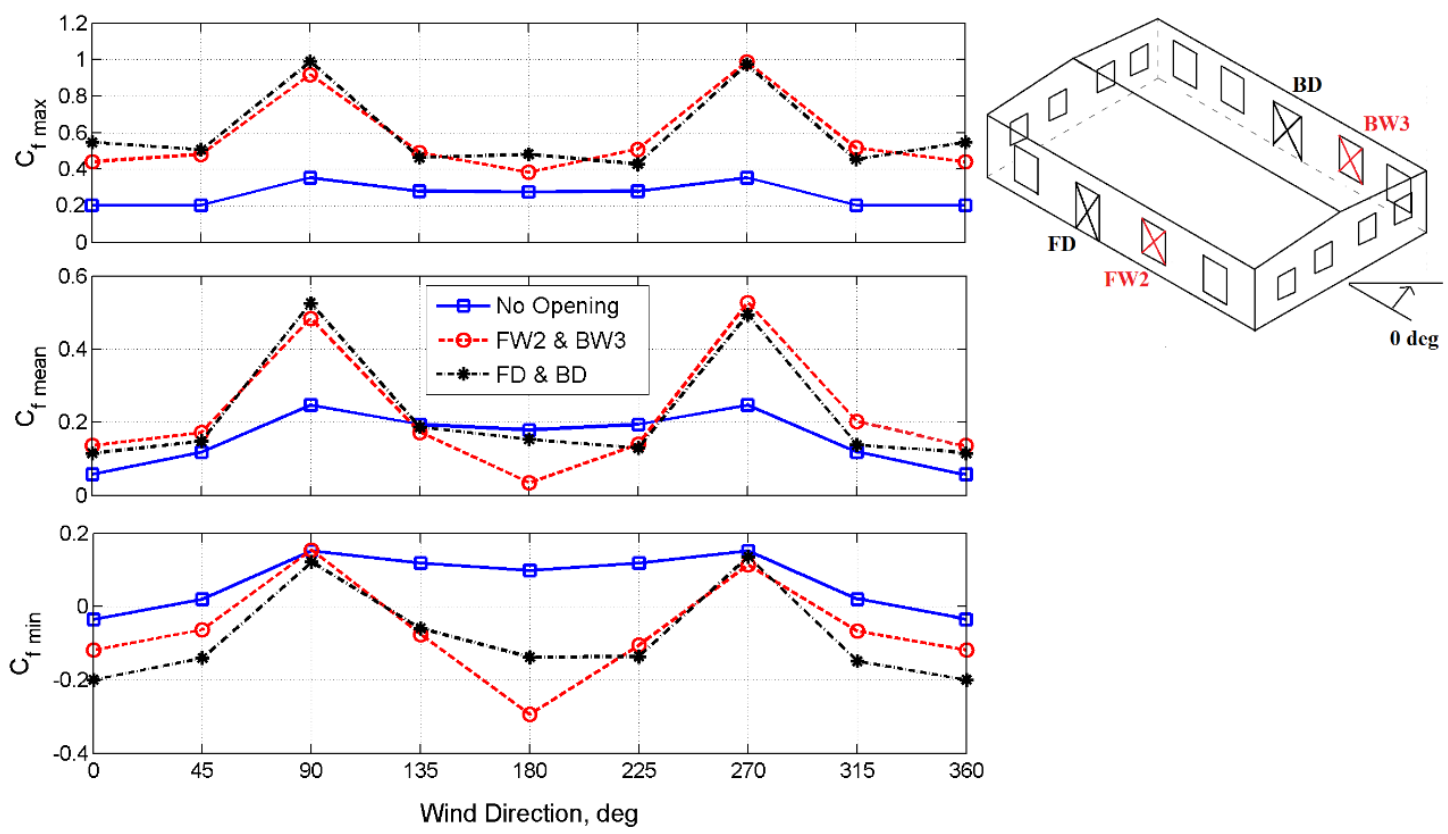

Figure 5.5. Mean and Maximum Roof Uplift Force Coefficients, $C_{f z}$, Multiple Openings

According to the definition for building enclosure classification of the ASCE 7-10, for the no opening test case the model is categorized as an enclosed building. In the progressive failure of openings test, the model becomes partially enclosed when the first dominant opening is created. The model then transitions back to enclosed building at test case 8 (openings: FW2, FW3, FW1, FD, BD, BW2, BW3, BW1). Figure 5.6 shows the maximum and mean effective contribution of internal pressures on total roof uplift evaluated during the progressive opening experiments, and compares them with the ASCE 7-10 provisions for internal pressure. The effective contribution of internal pressures is evaluated by deducting the uplift recorded for the no opening cases from those recorded when the building had openings. It can be seen that as more openings were created at the windward side, the mean uplift coefficient was barely affected while the maximum uplift decreased. The creation of openings at the leeward wall significantly reduced the total uplift 
forces. This agrees well with the observations made by Ginger et al. (1997) and Holmes (1978) using full-scale and wind tunnel experiments, respectively, that mean and fluctuating internal pressures increase with increasing windward to leeward open area ratio. Figure 5.6 also shows in all the test cases, except test case 8, the ASCE 7-10 provisions produced conservative results. Note that in test case 8 , the area of windward and leeward openings are equal. This implies that classifying multiple opening scenarios (particularly equal-sized cross-openings) under the same building enclosure category as no opening buildings might lead to under-estimation of internal pressures.
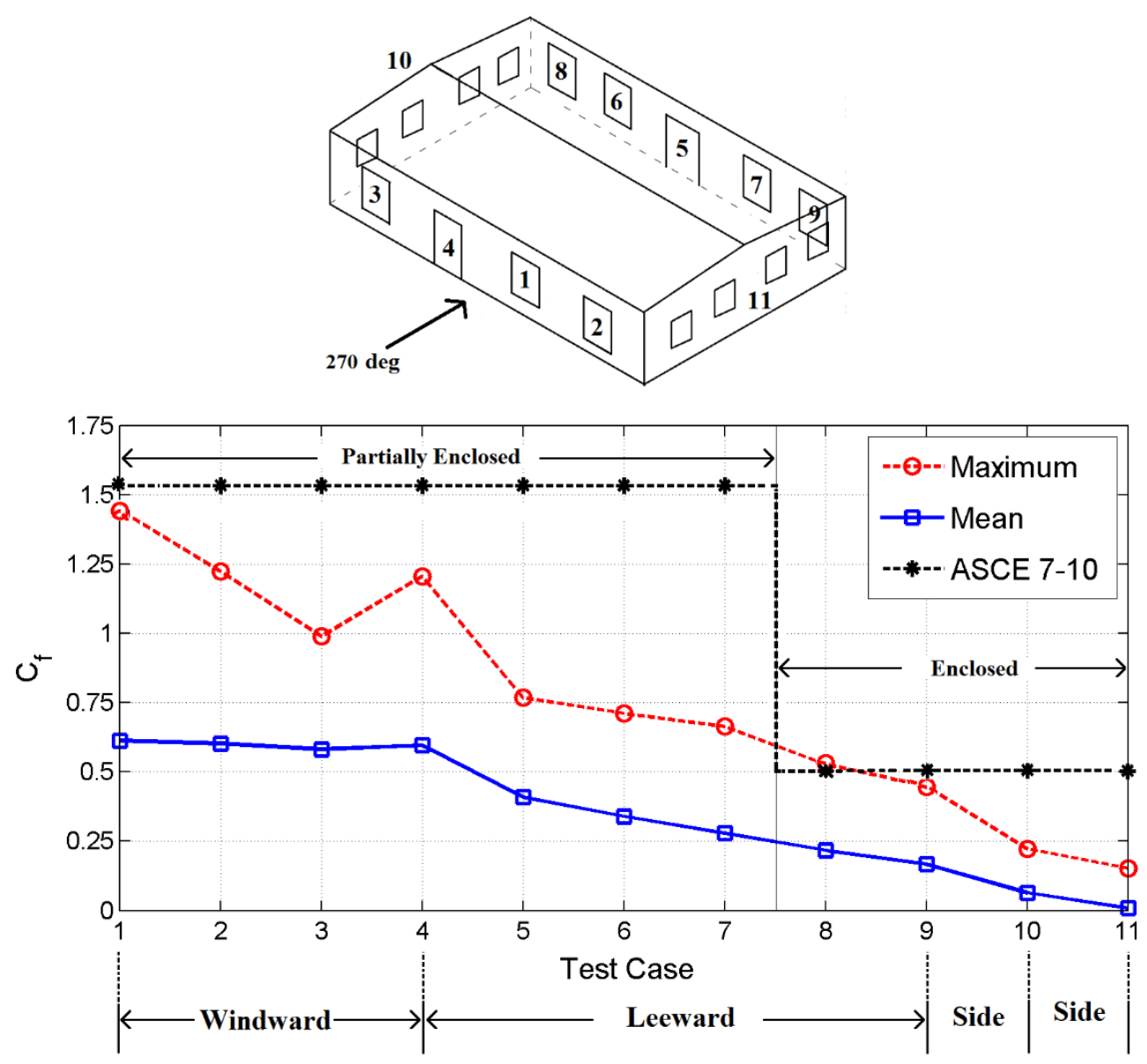

Figure 5.6. Mean and Maximum Roof Uplift Force Coefficients, $C_{f z}$ 


\subsection{Effects of Internal Pressure on Frame Forces}

It is generally agreed that wind-induced internal pressures in buildings with single or multiple openings can significantly increase the forces experienced by the buildings' structural system. In this section, the characteristics of frame forces, in buildings with single and multiple openings are investigated. The effective influence of experimentally recorded internal pressures on the net (total) frame forces are quantified, and compared with those evaluated using the ASCE 7-10 provisions for internal pressures. The buildings considered in this study are assumed to have a structural system consisting of equally spaced moment-resisting steel portal frames with webtapered members, spanning the width of the building (Figure 3.2). In addition, it is assumed that the models have no ceiling, and that the internal space is not partitioned. The same assumptions and procedures used in Section 3.3 for transferring wind loading from the roof and wall to the structural members are also used in this Section.

The distribution of wind pressures on a structure and the responses they induce vary with time. Hence, the design of a frame member should be based on the wind load distribution that produces the maximum response on that member when combined with gravity loads. That distribution may differ from member to member. "Pseudo-distributions" which envelop all the critical wind loading distributions are typically used in standards. Such distributions might lead to non-optimal designs. The DAD methodology computes time histories of wind-induced frame responses using pressure readings from taps tributary to the frames. DAD has the advantage of maintaining the synchrony of the pressures on large number of taps, both external and internal. This results in highly accurate estimates of wind induced frame responses. In the study presented in this chapter the DAD based windPRESSURE software package (Main and Fritz 2006) was used to compute the wind induced frame responses, following modifications aimed to accommodate time histories of measured internal pressures and code provided internal pressure coefficients. 
Time histories of the wind-induced frame forces, $r_{i j}(t, \theta)$ at cross section $j$ of frame $i$, due to a unit wind speed at building eave height, for wind direction $\theta$, are computed as

$$
r_{i j}(t, \theta)=1 / 2 \rho \sum_{k=1}^{n} N_{i j}^{k} A_{i}^{k} C_{p}^{k}(t, \theta)
$$

where $\rho$ is air density; $N_{i j}^{k}$ is the influence coefficient representing the internal force at cross section $j$ of frame $i$, due to a unit force applied at the $k$-th point of attachment (i.e. purlin or girt) to the frame $i$; and $A^{k}$ represents the tributary area of the $k$-th attachment point; $C_{p,}^{k}(t, \theta)$ is the time history of pressure coefficient applicable at the $k$-th attachment point, normalized by wind speed at eave height for wind direction $\theta$; and $n$ is the number attachment points on frame $i$. External, internal and net wind-induced responses are evaluated using external pressure coefficients $C_{p \text {, ext }}^{k}$ $(t, \theta)$, internal pressure coefficients, $C_{p, \text { int }}^{k}(t, \theta)$ and net pressure coefficients, $C_{p, \text { net }}^{k}(t, \theta)$ respectively in place of $C_{p}^{k},(t, \theta)$ in Eq. (5.3). Time histories of net pressure coefficients, $C_{p, \text { net }}$ $(t, \theta)$ are computed from time histories of external and internal pressures as follows:

$$
C_{p, \text { net }}(t, \theta)=C_{p, \text { ext }}(t, \theta)-C_{p, \text { int }}(t, \theta)
$$

Once the time histories of frame forces are evaluated, the peaks can be computed using peak estimation methods (the peak estimation methods used are described in the subsequent section). The peak effective contribution of internal pressures, $\hat{r}_{\text {int }}(\theta)$ to frame forces (i.e. after accounting for any lack of correlation between the external and internal time histories of frame responses) are computed from peak net frame forces, $\hat{r}_{n e t}(\theta)$ and peak external frame forces, $\hat{r}_{\text {ext }}(\theta)$ :

$$
\hat{r}_{i j, \text { int }}(\theta)=\widehat{r}_{i j, \text { net }}(\theta)-\widehat{r}_{i j, \text { ext }}(\theta)
$$

To compare with the ASCE 7-10 provisions for internal pressure, equivalent pressure coefficients, $G C_{p i}$ eq, were first evaluated using Eq. (5.2). The frame responses due to the positive/negative $G C_{p i}$ eq values, $r_{i j, A S C E}$, were then computed as shown in Eq. (5.6) 


$$
\left.\begin{array}{l}
r_{i j, A S C E}^{+}=1 / 2 \rho \sum_{k=1}^{n} N_{i j}^{k} A_{i}^{k} G C_{p i, e q}^{+} \\
r_{i j, A S C E}^{-}=1 / 2 \rho \sum_{k=1}^{n} N_{i j}^{k} A_{i}^{k} G C_{p i, e q}^{-}
\end{array}\right\}
$$

In this study, the frame responses selected for investigation are bending moments at the left knee, ridge and right knee of building frames. Peak moment coefficients, $\hat{C}_{m}$, are obtained from peak frame bending moments, $\hat{M}$, as follows:

$$
\hat{C}_{m}=\frac{\hat{M}}{0.5 \rho V_{H}^{2} \cdot B \cdot H \cdot f_{S}}
$$

where $f_{s}$ denotes frame spacing.

The following subsections present the results for single and multiple dominant opening cases.

\subsubsection{Peak Estimation Methods, and Validation of NIST and WOW Calculations}

For the NIST models, once the time histories of frame moments were evaluated using Eq. (5.3), peak moments were evaluated using the translational non-Gaussian peak estimation method proposed by Sadek and Simiu (2002) (henceforth referred to as the SAS method) and built in the windPRESSURE program (Main and Fritz 2006). The Sadek and Simiu (2002) method follows a translational approach to estimating peaks of time series with non-Gaussian marginal distributions, wherein the estimates of peaks are obtained under the assumption that those distributions are Gaussian, and are then subjected to non-linear mappings from Gaussian to nonGaussian distributions, which are typical for low-rise buildings. The SAS method uses the information contained in the entire time history. Its estimates are therefore more stable than estimates based on observed peak methods (Sadek and Simiu 2002). Note that the peaks presented in this section are expected hourly peaks.

As mentioned in Section 2.3.3, the WOW tests were performed in a flow field with partially simulated turbulence; hence, the turbulence intensity in the WOW was lower than that of an 
atmospheric boundary layer ( $\mathrm{ABL}$ ) flow containing the full spectrum of turbulence. This is mainly because low frequency turbulence cannot be simulated fully when using full or large-scale models due to the limited size of the wind testing facilities; only the high frequency end of the turbulence spectrum is simulated. In this section, the partial turbulence simulation method (henceforth referred to as PTS method) proposed by Asghari Mooneghi (2014) and Asghari Mooneghi et al. (2015) was used for data analysis that accounts for the missing low frequency turbulence. In this method, the turbulence is divided into two distinct statistical processes, one at high frequencies that can be simulated correctly in the wind tunnel, and one at low frequencies that can be treated in a quasi-steady manner. The joint probability of load from these two processes is derived, with one part coming from the WOW data and the remainder from the Gaussian behavior of the missing low frequency component.

The SAS method of peak estimation was used in the NIST models, while the PTS method was employed in the WOW model, hence providing comparison of peak responses evaluated using the two methods might be of interest. For the purpose of comparison, a model from the NIST database with geometry and full-scale dimensions identical to the WOW model's prototype was used. The NIST model was tested at a much lower length scale (i.e. 1:100), and lower wind velocity compared to the WOW model, this might entail inconsistencies related to differences in Reynolds number. Moreover, there were significant differences in pressure tap densities between the two models. The WOW model had full-scale average tap tributary areas of $14.21 \mathrm{ft}^{2}, 37.46 \mathrm{ft}^{2}$ and $26.91 \mathrm{ft}^{2}$ on the roof, the walls parallel to the ridge and the walls normal to the ridge, respectively. The NIST model had higher pressure tap density, with average tap tributary areas of $10.44 \mathrm{ft}^{2}, 24.97 \mathrm{ft}^{2}$ and $17.00 \mathrm{ft}^{2}$ on the roof, the walls parallel to ridge and normal to ridge respectively.

Figure 5.7 shows comparison of peak moment coefficients at the left knee of frames 1,2 , and 3 evaluated using the NIST model (with SAS method) and the WOW Model (with PTS 
method). The numbering of frames is shown in Figure 5.3a, and frame spacing of $13.94 \mathrm{ft}$ was used. It can be seen that, despite the differences in peak estimation methods fairly comparable values of $\hat{C}_{m}$ were achieved. It is believed that, using models with similar tap density and testing scales would have further improved the comparison.
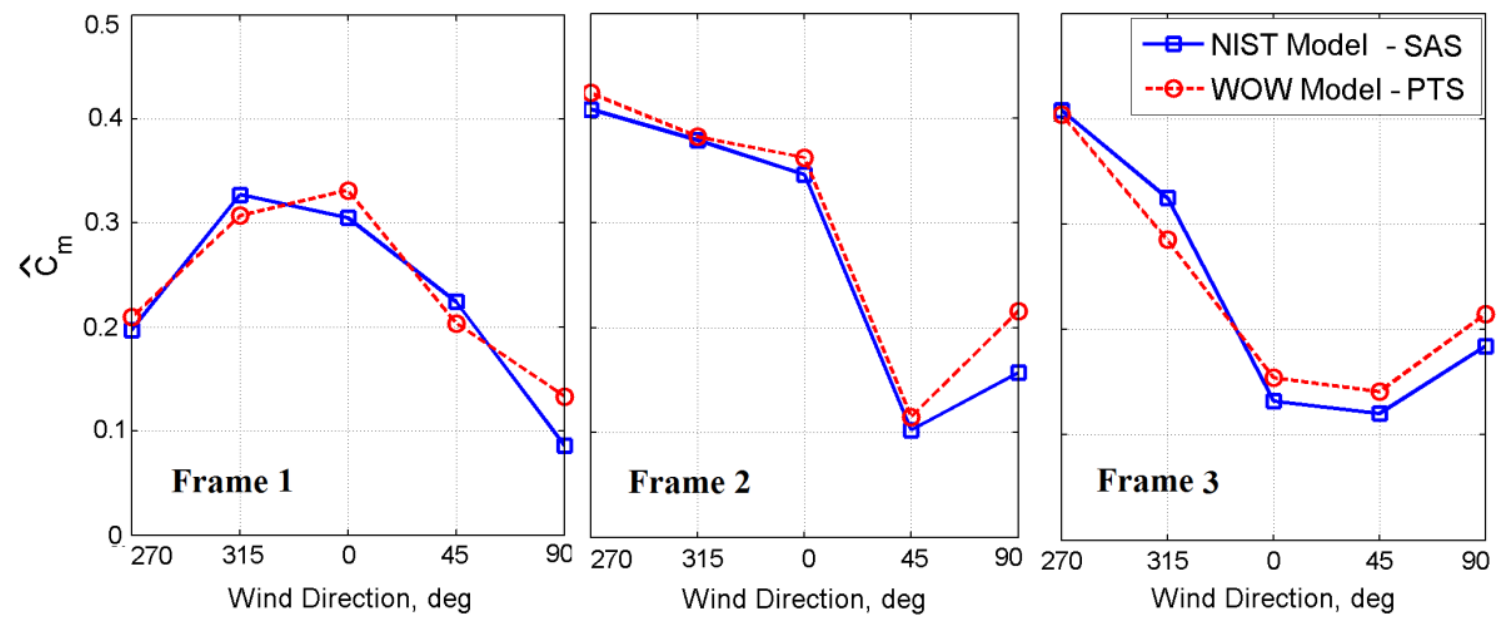

Figure 5.7 Comparison of $\hat{C}_{m}$ Evaluated Using the WOW Model and a NIST Model

\subsection{2. $\quad$ Single Dominant Opening}

Comparisons of time-histories between different taps inside the NIST models showed that the spatial variation of the internal pressure was minimal; hence, one internal tap was selected to represent building internal pressure. Figure 5.8 shows the layout of the NIST models with the frame numbering (frame spacing: $20.0 \mathrm{ft}$ is used), the location of the large opening, and the wind direction. Note that the opening shown in Figure 5.8 is not plotted to scale; it indicates the location of the opening with respect to the frame locations and the wind direction. 


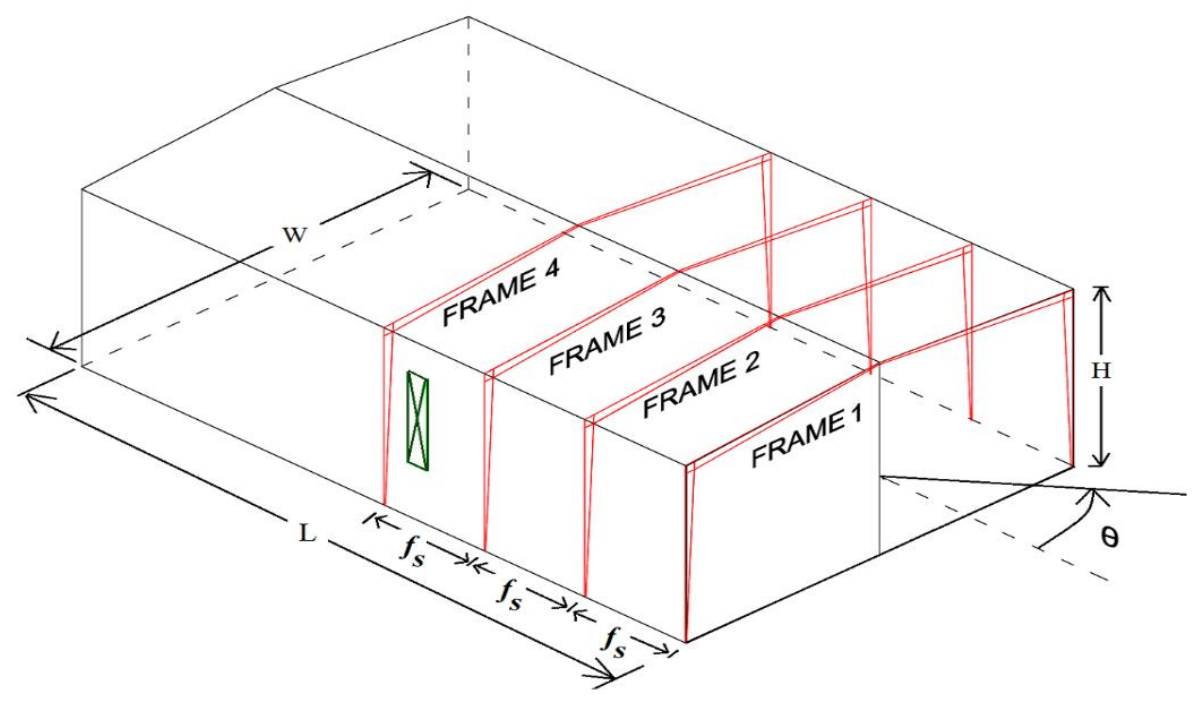

Figure 5.8 Layout of Frames, Opening, and Wind Directions for the NIST Models

Figure 5.9 and Figure 5.10 show peak moment coefficients at frame 1 and 4, respectively, for NIST model 1, in open terrain exposure. As expected, the effect of internal pressure on the frame forces is highest when the building opening is normal to the approaching wind. Since internal pressure was uniform inside the building, it produced identical moments at the left and right frame knees, however, its effect on the critical (highest of all directions) net frame responses highly varied depending on the location of the frame. For example, in frame 4 (Figure 5.10), the highest external $\hat{C}_{m}$ coefficients for all the cross sections being considered (which occurred at 270 deg wind direction) were increased significantly by the presence of an opening. However, for the case of frame 1 (Figure 5.9), the presence of dominant openings had a minor effect on the critical $\hat{C}_{m}$ 

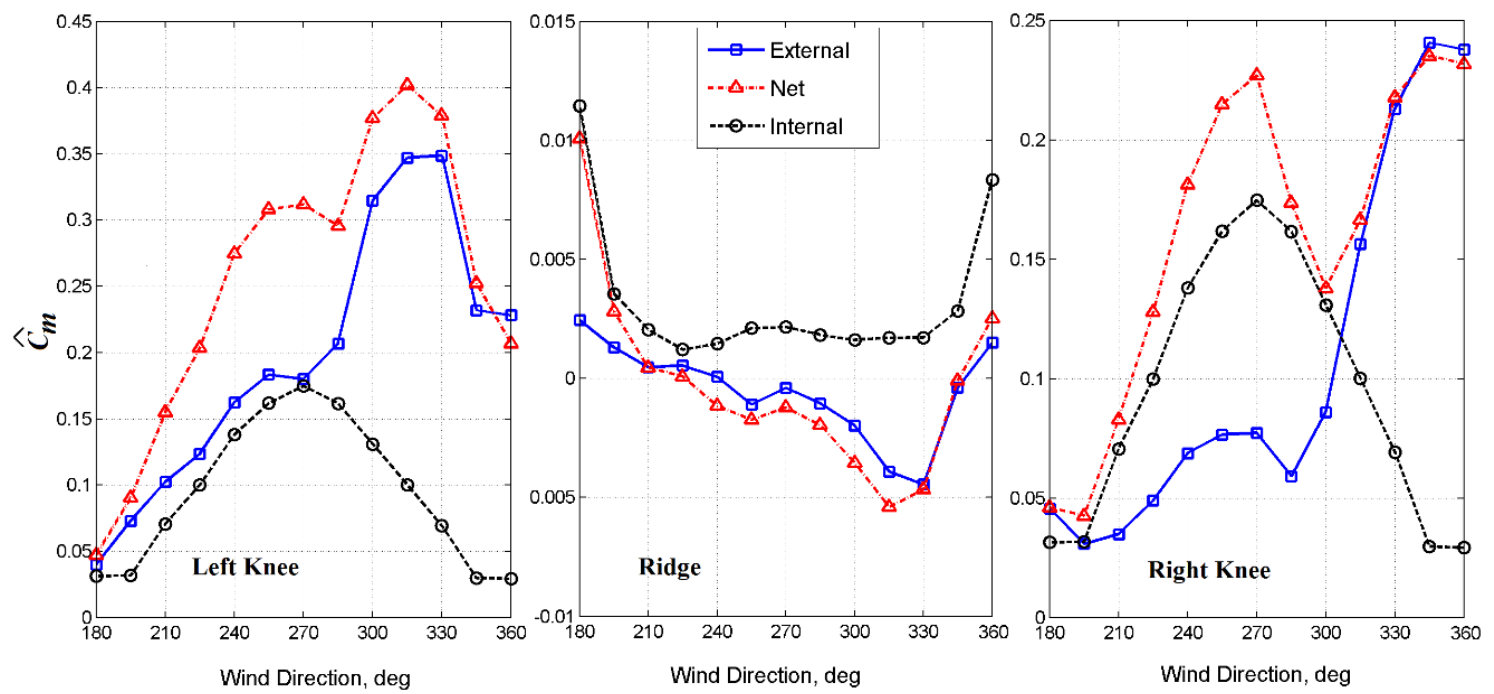

Figure 5.9 External, Internal and Net Moments, NIST Model 1, Frame 1
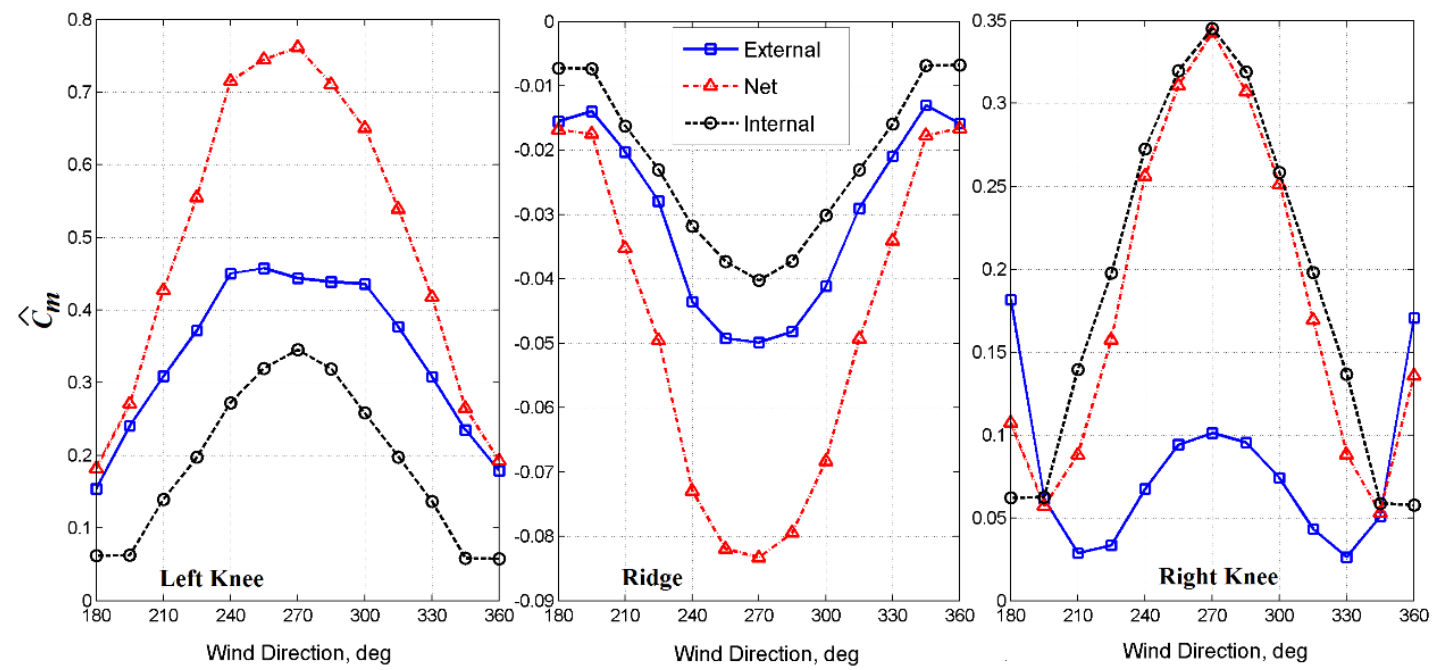

Figure 5.10 External, Internal and Net Moments, NIST Model 1, Frame 4

In addition, the effects of the internal pressure on the net moments varied significantly depending on the correlation between the time histories of the external and internal pressureinduced moments, which differed at different cross-sections of the same frame, as well as at different frame locations. To investigate this, correlation coefficients, $R_{c}$ between the timehistories of external pressure induced response, $r_{\text {ext }}(t)$ and time-histories of internal pressure induced responses, $r_{\text {int }}(t)$ were calculated by dividing the cross-correlations (at zero lag-time) by the product of the standard deviations of the two responses, as shown in Eq. (5.8) 


$$
R_{C}=\frac{\sum_{i=1}^{n}\left(r_{e x t}(t)-\bar{r}_{e x t}\right)\left(r_{\text {int }}(t)-\bar{r}_{\text {int }}\right)}{\sqrt{\sum_{i=1}^{n}\left(r_{e x t}(t)-\bar{r}_{\text {ext }}\right)^{2} \sum_{i=1}^{n}\left(r_{\text {int }}(t)-\bar{r}_{\text {int }}\right)^{2}}}
$$

where $\bar{r}_{\text {ext }}$ and $\bar{r}_{\text {int }}$ denote the mean values for the responses induced by the external and internal wind pressure; and $n$ represents the number of data points in the time-histories. Figure 5.11 shows correlation coefficients between time histories of moments induced by external and internal pressures on the frames of both NIST Model 1 and 2, for open terrain exposure. At 270 deg wind direction, high correlation between the time histories of moments due to external and internal wind pressure produced a very high net $\hat{C}_{m}$ at the left knee of frame 4 . However, the net $\hat{C}_{m}$ at the right knee was almost equal to the $\hat{C}_{m}$ due to internal pressure only; this is due to very low correlation between time histories of the internal pressure and the external pressures with the highest influence on the right knee (i.e. external pressure near the right knee). High positive correlation coefficients, reaching up to 0.67 were observed on frame 4 , particularly when the opening was on the windward side. However, for wind directions parallel to the frames' ridge the correlations were predominantly negative. In addition, correlation coefficients were observed to vary with frame location and were reduced as the frames were away from the opening. The lowest correlation coefficients were recorded on frame 1. Correlation coefficients between cladding external and internal pressures of $-0.9,-0.5$ and -0.64 were reported by Mehta et al. (1993), Beste and Cermak (1997) and Sharma and Richards (2005), respectively. The maximum correlation coefficient (i.e., 0.67) obtained in this study matches closely the value reported by Sharma and Richards (2005). Note that the difference in sign is due to the fact that Sharma and Richards (2005) evaluated correlation coefficients between the time-histories of pressures, while in this study correlation between the time histories of the induced responses are provided (i.e. is because internal and external pressures of opposite signs induce frame forces in the same direction). 


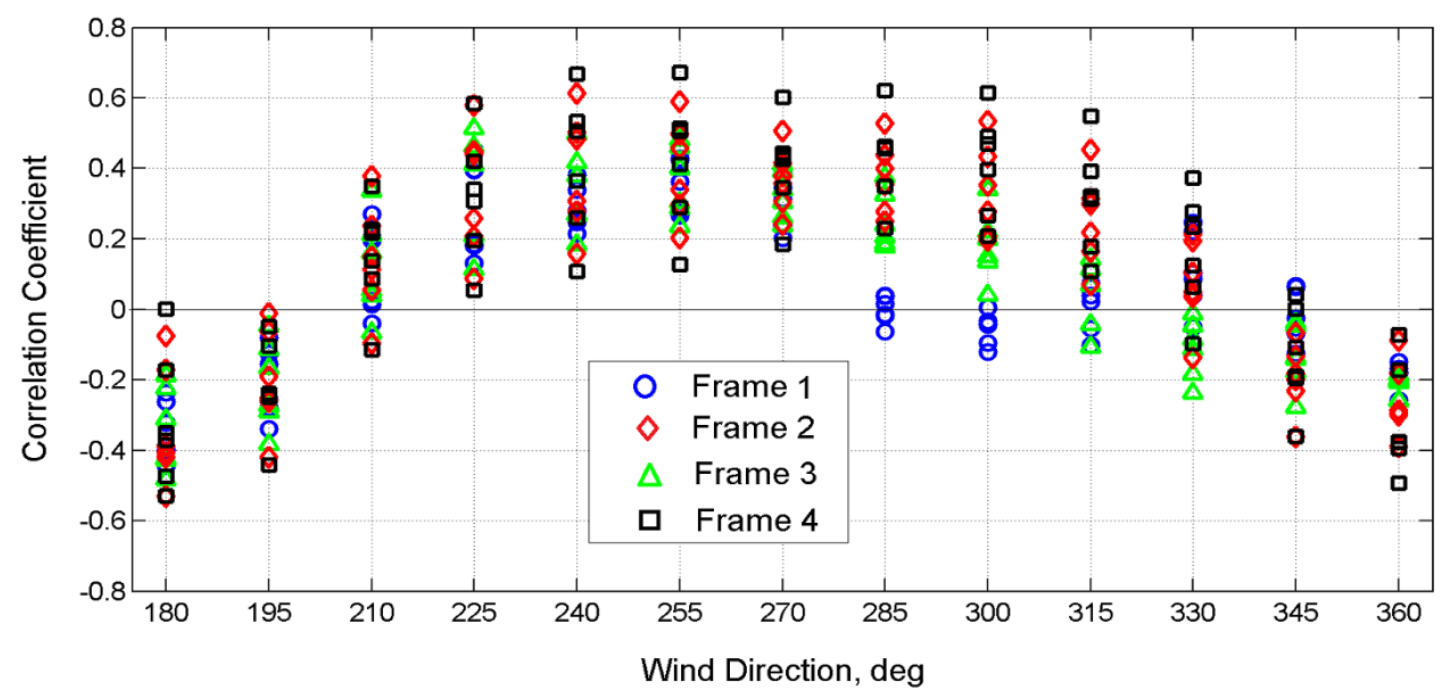

Figure 5.11 Correlation Coefficients, NIST Models 1 and 2

According to the ASCE 7-10, low-rise buildings with a single dominant opening considered herein are categorized as partially enclosed buildings. Moment coefficients at the frame crosssections corresponding to the $G C_{p i ~ e q}$ values shown in Table $5.2\left(\hat{C}_{m}{ }_{A S C E}\right)$ were computed, and compared with the effective contribution of the internal pressures to the peak net moments $\left(\hat{C}_{m}\right.$ int $)$. Figure 5.12 shows result of such comparison in terms of ratio of $\hat{C}_{m \text { int }}$ to $\hat{C}_{m}{ }_{A S C E}$ for NIST Model 1, in both open terrain and suburban exposures. It can be seen that the ACSE provisions can be highly unconservative for both open terrain and suburban exposure, particularly for the frames close to the building opening. High $\hat{C}_{m \text { int }} / \hat{C}_{m \text { ASCE }}$ ratios of up to 1.90 were observed. The low values of $\hat{C}_{m \text { int }} / \hat{C}_{m}$ ASCE depicted in Figure 5.12 show that at those wind direction, the ASCE 7-10 produces conservative estimates. 

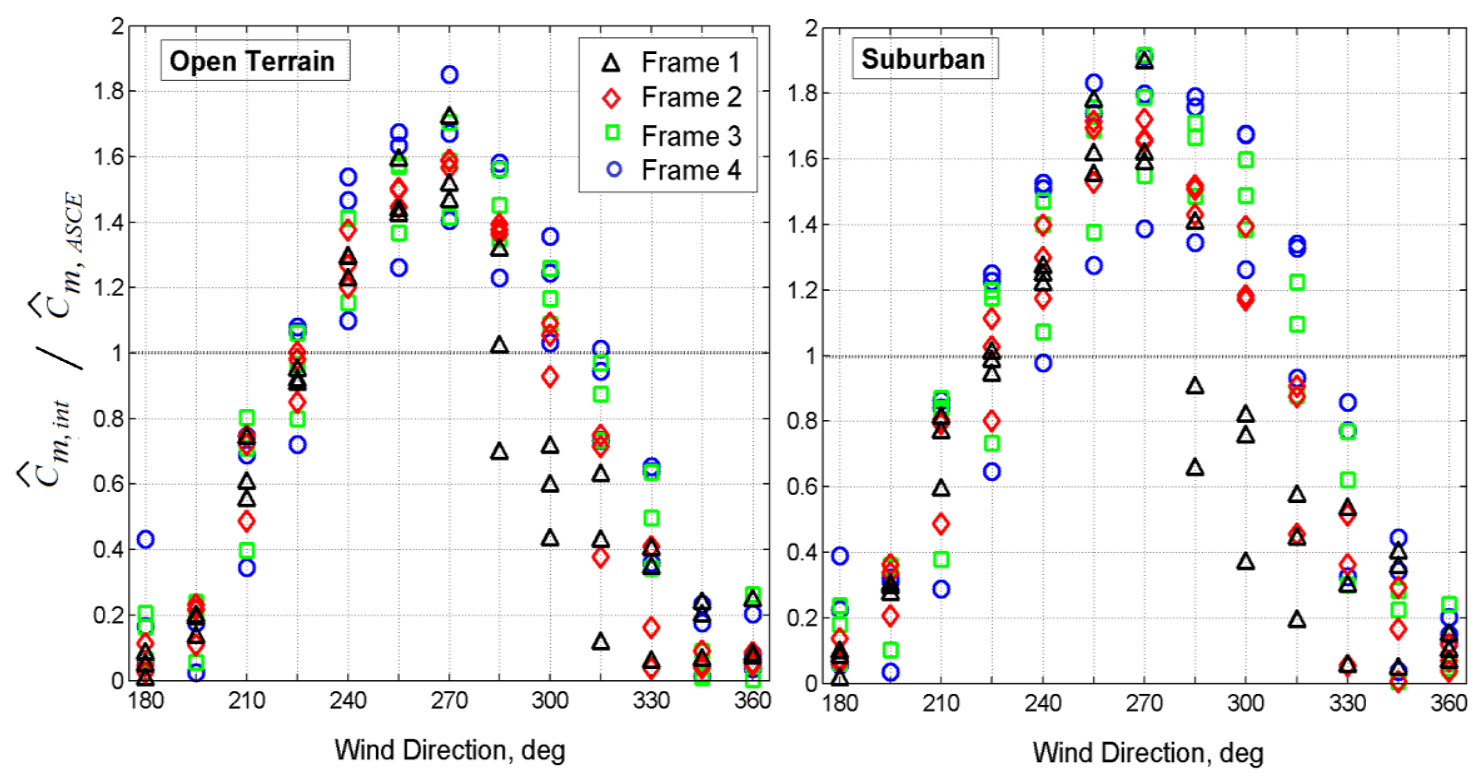

Figure $5.12 \hat{C}_{m \text { int }} / \hat{C}_{m A S C E}$ versus wind directions, NIST model 1

The highest values of $\hat{C}_{m \text { int }} / \hat{C}_{m \text { ASCE }}$ observed in Figure 5.12 occurred at wind directions close to 270 deg (i.e. normal to the building wall containing the opening). However, note that those wind directions might not be the critical directions for some frame forces (see Figure 5.10), and the effects of internal pressure on the critical forces, in such cases, might not be significant. Hence, critical net frame forces evaluated using time histories of internal wind pressures were compared to those evaluated using $G C_{p i \text { eq. }}$. Figure 5.13 shows results of such comparison for both NIST models 1 and 2, in both open country and suburban terrain exposures, and the WOW model (FW2 left open) in open terrain exposure. Note that every point in Figure 5.13 represents, for a certain cross section, the largest of the moment coefficients corresponding to all the wind directions considered. In Figure 5.13a, the critical responses computed using experimental records of internal pressure are compared to those evaluated using the ASCE 7-10 provisions, and it can be seen that for several cases the ASCE 7-10 provision produce unconservative results. This is in agreement with numerous previous investigation which reached the conclusion that internal pressure provisions in ASCE 7-10 might underestimate the actual internal pressures in partially enclosed low-rise buildings (Oh et al. (2007); Karava and Stathopoulos (2011); Kopp et 
al. (2008); Pan et al. (2012); Tecle et al. (2013)). Figure 5.13b shows a comparison of the critical bending moments to those evaluated using an enveloping $G C_{p i}$ value of \pm 1.0 . It can be seen that for $G C_{p i}$ value of \pm 1.0 produces conservative results.
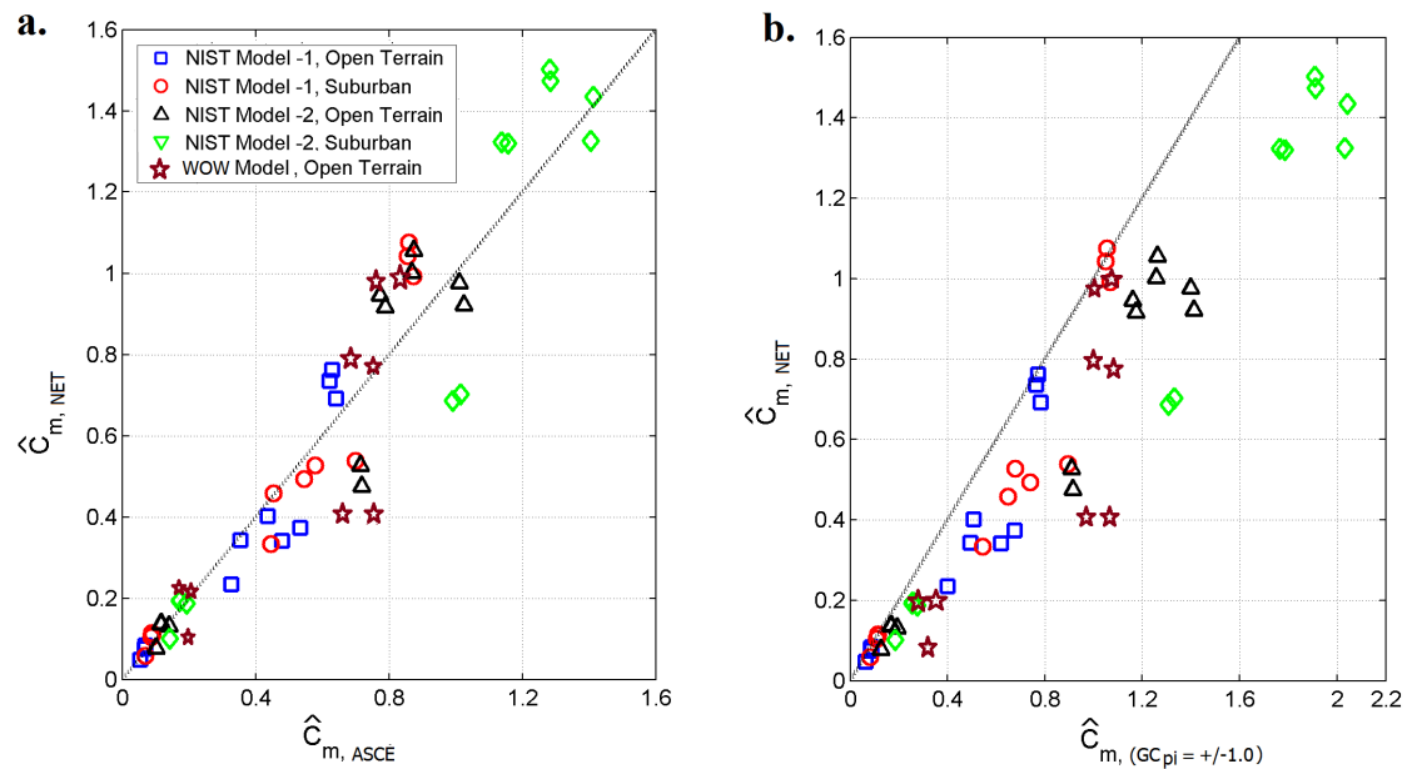

Figure 5.13 Experimental Computed $\hat{C}_{m}$ versus $\hat{C}_{m A S C E}$ and $\hat{C}_{m(\mathrm{GCpi}= \pm 1.0)}$

As shown previously, internal pressure produces the highest effect in frame forces when the wall containing the opening is on the windward side, and an enveloping $G C_{p i}$ value of \pm 1.0 can produce conservative results in partially enclosed buildings. The $G C_{p i}$ value of \pm 1.0 was reached after several attempts in which lower values failed to produce conservative results. Note that the value $G C_{p i}= \pm 1.0$ does not account for the possibility that when the storm reaches the building with the design speed, an opening occurs due to flying debris. There is a low probability that the wind will blow into the wall containing the dominant opening, and that its direction will be normal to the wall and that this direction is the most unfavorable as far as the aerodynamic effects are concerned, and a quantitative evaluation of this joint probability warrants future research. Note that windows that are operable and the availability of potential debris from the building's surroundings would increase the likelihood of an opening occurring during a storm (Irwin and Sifton, 1998). 


\subsubsection{Multiple Dominant Openings}

Figure 5.14 and Figure 5.15 show peak moment coefficients at frames 1 and 3, respectively, for the WOW model, with FW2 and BW3 left open. Frame moments induced by internal pressure were highest when the wind direction was normal to one of the openings. At those wind directions, the correlations between external and internal pressures induced moments were high (Figure 5.16). This caused the effect of internal pressure on net moments at those directions to be the highest. For frame 3, the critical directions for both the external and internal pressure induced moments were similar; this resulted in significantly high design net moments. This was not true for frame 1 , for which the external pressure induced moments were critical at wind direction of 0 deg. It can also be seen in Figure 5.14 that internal pressure had alleviating effects (of up to 15\%) on the critical (design) moments experienced by frame 1. This was due to the predominantly negative correlations between the external and internal pressure-induced moments at 0 deg wind direction, see Figure 5.16, which also shows that correlation coefficients of up to 0.55 were observed.
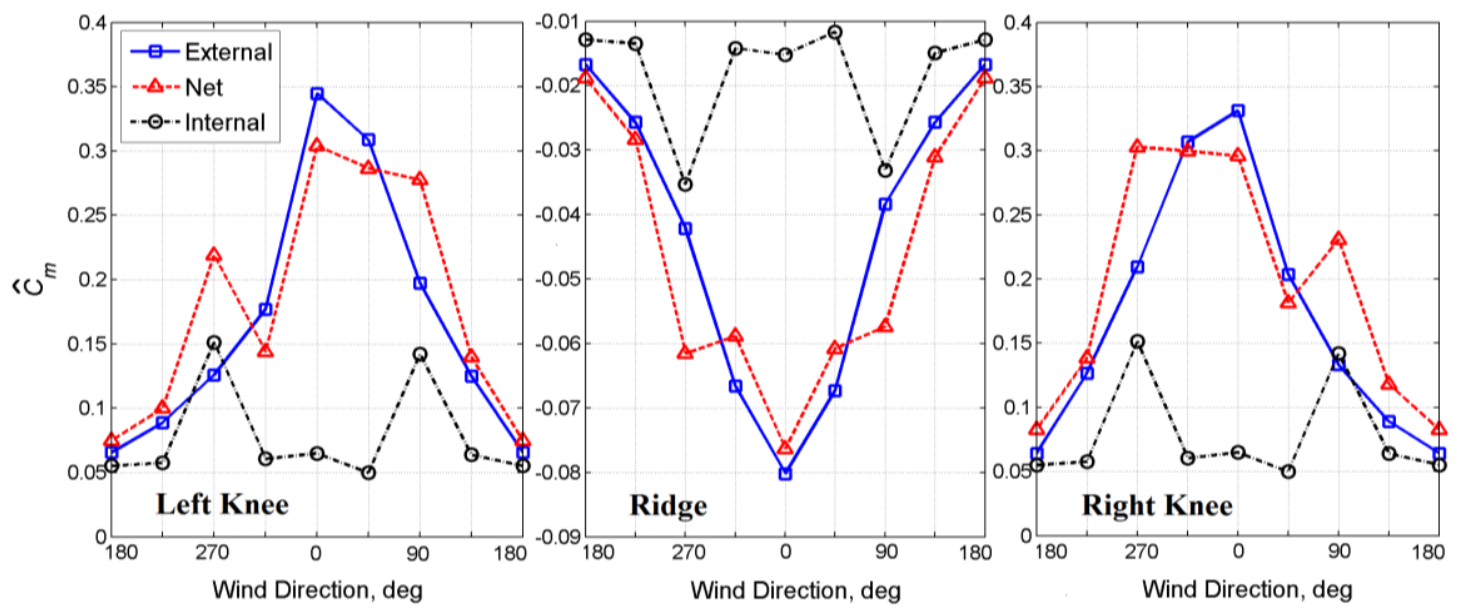

Figure 5.14 Peak External, Internal and Net Moment Coefficients, WOW Model, Frame 1 

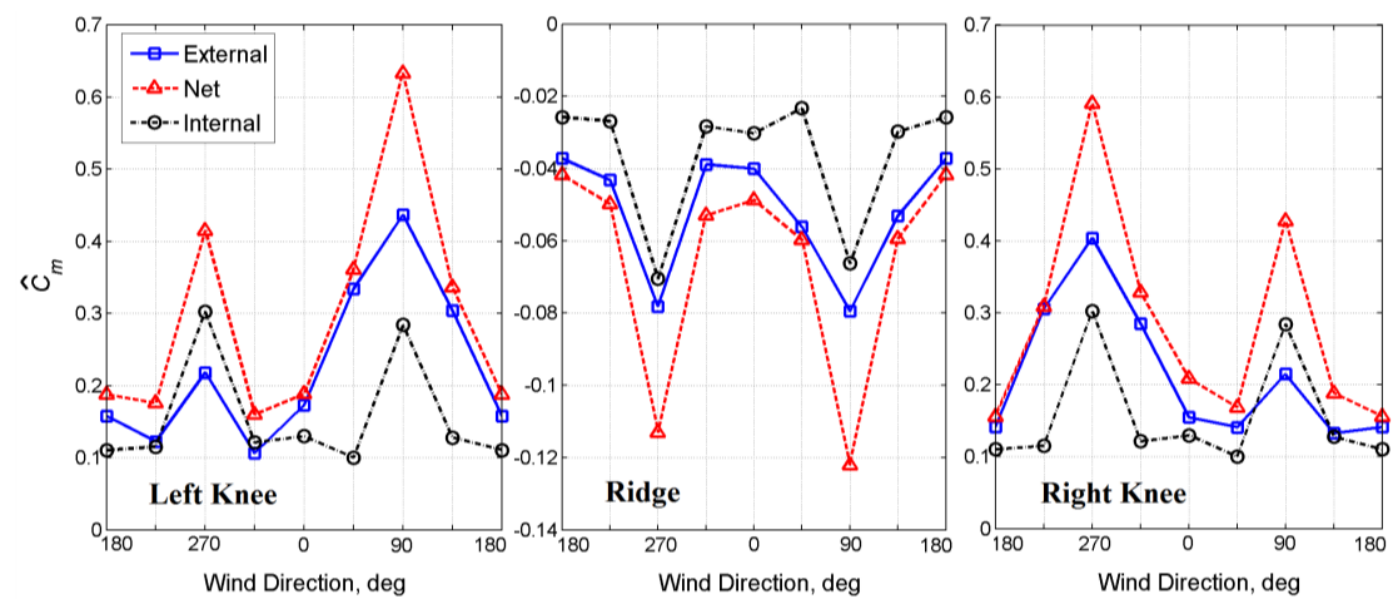

Figure 5.15 Peak External, Internal and Net Moment Coefficients, WOW model, Frame 3

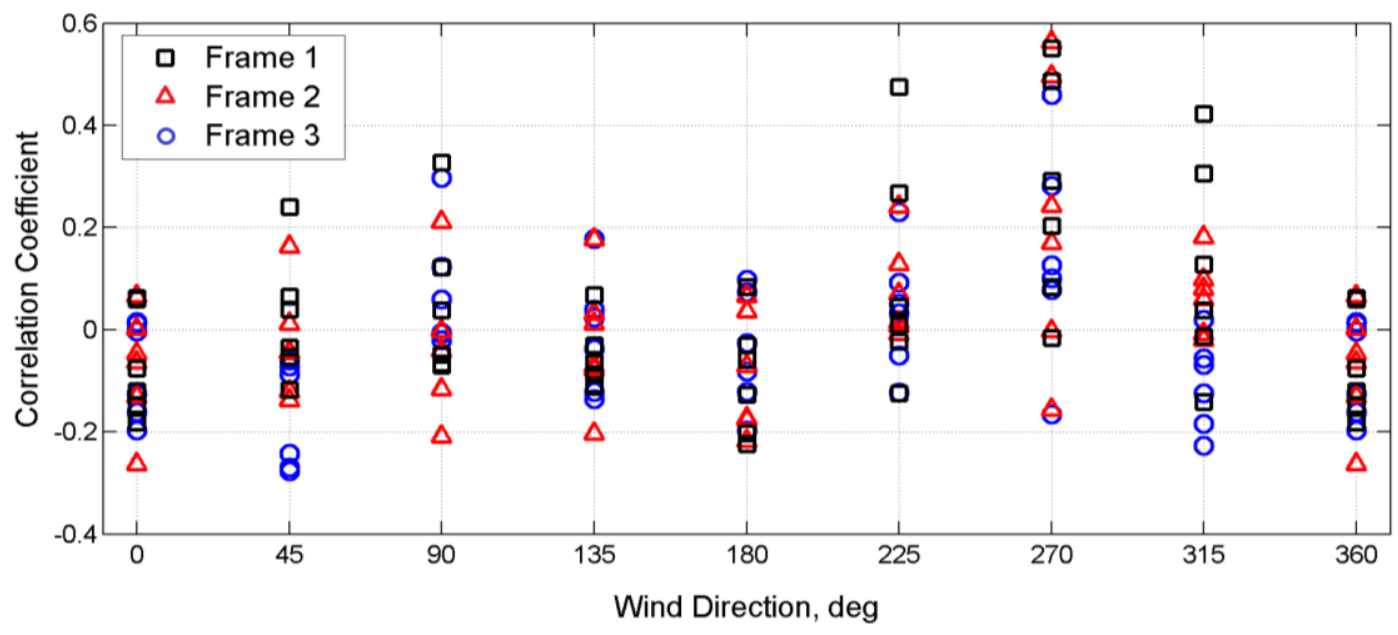

Figure 5.16 Correlation Coefficients, WOW model

Figure 5.17 shows results of comparisons between critical peak net moment coefficients computed using internal pressures from experimental measurements to those evaluated using ASCE 7-10 provisions, for two cases of multiple dominant openings (i.e. BW2 with FW3, and FD with BD). It can be seen that for several cases the ASCE 7-10 provision produced highly unconservative results, particularly for the case of openings BW2 with FW3. These results are in agreement with wind tunnel experiments on models with multiple openings conducted by Karava and Stathopoulos (2011) and Pan et al. (2012), which showed that ASCE 7-10 provisions underestimate internal pressures in enclosed buildings. More importantly, it shows that 
classifying buildings with equally sized openings on opposite walls as "enclosed buildings" can result in unconservative estimates of internal pressure induced frame forces. Figure $5.17 \mathrm{~b}$ shows that using an enveloping internal pressure value of \pm 0.42 produced conservative results.
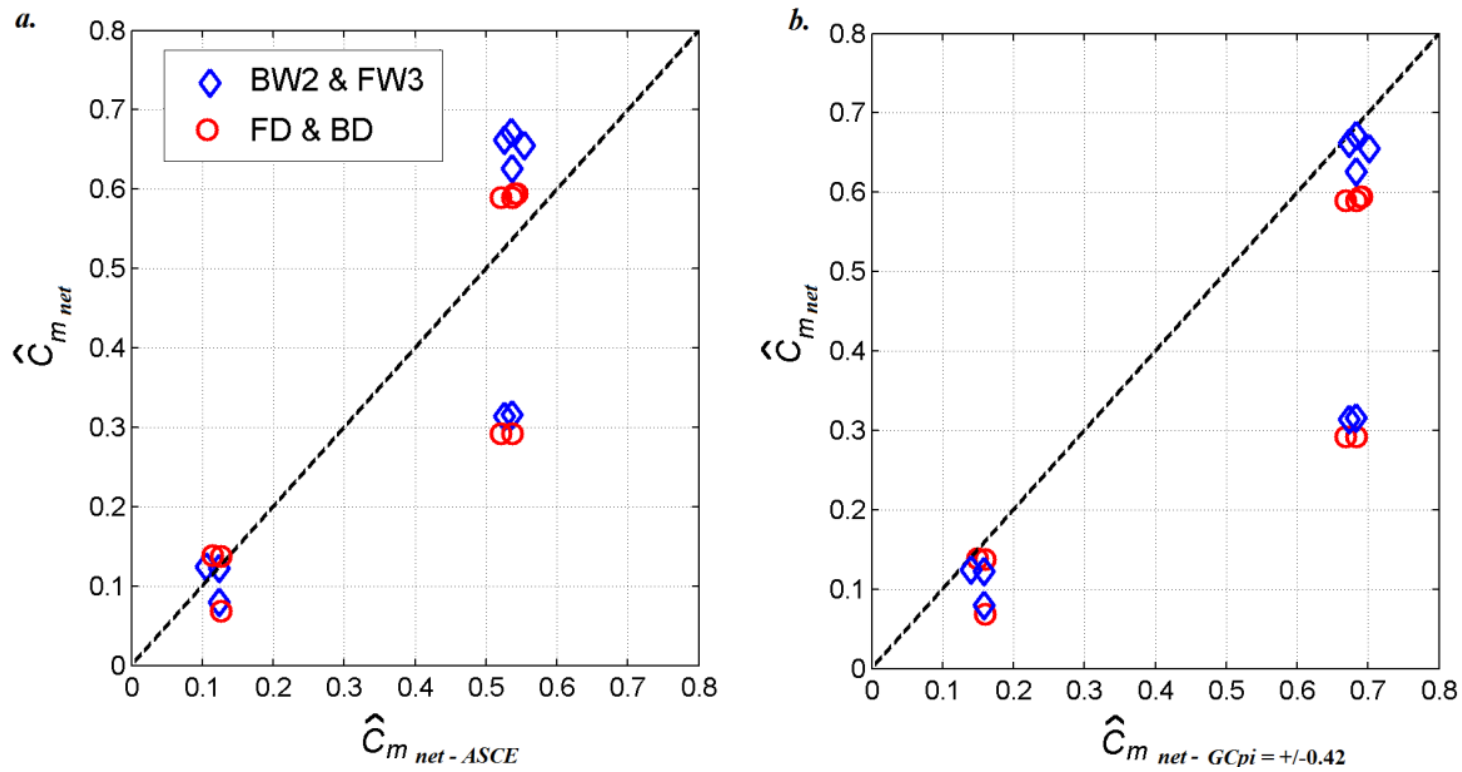

Figure $5.17 \hat{C}_{m}$ versus $\hat{C}_{m}$ ASCE , WOW model

\subsection{Effects of Internal Pressure on Frame DCI's}

This section presents results of case studies which compare (i) demand-to-capacity indexes (DCIs) based on time histories of net pressure coefficients (denoted by $D C I_{n e t}$ ), to DCIs based on external pressure coefficients (denoted by $D C I_{e x t}$ ) (Figure 5.18), and (ii) net DCIs based on experimentally recorded internal pressures, $D C I_{n e t}$, to those based on ASCE 7-10's provisions for internal pressures, $D C I_{\text {asce }}$, (Figure 5.19). NIST model 1 with large opening (which falls under partially enclosed building category) was used in those comparisons. Assumed dead and roof-live loads of 2 psf and 20 psf, respectively were used, and the building was assumed to be situated in Miami, FL. It can be seen in Figure 5.18 that, internal pressure in models with large dominant openings can increase frame DCIs by up to $100 \%$ and $90 \%$ in open terrain and suburban exposures respectively. Figure 5.19 shows that using ASCE 7-10 provisions for internal pressure can result in underestimations of frame DCIs by up to $70 \%$. 

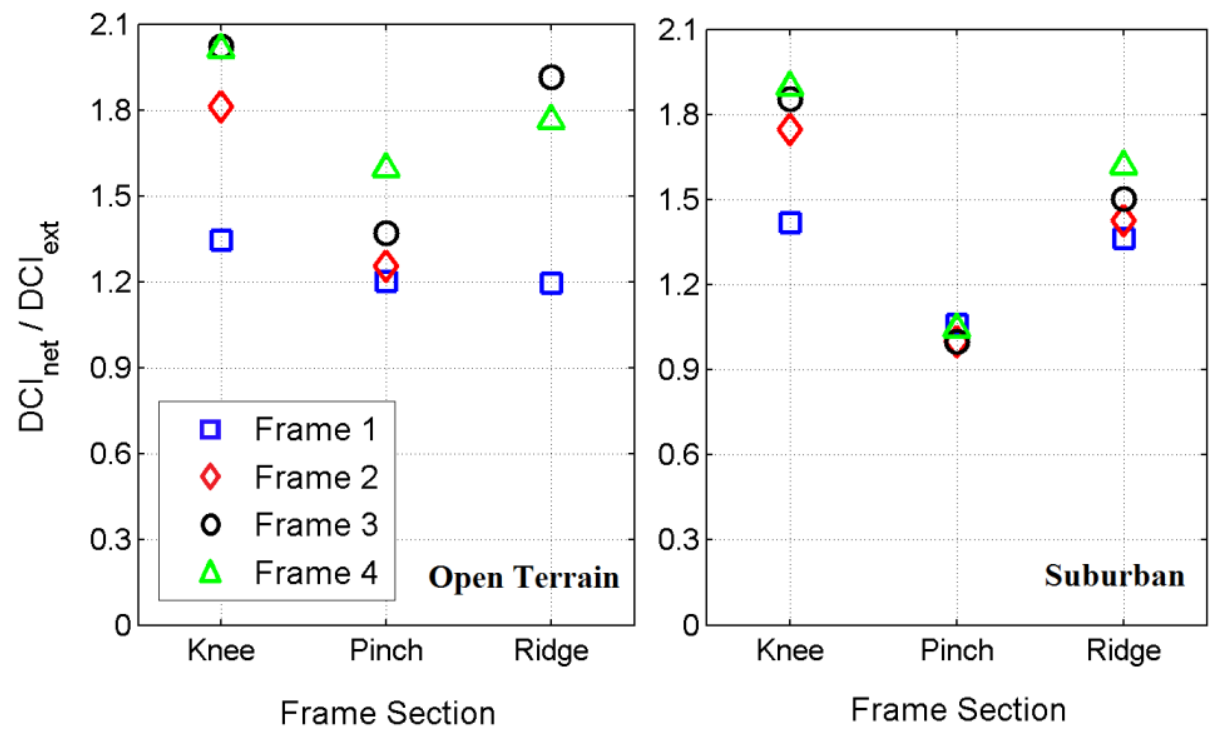

Figure 5.18DCI net $/ D C I_{e x t}$ versus wind directions, NIST model 1
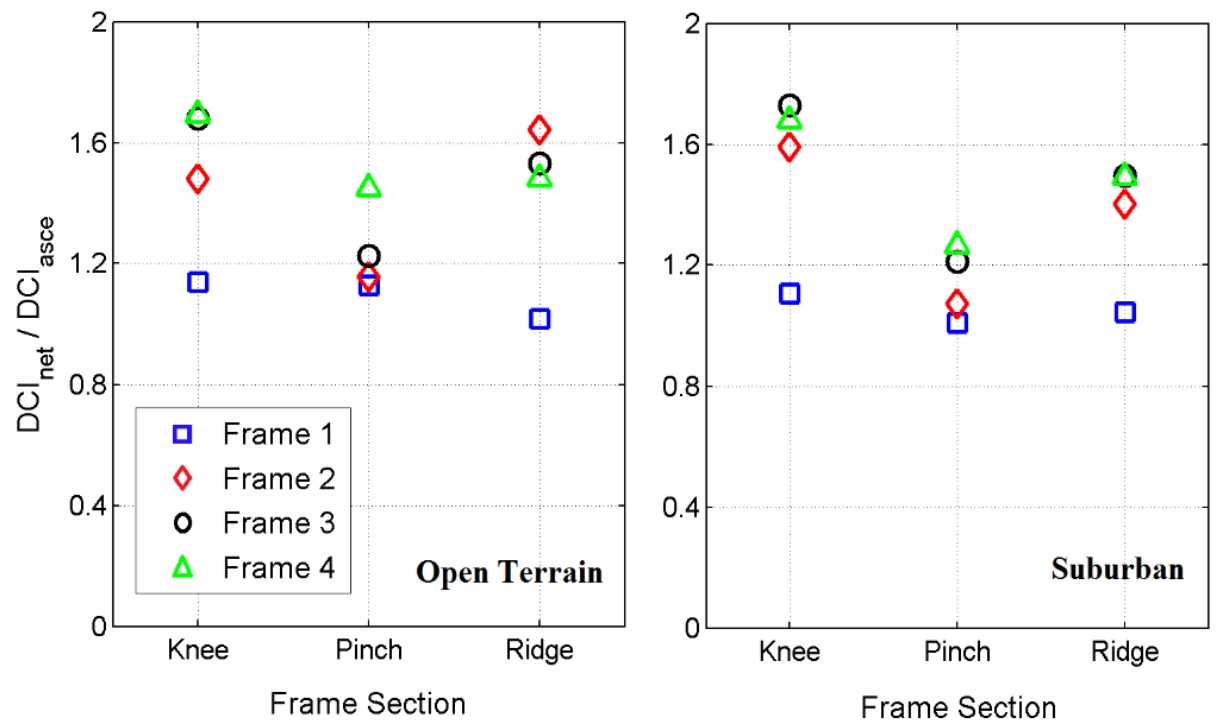

Figure 5.19 $D C I_{\text {net }} / D C I_{\text {asce }}$ versus wind directions, NIST model 1

The current investigation of the effects of internal pressure on global roof uplift, frame forces, and frame DCIs showed that ASCE 7-10 recommended internal pressure values can produce unconservative results in both partially enclosed and enclosed building categories. Using the assumption that a slug of air moves in and out of a building through an opening in response to the external pressure changes near the opening, Holmes (1979) derived Eq. (5.9) to describe the 
time dependent internal pressure in a building, $C_{p i}$, in response to the external pressure, $C_{p e}$, near the building's openings

$$
\frac{\rho l_{e} V}{n p_{o} A} \ddot{C}_{p i}+\left(\frac{\rho V \bar{U}_{H}}{2 n k A p_{o}}\right)^{2} \dot{C}_{p i}\left|\dot{C}_{p i}\right|+C_{p i}=C_{p e}
$$

where $\dot{C}_{p i}$ and $\ddot{C}_{p i}$ represent the first and second derivatives of $C_{p i} ; \rho$ and $p_{0}$ denote air density and ambient atmospheric pressure respectively; $A$ and $V$ are area of the opening and volume of the building respectively; $l_{e}$ is the effective length of the slug of air moving in and out of the opening; $n$ is the ratio of specific heats of air; $\bar{U}_{H}$ is mean wind speed at building eave height; and $k$ is opening discharge coefficient (Holmes and Ginger 2012). Ginger et al. (1997) and Oh et al. (2007) have shown that such theoretical models can, with satisfactory accuracy, determine timeseries of internal pressure fluctuations from measurements of external pressures near openings. Hence, the use of internal pressure prediction models is recommended for applications that make use of pressure time histories, such as DAD.

\section{Conclusions}

This chapter presented results of an investigation conducted to quantify and understand the characteristics of net roof uplift and net structural frame forces in low-rise buildings with single or multiple dominant openings. Experimental measurements of wind-uplift forces on a low-rise building with multiple openings were conducted using load cells installed at the model's corners, in the WOW facility at FIU. Frame internal forces and DCIs were also computed using databaseassisted design (DAD) methodology and pressure data (external and internal) from the NIST database for single dominant openings, and experimentally collected at the WOW for multiple dominant openings.

The results showed that the presence of openings has pronounced effects on the total uplift force, and its effects on roof uplift were significantly higher than the external pressure in both single and multiple opening cases. This is due to the spatial uniformity of internal pressure inside 
a building. In some cases, the total uplift forces can be increased by over $300 \%$. The presence of openings with equal sizes on opposite walls of the model can also significantly increase the total uplift forces experienced when one of the openings is on the upwind side. Comparison of the effective contributions of the internal pressure to net uplift forces with the provisions of the ASCE 7-10 for internal pressure showed that categorizing low-rise buildings with openings of equal dimensions on the windward and leeward sides as "enclosed" can result in unconservative estimates.

The effect of internal pressure on frame forces was not only different for different frames (i.e., that effect depended on the location of a frame in reference to the building openings); it also varied within different cross-sections of the same frame. It was highly dependent on the correlation between the forces induced by the external and internal pressures. For frames near an opening, internal pressure can increase the net response by up to $65 \%$ and $45 \%$ of the external pressure induced forces in single and multiple openings respectively. However, in frames located away from the openings, the internal pressure has milder effects on the critical net forces, and can even reduce the critical forces in some cross-openings cases. Generally high correlation coefficients, up to 0.67 and 0.55 for single and multiple dominant openings, respectively, can be observed between time histories of external and internal pressure induced frame forces. The presence of an opening was observed to increase frame DCIs by up to $100 \%$.

Comparisons of frame forces and DCIs evaluated using experimentally recorded internal pressures to those based on ASCE 7-10 provisions showed that ASCE 7-10 based estimates can be unconservative in buildings with single and multiple openings. Hence in methods seeking to produce highly accurate estimates of wind effects, such as DAD, the use of internal pressure prediction models is recommended. 


\section{References}

ASCE 7-10. (2010). Minimum design loads for building and other structures. American Society of Civil Engineers, Reston, VA.

Asghari Mooneghi, M. (2014). "Experimental and Analytical Methodologies for Predicting Peak Loads on Building Envelopes and Roofing Systems." FIU Electronic Theses and Dissertations, FIU.

Asghari Mooneghi, M., Irwin, P., and Chowdhury, A. G. (2015). "Partial Turbulence Simulation Method for Small Structures." 14th. International Conference on Wind Engineering, Porto Alegre, Brazil.

Asghari Mooneghi, M., Irwin, P., and Gan Chowdhury, A. (2014). "Large-scale testing on wind uplift of roof pavers." Journal of Wind Engineering and Industrial Aerodynamics, 128, $22-36$.

Ginger, J. D., Mehta, K. C., and Yeatts, B. B. (1997). "Internal pressures in a low-rise full-scale building." Journal of wind engineering and industrial aerodynamics, 72, 163-174.

Habte, F., and Chowdhury, A. G. (2015). "Experimental Investigation of Wind-Induced Torsional Loads on a Low-Rise Building." Structures Congress 2015, ASCE, 2655-2666.

Holmes, J. D. (1979). Mean and fluctuating internal pressures induced by wind. Department of Civil and Systems Engineering, James Cook University of North Queensland.

Holmes, J. D., and Ginger, J. D. (2012). "Internal pressures - The dominant windward opening case - A review." Journal of Wind Engineering and Industrial Aerodynamics, 100(1), 70-76.

Ho, T. C. E., Surry, D., and Morrish, D. (2003a). NIST/TTU Cooperative Agreement-Windstorm Mitigation Initiative: Wind Tunnel Experiments on Generic Low Buildings. Tech. Rep. BLWT-SS20-2003, The Boundary Layer Wind Tunnel Laboratory, The University of Western Ontario, London, Ontario, Canada.

Ho, T. C. E., Surry, D., and Nywening, M. (2003b). "NIST/TTU cooperative agreementwindstorm mitigation initiative: further experiments on generic low buildings." BLWTSS21-2003, Phase, 2.

Irwin, H., Cooper, K. R., and Girard, R. (1979). "Correction of distortion effects caused by tubing systems in measurements of fluctuating pressures." Journal of Wind Engineering and Industrial Aerodynamics, 5(1), 93-107.

Irwin, P. A., and Sifton, V. L. (1998). "Risk considerations for internal pressures." Journal of Wind Engineering and Industrial Aerodynamics, 77, 715-723.

Karava, P., and Stathopoulos, T. (2011). "Wind-induced internal pressures in buildings with large façade openings." Journal of Engineering Mechanics, 138(4), 358-370. 
Kopp, G. A., Oh, J. H., and Inculet, D. R. (2008). "Wind-induced internal pressures in houses." Journal of structural engineering, 134(7), 1129-1138.

Main, J. A., and Fritz, W. P. (2006). Database-assisted design for wind: concepts, software, and examples for rigid and flexible buildings. National Institute of Standards and Technology, Technology Administration, US Department of Commerce.

Oh, J. H., Kopp, G. A., and Inculet, D. R. (2007). "The UWO contribution to the NIST aerodynamic database for wind loads on low buildings: Part 3. Internal pressures." Journal of wind engineering and industrial aerodynamics, 95(8), 755-779.

Pan, F., Cai, C. S., and Zhang, W. (2012). "Wind-induced internal pressures of buildings with multiple openings." Journal of Engineering Mechanics, 139(3), 376-385.

Sadek, F., and Simiu, E. (2002). "Peak non-Gaussian wind effects for database-assisted low-rise building design." Journal of Engineering Mechanics, 128(5), 530-539.

Sharma, R. N., Mason, S., and Driver, P. (2010). "Scaling methods for wind tunnel modelling of building internal pressures induced through openings."

St Pierre, L. M., Kopp, G. A., Surry, D., and Ho, T. C. E. (2005). “The UWO contribution to the NIST aerodynamic database for wind loads on low buildings: Part 2. Comparison of data with wind load provisions." Journal of wind engineering and industrial aerodynamics, 93(1), 31-59.

Tecle, A. S., Bitsuamlak, G. T., and ALY, A. M. (2013). "Internal pressure in a low-rise building with existing envelope openings and sudden breaching." Wind and Structures, 16(1), 2546.

Vickery, B. J. (1986). "Gust-factors for internal-pressures in low rise buildings.” Journal of Wind Engineering and Industrial Aerodynamics, 23, 259-271.

Womble, J. A. (1994). "Wind-induced internal building pressures."

Woods, A. R., and Blackmore, P. A. (1995). "The effect of dominant openings and porosity on internal pressures." Proceedings of the First IAWE European and African Regional Conference, 57(2-3), 167-177. 


\title{
6. INTERPOLATION AND AERODYNAMIC DATA COMPARISON TO ALLEVIATE SCARCITY OF COMPREHENSIVE AERODYNAMIC DATABASES
}

\begin{abstract}
Database-assisted design (DAD) is an integrated methodology that calculates wind loadings and wind-induced internal forces. It can also calculate demand-to-capacity indexes for each structural member, and by checking whether they differ significantly from unity, determines the adequacy of the members' structural design. Its practical usefulness depends on the availability of comprehensive aerodynamic databases. A public domain aerodynamic database produced in 2003 by the University of Western Ontario (UWO) is not sufficiently extensive to satisfy design needs generally encountered in practice. Recently the Tokyo Polytechnic University (TPU) developed comprehensive sets of aerodynamic databases that are publicly available and would fill large voids present in the UWO database. With the objective of alleviating to some extent the scarcity of available aerodynamic databases for use in DAD, this study: (1) develops a novel time-history of responses interpolation scheme, allowing the design of buildings with dimensions not covered in the databases, and (2) provides a detailed comparison of the NIST and TPU aerodynamic databases to help assess the extent to which the respective aerodynamic pressure measurements are comparable. Highly accurate estimates of frame responses and DCI's were obtained when interpolating between different heights. When interpolating between models with different roof slopes, the accuracy of the estimated frame responses tends to increase as the roof slope of the building of interest increases. The results of the comparison between the NIST and TPU databases suggest that TPU and UWO pressure simulations are reasonably equivalent, and may in practice be used for the design of main wind force resisting systems.
\end{abstract}




\subsection{Introduction}

The Commentary to the ASCE 7-10 Standard (Section C31.4) mentions the paucity of available aerodynamic data as the main barrier to the widespread use of the database-assisted design (DAD) methodology. The National Institute of Standards and Technology (NIST) public aerodynamics database, which was created for the purpose of providing time series of wind load data for public access for use in $\mathrm{DAD}$, was until recently the largest existing public aerodynamic database. As described in Chapter 2, the NIST database covers a basic building configuration, characterized by rectangular shape in plan, gable roofs with various slopes, no overhangs and, except for two cases, no parapets. The corresponding structural system consists of portal frames in planes normal to the ridge, and braces in the direction parallel to the ridge. The total number of buildings with distinct dimensions and roof slopes covered by the database is only 37 , which is in practice too small to allow the use of DAD in lieu of conventional design methods for wind.

Recently the Tokyo Polytechnic University (TPU) has produced publicly available aerodynamic databases covering both low-rise and high-rise buildings (Tamura, 2013). As described in chapter 2, the TPU database includes five distinct categories: (1) high-rise buildings, (2) sets of two adjacent tall buildings, (3) isolated low-rise buildings with gable, flat, or hip roofs, without overhangs, (4) isolated low-rise buildings with overhangs, and (5) non-isolated low-rise buildings. The isolated low-rise buildings without overhang category, covers 4 ratios of building height to building width $(1 / 4,2 / 4,3 / 4$, and $4 / 4), 3$ ratios of building height to building depth $(2 / 2$, $3 / 2$, and $5 / 2$ ), and 8 roof slopes. Thus, the total number of distinct building sizes and roof slopes is $4 \times 3 \times 8=96$, which is more than twice larger than for the NIST database.

With the objective of alleviating to some extent the scarcity of available aerodynamic databases for use in DAD, this study: (1) develops a novel time-history of responses interpolation scheme, allowing the design of buildings with dimensions not covered in the databases, and (2) provides a detailed comparison of the NIST and TPU aerodynamic databases to help assess the 
extent to which the respective aerodynamic pressure measurements are comparable. If the results are satisfactory, this will considerably increase the amount of publicly available aerodynamic data as well as strengthen confidence in both databases.

\subsection{Interpolation of time-histories of frame responses}

An alternative for alleviating the scarcity of aerodynamic databases is using simple and reliable interpolation schemes that enable the prediction of wind responses for building dimensions intermediate between those covered in the available database. Previous research efforts on interpolation schemes for DAD fall mainly into two categories: (1) interpolation of aerodynamic pressures, this was mainly conducted by researchers at the University of Florida (Chen et al. (2003a; 2003b); Kopp and Chen 2006; Gavalda et al. 2011), and (2) interpolation of the computed frame responses, this was led by researchers at NIST (Main and Fritz 2006; Main 2007).

Using Reynolds turbulence decomposition, Chen et al. (2003a) developed a model that can interpolate between time-series of pressure coefficients $C_{p, e s t}(t)$ (Eq. (6.1)). The mean pressure coefficients $\bar{C}_{p, e s t}$ for the building of interest are first predicted. Next, the fluctuations are obtained by correcting a reference time series of pressures fluctuations $C_{p, r e f}(t)$ via multiplication by the ratio of predicted root mean square (rms) values $\tilde{C}_{p, e s t}$ to reference rms values $\tilde{C}_{p, \text { ref }}$

$$
C_{p, e s t}(t)=\bar{C}_{p, e s t}+C_{p, r e f}(t) \frac{\tilde{C}_{p, e s t}}{\tilde{C}_{p, r e f}}
$$

Chen et al. (2003a) used artificial neural network (ANN) models trained to recognize functional relationships between building geometry, flow conditions and pressure coefficients to predict mean and rms values of pressure coefficients for the building of interest. Any other method that can accurately predict the mean and rms of pressure coefficients for the structure of interest can also be used. 
Main (2007) developed a procedure that can, with acceptable accuracy, determine structural responses induced by unit wind speeds at eave height from various directions (i.e. Directional Influence Factors, or DIFs) in a building with dimensions $\left\{\mathrm{d}_{\mathrm{j}}\right\}$ not available in the aerodynamic database. This is done by interpolation between responses of two or more building models with dimensions $\left\{\mathrm{d}_{\mathrm{j}}+\Delta_{\mathrm{j}}^{+}\right\}$and $\left\{\mathrm{d}_{\mathrm{j}}-\Delta_{\mathrm{j}}{ }^{-}\right.$, where ${\Delta_{\mathrm{j}}}^{+} \neq 0$ and $\Delta_{\mathrm{j}}{ }^{-} \neq 0$ for at least one of the dimensions $d_{j}$. In the interpolation procedure developed by Main (2007), instead of time-histories of wind pressures, interpolation of peak structural responses is performed. This eliminates the necessity of explicitly accounting for spatial and temporal correlations in the interpolation scheme. The procedure includes the following steps:

(i) Dimensions defining locations of the pressures taps on the models with different dimensions (i.e. the dimensions used in the interpolation) are scaled to match the dimensions of the building of interest. The scaled coordinates, $x_{s i}, y_{s i}$, and $z_{s i}$ are computed as;

$$
x_{s i}=\frac{B_{0}}{B_{i}} x_{i} ; \quad y_{s i}=\frac{L_{0}}{L_{i}} y_{i} ; \quad z_{s i}=\left\{\begin{array}{cc}
\left(H_{0} / H_{i}\right) z_{i}, & z_{i} \leq H \\
H_{0}+\left(R_{0} / R_{i}\right)\left(z_{i}-H_{i}\right), & z_{i}>H
\end{array}\right.
$$

where $x, y$, and $z$ denote the coordinates of a pressure tap on the building of interest; $B, L, H$, and $R$ denote building width, length, height and roof rise; subscripts $O$ and $i$ represent the building of interest and model used in interpolation.

(ii) They are then used in conjunction with influence coefficients of responses computed for building of interest to calculate DIFs with dimensional deviations, denoted by $D I F_{i}$.

(iii) Finally, estimates of the DIFs for the building of interest (denoted by $D I F_{0}$ ) are obtained as weighted averages (giving more weight to the models whose dimensions match more closely to the building of interest) of the $D I F_{i}$ s, as shown in Eq. (6.3). 
$D I F_{0}=\sum_{i=1}^{b} \frac{\gamma}{\left\|\Delta d_{i}\right\|} D I F_{i}$

where $\gamma=\left(\sum_{i=1}^{b} \frac{1}{\left\|\Delta d_{i}\right\|}\right)^{-1}, \Delta d_{i}=d_{i}-d_{0} ;$ and $d_{i}=\left[\frac{B_{i}}{B_{0}} \frac{L_{i} / B_{i}}{L_{0} / B_{0}} \frac{H_{i} / B_{i}}{H_{0} / B_{0}} \frac{R_{i} / B_{i}}{R_{0} / B_{0}}\right]^{T}$

where $d_{i}$ and $d_{0}$ are normalized vectors of building dimensions of the model used for interpolation and the building of interest respectively; $b$ is the total number of building models used for interpolations; $\|\cdot\|$ denotes norm operator; and $W, L, H$ and $R$ represent building width, length, height and roof rise respectively. This method, explained in detail in Main (2007) and Main and Fritz (2006), produces satisfactory results and is relatively simpler because interpolation is performed between peaks of structural responses instead of pressure coefficients. This method can be made more effective by determining the sensitivity of the peak responses to changes in the different building dimensions (i.e. sensitivity to changes in building height as opposed to changes in building width).

In Chapter 3, an iterative design procedure for rigid frame buildings which requires the whole time-histories of responses to producing time-histories of demand-to-capacity indexes (DCIs) was developed. This necessitated the need for interpolation scheme that can produce timehistories of responses (not just the peaks) for the building of interest from two or more aerodynamic models with different dimensions. Hence, based on the approaches used in Chen et al. (2003a) and Main (2007), a modified interpolation scheme was developed. This new interpolation scheme has the following three steps:

1. Two or more time histories of structural responses are evaluated by (i) scaling dimensions that define the locations of pressure taps in the building models with different dimensions to match the dimensions of the structure of interest (using Eq. (6.2)) and (ii) using influence coefficients obtained for the building of interest. The time histories of 
responses computed using pressures from the model with the least dimensional deviation from the building of interest are named the reference response $r_{r e f}(t)$.

2. The mean $\bar{r}_{e s t}$ and rms $\tilde{r}_{e s t}$ of the responses for the structure of interest are evaluated as weighted averages of the mean and rms of the response time histories calculated in step 1. A procedure similar to Eq. (6.3) (i.e. the interpolation scheme developed by Main (2007)) which gives more weight to the models with the least dimensional deviation from the building of interest is used to compute $\bar{r}_{e s t}$ and $\tilde{r}_{e s t}$.

3. Finally, the $\bar{r}_{e s t}$ and $\tilde{r}_{e s t}$ evaluated in step 2 are used to estimate time-history of responses, $r_{\text {est }}(t)$ for the building of interest as shown in Eq. (6.4):

$$
r_{e s t}(t)=\bar{r}_{e s t}+r_{r e f}^{\prime}(t) \frac{\tilde{r}_{e s t}}{\tilde{r}_{r e f}}
$$

In Eq. (6), fluctuations of the required time-series of responses are estimated by rescaling the fluctuations of a reference response $r_{r e f}^{\prime}(t)$ using ratios of $\tilde{r}_{e s t}$ to rms of the reference response, $\tilde{r}_{r e f}$. The assumption that fluctuations of responses can be obtained by re-scaling from a reference response is reasonable as long as the aerodynamics does not change significantly over the range of interpolation. The fluctuation of the reference response are computed using Eq. (6.5),

$$
r_{r e f}^{\prime}(t)=r_{r e f}(t)-\bar{r}_{r e f}
$$

where $\bar{r}_{\text {ref }}(t)$ and $\bar{r}_{\text {ref }}$ are the time history and mean of the reference response respectively.

The following subsections provide results on comparisons of peak responses and DCIs evaluated using existing models to those evaluated using the interpolation procedure described above.

\subsubsection{Comparison of Frame Responses}

Figure 6.1 and Figure 6.2 compare statistics of structural responses computed using existing aerodynamic building models to those computed by interpolation from models with different 
dimensions. The peaks in Figure 6.1 and Figure 6.2 were evaluated using the peak estimation method for non-Gaussian processes developed by Sadek and Simiu (2002).

In Figure 6.1, interpolation is performed using data from NIST database between models with different eave heights, all other dimensions being the same. The building of interest has width $B=80 \mathrm{ft}$, length $L=125 \mathrm{ft}$, eave height $H=24 \mathrm{ft}$, roof slope $=4.8 \mathrm{deg}$, and frame spacing $25 \mathrm{ft}$. Time series of bending moments at the knee and ridge of the first interior frame were calculated using an identical model from the NIST database, and compared to those interpolated from two models with eave heights $\mathrm{H}=16 \mathrm{ft}$ and $\mathrm{H}=32 \mathrm{ft}$. The interpolation scheme was found to be remarkably successful when interpolating between models with different eave heights.

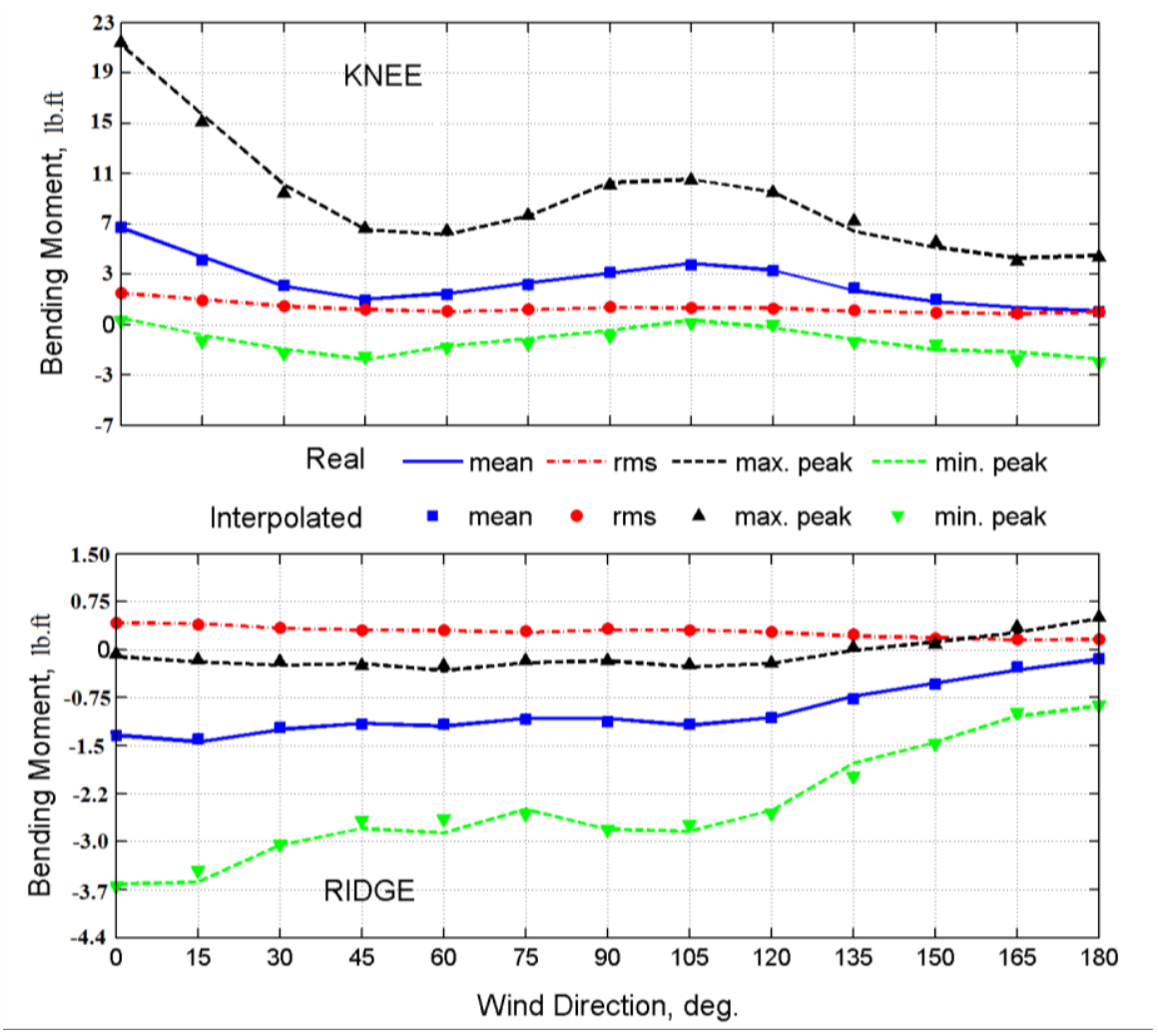

Figure 6.1 Interpolation between Models with Different Eave Heights

Figure 6.2 shows comparisons between bending moments at the knee of the first interior frame calculated for existing models from the TPU database on the one hand and by interpolation from models with different roof slopes on the other. Three cases were considered. In the first case 
the building of interest had dimensions $B=52.5 \mathrm{ft}, L=78.7 \mathrm{ft}$., $H=13.1 \mathrm{ft}$, and $14 \mathrm{deg}$ roof slope. The interpolation was performed from models with $10 \mathrm{deg}$ and $18 \mathrm{deg}$ roof slopes. In the second case, the roof slope of the building of interest was $18 \mathrm{deg}$, and the interpolation was performed using models with $14 \mathrm{deg}$ and $22 \mathrm{deg}$ roof slopes. In the third case, the roof slope of the building of interest was $22 \mathrm{deg}$, and the interpolation was performed using models with 18 deg and $27 \mathrm{deg}$ roof slopes. It was observed that as the roof slope increases the interpolation scheme produces better results.

In some instances, results obtained by interpolation differed significantly from their counterparts obtained for existing models. However, considering for example case 1 , note that because the model with 14 deg roof slope is in fact available in the database, interpolations would be made for design purposes between models with $10 \mathrm{deg}$ and $14 \mathrm{deg}$ roof slopes or with $14 \mathrm{deg}$ and $18 \mathrm{deg}$ roof slope, rather than between models with $10 \mathrm{deg}$ and $18 \mathrm{deg}$ slope. This would result in errors due to interpolation about half as large or less than those represented in Figure 6.2. 

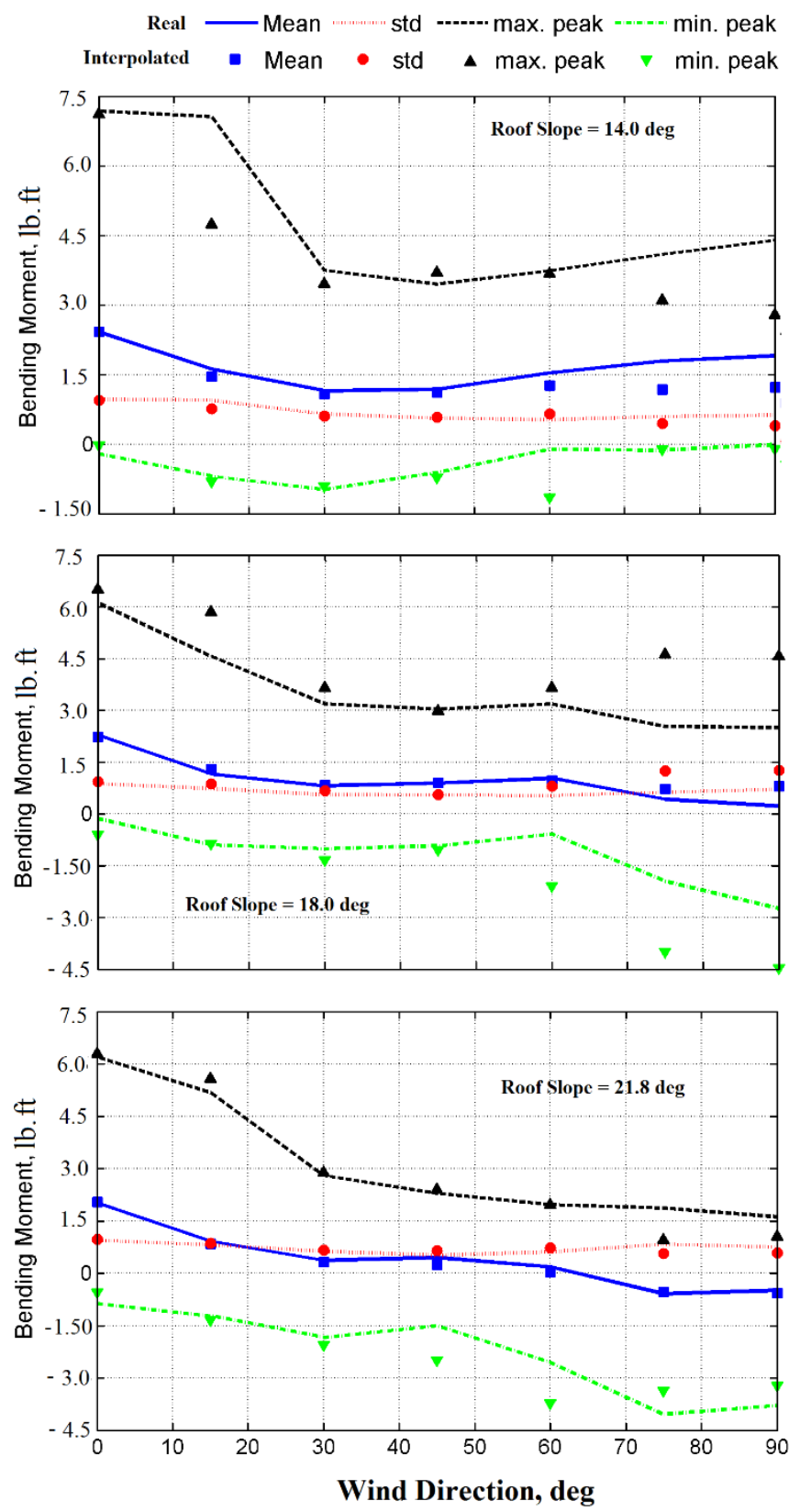

Figure 6.2 Interpolation between models with different roof slopes

\subsubsection{Comparison of Demand-to-Capacity Indexes (DCIs)}

In this section, comparison of DCI values computed using models available in the aerodynamic databases to those obtained by interpolation from aerodynamic models with different dimensions are provided. The buildings were assumed to be located in Miami, FL. The assumed frame spacing was $18.5 \mathrm{ft}$. Results are shown for the end, first interior, and second 
interior frames designated in the figures as Frame 1, Frame 2 and Frame 3, respectively. The assumed dead and roof-live loads are 2 psf and 20 psf, respectively. The frames supports were assumed to be pinned, and all the calculations were conducted for the "enclosed" building enclosure category.

Case 1. Figure 6.3 shows comparisons of $700-\mathrm{yr} \mathrm{DCI}^{\mathrm{PM}} \mathrm{s}$ calculated using a model available in the aerodynamic databases to those obtained by interpolation from aerodynamic models with different eave heights. The building of interest has the following dimensions: $B=52.5 \mathrm{ft}, L=78.7$ $\mathrm{ft}, H=26.2 \mathrm{ft}$, and $14 \mathrm{deg}$ roof slope. The models used in the interpolation had all their dimensions and roof slopes identical to those of the model of interest, except for the eave heights which were $13.1 \mathrm{ft}$ and $39.3 \mathrm{ft}$. The models were from the TPU database, and suburban terrain exposure was assumed. $\mathrm{DCI}^{\mathrm{PM}}$ values for the knee and ridge computed through interpolation were close to those computed using the existing model. Larger differences were observed for the frame pinch.

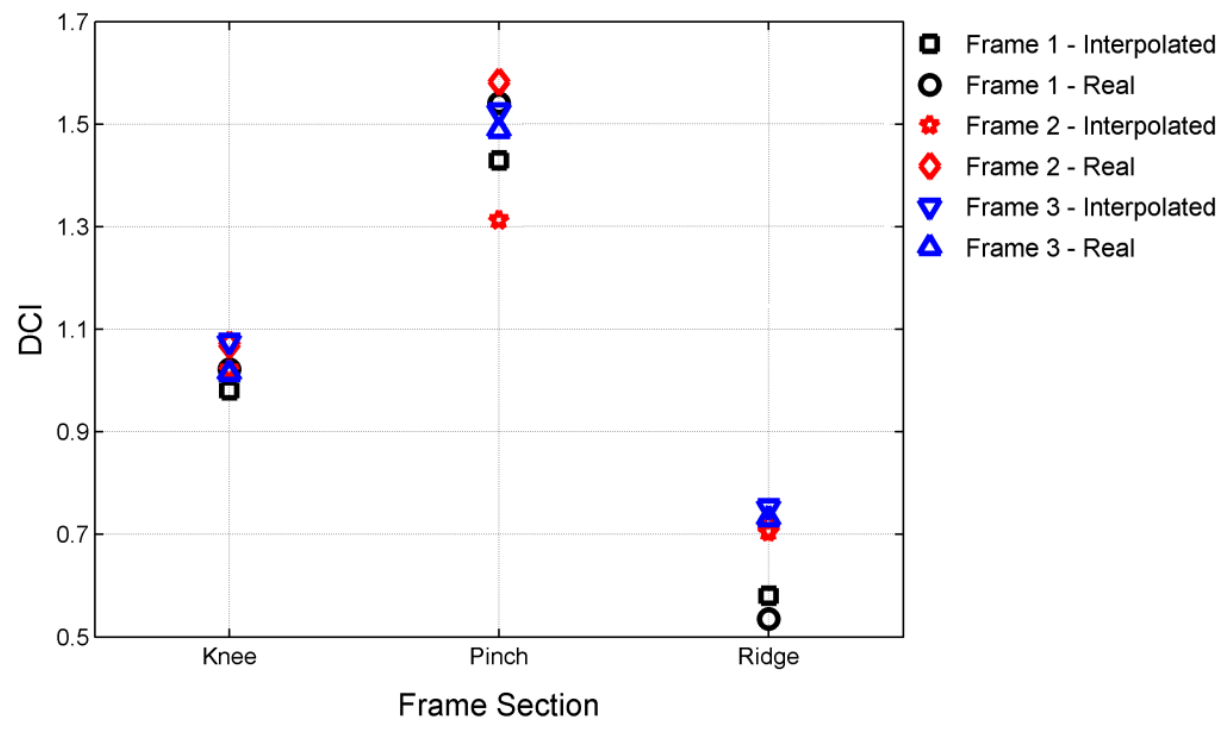

Figure 6.3 $\mathrm{DCI}^{\mathrm{PM}}$ s Based on Model of Building and on Interpolations From Models with Different Eave Heights.

Case 2. DCIs with 700-yr MRI were calculated, based on TPU data, for a building with suburban exposure and the following dimensions: $B=52.5 \mathrm{ft}, L=78.7 \mathrm{ft}$, and $H=13.1 \mathrm{ft}$, and a $22 \mathrm{deg}$ 
roof slope. The DCIs were then compared to interpolated 700-yr DCIs based on TPU data for buildings with the same dimensions but with $18 \mathrm{deg}$ and 27 deg roof slopes. Results of the DCI comparisons are shown in Figure 6.4. It can be seen that in these cases the interpolation scheme described previously produces DCI values that closely match the DCI values evaluated using an existing model.

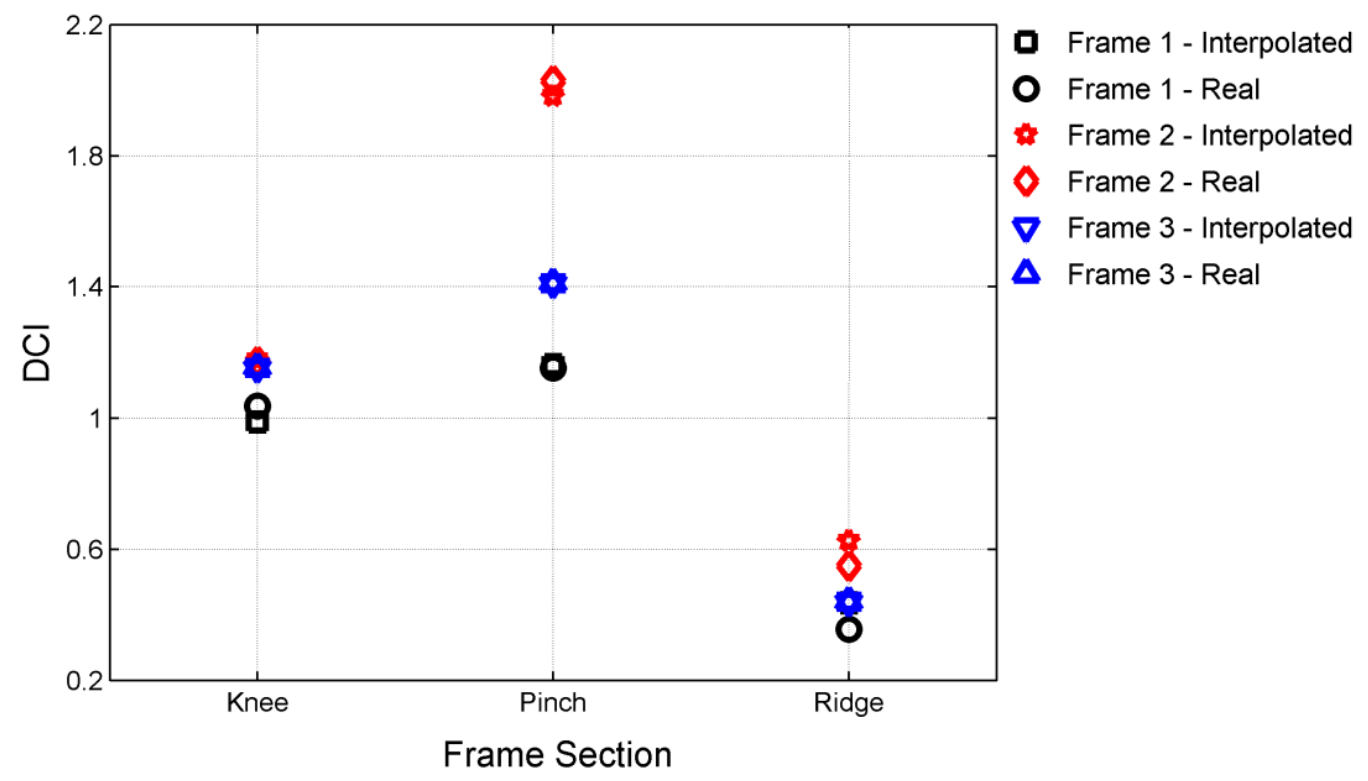

Figure 6.4 $\mathrm{DCI}^{\mathrm{PM}} \mathrm{s}$ Based on Scaled Model of Building and on Interpolations from Models with Different Roof Slopes.

Case 3. $\mathrm{DCI}^{\mathrm{PM}} \mathrm{s}$ were computed for a building with $B=52.5 \mathrm{ft}, L=78.7 \mathrm{ft}, H=26.2 \mathrm{ft}$, and roof slope $=14 \mathrm{deg}$, and were compared to $\mathrm{DCI}^{\mathrm{PM}} \mathrm{S}$ calculated by interpolation from buildings with dimensions $B=52.5 \mathrm{ft}, L=78.7 \mathrm{ft}$, and $H=13.1 \mathrm{ft}, 22 \mathrm{deg}$ roof slope, and $B=52.5 \mathrm{ft}, L=78.7$ $\mathrm{ft}$, and $H=39.4 \mathrm{ft}, 10 \mathrm{deg}$ roof slope. The models are from the TPU database and have suburban terrain exposure. The results of this comparison are shown in Figure 6.5. It can be seen that interpolation can produce DCIs of acceptable accuracy even from models with more than one different dimension. Note, however, that this would not be the case if the roof slopes being considered corresponded to qualitatively different aerodynamic behaviors, as is the case if one of the slopes is lower than, while the other slope exceeds, approximately $22 \mathrm{deg}$. 


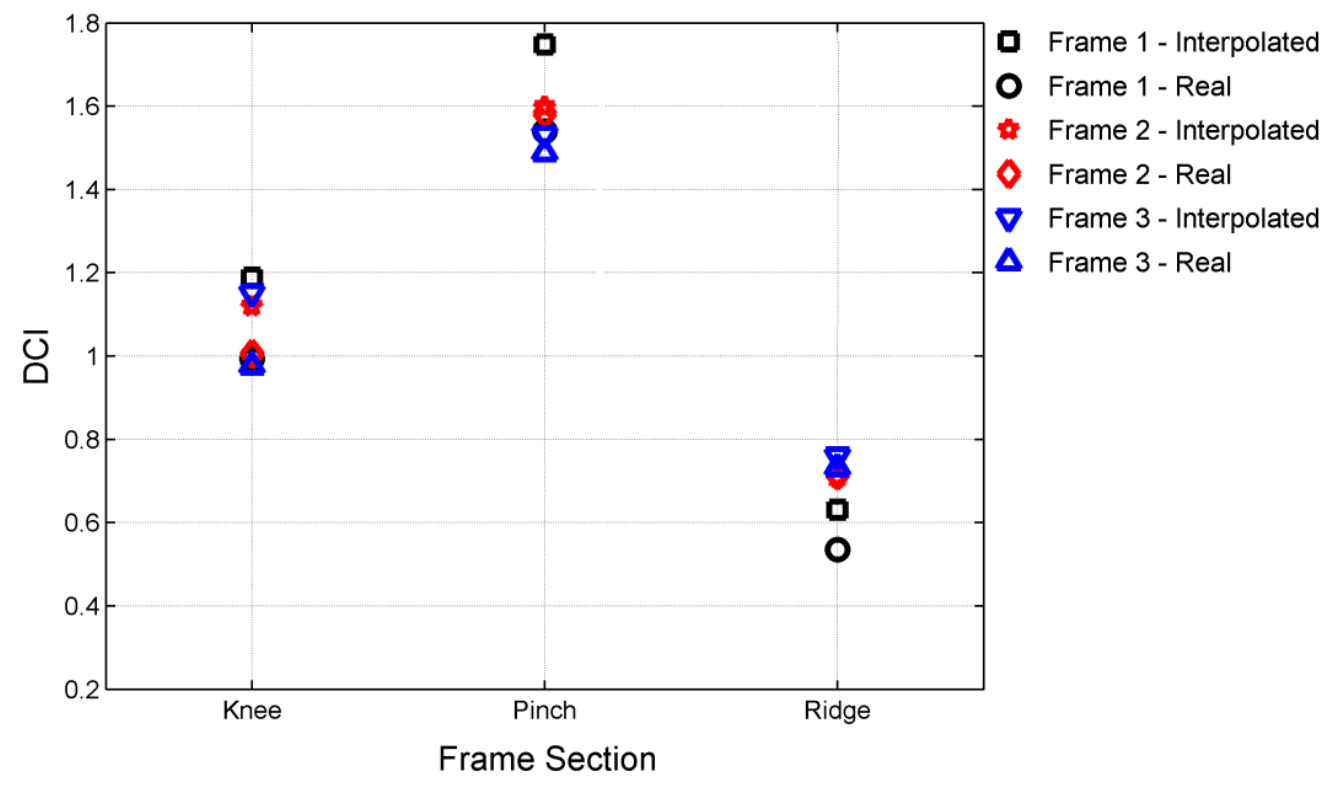

Figure 6.5 $\mathrm{DCI}^{\mathrm{PM}}$ s Based On Scaled Model of Building and On Interpolations from Models with Different Eave Heights and Roof Slopes.

\subsection{Comparison of the NIST and TPU Aerodynamic Databases}

As shown in Fritz et al. (2008), pressures determined by aerodynamic testing can be strongly dependent upon the laboratory in which the tests were conducted. This dependence was quantified by using measurements conducted at six wind tunnel laboratories: University of Western Ontario, Colorado State University, Clemson University, Texas Tech University, Centre Scientifique et Technique du Bâtiment (Nantes, France), and Building Research Institute (Tsukuba, Japan). Pressure measurements were reported for four building models. Comparisons were made between estimated 50th percentiles of (1) peak moments at portal frame knees, and (2) peak pressure coefficients at a roof tap nearest a building corner. Ratios of maximum to minimum peak moments at the frame knee obtained from measurements at the six laboratories exceeded in most cases 1.6 for open terrain, and were on average higher, reaching as much as 2.5 for suburban terrain. Ratios of maximum to minimum 50th percentile negative pressures at a corner tap varied between 1.2 and 3.0 for open terrain and 1.5 and 2.1 for suburban terrain. 
In view of these results, it is of interest to compare TPU and NIST aerodynamic databases. The finding that the TPU and NIST database do not differ significantly from each other would increase the confidence in both sets of data, and standard committees as well as other interested parties could consider using them for the development of improved standard provisions on wind pressures. As noted by Irwin (2009), such development is a necessary task.

Both the NIST and TPU pressure measurements being compared were performed in wind tunnel flow corresponding nominally to suburban terrain exposure developed by using turbulence generating spires and roughness elements. Both the University of Western Ontario (UWO) and TPU wind tunnels are state-of-the-art facilities, and their wind tunnel flows and instrumentations are consistent with the ASCE 7-10, Section 31.2, Items 1-7 requirements (ASCE 7-10). Their nominal conformity to ASCE 7 Standard requirements notwithstanding, the two wind tunnels could be expected to produce test results that will differ from each other. The question of interest is whether those differences are acceptable from a structural engineering viewpoint. This section provides results of comparisons aimed at helping to answer this question.

The fact that dimensions of buildings in the two databases differed limited the choices of buildings that could be used for comparison. However, this does not preclude the possibility of meaningful comparisons, which can be performed by considering TPU and NIST building models with identical roof slopes, almost identical eave heights, and horizontal dimensions within which partial roof and wall areas may be selected that are identical or almost identical and are comparable from an aerodynamic response viewpoint. In this study, comparisons of (i) aerodynamic roof and wall pressures, (ii) internal frame forces, and (iii) demand-to-capacity indexes evaluated using NIST and TPU aerodynamic databases were performed.

\subsubsection{Comparison of Aerodynamic Pressures}

To allow meaningful comparisons between peak pressures, for both NIST and TPU data expected values rather than observed values of the peak pressure coefficient, estimated under the 
assumption that the duration of the records is $60 \mathrm{~min}$. This required the application to the TPU time series of the algorithm developed by Sadek and Simiu (2002), based on Rice theory and translation transformations from Gaussian to non-Gaussian marginal distributions. For the NIST database, 60 min duration peak was estimated from 60 min record length, and for the TPU database $60 \mathrm{~min}$ duration peak was estimated from $10 \mathrm{~min}$ record length. Hence, the peak pressure coefficients for 60-min based on mean hourly wind speeds at mean roof height $h$ for NIST and TPU are obtained as follows:

$$
\begin{gathered}
C_{p_{p k, h}^{N I S T, 60 \mathrm{~min}}}^{p_{p k}}=\frac{p_{p k}^{N I S T, 60 \mathrm{~min}}}{\frac{1}{2} \rho\left(V_{\text {mean }, h}^{N I S T}\right)^{2}} \\
C_{p_{p k, h}}^{T P U, 60 \mathrm{~min}}=\frac{p_{p k}^{T P U, 60 \mathrm{~min}}}{\frac{1}{2} \rho\left(V_{\text {mean }, h}^{T P U}\right)^{2}}
\end{gathered}
$$

where $p_{p k}{ }^{\text {NIST 60min }}$ and $p_{p k}{ }^{\text {TPU 60min }}$ denote the hourly expectation of the peak pressures for the NIST and TPU data respectively, note that pressures in both cases are both on $0.006 \mathrm{~s}$ moving average;

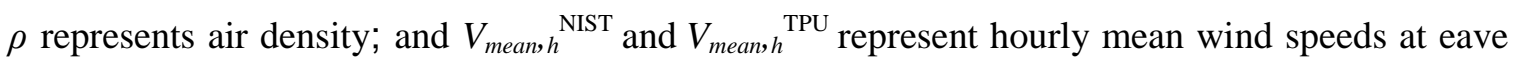
height for the NIST and TPU models respectively.

Numerous pressure taps extracted from the walls and roofs of the two pairs of building models shown in Table 6.1 were subjected to comparison. The compared buildings models are referred to as Case 1-1 and Case 1-2. In both cases, the selected roof pressure taps were close to roof edges and relatively distant from ridges, and the selected wall pressure taps were close to the upwind corners. Comparisons were performed for three wind directions, $\theta=0^{\circ}, 45^{\circ}$ and $90^{\circ}$. 
Table 6.1. Dimensions and Roof Slopes of Buildings Selected for Comparisons.

\begin{tabular}{|l|c|c|c|c|c|}
\hline Case & Database & $\begin{array}{c}\text { Width } \\
(\mathrm{ft})\end{array}$ & $\begin{array}{c}\text { Length } \\
(\mathrm{ft})\end{array}$ & $\begin{array}{c}\text { Eave Height } \\
(\mathrm{ft})\end{array}$ & $\begin{array}{c}\text { Roof Slope } \\
(\mathrm{deg} .)\end{array}$ \\
\hline \multirow{3}{*}{$1-1$} & NIST & 40 & 62.5 & 40 & 4.76 \\
\cline { 2 - 6 } & TPU & 52.5 & 78.7 & 39.4 & 4.76 \\
\hline \multirow{2}{*}{$1-2$} & NIST & 80 & 125 & 40 & 4.76 \\
\cline { 2 - 6 } & TPU & 52.5 & 131.2 & 39.4 & 4.76 \\
\hline
\end{tabular}

Case 1-1. Prototype dimensions and highlights of the roof and wall portions selected for comparison (indicated by red and black rectangles for the NIST and TPU models respectively) are shown in Figure 6.6. And the roof and wall portions selected for comparison, with their respective rows of taps selected for comparison within those portions are shown in Figure 6.7. Plots of the expectation of peak pressures for the roof and wall taps are shown in Figure 6.8 and Figure 6.9, respectively.
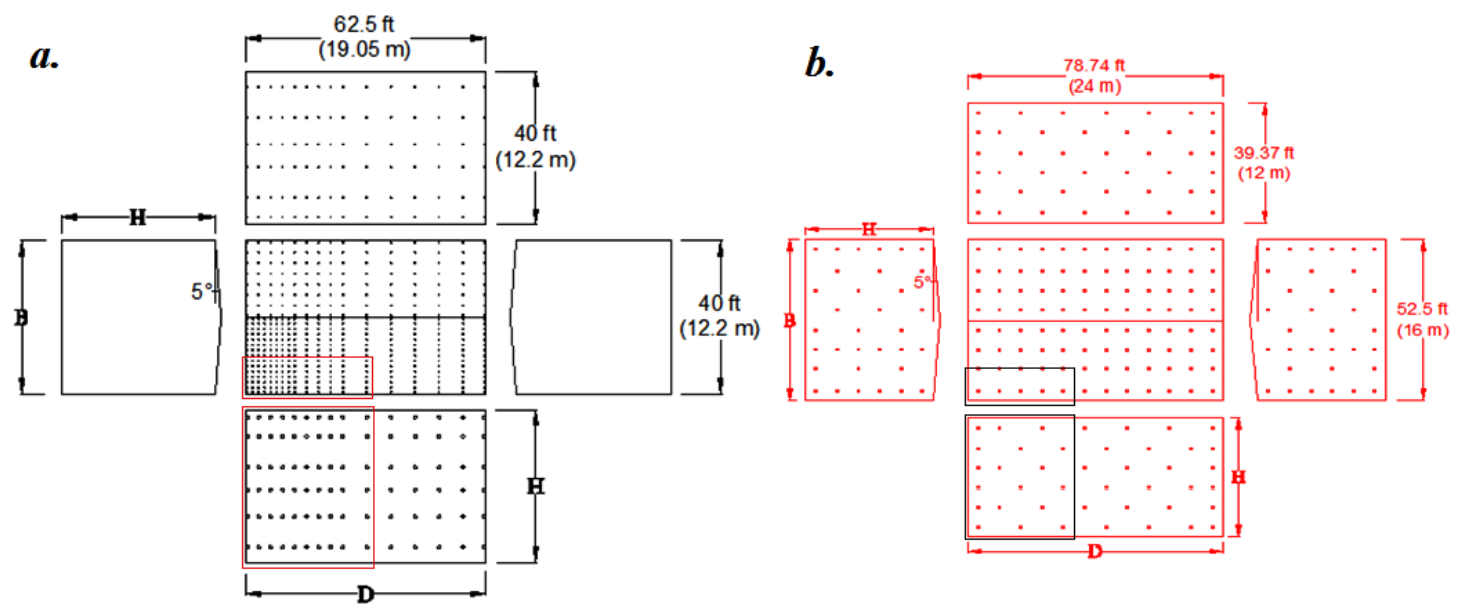

Figure 6.6 Exploded View: Buildings with Taps (Case 1-1), a. NIST and b. TPU. 
a.

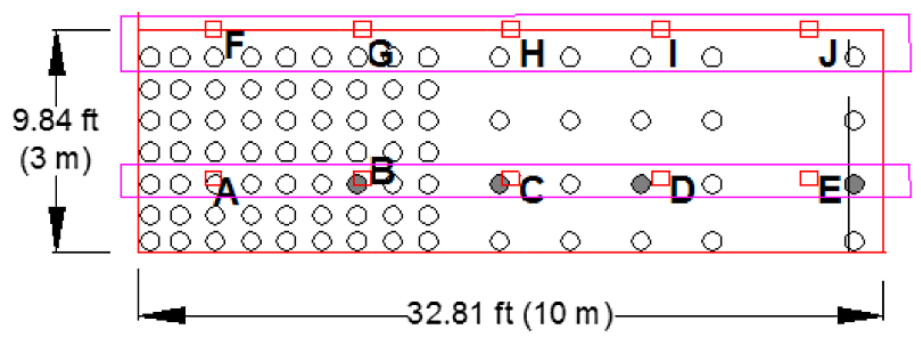

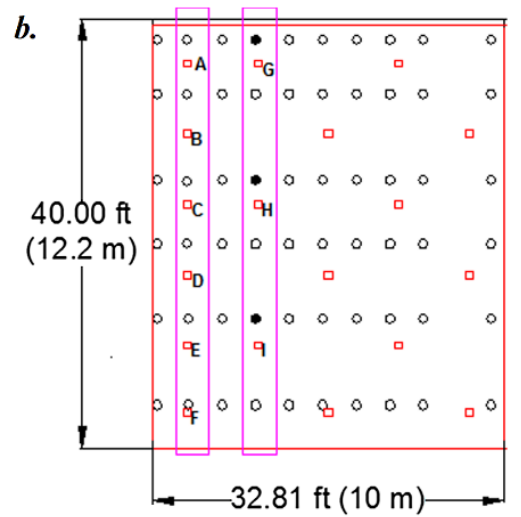

Figure 6.7 Details of Pressure Taps Selected for Comparison (Case 1-1), a. Roof and b. Wall.
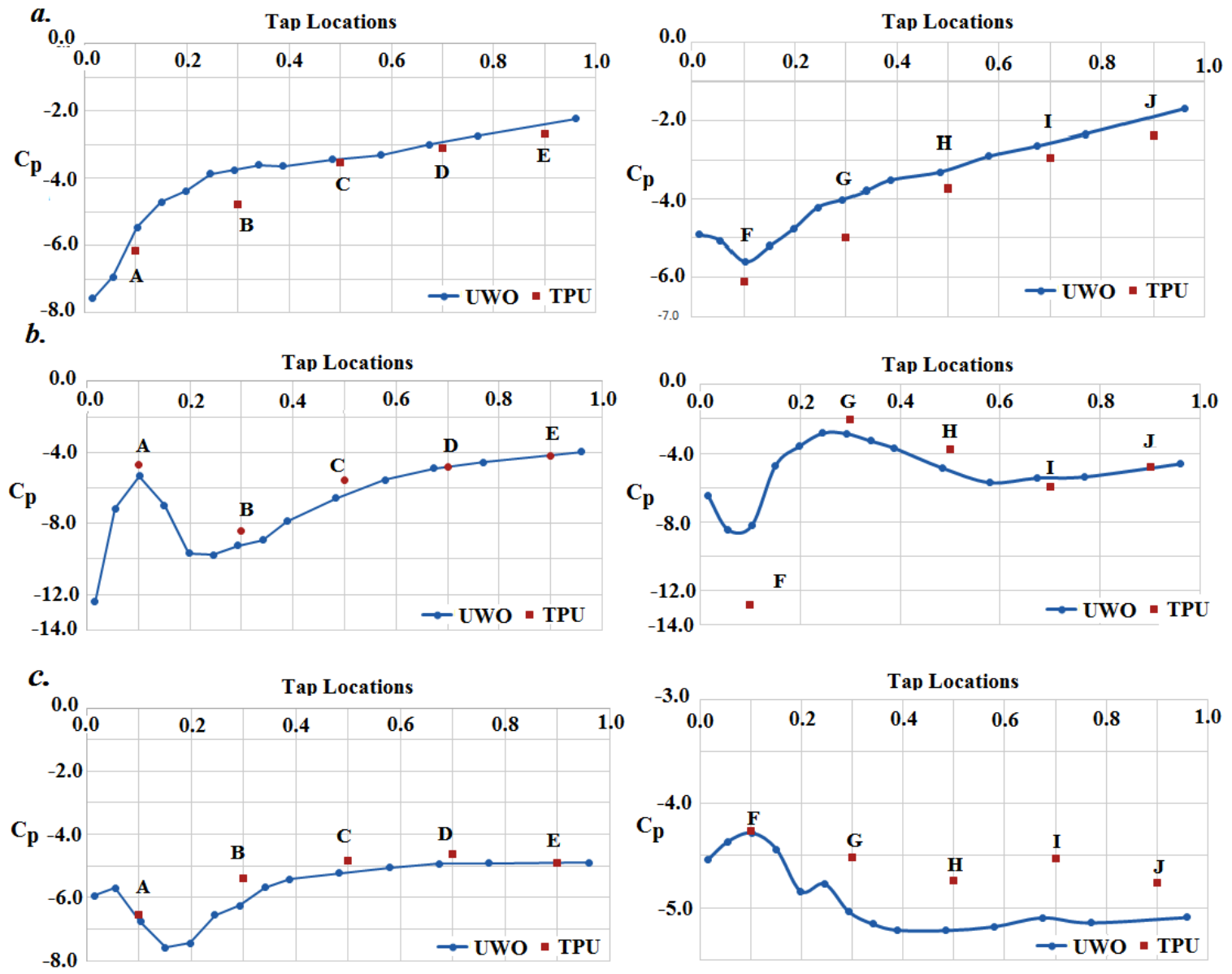

Figure 6.8 Expectation of Peak Pressure Coefficients (Case 1-1), a. 0 deg, b. 45 deg and c. $90 \mathrm{deg}$, roof. 

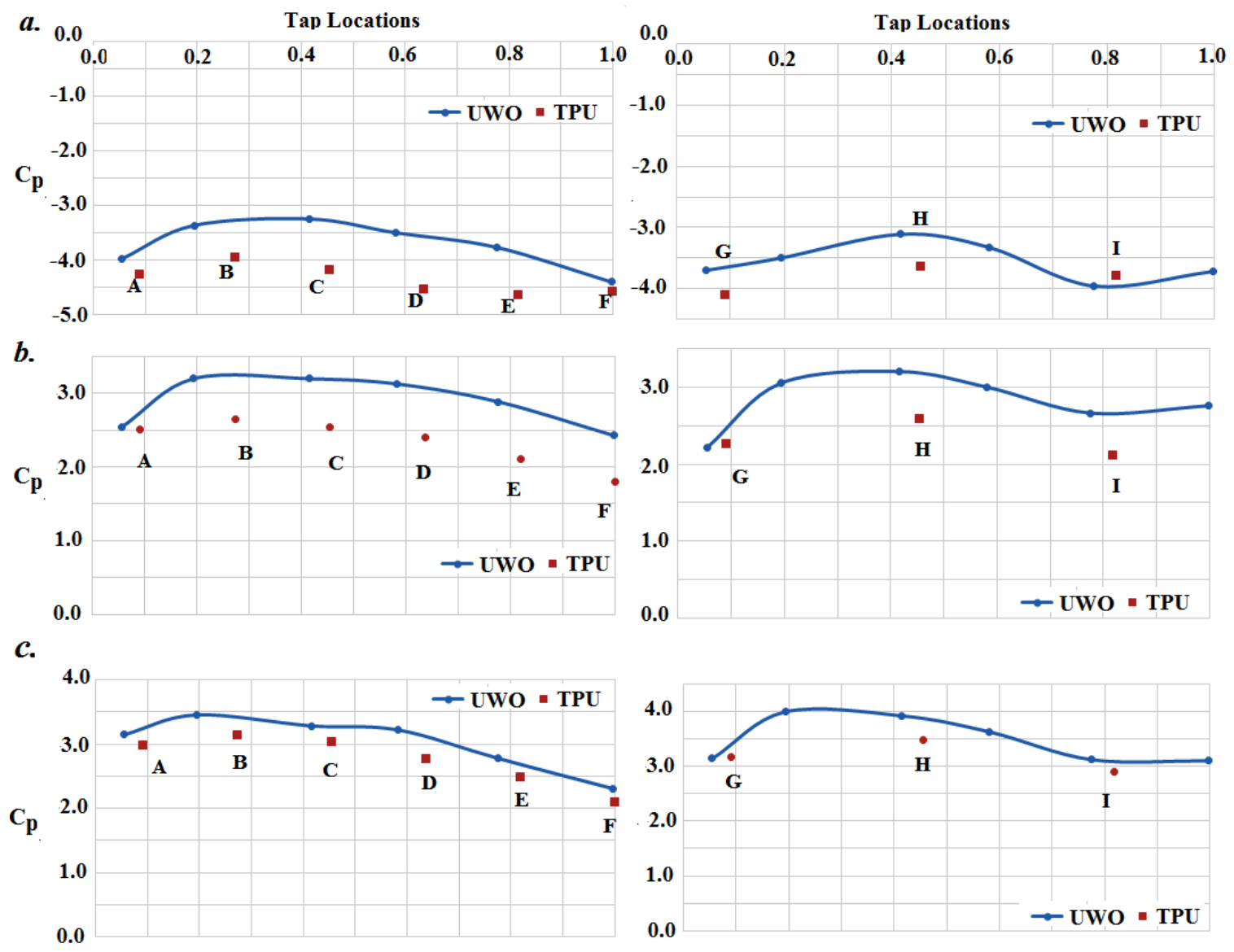

Figure 6.9 Expectation of Peak Pressure Coefficients (Case 1-2), a. 0 deg, b. 45 deg and c. $90 \mathrm{deg}$, wall.

Case 1-2. Prototype dimensions and highlights of the roof and wall sections selected for comparison (indicted by red rectangles in the NIST model and black rectangles in the TPU model) are shown in Figure 6.10. And the roof and wall portions selected for comparison, with their respective rows of taps selected for comparison are shown in Figure 6.11. NIST taps are indicated as circles and TPU taps are depicted in squares. Plots of the expectation of peak pressures for the roof and wall taps are shown in Figure 6.12 and Figure 6.13 respectively. 
a.

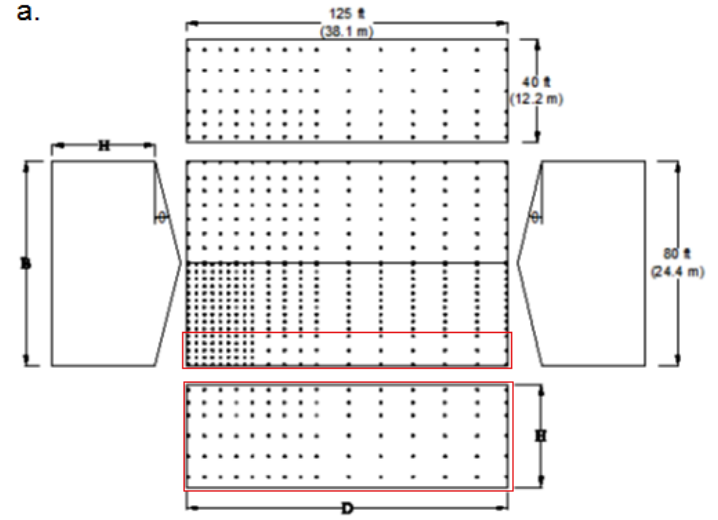

b.

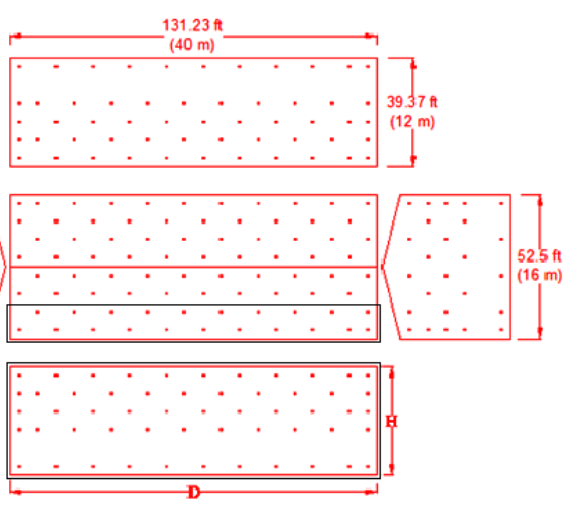

Figure 6.10 Exploded View: Buildings with Taps (Case 1-2), a. NIST and b. TPU.

a.

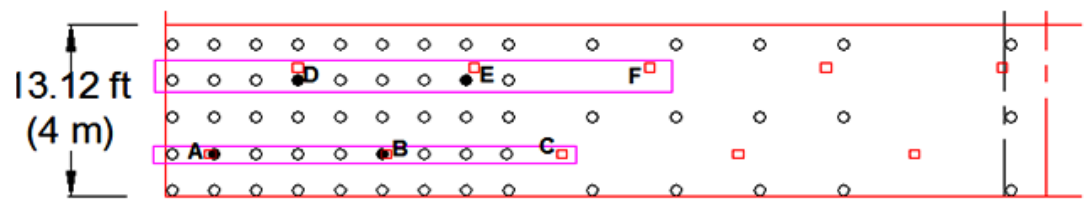

b.

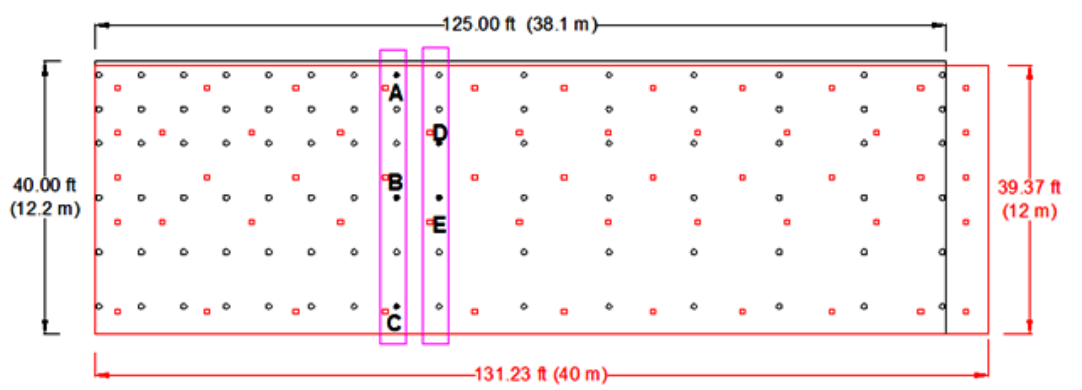

Figure 6.11 Details of Pressure Taps Selected for Comparison (Case 1-2), a. Roof and b. Wall 

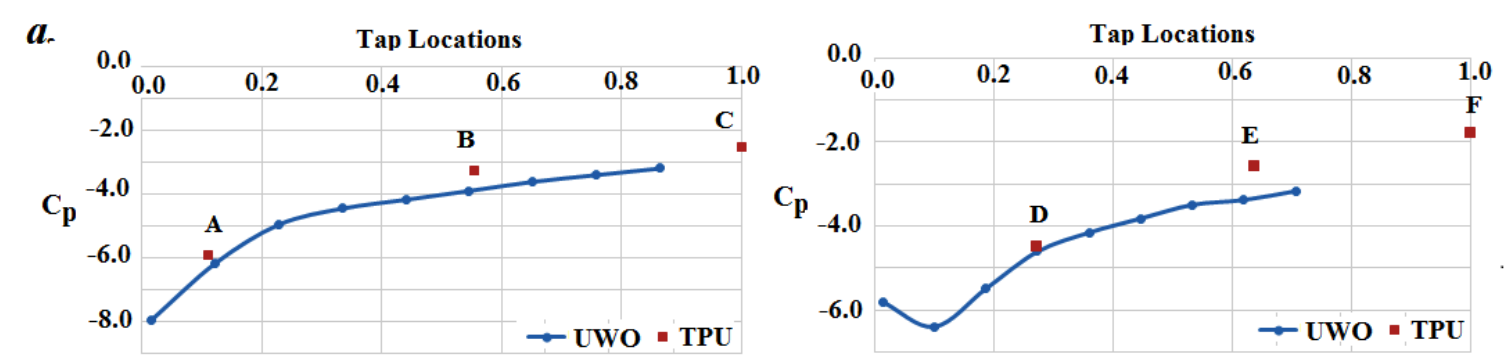

b.
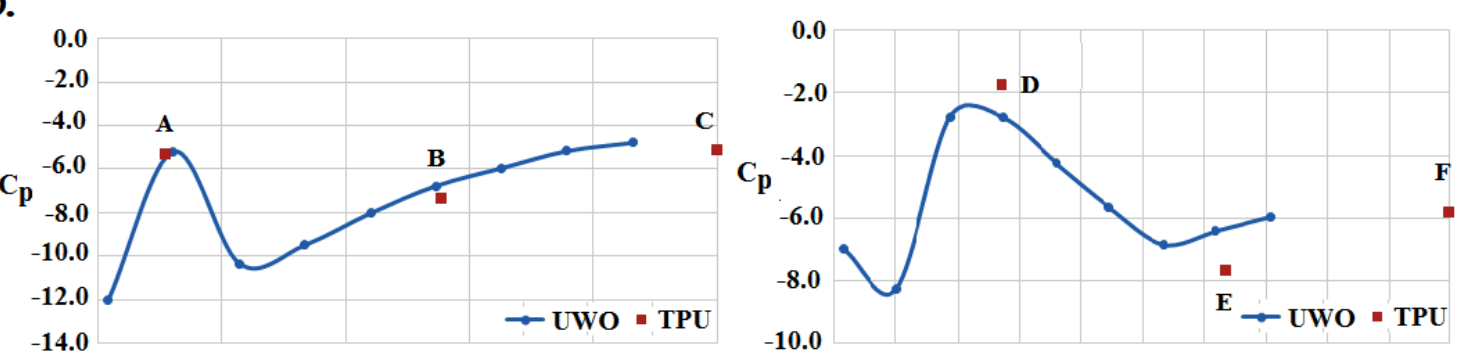

c.
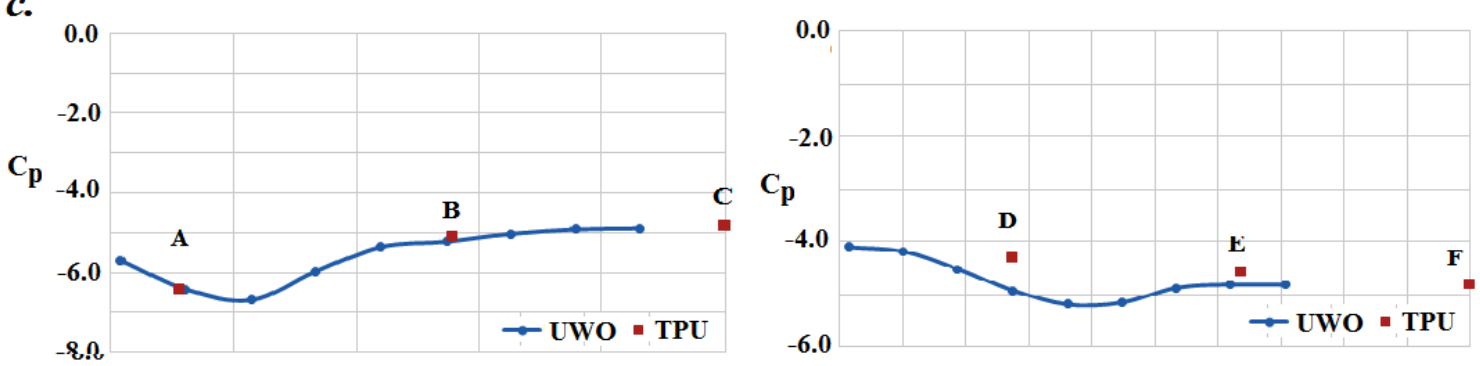

Figure 6.12 Expectation of Peak Pressure Coefficients (Case 1-2), a. 0 deg, b. 45 deg and c. $90 \mathrm{deg}$, roof. 

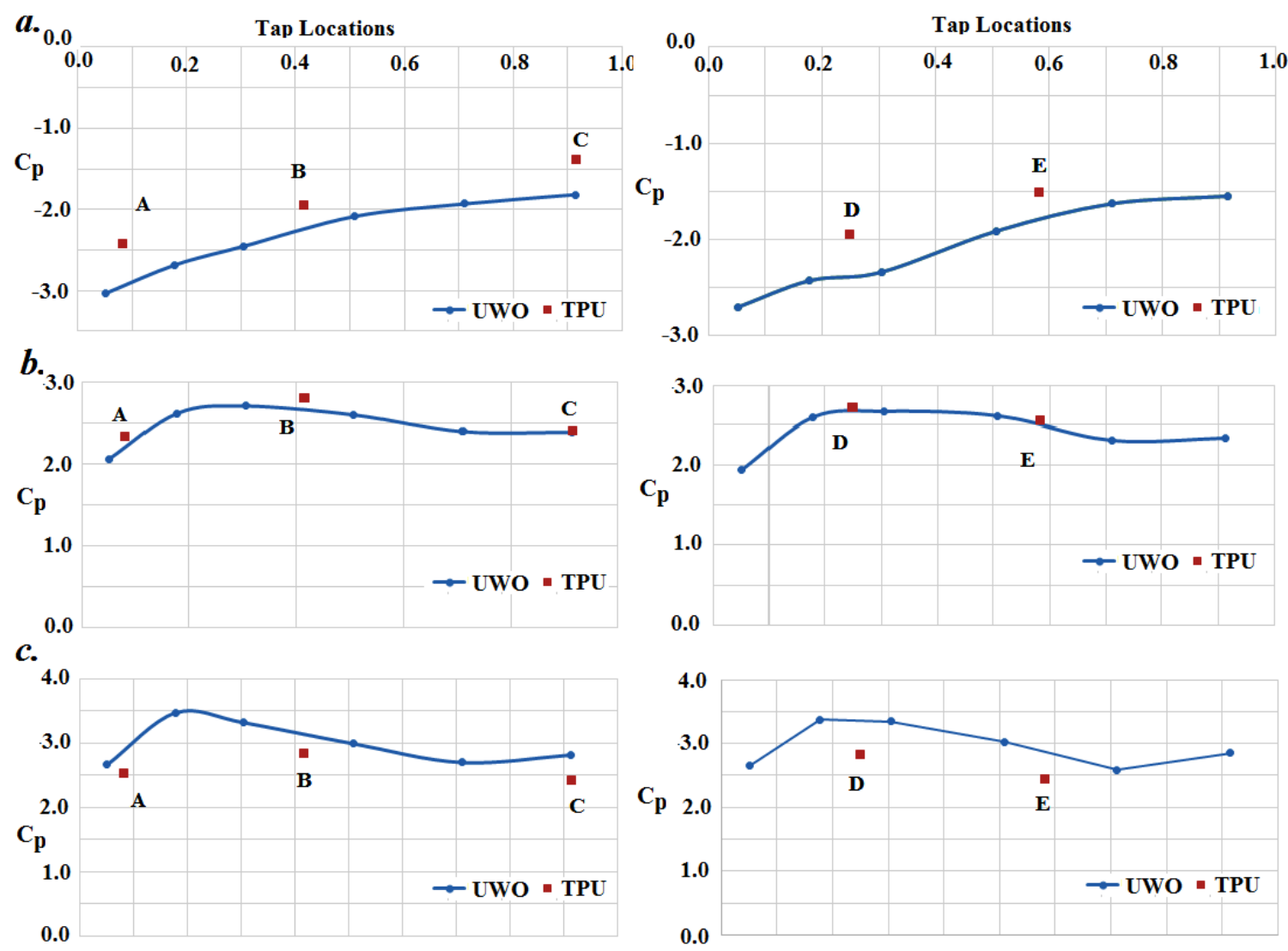

Figure 6.13 Expectation of Peak Pressure Coefficients (Case 1-2), a. 0 deg, b. 45 deg and c. $90 \mathrm{deg}$, wall.

For each wind direction, pressures at 30 TPU taps were compared to their NIST tap counterparts. The differences between the NIST- and TPU-based values, divided by the NIST values, were distributed as shown in Table 6.2. It can be seen that the absolute values of the differences were less than or equal to $15 \%$ in $82 \%$ of the cases. They were between $15 \%$ and 25 $\%$ in $11 \%$ of the cases, and larger than $25 \%$ in $7 \%$ of the cases; with only one exception the differences larger than $15 \%$ occurred for relatively low values of the pressures. Excluding one outlier (tap F, Figure 6.8), likely due to measurement or recording errors, in about one third of these cases the TPU pressures were higher than their NIST counterparts while in two thirds of the cases they were lower. These differences are much lower than those observed in Fritz et al. (2008). 
Table 6.2. Distribution of relative differences between TPU and NIST estimates of expected peak pressures.

\begin{tabular}{|l|c|c|c|c|}
\hline Differences & $<5 \%$ & $5 \%-15 \%$ & $15 \%-25 \%$ & $>25 \%$ \\
\hline Distribution & $51 \%$ & $31 \%$ & $11 \%$ & $7 \%$ \\
\hline
\end{tabular}

Note. The pressure at tap $\mathrm{F}\left(\theta=45^{\circ}\right)$ is an outlier likely due to a measurement or recording error.

\subsubsection{Comparison of Internal Frame Responses}

In addition to comparisons of pressures at individual ports, it is also necessary to compare wind-induced internal forces in the main-wind force resisting systems evaluated using the different databases. As mentioned earlier, the building dimensions present in the NIST and TPU aerodynamic databases were different, and this limited the number of building cases that could be used for comparison. Nonetheless, one building case was selected by emphasizing more on eave height, building width and roof slope. The NIST building model selected for comparison had the following dimensions: Width, $B=50 \mathrm{ft}$, Length, $L=100 \mathrm{ft}$, Eave height, $H=12 \mathrm{ft}$, Roof slope = $4.8 \mathrm{deg}$ and the TPU model has the following dimensions; $B=52.5 \mathrm{ft}, L=78.7 \mathrm{ft}, H=13.1 \mathrm{ft}$ and Roof slope $=5 \mathrm{deg}$. A frame spacing of $20 \mathrm{ft}$ was used in both buildings, and comparison was performed by assuming both models to be situated in suburban exposure. Plan view of the building models, orientation of the frames and wind directions used for comparison are shown in Figure 6.14. 


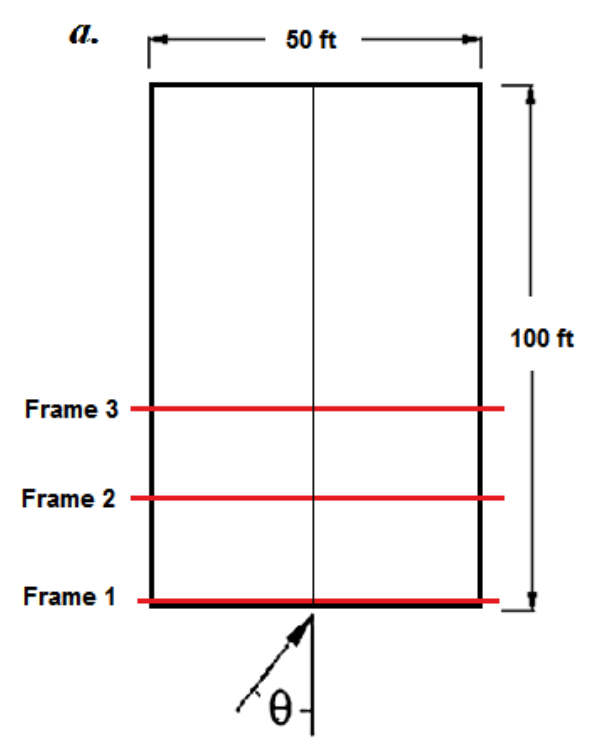

b.

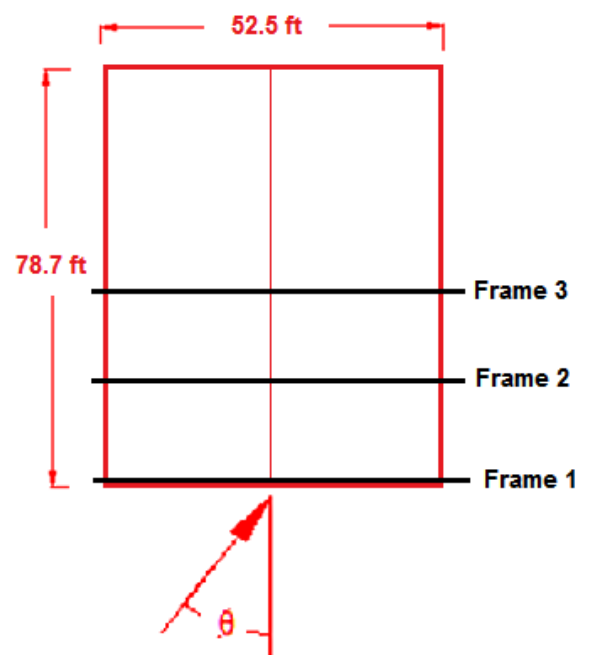

Figure 6.14 Plan View and Frame Layout of a. NIST and b. TPU Models Considered in Comparison

Expectations of peaks of the hourly bending moment coefficients, $C_{m},{ }_{p k}^{60 \mathrm{~min}}$ at left knee and ridge of frames 1, 2 and 3 were used for comparison. Peaks were estimated using the Sadek and Simiu (2002) translational peak estimation method. For the NIST database, 60 min duration peak was estimated from $60 \mathrm{~min}$ record length, and for the TPU database 60 min duration peak was estimated from 10 min record length. Hence, the peak moment coefficients for 60-min based on mean hourly wind speeds at mean roof height $h$ for NIST and TPU were obtained as follows:

$$
\begin{aligned}
C_{m_{p k, h}}^{N I S T, 60 \mathrm{~min}} & =\frac{M_{p k}^{N I S T, 60 \mathrm{~min}}}{\frac{1}{2} \rho\left(V_{\text {mean }, h}^{N I S T}\right)^{2} * B H^{2}} \\
C_{m_{p k, h}^{T P U, 60 \mathrm{~min}}}^{\text {N }} & =\frac{M_{p k}^{T P U, 60 \mathrm{~min}}}{\frac{1}{2} \rho\left(V_{\text {mean }, h}^{T P U}\right)^{2} * B H^{2}}
\end{aligned}
$$

where $M_{p k}{ }^{\text {NIST } 60 \mathrm{~min}}$ and $M_{p k}{ }^{\text {TPU }}{ }^{60 \mathrm{~min}}$ denote the hourly expectation of the peak moments for the NIST and TPU data respectively. Figure 6.15 shows the results of the comparison process, it can be seen that the absolute values of the differences between the peak moment coefficients were 
less than or equal to $15 \%$ in $70 \%$ of the cases, between $15 \%$ and $25 \%$ in $20 \%$ of the cases, and larger than $25 \%$ in $10 \%$ of the cases. Owing to the difference in geometrical dimensions of the compared buildings models, the results can be considered to be satisfactory.
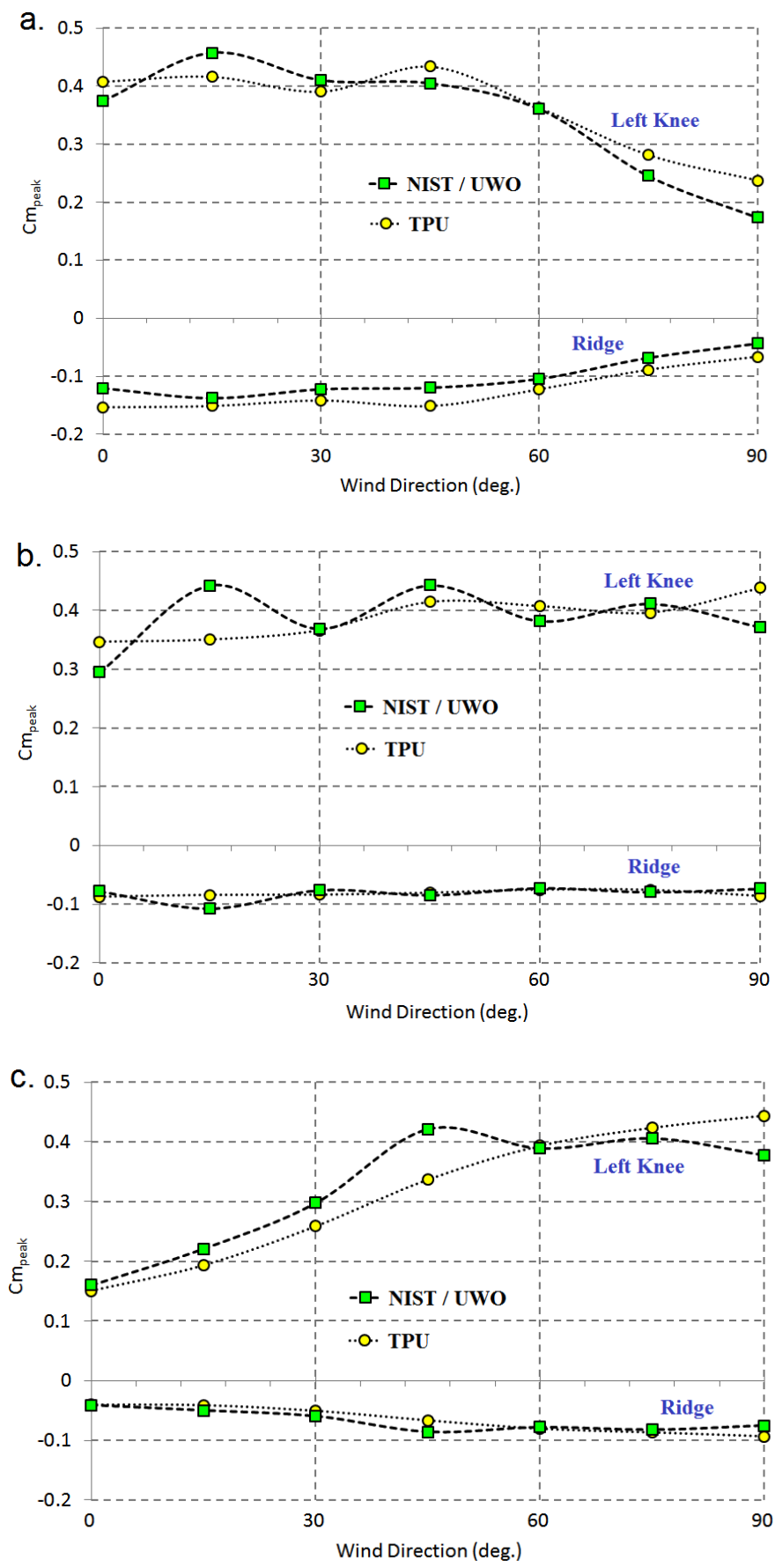

Figure 6.15 Peak Moment Coefficients, a. Frame 1, b. Frame 2 and c. Frame 3 


\subsubsection{Comparison of Demand-to-Capacity Index (DCI)}

Figure 6.16 shows comparisons of 700-yr DCIs computed using NIST and TPU databases. The calculation of DCIs was conducted using the method developed in Chapter 3. The NIST and TPU building used in the comparison are identical to those used in Section 6.3.2. Comparisons of DCIs were conducted for the end, first interior, and second interior frame, and a frame spacing of $20 \mathrm{ft}$ was used. The buildings were assumed to be located in Miami, FL. The assumed dead and roof-live loads are 2 psf and 20 psf, respectively. The frames supports were assumed to be pinned, and all the calculations were conducted for the "enclosed" building enclosure category. It can be seen that DCI values computed using the different databases produced comparable results.

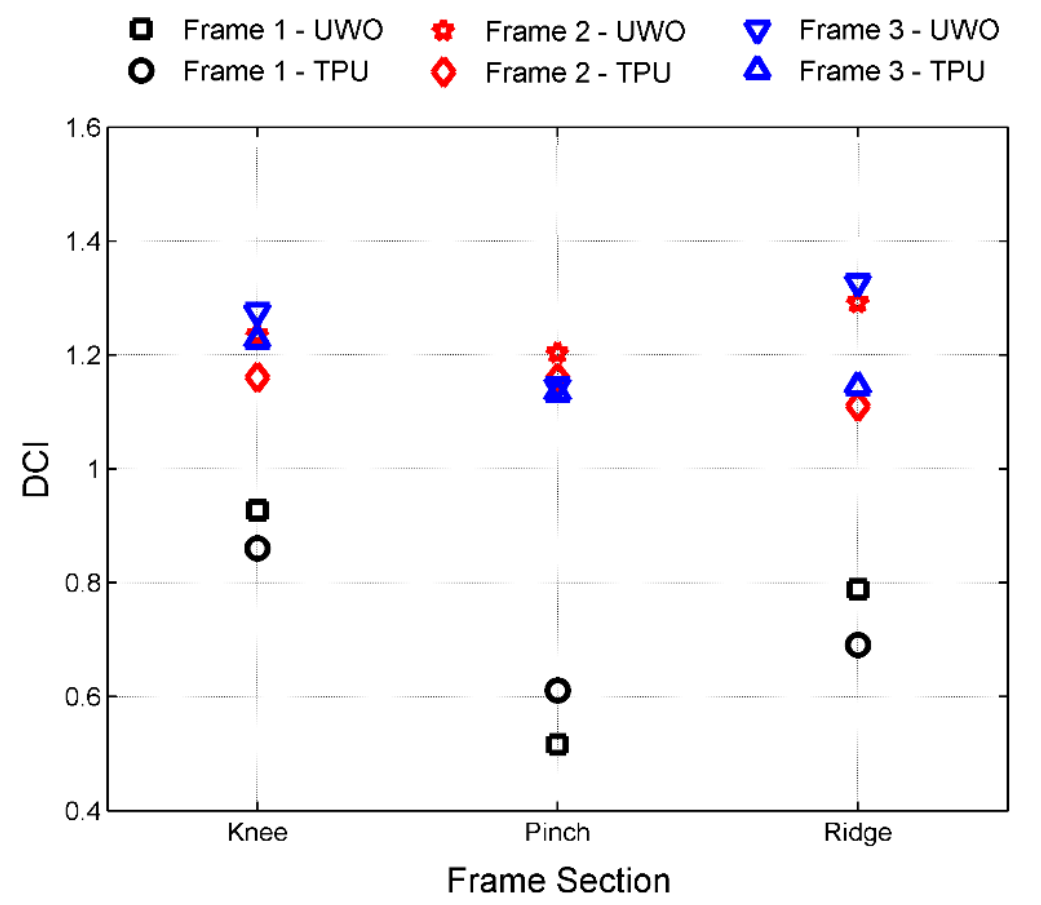

Figure 6.16 Comparison of DCI ${ }^{\mathrm{PM}} \mathrm{s}$ Calculated using NIST and TPU Databases

\section{Conclusions}

One of the main barriers to the use of DAD has been the lack of a sufficiently large aerodynamic database. Hence, in an effort to alleviate the lack of aerodynamic databases the current study (1) developed a novel time-history of responses interpolation scheme, allowing the 
estimation of time-histories of DCIs and design of buildings with dimensions not covered in the databases, and (2) provided a detailed comparison of the NIST and TPU aerodynamic databases to help assess the extent to which the respective aerodynamic databases are comparable.

In the first section of this chapter, a novel interpolation scheme capable of estimating timehistories of responses for a building of interest not available in an aerodynamic database, from models available in the database is presented. Interpolation of time-histories of responses is necessary for computing time-histories of DCIs which in turn is required for performing iterativedesign of frame members. The interpolation scheme uses Reynolds turbulence decomposition and linear interpolation. Comparisons of peak frame responses and DCIs computed using existing aerodynamic building models to those computed by interpolation from models with different dimensions was performed. The results showed that highly accurate estimates of frame responses can be obtained when interpolating between different heights. When interpolating between models with different roof slopes, the accuracy of the estimated frame responses tends to increase as the roof slope of the building of interest increases. Better DCI comparisons were attained at frames' knee and ridge sections than at frames' pinch.

In the second part of this chapter, pressure coefficients, internal frame responses and demand-to-capacity indexes (DCIs) based on the TPU database were compared to their NIST counterparts corresponding to approximately equivalent aerodynamic conditions. Estimated expected peak pressures were compared for 30 taps (three wind directions each). The absolute values of the differences were less than or equal to $15 \%$ in $82 \%$ of the cases, and in most cases the differences larger than $15 \%$ occurred for relatively low values of the pressures. Excluding one outlier, likely due to measurement or recording errors, in about one third of these cases the TPU pressures were higher than their NIST counterparts while in two thirds of the cases they were lower. The differences between the compared peak moment coefficients were less than or equal to $15 \%$ in $70 \%$ of the cases; between $15 \%$ and $25 \%$ in $20 \%$ of the cases, and larger than 
$25 \%$ in $10 \%$ of the cases. Comparisons were also made between DCIs, at the knee, pinch and ridge sections of three building frames. Despite the fact that buildings with different dimensions were used, comparable values of DCIs were obtained. The differences between pressures and between forces are considerably lower than typical differences inherent in other existing sets of comparisons published in the literature. Hence, the results of the comparisons suggest that, to within differences we regard as tolerable, the TPU and NIST databases are reasonably equivalent for practical engineering purposes.

Reference

ASCE 7-10. (2010). Minimum design loads for building and other structures. American Society of Civil Engineers, Reston, VA.

Chen, Y., Kopp, G. A., and Surry, D. (2003a). "Prediction of pressure coefficients on roofs of low buildings using artificial neural networks." Journal of wind engineering and industrial aerodynamics, 91(3), 423-441.

Chen, Y., Kopp, G. A., and Surry, D. (2003b). "Interpolation of pressure time series in an aerodynamic database for low buildings." Journal of Wind Engineering and Industrial Aerodynamics, 91(6), 737-765.

Fritz, W. P., Bienkiewicz, B., Cui, B., Flamand, O., Ho, T. C., Kikitsu, H., Letchford, C. W., and Simiu, E. (2008). "International comparison of wind tunnel estimates of wind effects on low-rise buildings: Test-related uncertainties.” Journal of structural engineering, 134(12), $1887-1890$.

Gavalda, X., Ferrer-Gener, J., Kopp, G. A., and Giralt, F. (2011). "Interpolation of pressure coefficients for low-rise buildings of different plan dimensions and roof slopes using artificial neural networks." Journal of wind engineering and industrial aerodynamics, 99(5), 658-664.

Irwin, P. A. (2009). "Wind engineering research needs, building codes and project specific studies." 11th Americas conference on wind engineering.

Kopp, G. A., and Chen, Y. (2006). "Database-assisted design of low-rise buildings: aerodynamic considerations for a practical interpolation scheme." Journal of structural engineering, 132(6), 909-917.

Main, J. A. (2007). "Interpolation procedures for database-assisted design.” Proc., 12th Int. Conf. on Wind Engineering, 1-6.

Main, J. A., and Fritz, W. P. (2006). Database-assisted design for wind: concepts, software, and examples for rigid and flexible buildings. National Institute of Standards and Technology, Technology Administration, US Department of Commerce. 
Sadek, F., and Simiu, E. (2002). "Peak non-Gaussian wind effects for database-assisted low-rise building design." Journal of Engineering Mechanics, 128(5), 530-539. 


\title{
7. REDUCTION OF AERODYNAMIC DATA VOLUME AND COMPUTATIONAL TIMES FOR DATABASE-ASSISTED DESIGN CALCULATIONS
}

\begin{abstract}
Whether they are obtained by laboratory testing or by Computational Fluid Dynamics techniques, aerodynamic pressure data sets required for Database-Assisted Design purposes are typically very large. Techniques for the estimation of wind effects based on such data sets are currently closer to being used in design offices. It is therefore of interest to explore the possibility of reducing the volume of aerodynamic data and computation times without compromising the validity of the results being sought. This study examines the effectiveness of the following four (two transformational and two direct) simple methods of aerodynamic data volume and computation time reductions: (1) using discrete Frequency transform for data compression; (2) using discrete wavelet transform for data compression; (3) reducing the length of the time series data; (4) reducing the data sampling rate. The investigation is limited to Main Wind Force Resisting Systems in rigid buildings. The transformational compression methods are effective in reducing the volume of stored data (specially the Fourier transform approach). However, the reconstructed time series has the same length as the original time series. Therefore the translational methods of compression offers no advantage in terms of computation time reduction. The reduction in the volume of data and computation time can be achieved with acceptably small loss of information by the sampling rate reduction method, which is more effective than the record length reduction method. Moreover, higher compression can be achieved using the sampling rate reduction method by modifying the peak estimation methods (for instance adjusting the mean upcrossing rate in translational methods of peak estimation).
\end{abstract}




\subsection{Introduction}

Whether they are obtained by wind tunnel testing, testing in large-scale facilities, or by Computational Fluid Dynamics techniques, aerodynamic pressure datasets required in estimation of wind effects or in performing designs of frame members using Database-Assisted Design (DAD) procedures are typically very large. While the issue of data storage is becoming less and less important, large datasets typically imply large volumes of calculations. For some building types, pressures are measured at hundreds of taps. For a one-story typical industrial building model with a main wind force resisting system (MWFRS) consisting of portal frames, the size of the data set measured at the University of Western Ontario (UWO) is of the order of 1.5GB per building model. Structural calculations based on the use of aerodynamic data sets need to be performed, for each of at least 16 wind directions, for hundreds or in the case of large structures, for up to tens of thousands of member cross sections. In addition, if the dimensions of the building being considered are different from the dimensions of the buildings covered in the database, the volume of calculations is significantly increased by the operations required for interpolations. Therefore, as techniques for estimating wind effects based on large sets of aerodynamic data are maturing, it is of interest to explore the possibility of reducing the volume of such data, and the computation times inherent in that volume, without compromising the accuracy of the results being sought.

For large-scale aerodynamic facilities, the high cost of testing is an important issue, and records of short duration are therefore desirable for reasons of economy. This issue was first addressed by $\mathrm{Fu}$ et al. (2012) and continues to be the object of similar studies at Florida International University (FIU). The investigation presented in this chapter is limited to Main Wind Force Resisting Systems (MWFRS) of rigid buildings. Its purpose is to examine the effectiveness of different methods of aerodynamic data volume and computation time reductions for application in DAD. One of the main advantages of the DAD methodology is it produces 
highly accurate responses by maintaining the phase similarity between pressures measured by different pressure taps on a model. An efficient data volume reduction method applicable to DAD should also maintain the phase similarity between different taps.

Data compression methods are either lossy or lossless in nature. Most time-series data compression methods are lossy and mainly fall into two groups; (i) direct methods, in which the actual time histories are analyzed (in time domain), and (ii) transformational methods, in which the time histories are transformed and energy or spectral analysis is performed. Direct methods are superior in terms of simplicity, but transformational methods usually achieve higher compression (Oinam et al. 2013). In this study, the efficiencies of two transformational methods (i.e. data compression using discrete Fourier transforms and discrete wavelet transforms), and two direct methods (i.e. data compression by reducing the data record length, and by reducing the data sampling rate) in reducing data volumes of aerodynamic datasets and computation times of DAD calculations are investigated. In a first set of calculations, the four methods are applied to the original time series (i.e., the full time series contained in the NIST database). In a second set of calculations the four methods are applied to time series obtained from the original time series by following a Tokyo Polytechnic University moving average procedure described subsequently in the paper. Time series so obtained are referred to as moving-averaged time series.

The time series being considered in this work consist of wind pressure coefficients measured on a 1:100 model of an industrial gable roof building with dimensions $120 \mathrm{ft} \times 187.5 \mathrm{ft} \times 18 \mathrm{ft}$ (eave height) and $4.76 \mathrm{deg}$ roof slopes, and are available in the NIST aerodynamic database. Details on the tests that yielded the data are available in Ho et al. (2003). The duration of the time series is $100 \mathrm{~s}$, and the sampling rate is $500 \mathrm{~Hz}$. The velocity scale is of the order of 1:3, meaning that the prototype duration of the record corresponding to its 100 -s model duration is of the order of one hour. Time series of the bending moment at the upwind bent, and of the axial force in the upwind column, were obtained for frames 2 and 5 (Figure 7.1), by using the DAD based 
MATLAB software windPRESSURE (Main and Fritz 2006), from the time series of the taps tributary to those frames. The loss of information inherent in the data volume reduction methods were then assessed using ratios of expected peak response estimates computed using compressed reduced time series to those estimated using the original time series. A similar measure is applied to the moving-averaged time series. Expectations of peaks are estimated using the software listed on www.nist.gov/wind, item IIIB. The software implements a translational approach to estimating peaks of time series with non-Gaussian marginal distributions wherein the estimates of peaks are obtained under the assumption that those distributions are Gaussian, and are then subjected to non-linear mappings from Gaussian to non-Gaussian distributions (Sadek and Simiu 2002). Alternative procedures for estimating peaks are available and may be used as needed.

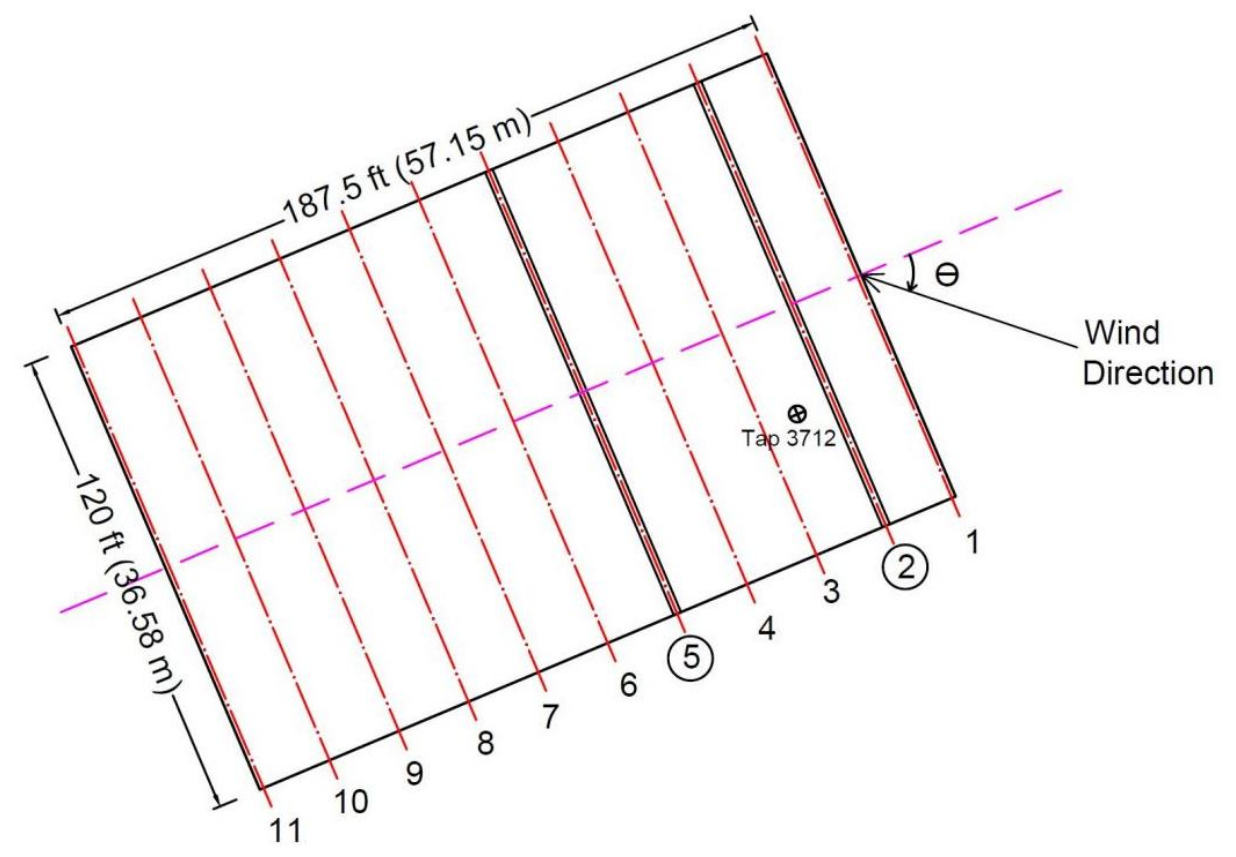

Figure 7.1 Plan view of the building

As stated in Chapter 6, pressures and frame responses evaluated using aerodynamic wind tunnel data are strongly dependent on the laboratory in which the tests were conducted. This was shown in the comparison performed between peak moments at portal frame knees evaluated using pressure measurements conducted at six wind tunnel laboratories by Fritz et al. (2008). Even for 
the same wind-tunnel laboratory, values of frame responses might vary within each run, and between runs. As pointed out by Possolo et al. (2009) the between runs variability provides a standard against which one should assess the severity of any loss of data due to compression, and an error of around $5 \%$ due to data compression can be considered acceptable.

The following sections present and discuss the data volume reduction procedures, results of the calculations, and conclusions based on those results. Note that the level of data volume reduction is evaluated based on the ratio of number of data points in the original data to those in the compressed data, and not based on the disk size (note that disk size can vary depending on several factors including type of variable and the file saving format).

\subsection{Data Volume Reduction Based on Original Time Series}

As was noted earlier, the original time series are 100-s long and sampled at a rate of $500 \mathrm{~Hz}$.

\subsubsection{Data Compression using Transformational Methods}

\subsubsection{Discrete Fourier Transform}

The Fourier transform is used to convert data from the time domain into frequency domain. Data transformed into the frequency domain are characterized by vectors of complex number coefficients, with each coefficient having an amplitude and a phase component. The Fourier transform, $F_{n}$, of a discrete time series function, $f(t)$, (where the $k^{\text {th }}$ element of the function is represented as $f_{k}$ ) with $N$ number of elements can be written as

$$
F_{n}=\sum_{k=0}^{N-1} f_{k} e^{-2 \pi i n k / N}
$$

The fast Fourier transform $(f f t)$ is a very efficient discrete Fourier transform algorithm which reduces the number of computations needed for a data with $N$ points from $2 N^{2}$ to $2 N \log _{2} N$ (Weisstein 2015). In this discrete Fourier transform based data compression method, data volume reduction is achieved by only retaining the complex coefficients whose magnitudes are larger than a suitably chosen threshold. The compression procedure consists of the following steps; 
(i) The discrete Fourier transform of the pressure time history is computed using the fft algorithm without windowing or averaging (assuming a sampling frequency of $1 \mathrm{~Hz}$ ). $f f t$ then produces a vector of complex coefficients with length equal to the original time-series data, wherein the first coefficient is a real number which represents the first moment of the data, and the remaining half of the coefficients are complex conjugates of the other half (in a symmetrical about a mid-point format). Hence it is only needed to store the first $N / 2+1$ coefficients.

(ii) A threshold is then set as the $\alpha^{\text {th }}$ percentile of the magnitudes of the remaining $N / 2+1$ complex coefficients, where $\alpha$ represents the desired percentage of compression.

(iii) All the coefficients with magnitudes less than the threshold of step (ii) are set to zero.

(iv) Finally only the non-zero coefficients and their indexes are stored.

The indexes of the non-zero coefficients are important for correct reconstruction of the compressed data. Once reconstructed, the inverse Fourier transform algorithm, ifft is applied to return the data into time-domain. For instance if a time-series has 1000 elements applying the $f f t$ algorithm produces 1000 complex coefficients, but we only need to keep the first 501 coefficients. Compression of around $90 \%$ can be then achieved by removing all but the 51 coefficients with largest magnitudes and their 51 indexes. Figure 7.2 shows amplitudes of the complex coefficients for time history of pressure data from tap 3712 (Figure 7.1), at different levels of compression. 

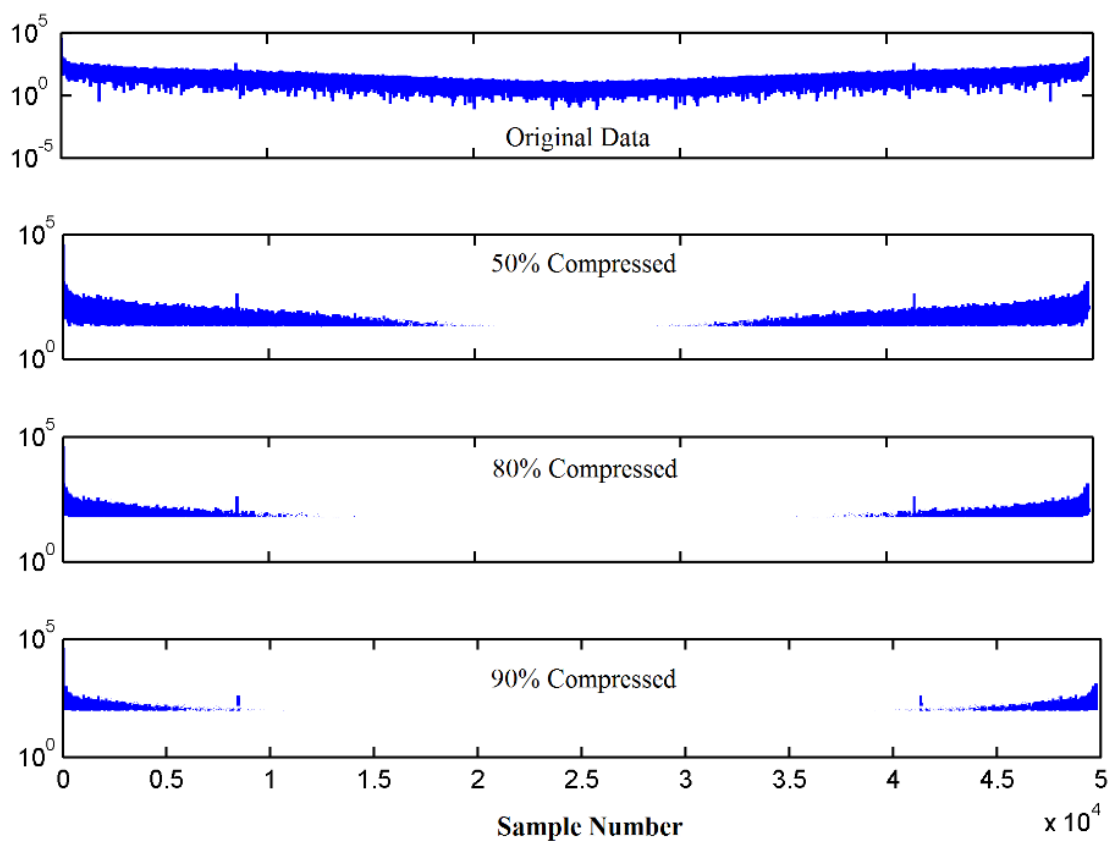

Figure 7.2 Amplitudes of Fourier Complex Coefficients at Different Levels of Compression

\subsubsection{Discrete Wavelet Transform}

A wavelet is a finite duration waveform which has an average value of zero. While the Fourier analysis consists of breaking up a signal into sine and cosine waves of various frequencies, wavelet analysis is the breaking up of a signal into shifted and scaled versions of the original (or mother) wavelet. Wavelet analysis has the capability of keeping the time information which is typically lost when transferring a time-series in to a frequency domain using Fourier analysis. Hence, wavelets are considered especially superior in dealing with non-stationary signals. The discrete wavelet transform of time-series data is defined by a mother wavelet and $N$ coefficients, where $N$ is equal to the length of the time-series data. In discrete wavelet transform, a data is decomposed into a wavelet smooth $(s 1)$ and a wavelet detail $(d 1)$, the wavelet smooth, $s 1$ is further divided in to another wavelet smooth $(s 2)$ and wavelet detail $(d 2)$, and the decomposition is repeated $l-2$ times, where $l$ represents the selected level of details. Figure 7.3 shows portions of reconstructed wavelet smooth and 3 levels of wavelet detail for pressure coefficients recorded on pressure tap 3712 (Figure 7.1). 

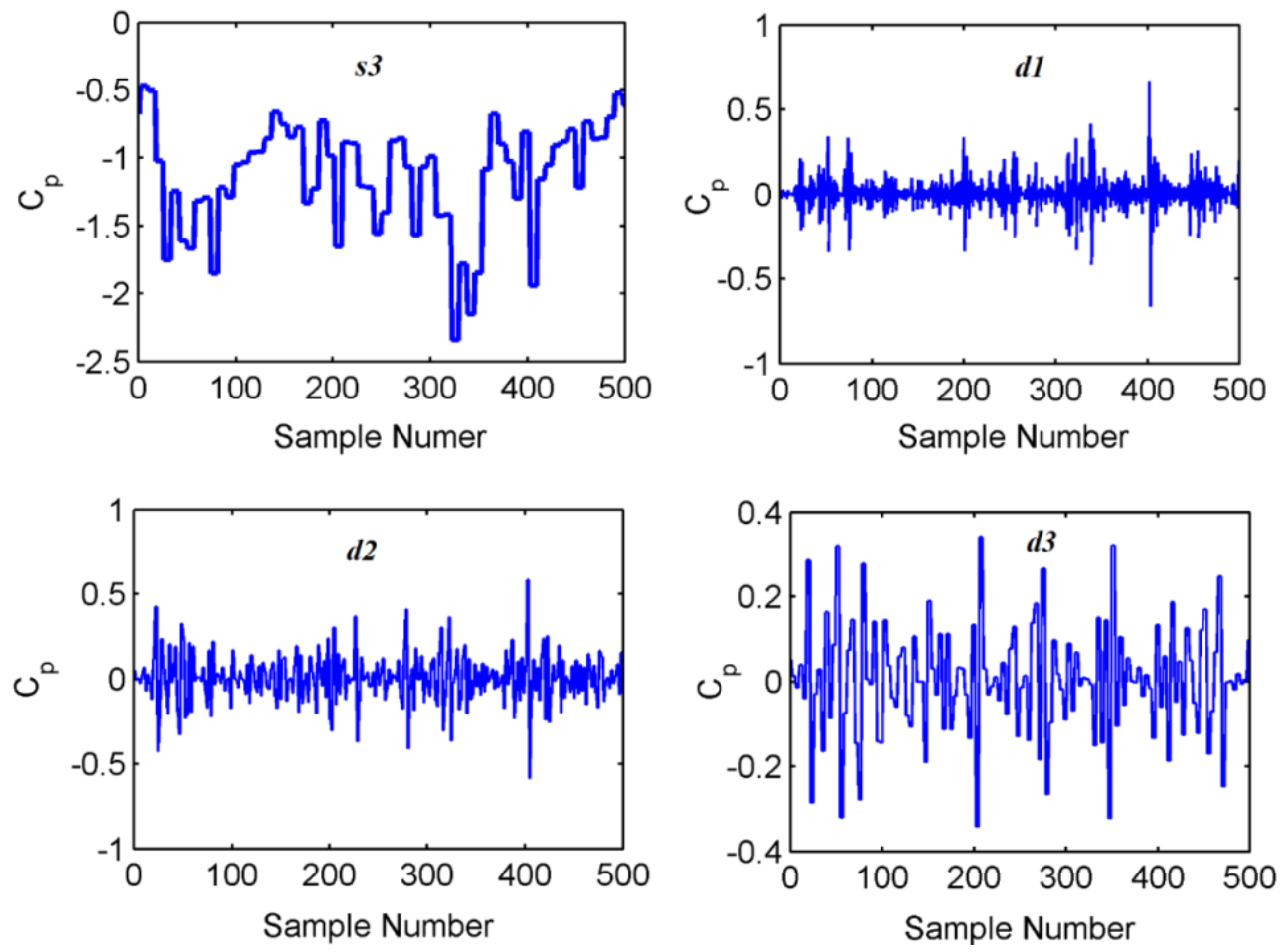

Figure 7.3 Multi-Level Discrete Wavelet Transformation

In this discrete wavelet transform ( $d w t)$ based compression method, data volume reduction was achieved by removing all wavelet coefficients whose absolute values were smaller than a suitably chosen threshold. This approach of compressing time histories of bluff low-rise building aerodynamic pressure coefficients was previously applied by Possolo et al. (2009), and a very similar procedure was followed here. The compression procedure consisted of the following steps;

(i) The discrete wavelet transform of the time history is computed,

(ii) A threshold is set as the $(100+\alpha) / 2$ th percentile of the absolute values of the wavelet coefficients, where $\alpha$ represents the percentage of compression

(iii) All wavelet coefficients whose absolute values are less than the threshold are set to zero,

(iv) Finally only the non-zero wavelet coefficients and their indexes are stored. 
For instance if the original data has 1000 elements, $90 \%$ compression can be achieved by removing all but the 50 absolute largest wavelet coefficients and their 50 indexes. The mother wavelet selected for the analysis was the Daubechies least asymmetric wavelet LA (20), found by Possolo et al. (2009) to outperform many other alternatives in a comparative study that assessed the maximum absolute error and the root mean square error in the reconstructions produced for a 90\% compression ratio. Periodic boundary conditions and 1 "smooth" and 9 levels of "detail" were used throughout. For full details, including software listing, see Possolo et al. (2009). Figure 7.4 is an example of the loss of information inherent in the wavelet compression method for various compression levels.

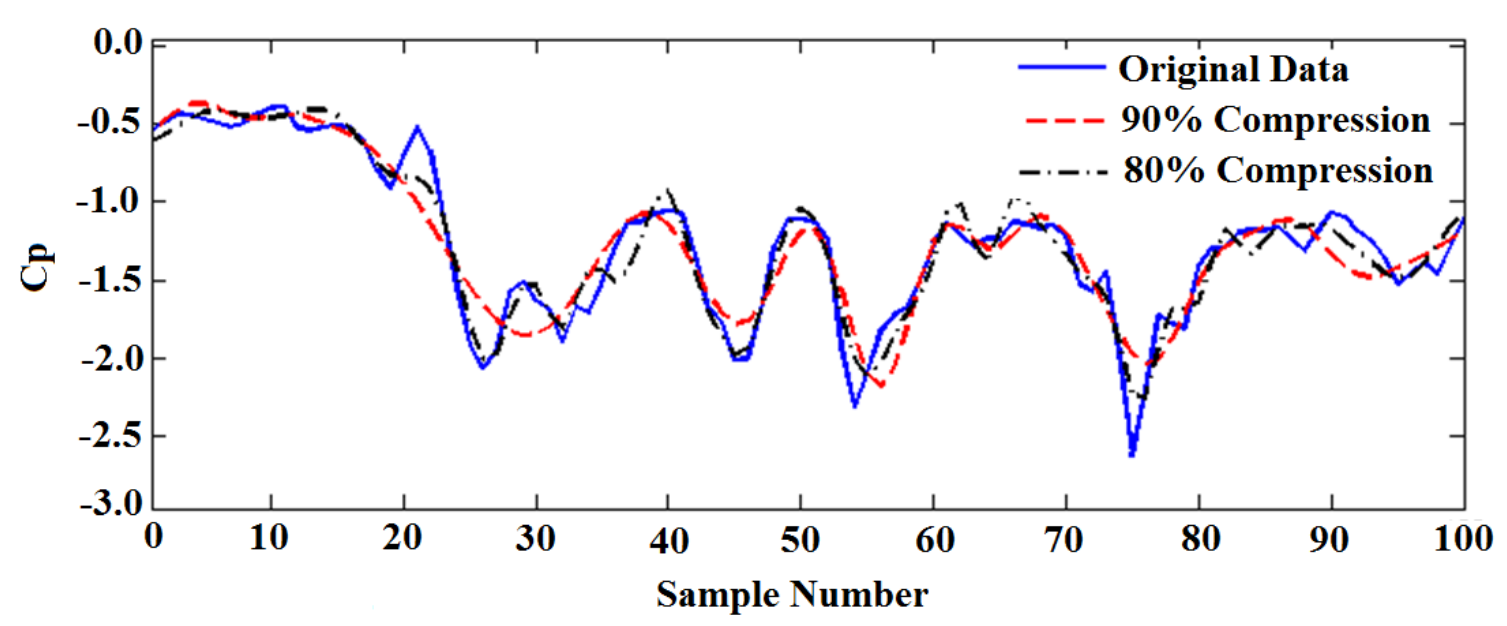

Figure 7.4. Comparison of Original Pressure Time Series to $d w t$ Compressed Time Series, Tap 3712

\subsubsection{Assessment of Efficiency of the Transformational Compression Methods}

To assess the effectiveness of the $f f t$ and $d w t$ based data compression techniques when applied to DAD, time-histories and peak structural responses evaluated using those compression techniques were compared to those evaluated using the original time series. Figure 7.5 compares response time histories evaluated using original and $90 \%$ compressed data. The selected response is bending moment at the left knee of Frame 2, at $45 \mathrm{deg}$ wind direction. The superiority of the fft based compression method is evident. 


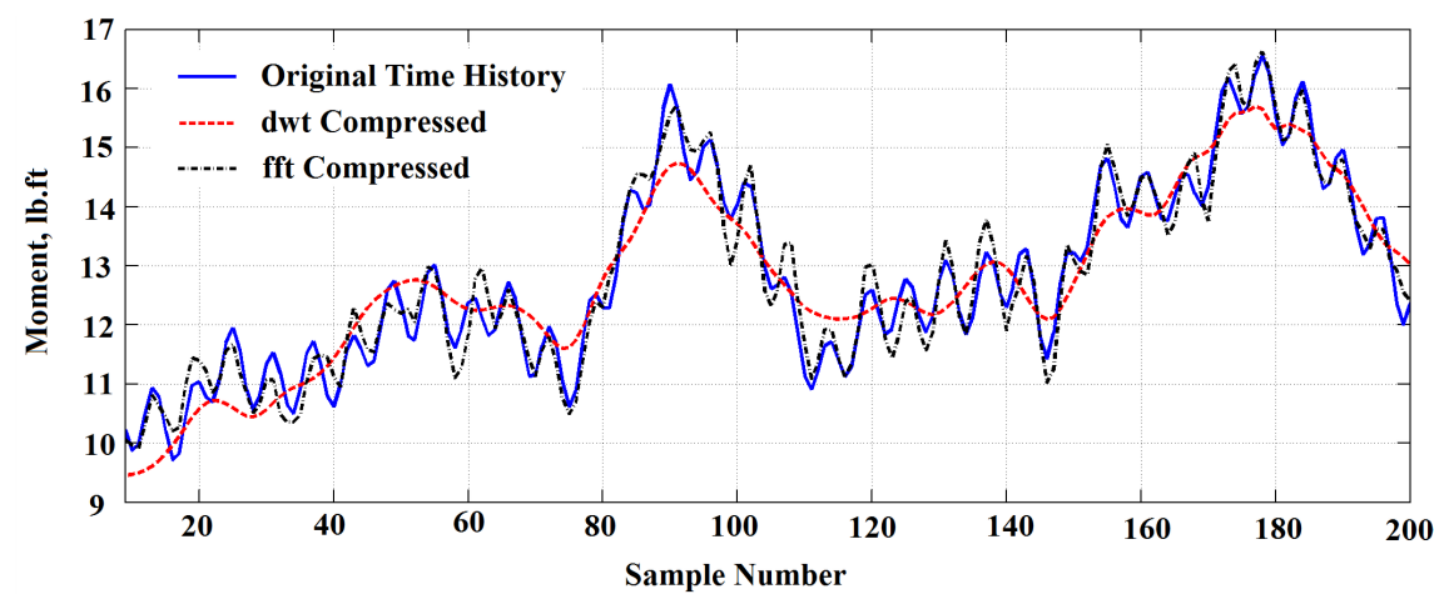

Figure 7.5 Comparison of Moment Evaluated Using Original Time Series and Compressed Data

Figure 7.6 shows ratios of peaks estimated using $90 \%$ compressed data to peaks estimated using original data for various wind directions, in open and suburban terrain exposures. It can be seen that for the same level of data compression (i.e. $90 \%$ ), the respective underestimates of peak responses computed using the $d w t$ compressed data are higher than those computed using the fft compressed data. The results obtained by using $90 \% d w t$ compression are unsatisfactory, while those obtained using $90 \% f f t$ compression can be considered satisfactory. 

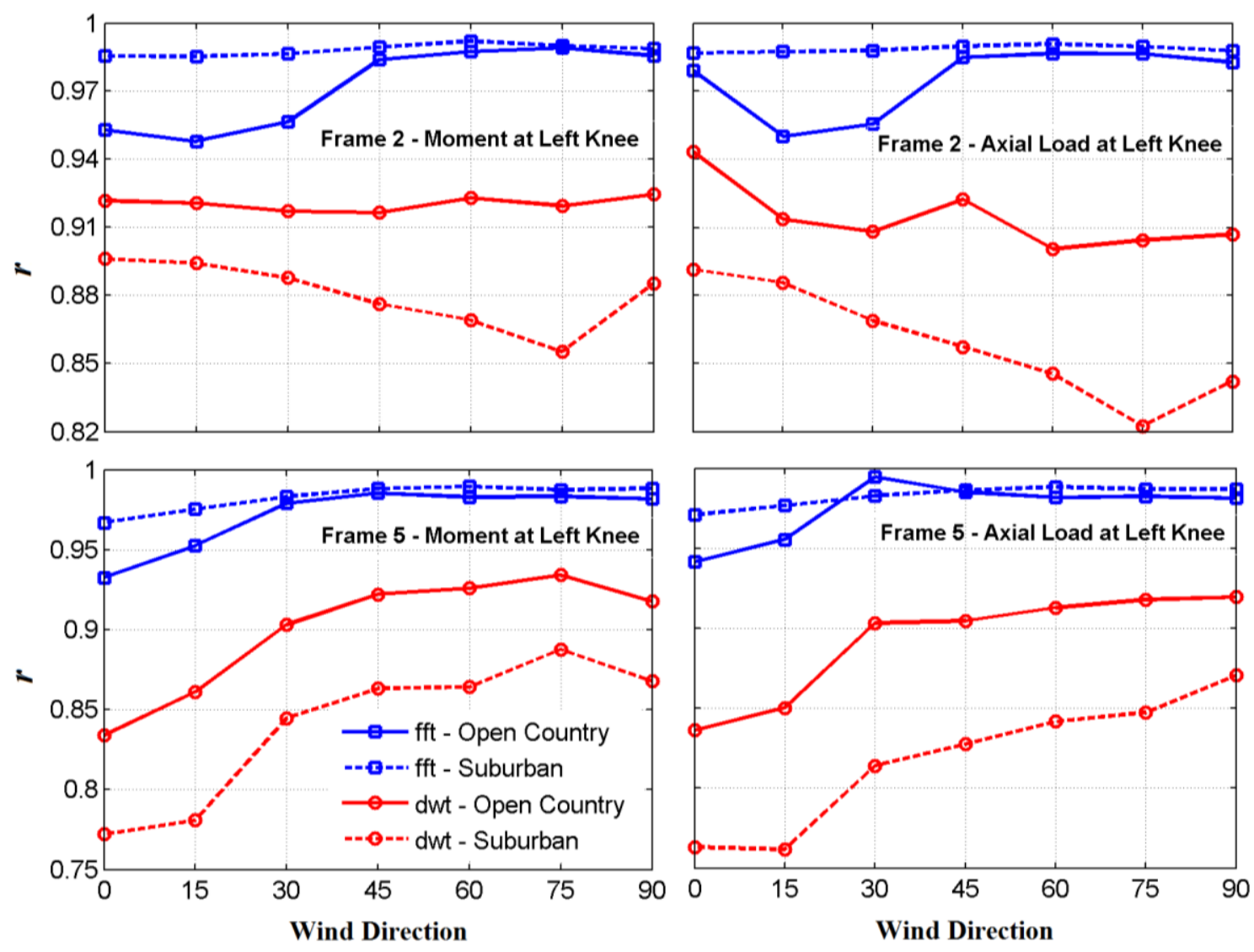

Figure 7.6 Comparison of $r_{M}$ and $r_{P}$ Evaluated at 90\% Compression using $f f t$ and $d w t$ Methods

The transformational techniques of data compression used here are effective in reducing the volume of stored data, that is, of the frequency representation or wavelet representation coefficients. The time series reconstructed from the stored data and used for the estimation of peak effects are equivalent in size to the original time series. Also, calculations showed that the application of compression and record length or sampling rate reduction on the reconstructed data yielded typically unsatisfactory results. It thus appears that the transformational compression techniques offer no advantage in terms of computation time reduction. 


\subsubsection{Data Compression using Direct Methods}

\subsubsection{Record Length Reduction}

The length of records typically obtained in the UWO wind tunnel laboratory corresponds to prototype duration of approximately $60 \mathrm{~min}$. On the other hand, the Tokyo Polytechnic University (TPU) aerodynamic database (Tokyo Polytechnic University 2011) - the largest in existence as of this writing - corresponds to a prototype length of only $10 \mathrm{~min}$, while having the same sampling rate as the UWO records (i.e., $500 \mathrm{~Hz}$ ). An investigation into the adequacy of record lengths shorter than the typical University of Western Ontario $60 \mathrm{~min}$ record length is therefore of interest.

The effectiveness of the record length reduction is assessed by using the following five-step procedure. First, the original pressure coefficient time series at all taps tributary to the frame being considered are used, in conjunction with relevant influence coefficients, to obtain the 100 -s time history of the wind effect of interest. Second, an estimate is performed of the expected value of that time history's peak, as noted in the Introduction. Third, the 100-s time history of the wind effect being considered which, as noted earlier, corresponds to a prototype record length of the order of one hour is divided into $n$ equal segments (time series). The values of $n$ being considered are $2,3,4,5$, and 6 . Fourth, the expected values of the peak bending moment $M$ and the peak axial force $P$ of a hypothetical 100-s time series are estimated for each of the time series with length $(100 / n)$ s. Fifth, ratios are calculated between the peaks estimated in the fourth step and the peak estimated in the second step.

Table 7.1 lists, for each $n$, the lowest values of those ratios for various angles $\theta$ (Figure 7.1), for open and suburban terrain exposure. For example, for $\theta=45^{\circ}, n=6$, open terrain, the lowest ratio $r_{M}$ based on a $100 / 6=16.7$-s long reduced time series is 0.86 , and the ratio $r_{P}$ is 0.79 . Table 7.1 indicates that, for $n=6$, an estimated peak based on a $(100 / n)$-s long time series can 
underestimate the peak based on the original 100 -s time series by as much as $21 \%$. The underestimation is in most cases stronger for suburban than for open terrain exposure.

Table 7.1 Ratios $r_{M}$ and $r_{P}$ based on time series of length (100/n) s with the least expected peak, obtained from original $(500 \mathrm{~Hz}, 100 \mathrm{~s}$ length) time series.

\begin{tabular}{|c|c|c|c|c|c|c|c|c|c|}
\hline \multirow{3}{*}{ Dir. $\theta$} & \multirow{3}{*}{$n$} & \multicolumn{4}{|c|}{ Frame 2} & \multicolumn{4}{|c|}{ Frame 5} \\
\hline & & \multicolumn{2}{|c|}{ Open } & \multicolumn{2}{|c|}{ Suburban } & \multicolumn{2}{|c|}{ Open } & \multicolumn{2}{|c|}{ Suburban } \\
\hline & & $r_{M}$ & $r_{P}$ & $r_{M}$ & $r_{P}$ & $r_{M}$ & $r_{P}$ & $r_{M}$ & $r_{P}$ \\
\hline \multirow{5}{*}{$45^{\circ}$} & 6 & 0.90 & 0.89 & 0.95 & 0.98 & 0.94 & 0.96 & 0.86 & 0.79 \\
\hline & 5 & 0.96 & 0.96 & 0.91 & 0.90 & 0.92 & 0.82 & 0.89 & 0.82 \\
\hline & 4 & 0.91 & 0.92 & 0.99 & 0.96 & 0.94 & 0.97 & 0.84 & 0.81 \\
\hline & 3 & 0.97 & 0.99 & 0.99 & 0.97 & 0.96 & 0.97 & 0.91 & 0.85 \\
\hline & 2 & 0.98 & 1.00 & 0.97 & 0.98 & 1.00 & 0.98 & 0.96 & 0.96 \\
\hline \multirow{5}{*}{$90^{\circ}$} & 6 & 0.89 & 0.88 & 0.90 & 0.94 & 0.90 & 0.92 & 0.86 & 0.88 \\
\hline & 5 & 0.91 & 0.91 & 0.89 & 0.89 & 0.87 & 0.91 & 0.87 & 0.90 \\
\hline & 4 & 0.95 & 0.93 & 0.90 & 0.94 & 0.93 & 0.94 & 0.88 & 0.92 \\
\hline & 3 & 0.93 & 0.93 & 0.89 & 0.97 & 0.91 & 0.92 & 0.88 & 0.96 \\
\hline & 2 & 0.99 & 0.98 & 0.98 & 1.00 & 0.96 & 0.98 & 0.96 & 0.98 \\
\hline
\end{tabular}

The reductions of the data volume result in a reduction in computation times. The computation times required to obtain the time series of the internal forces, once the pressure coefficients have been extracted from the database, were found to be approximately 1.5, 2.2, 2.3, 2.4 and 2.5 times shorter for the records with sampling rate corresponding to, respectively $m=2$, $3,4,5$ and 6 than for the full record $(n=1)$.

Since storage is a far less important issue than computation time, it is suggested on the basis of the results listed in Table 7.1 that estimates of expected peaks of 100-s time series be based on 
segments of length $(100 / 2)=50 \mathrm{~s}$. It can be seen in Table 7.1 that the loss of information inherent in the use of $50 \mathrm{~s}$ segments $(n=2)$ is relatively low.

An alternative approach to data volume reduction consists of using moving averages to select from the 100-s record the segment of length $(100 / n)$-s that has the largest mean value. However, the estimated expected peak internal forces based on that segment are not necessarily larger than those of other (100/n)-s segments within the 100-s record. Finally, instead of using $n$ non-intersecting segments of length $100-\mathrm{s} / n$, it is possible to use a larger number of intersecting segments. For example, if $n=2$, one could consider the segments starting and ending, respectively, at time $t=0$ and $t=50 \mathrm{~s} ; t=(1 / 500)$-s and $t=(50+1 / 500) \mathrm{s}$; and so forth. However, this procedure becomes computationally onerous, and is not warranted in practice.

\subsubsection{Sampling Rate Reduction}

In this method the reduction of the volume of data is achieved by decreasing the sampling rate of the original time series. The following five-step procedure is employed. The first two steps of the procedure are identical to the first two steps in the record length reduction method. Third, the reduced time series being considered are obtained by retaining from the original time series the first, the $(m+1)$ th, $(2 m+1)$ th, $(3 m+1)$ th, $\ldots$, data points; the second, $(m+2)$ th, $(2 m+2)$ th, $(3 m+2)$ th, $\ldots$, data points; $\ldots$, and the $(m)$ th, $(2 m)$ th, $(3 m)$ th, $\ldots$, data points, for $m=2,3,4, \ldots$ Fourth, the expected values of the peak bending moment $M$ and the peak axial force $P$ are estimated for the time series obtained in the third step. Fifth, ratios are calculated between the peaks estimated in the fourth step and the peak estimated in the second step. For the bending moments and the axial forces the ratios are denoted by $r_{M}$ and $r_{P}$, respectively. Table 7.2 lists, for each $m$, the lowest values of these ratios for various angles $\theta$ (Figure 7.1), for open and suburban terrain exposures. As $m$ increased (or as sampling rate decreased), the estimate peaks for all the responses were observed to decrease. Figure 7.7 shows an example of a record based on the original time series with $500 \mathrm{~Hz}$ sampling rate and the corresponding record based on the time 
series with reduced sampling rates $(m=4$, and $m=8)$. The computation times required to obtain the time series of the internal forces, once the pressure coefficients have been extracted from the database, were found to be approximately 1.5, 2.2, 2.3, 2.4 and 2.5 times shorter for the records with sampling rate corresponding to, respectively $m=2,3,4,5$ and 6 than for the full record ( $m$ $=1)$.

Table 7.2 Ratios $r_{M}$ and $r_{P}$ based on time series with sampling rates $500 \mathrm{~Hz} / m$ with the least estimated peak, obtained from original $(500 \mathrm{~Hz}, 100 \mathrm{~s}$ length) time series.

\begin{tabular}{|c|c|c|c|c|c|c|c|c|c|}
\hline \multirow{3}{*}{ Dir. $\theta$} & \multirow{3}{*}{$m$} & \multicolumn{4}{|c|}{ Frame 2} & \multicolumn{4}{|c|}{ Frame 5} \\
\hline & & \multicolumn{2}{|c|}{ Open } & \multicolumn{2}{|c|}{ Suburban } & \multicolumn{2}{|c|}{ Open } & \multicolumn{2}{|c|}{ Suburban } \\
\hline & & $r_{M}$ & $r_{P}$ & $r_{M}$ & $r_{P}$ & $r_{M}$ & $r_{P}$ & $r_{M}$ & $r_{P}$ \\
\hline \multirow{5}{*}{$45^{\circ}$} & 6 & 0.94 & 0.92 & 0.89 & 0.87 & 0.93 & 0.93 & 0.88 & 0.86 \\
\hline & 5 & 0.94 & 0.94 & 0.92 & 0.91 & 0.95 & 0.95 & 0.92 & 0.91 \\
\hline & 4 & 0.96 & 0.96 & 0.95 & 0.95 & 0.97 & 0.97 & 0.96 & 0.96 \\
\hline & 3 & 0.98 & 0.98 & 0.97 & 0.98 & 0.98 & 0.98 & 0.98 & 0.98 \\
\hline & 2 & 0.99 & 0.99 & 0.99 & 0.99 & 0.99 & 0.99 & 0.99 & 0.99 \\
\hline \multirow{5}{*}{$90^{\circ}$} & 6 & 0.93 & 0.93 & 0.86 & 0.87 & 0.93 & 0.93 & 0.87 & 0.88 \\
\hline & 5 & 0.95 & 0.94 & 0.92 & 0.92 & 0.94 & 0.94 & 0.91 & 0.92 \\
\hline & 4 & 0.96 & 0.96 & 0.95 & 0.95 & 0.96 & 0.96 & 0.96 & 0.95 \\
\hline & 3 & 0.98 & 0.98 & 0.98 & 0.98 & 0.97 & 0.98 & 0.97 & 0.98 \\
\hline & 2 & 0.99 & 0.99 & 0.99 & 0.99 & 0.99 & 0.99 & 0.99 & 0.99 \\
\hline
\end{tabular}

From a comparison of Table 7.1 and Table 7.2 it can be seen that, for the same reduction in data volume, the underestimation of the peak based on the original 100-s time series is in most cases less pronounced for sampling rate reduction than for record length reduction. In particular, for $m=2$ and $m=3$ the underestimation was insignificant from a structural engineering point of view. 


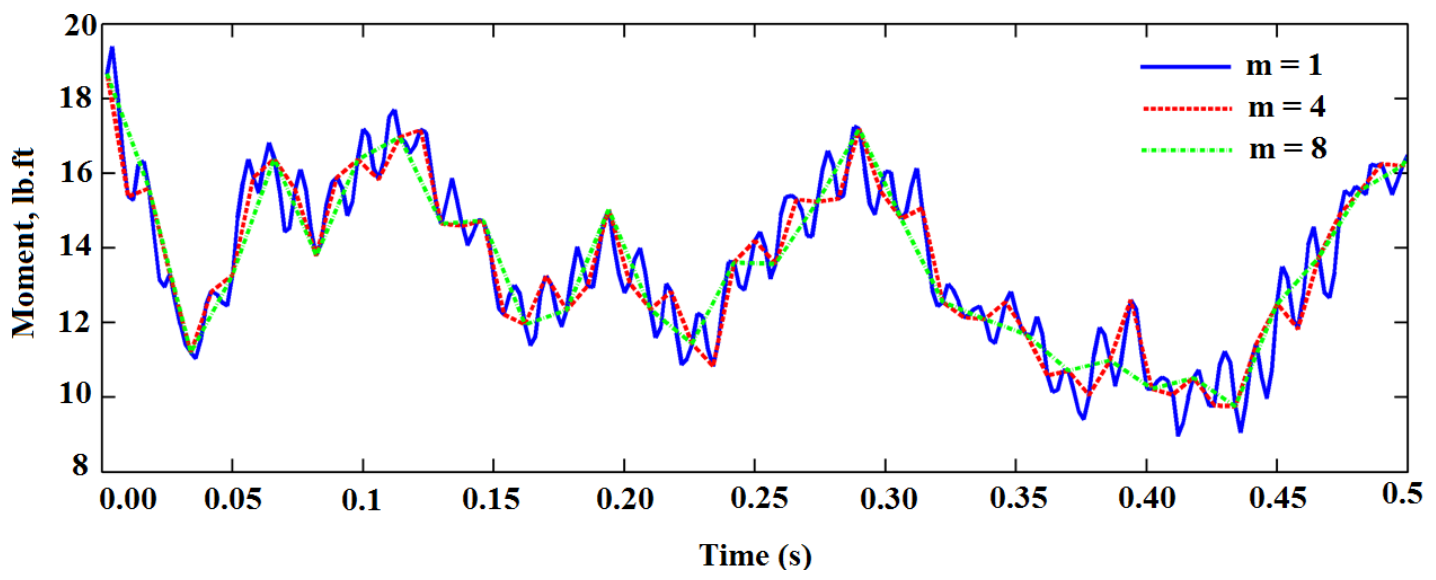

Figure 7.7 Example of frame response valuated using $500 \mathrm{~Hz}$ sampling rate $(m=1) \mathrm{vs.}$ obtained from data with reduced sampling rate $(m=4$, and $m=8)$

For the same reduction in data volume, the computation time was comparable for the records obtained by the record length and sampling rate reduction approaches. Since the bias error is typically smaller for the latter than for the former, it is concluded that the sampling rate reduction is more advantageous than the record length reduction approach.

Table 7.3 Ratios $r_{M}$ for five samples with reduced sampling rate obtained from original time series (frame 2, open, $m=5$ ).

\begin{tabular}{|c|c|c|c|c|}
\hline \multirow{2}{*}{ Sample } & \multicolumn{4}{|c|}{$\boldsymbol{r}_{M}$} \\
\cline { 2 - 5 } & $\boldsymbol{\theta}=\mathbf{1 5}^{\circ}$ & $\boldsymbol{\theta}=\mathbf{4 5}^{\circ}$ & $\boldsymbol{\theta}=\mathbf{7 5}^{\circ}$ & $\boldsymbol{\theta}=\mathbf{9 0}$ \\
\hline
\end{tabular}

An interesting and useful feature of the sampling rate reduction method is that internal forces in main wind force resisting systems obtained from the $m$ samples were found to differ insignificantly from each other, if they differed at all. An example is shown in Table 7.3. Recall that, in the case of record length reduction, determining the ratios $r_{M}$ and $r_{P}$ required calculations performed for each of the $n$ records with reduced length and selecting the record yielding the 
lowest ratios. In contrast, in the case of sampling rate reduction, the variability of the estimated peaks is lower among the reduced time series, and it is therefore sufficient in practice to perform calculations only for one of the $m$ records with reduced sampling rate. This is a second, and significant, advantage of the sampling rate reduction approach.

The probability distributions of original response time-histories were compared to probability distributions of response time-histories obtained using the duration reduction and sampling-rate reduction schemes. Figure 7.8 shows the cumulative probability curves of moment at left knee of frame 2, wind direction $45 \mathrm{deg}$, in both open and suburban terrains evaluated using original and compressed pressure data (at compression level of $85 \%$, or at $m$ and $n=6$ ). The cumulative distribution function (CDF) curves of the sampling-rate reduced data matched much better to the CDF curves of the original time-series; they even appear as single lines in Figure 7.8. The two-sample Kolmogrov-Smirnov non parametric test (Massey Jr 1951), at a significance level of 0.05 was also used to test the probability distribution similarity of the original time series and the compressed data. The Kolmogrov-Smirnov null hypothesis that "the original time series and compressed data come from populations with the same distribution", failed consistently in the case of duration reduced data, even for very low levels of data compression. But in the case of sampling rate reduced data, the Kolmogrov-Smirnov null hypothesis passed consistently even for high level of compression. This showed the superiority of data compressed using the reduced sampling rate approach in better representing probability distributions of the original time series. 


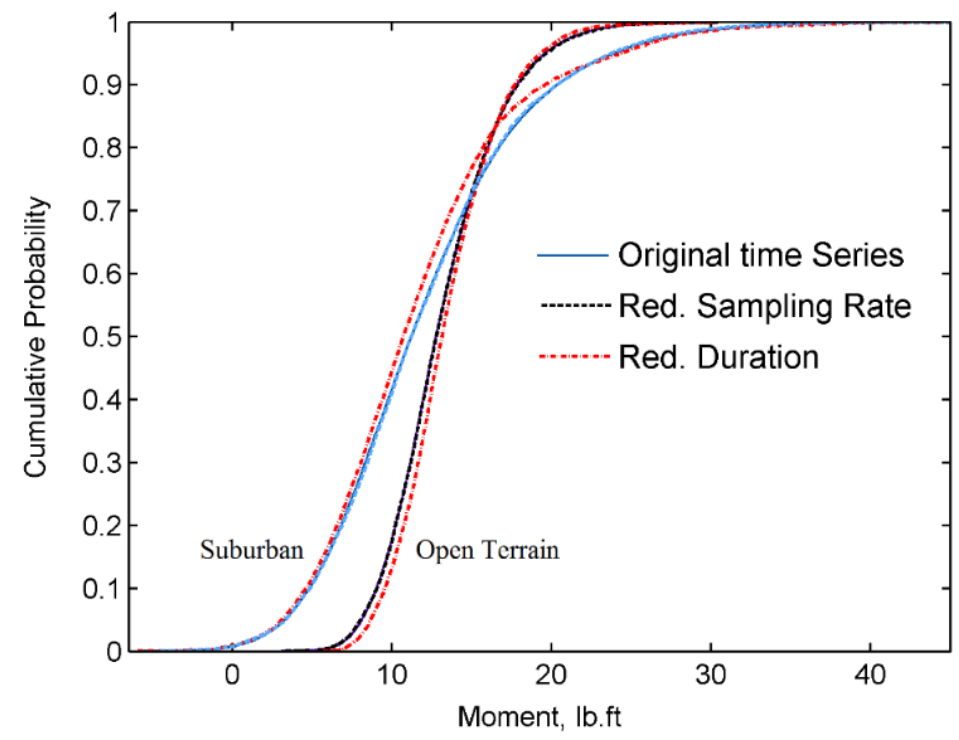

Figure 7.8 Comparisons of CDF of original time series to compressed time series

\subsubsection{Refinement of the Sampling Rate Reduction Method}

Time histories of wind-induced pressures or structural responses in low-rise buildings are typically non-Gaussian. Translational methods of peak estimation (e.g. the one used in this study) account for the non-Gaussian behavior and use the entire range of time-history when estimating peaks. This produces peaks which are more stable than those estimated using observed peak methods (Sadek and Simiu 2002). The following paragraph provides summary of translational approach of peak estimation in a non-Gaussian process.

For a process $y$ with marginal normal distribution $\Phi[y]$, the CDF of its largest peaks during time interval $T, F_{y_{p k}}\left(y_{p k}, T\right)$, can be obtained using Equation (7.2) (Rice 1945)

$$
F_{y_{p k, T}}\left(y_{p k}, T\right)=\exp \left[-v_{0, y} T \exp \left(-y_{p k}^{2} / 2\right)\right]
$$

where $v_{0, y}$ is the mean zero up-crossing rate of the Gaussian process $y$. For a non-Gaussian process, $x$ (given that $x$ can be represented as $x=g(y)$, where $g()$ denotes translation) the CDF of its largest peaks, $F_{x k}(x, T)$, can be determined from $F_{y_{p k}}(y, T)$, by translation. Translation can be carried out through CDF mapping (Sadek and Simiu (2002), Tieleman et al. (2006), Huang et al. 
(2013)) or polynomial approximation (Kwon and Kareem (2011)). The mean zero up-crossing rate of $y, v_{0, y}$ can be estimated by evaluating the median up-crossing rate $\left(v_{m d}\right)$ of the process $x$, or using equation (7.3). In equation (7.3), $n=$ frequency and $S_{x}(n)=$ one-sided spectral density function of the process $x$.

$$
v_{0, y}=\sqrt{\frac{\int_{0}^{\infty} n^{2} S_{x}(n) d n}{0}}
$$

In translational methods of peak estimation, the probability distribution of the peaks of a non-Gaussian time series for specific time duration, $T$, depends on the probability distribution and median up-crossing rate $\left(v_{m d}\right)$ of the non-Gaussian process. The $v_{m d}$ determines the CDF of the largest peaks for the underlying Gaussian process, i.e., $F_{y_{p k}}(y, T)$ and the translation from $F_{y_{p k}}(y$, $T)$ to $F_{x_{p k}}(x, T)$ are governed by the probability distribution of the non-Gaussian process. In Figure 7.8 it was shown that probability distributions of wind-induced frame responses compressed using the sampling rate reduction method match very well the probability distribution of the original response time histories, even at high values of $m$. But $v_{m d}$ was observed to decrease as $m$ increased (Figure 7.9), which is the main reason for the decrease in the expected peak responses observed at lower sampling rates (Table 7.2). 

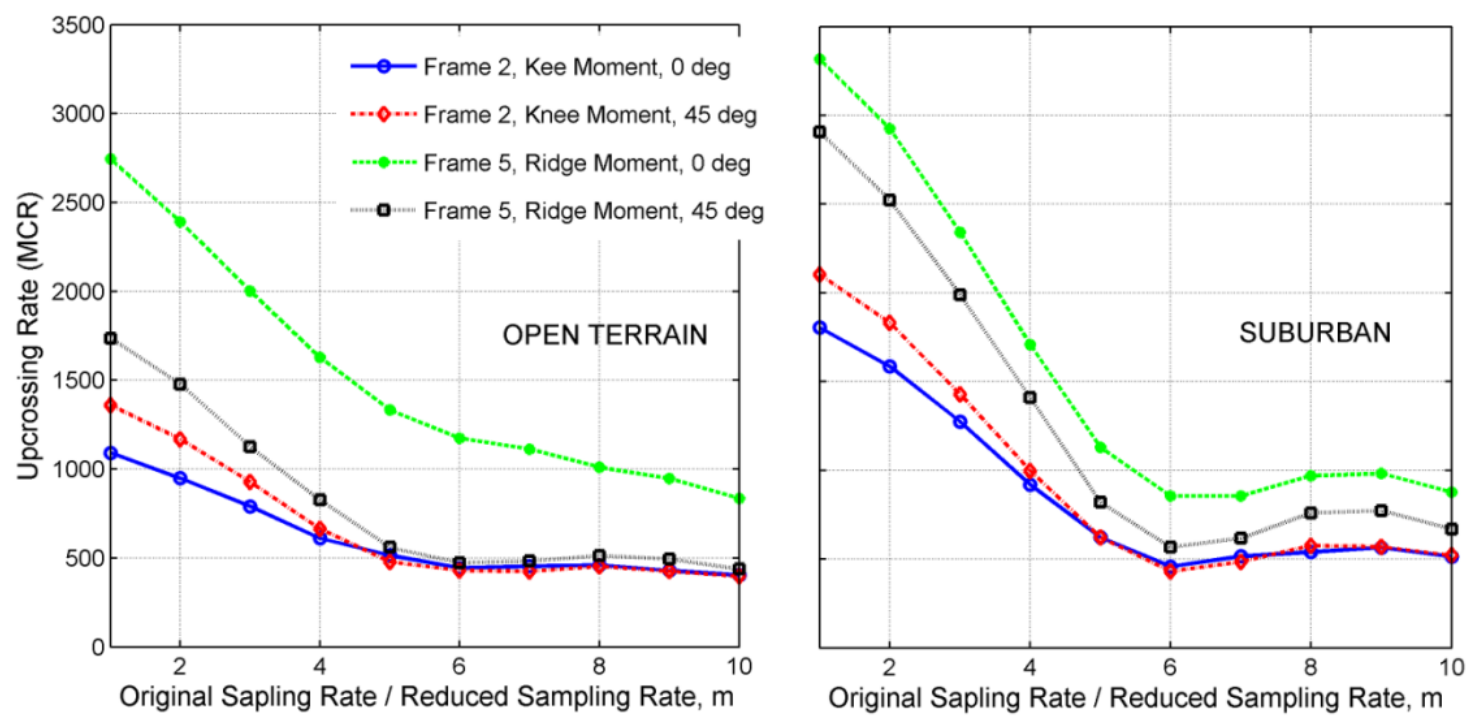

Figure 7.9 Median up-crossing rates at different $m$

Table 7.4 shows values of $r_{m}$ and $r_{p}$ evaluated by adjusting the $v_{m d}$ of reduced sampling rate data to match or at least be close to the $v_{m d}$ of the original time-series. In the case of open terrain, $v_{m d}$ was multiplied by $m^{0.65}$, and in suburban terrain $v_{m d}$ was multiplied by $m^{0.75}$, where $m$ as previously defined is the ratio of the original sampling rate to sampling rate of the compressed data. It can be seen that significantly improved values of $r_{m}$ and $r_{p}$ are attained by modifying $v_{m d}$ of the compressed data, and $m$ of up to 10 can be achieved at acceptable error levels.

Table 7.4 Ratios $r_{M}$ and $r_{P}$ based on time series with sampling rates $500 \mathrm{~Hz} / \mathrm{m}$ and adjusted $v_{m d}$ values

\begin{tabular}{|c|c|c|l|l|l|l|l|l|l|}
\hline \multirow{3}{*}{ Dir. $\theta$} & \multirow{3}{*}{$m$} & \multicolumn{4}{|c|}{ Frame 2 } & \multicolumn{5}{c|}{ Frame 5 } \\
\cline { 3 - 10 } & & \multicolumn{2}{|c|}{ Open } & \multicolumn{2}{|c|}{ Suburban } & \multicolumn{2}{c|}{ Open } & \multicolumn{2}{c|}{ Suburban } \\
\cline { 3 - 10 } & & $\boldsymbol{r}_{M}$ & $\boldsymbol{r}_{P}$ & $\boldsymbol{r}_{M}$ & $\boldsymbol{r}_{P}$ & $\boldsymbol{r}_{M}$ & $\boldsymbol{r}_{P}$ & $\boldsymbol{r}_{M}$ & $\boldsymbol{r}_{P}$ \\
\hline \multirow{5}{*}{0} & 10 & 0.99 & 1.01 & 1.02 & 1.01 & 1.00 & 1.00 & 1.01 & 1.00 \\
\cline { 3 - 10 } & 8 & 1.02 & 1.01 & 1.02 & 1.01 & 1.00 & 1.00 & 1.00 & 1.00 \\
\cline { 2 - 10 } & 6 & 0.99 & 1.00 & 0.99 & 0.98 & 0.92 & 0.91 & 0.91 & 0.96 \\
\cline { 2 - 10 } & 4 & 1.01 & 1.01 & 1.02 & 1.02 & 1.01 & 1.01 & 1.02 & 1.02 \\
\cline { 2 - 9 } & 2 & 1.01 & 1.01 & 1.02 & 1.02 & 1.02 & 1.01 & 1.02 & 1.02 \\
\hline
\end{tabular}




\begin{tabular}{|c|c|c|c|c|c|c|c|c|c|}
\hline \multirow{5}{*}{$45^{\circ}$} & 10 & 1.01 & 1.00 & 1.01 & 1.01 & 0.99 & 0.99 & 1.00 & 0.99 \\
\cline { 2 - 10 } & 8 & 1.01 & 1.00 & 1.01 & 1.00 & 1.00 & 1.00 & 1.00 & 0.99 \\
\cline { 2 - 10 } & 6 & 0.99 & 0.98 & 0.97 & 0.96 & 0.97 & 0.98 & 0.95 & 0.93 \\
\cline { 2 - 10 } & 4 & 1.01 & 1.00 & 1.02 & 1.02 & 1.00 & 1.00 & 1.01 & 1.01 \\
\cline { 2 - 10 } & 2 & 1.01 & 1.01 & 1.02 & 1.02 & 1.02 & 1.01 & 1.02 & 1.02 \\
\hline \multirow{5}{*}{$90^{\circ}$} & 10 & 1.00 & 0.99 & 0.99 & 0.99 & 0.98 & 0.99 & 0.98 & 1.00 \\
\cline { 2 - 10 } & 8 & 1.00 & 0.98 & 1.00 & 1.00 & 0.98 & 1.00 & 0.98 & 1.00 \\
\cline { 2 - 10 } & 6 & 0.98 & 0.96 & 0.93 & 0.94 & 0.98 & 0.98 & 0.93 & 0.93 \\
\cline { 2 - 9 } & 4 & 1.00 & 1.00 & 1.01 & 1.01 & 1.00 & 1.00 & 1.01 & 1.01 \\
\cline { 2 - 9 } & 2 & 1.01 & 1.01 & 1.02 & 1.02 & 1.01 & 1.01 & 1.02 & 1.02 \\
\hline
\end{tabular}

\subsection{Data Volume Reduction Based on Moving Averaged Time Series}

This section considers time series obtained from the original 100-s time series by taking moving averages over a time interval of $3 \times(1 / 500) \mathrm{s}=0.006 \mathrm{~s}$ (For a 1:100 model scale and a 1:3 velocity scale this interval corresponds at full scale to about $0.2 \mathrm{~s}$ and to a full scale nominal turbulent eddy size of the order of $1 \mathrm{~m}$.) For example, if successive ordinates of the original time series were $1,3,2,4,7,6, \ldots$, the ordinates of the moving-averaged time series would be 2 (i.e., $(1+3+2) / 3), 3,4.33,5.67, \ldots$ The moving average operation tends to smooth out sharp peaks and was adopted by Tokyo Polytechnic University to eliminate artificially high peaks corresponding to eddy sizes that are too small to be effective from a structural point of view. For an example of the differences between an original time series and a time series obtained by subjecting the latter to the moving average procedure just described, see Figure 7.10. 


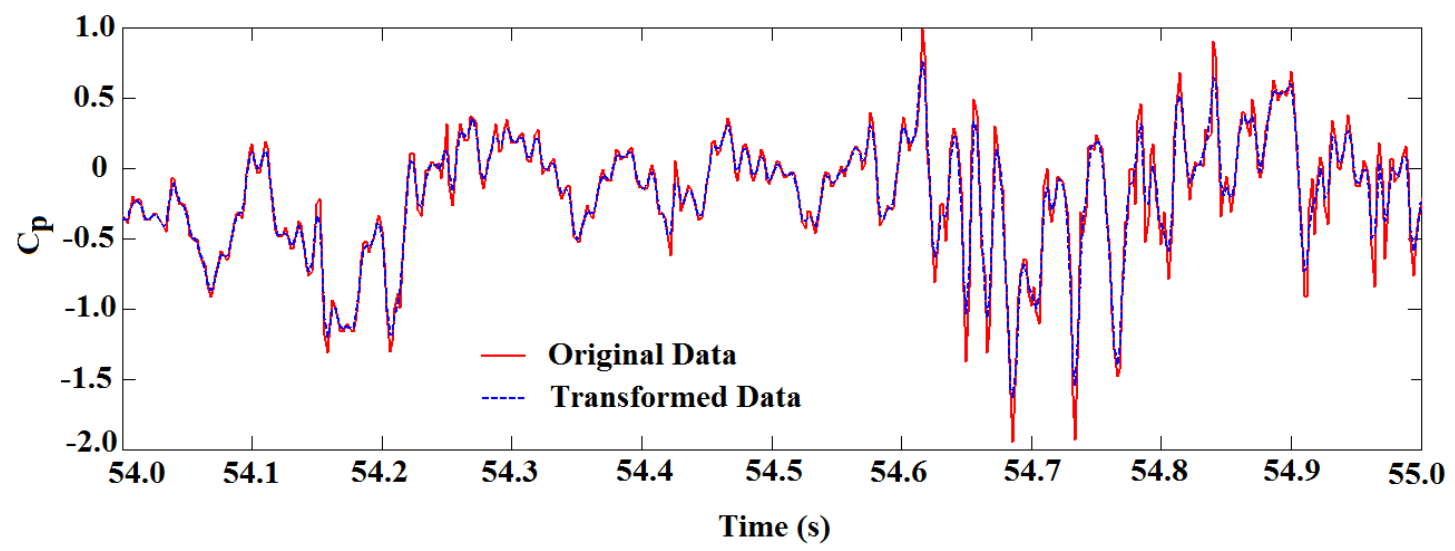

Figure 7.10 Example of original record (solid line) vs. record obtained from it by movingaveraged operation (dotted line).

Following the construction of moving-averaged $100-\mathrm{s}, 500-\mathrm{Hz}$ time series, as indicated earlier, calculations were performed for records derived from these time series by: reducing the record length by a factor $n=5$; reducing the sampling rate by a factor $m=5$; and applying an 80 $\%$ compression rate. It was found that in all cases the ratios $r_{M}$ and $r_{P}$ were marginally higher (typically by $1 \%$ or $2 \%$ ) than for the corresponding cases pertaining to the original records.

\section{Conclusions}

Database-assisted design calculations were performed to determine peak bending moments and axial forces in portal frames of a typical industrial building subjected to wind loads. The purpose of the calculations was to determine the extent to which it is possible to reduce the volume of pressure coefficient data contained in the time series of the University of Western Ontario (UWO) aerodynamic database without significant errors in the estimation of windinduced internal forces in the frames. The length of these time series is $100 \mathrm{~s}$, corresponding nominally to a full-scale length of the order of one hour; their sampling rate is $500 \mathrm{~Hz}$. The investigation was limited to database volume reduction for calculations pertaining to main wind force resisting systems (MWFRS) of rigid buildings. 
The following four (two transformational and two direct) compression methods for achieving the data volume reduction were presented and their effectiveness was analyzed: (1) using discrete Frequency transform for data compression; (2) using discrete wavelet transform for data compression; (3) reducing the length of the time series data; (4) reducing the data sampling rate.

The transformational compression methods are effective in reducing the volume of stored data (specially the Fourier transform approach). However, the reconstructed time series has the same length as the original time series. Therefore the translational methods of compression offers no advantage in terms of computation time reduction.

The reduction in the volume of data and computation time can be achieved most effectively, with acceptably small loss of information, by the sampling rate reduction method. Moreover, if translational methods of peak estimation are used, higher effectiveness can be achieved by increasing the median upcrossing rates of the compressed data by appropriate factors, say $m^{0.65}$ and $m^{0.75}$ for open and suburban terrains respectively, $m$ denotes the ratio of sampling rate reduction. The data duration reduction method was not as effective as the sampling rate reduction. The use of wind tunnel records corresponding to 10-min, as opposed to 60-min, prototype duration entails errors that may need to be accounted for in structural reliability calculations. Future research is needed to clarify this point.

As was noted in the paper, the computations were performed in this work by using the software "windpressure," which is based on MATLAB, a package widely considered to be userfriendly. That to a reduction of the vnolume of data by a factor $n=6$ there corresponds a reduction of the computation time by a factor of only about 2.5 is an indication that, for the applications considered in this work, the MATLAB-based software has relatively high "overhead." More efficient software is available, and may be used in such applications in the future. This would reduce the computation times by factors larger than 2 to 2.5 . 


\section{References}

Fritz, W. P., Bienkiewicz, B., Cui, B., Flamand, O., Ho, T. C., Kikitsu, H., Letchford, C. W., and Simiu, E. (2008). "International comparison of wind tunnel estimates of wind effects on low-rise buildings: Test-related uncertainties.” Journal of structural engineering, 134(12), 1887-1890.

Fu, T.-C., Aly, A. M., Chowdhury, A. G., Bitsuamlak, G., Yeo, D., and Simiu, E. (2012). “A proposed technique for determining aerodynamic pressures on residential homes." Wind and Structures, 15(1), 27.

Ho, T. C. E., Surry, D., and Morrish, D. (2003). NIST/TTU Cooperative Agreement-Windstorm Mitigation Initiative: Wind Tunnel Experiments on Generic Low Buildings. Tech. Rep. BLWT-SS20-2003, The Boundary Layer Wind Tunnel Laboratory, The University of Western Ontario, London, Ontario, Canada.

Huang, M. F., Lou, W., Chan, C. M., Lin, N., and Pan, X. (2013). "Peak distributions and peak factors of wind-induced pressure processes on tall buildings." Journal of Eng. Mechanics.

Kwon, D. K., and Kareem, A. (2011). "Peak factors for non-Gaussian load effects revisited." Journal of Structural Engineering, 137(12), 1611-1619.

Main, J. A., and Fritz, W. P. (2006). Database-assisted design for wind: concepts, software, and examples for rigid and flexible buildings. National Institute of Standards and Technology, Technology Administration, US Department of Commerce.

Massey Jr, F. J. (1951). "The Kolmogorov-Smirnov test for goodness of fit." Journal of the American statistical Association, 46(253), 68-78.

Oinam, S., Kumar, H., and Patil, S. B. (2013). "Compression of Time series signal using Wavelet Decomposition, Wavelet Packet and Decimated Discrete Wavelet compression Transforms Techniques and their Comparison." signal, 2(3).

Possolo, A., Kasperski, M., and Simiu, E. (2009). "Tunable compression of wind tunnel data." Wind and Structures, 12(6), 505-517.

Rice, S. O. (1945). "Mathematical analysis of random noise." Bell System Technical Journal, The, 24(1), 46-156.

Sadek, F., and Simiu, E. (2002). "Peak non-Gaussian wind effects for database-assisted low-rise building design." Journal of Engineering Mechanics, 128(5), 530-539.

Tieleman, H. W., Elsayed, M. A., and Hajj, M. R. (2006). "Peak wind load comparison: theoretical estimates and ASCE 7." Journal of Structural Engineering, 132(7), 11501157.

Tokyo Polytechnic University. (2011). “Aerodynamic Database for Low-rise Buildings.”

Weisstein, E. W. (2015). "Fast fourier transform." 


\section{CONCLUSION AND FUTURE RESEARCH RECOMMENDATIONS}

\subsection{Summary and Conclusions of Dissertation}

The turbulent nature of the wind flow coupled with additional turbulence created by the wind-building interaction result in highly non-uniform, fluctuating wind-loading on building envelopes. This is true even for simple rectangular symmetric buildings. Building codes and standards should reflect the information on which they are based as closely as possible, and this should be achieved without making the building codes too complicated and/or bulky. However, given the complexity of wind loading on low-rise buildings, its codification can be difficult, and

it often entails significant inconsistencies. As a result, wind loads determined using building codes can differ from wind loads consistent with laboratory measurements by significant amounts. Moreover, large differences in wind loads estimated using different building codes have also been noted. Even different methods for determining wind loading included in the same building code can produce different values of the loading for the same structures; this is the case, for example, with the directional and envelope methods of the ASCE 7-10 Standard. This state of affairs required the development of alternative design methods that can produce more accurate and risk-consistent estimates of wind loads or their effects.

Researchers at the National Institute of Standards and Technology (NIST) proposed an alternative approach for computing wind effects and performing designs which is commonly referred to as Database-Assisted Design (DAD). DAD is a computer-intensive, user-friendly automated design procedure for the calculation of wind effects on structures, made possible by advances in wind tunnel technology and in computational and digital storage capabilities. DAD is a synthesis of wind and structural engineering that eliminates or reduces significantly inefficiencies inherent in conventional approaches to estimating wind effects. Another approach, with objectives similar to DAD, referred to as database-enabled design (DED) is being studied by researchers at the University of Notre Dame. 
In this dissertation, DAD for rigid-structures has been further developed into a design tool capable of automatically helping to size member cross sections that closely meet codified strength and serviceability requirements. This was achieved by the integration of the wind engineering and structural engineering phases of designing for wind and gravity loads, similar to the existing integration of earthquake engineering and structural engineering phases of structural design for seismic and gravity loads. All the calculations are performed in the time-series domain, allowing rigorous combination of imperfectly correlated time histories of wind pressure, thus eliminating errors due to subjective estimates of combined effects. In addition, frame member Demand-toCapacity Indexes (DCIs) are evaluated by direct combination of instantaneous wind effects (for example axial force and bending moment). The wind effects are computed using influence coefficients that are updated as the design process progresses. The design method can make use of either directional or non-directional simulated wind speeds for large numbers of events, in both hurricane- and non-hurricane-prone regions, for single or mixed wind climates.

This design methodology is applicable to any rigid structure. A practical application of the design methodology is presented for a simple case of gable-roofed rectangular buildings, with structural systems consisting of equally spaced moment resisting steel portal frames spanning the width of the building. Useful features of this work also include: the capability to make use of the two largest building aerodynamics databases available worldwide; analysis based on time series of response; first order analysis for stability; an effective multiple-points-in-time algorithm for estimating peaks; large simulated extreme wind databases for hurricane- and non-hurricane-prone regions; and parameter-free methods for estimating DCIs with specified mean recurrence intervals. DCIs obtained using this method were compared to those obtained using the ASCE 710 envelope procedure. The results confirmed the existence of inadequacies in the ASCE 7-10 envelope procedure, and DAD's potential for practical use in structural design. 
The final step of the presented design methodology involves synthesizing building aerodynamics and structural data with site-specific climatological data. Two approaches, namely non-directional and directional, for combining DCI databases (based on aerodynamic and structural data) with climatological databases (matrices of directional wind speeds) in building with unknown orientation are discussed in detail. Ratio of DCIs computed using those two methods were evaluated for several cases of buildings located in both hurricane and nonhurricane regions. Factors of 0.90 and 0.85 were recommended for use with the non-directional method for hurricane and non-hurricane prone regions respectively. A similar DAD based methodology is also used to evaluate wind directionality factors (as defined in building codes) for different cases of building forces, terrain exposures, mean recurrence intervals, and type of climate. Higher directionality factors were recommended for use in hurricane prone regions when compared to non-hurricane regions (i.e. $K_{d}=0.90$ and 0.85 respectively).

It is well known that wind-induced internal pressures can significantly modify the aerodynamics of low-rise buildings. However, previous research on DAD was entirely focused on external pressures, and internal pressures were taken from building codes if needed. This work reports on a comprehensive DAD-based investigation aimed at understanding the effects of measured, fluctuating internal pressure on the structural design of low-rise buildings. The study included buildings with single and multiple dominant openings (using data from the NIST database and data measured at the Wall of Wind, respectively). The results showed that breaching of a dominant opening can increase total roof uplift on a low-rise building by up to $300 \%$. This high increase is due to the spatial uniformity of internal pressure inside a building. The effect of internal pressure on frames was observed to vary not only with location of the frame with respect to the building openings, but also with cross-section position in the same frame. That effect was also highly dependent on the correlation between the forces induced by the external and internal pressures (correlation coefficients of up to 0.67 and 0.55 were observed for single and multiple 
dominant openings). For frames located near an opening, internal pressure can increase net frame forces by up to $65 \%$ and $45 \%$ of the external pressure induced forces for cases of single and multiple openings, respectively. However, in frames located away from the openings, the internal pressure has milder effects on the critical net forces, and can even reduce the critical forces in some cross-openings cases. The presence of an opening was observed to increase frame DCIs by up to $100 \%$. Comparisons of frame forces and DCIs evaluated using experimentally recorded internal pressures to their counterparts based on ASCE 7-10 provisions showed that ASCE 7-10 based estimates can be unconservative in buildings with single and multiple openings. Hence the use of internal pressure prediction models is recommended.

This dissertation also addressed some key issues that can significantly affect the extent to which the DAD methodology is used in engineering practice. Those issues include: insufficiently comprehensive aerodynamic databases for various types of building shapes (which is mentioned in the Commentary to the ASCE 7-10 Standard Sect. C31.4 as a barrier to the widespread use of the DAD methodology), and the large volume of existing aerodynamic databases (which can create issues related to data transmission, and required PC computation memory and computation times). A novel interpolation scheme was developed allowing the estimation of the time-histories of responses of a building of interest not available in an aerodynamic database from available models. The interpolation scheme employs decomposition of the fluctuating responses and linear interpolation between models of different dimensions. Comparisons between peak frame responses and DCIs computed using existing aerodynamic building models on the one hand and obtained by interpolation from models with different dimensions showed that highly accurate estimates of frame responses can be obtained when interpolating between models with different eave heights. When interpolating between models with different roof slopes, the accuracy of the estimated frame responses tends to increase as the roof slope of the building of interest increases. 
The interpolation scheme produced DCIs of acceptable accuracy even from models with more than one different dimension. Typical errors due to interpolation were found to be less than $10 \%$.

Thorough comparison of the two largest publicly available aerodynamic databases, i.e. the NIST and TPU databases was also performed. The objective was to not only alleviate the shortage of databases and but also increase user confidence in both databases. Comparisons of cladding pressures, frame forces and DCIs computed using the two databases were conducted. The absolute values of the differences between the compared pressure coefficients were less than or equal to $15 \%$ in $82 \%$ of the cases, and differences between the compared peak moment coefficients were less than or equal to $15 \%$ in $70 \%$ of the cases. In both pressure and frame forces, the larger discrepancies were observed in the cases of the smaller coefficients. In the comparisons made between DCIs, despite the fact that buildings with different dimensions were used, comparable values of DCIs were attained. The differences between the compared pressures and forces are considerably lower than typical differences inherent in other existing sets of comparisons published in the literature. Hence, the results of the comparisons suggest that, the TPU and NIST databases are reasonably equivalent for practical engineering purposes.

To address the issues of data volume and computational time reduction, which will eventually become irrelevant with upgrades in the storage and processor capacities of average engineering office computers, the efficiency of various methods of data reduction was investigated. The efficiency was measured by the capability of the data reduction method to effectively reduce the data without compromising the accuracy of the results being sought. The following four (two transformational and two direct) compression methods for achieving the data volume reduction were presented and their effectiveness was analyzed: (1) using discrete Frequency Transform for data compression; (2) using discrete Wavelet Transform for data compression; (3) reducing the length of the time series data; (4) reducing the data sampling rate. The transformational compression methods (which used thresholding to compress the data), were 
effective in reducing the volume of stored data (specially the Fourier transform approach). However, the reconstructed time series has the same length as the original time series, therefore the transformational methods offer no advantage in terms of computation time reduction. The reduction in the volume of data and computation time can be achieved most effectively, with acceptably small loss of information, by the sampling rate reduction method. Moreover, the effectiveness of the sampling rate reduction method can be significantly improved by manipulating the peak estimation methods used (for example, if translational methods of peak estimation are used, the median upcrossing rates of the compressed data can be increased by appropriate factors, say $m^{0.65}$ and $m^{0.75}$ for open and suburban terrains respectively, where $m$ denotes the ratio of sampling rate reduction). The data duration reduction method was not as effective as the sampling rate reduction.

This dissertation is part of an initiative to advance practical approaches to wind loading and effects estimation and structural design for wind. The research is transformative insofar as it will enable designs that are safe and economical owing to the risk-consistency inherent in DAD, meaning that enough structural "muscle" is provided to assure safe behavior, while "fat" is automatically eliminated in the interest of economy and $\mathrm{CO}_{2}$ footprint reduction. DAD also creates designs for wind that are transparent and fully documented, thus promoting accountability in all phases of the design process, including the wind engineering phase. This research work has not only advanced the state of the art of DAD methodology for rigid buildings, but it also promotes the widespread use of methods for designing any structure for wind loads by making full use of modern experimental and computational capabilities. A software pertaining to the applications developed in this dissertation is available for public use at www.nist.gov/wind, under section Wind Design. Software user manual, sample building input files, sample aerodynamic and climatological datasets are also available in the same directory. 


\subsection{Recommendation for Future Research}

The following future work is recommended by the author:

- This dissertation was focused on simple rectangular buildings with gable roofs, and relatively simple structural system. A research potential exists in expanding DAD to include other building shapes and more complicated structural systems.

- Wind tunnel experimentation is currently the main source of aerodynamic data for DAD. However, DAD can also be used with time-histories of wind pressure generated using Computational Fluid Dynamics (CFD) techniques. Though much work remains to be done before CFD can replace wind tunnel testing, it offers an exciting research opportunity, and eventually it is expected to advance DAD's popularity as a design tool.

- In this research work as well as in much of the previous research work on DAD the analysis has been carried out for linear elastic case. However, it would be of great interest to build upon and expand DAD methodology based on non-linear analysis.

- DAD has been focused primarily on the main structural support system of buildings; however, it can also be applied to include design of building cladding, components and connections. It is known that compared to building codes, DAD will produce more accurate estimates of peak loads on building connections. But more importantly, DAD's use of influence coefficients and time-domain approach, offers the potential for capturing the vibrations that might be experienced by building connections. Note that wind induced cyclic vibrations can induce fatigue failures under low, but long lasting winds. 


\section{FILMON FESEHAYE HABTE}

Born, Bahardar, Ethiopia

$2002-2008$

B.A., Civil Engineering

University of Asmara

Asmara, Eritrea

$2009-2011$

Graduate Assistant

Hamelmalo Agricultural College

Hamelmalo, Eritrea

$2012-2014$

Presidential Fellow

Florida International University

Miami, Florida

$2014-2016$

Research and Teaching Assistant

Florida International University

Miami, Florida

2015

M.Sc., Civil Engineering

Florida International University

Miami, Florida

$2012-2016$

Doctoral Candidate

Florida International University

Miami, Florida

\section{PUBLICATIONS AND PRESENTATIONS}

Hagos, A., Habte, F., Chowdhury, A. G and Yeo, D. (2014). Comparisons of Two Wind Tunnel Pressure Databases and Partial Validation against Full-Scale Measurements. Journal of Structural Engineering, 140(10), 04014065.

Habte, F., Chowdhury, A. G., Yeo, D., and Simiu, E. (2014). Wind Directionality Factors for Non-hurricane and Hurricane-Prone Regions. Journal of Structural Engineering, 141(8), 04014208.

Habte, F., Chowdhury, A. G., Yeo, D., and Simiu, E. (2015). Closure to "Wind Directionality Factors for Nonhurricane and Hurricane-Prone Regions" by Filmon Habte, Arindam Gan Chowdhury, DongHun Yeo, and Emil Simiu. Journal of Structural Engineering,142(2), 07015010. 
Habte, F., Mooneghi, M. A., Chowdhury, A. G., and Irwin, P. (2015). Full-scale testing to evaluate the performance of standing seam metal roofs under simulated wind loading. Engineering Structures, 105, 231-248.

Habte, F., Mooneghi, M. A., Baheru, T., Zisis, I., Chowdhury, A. G., Masters, F. , and Irwin, P. (2016). Wind Loading on Ridge, Hip and Perimeter Roof Tiles: A Full-Scale Experimental Study. Journal of Wind Engineering and Industrial Aerodynamics (Under review)

Habte, F., Chowdhury, A. G., Yeo, D., and Simiu, E. (2016). Iterative Design of Rigid Structures for Wind using Time-Series of Demand-to-Capacity Indexes. Engineering Structures, (Under review)

Habte, F., Chowdhury, A. G., and Zisis, I. (2016). Effect of Wind-Induced Internal Pressure on Local Frame Forces of Low-Rise Buildings. Engineering Structures, (Under review)

Baheru, T., Habte, F., Moravej, M., \& Chowdhury, A. G. (2014). Full-Scale Testing to Evaluate Wind Effects on Residential Tiled Roofs. Paper presented at International Conference on Building Envelope Systems and Technologies (ICBEST), Aachen, Germany.

Habte, F., and Chowdhury, A. G. Experimental Investigation of Wind-Induced Torsional Loads on a Low-Rise Building. Paper presented in Structures Congress 2015 (pp. 26552666) ASCE, Portland, Oregon.

Habte, F., Mooneghi, M. A., Chowdhury, A. G., and Irwin, P. (2015). Performance of standing seam metal roofs under realistic wind loading. Presented in 14th international conference on wind engineering, Porto Alegre, Brazil.

Habte, F., and Chowdhury, A. G. (2015). Performance of standing seam metal roofs under realistic wind loading. Presented in 14th international conference on wind engineering, Porto Alegre, Brazil. 